\title{
Using paleomagnetism to test rolling hinge behaviour of an active low angle normal fault, Papua New Guinea
}

\author{
By Emma Jane Watson
}

A thesis

Submitted to Victoria University of Wellington

In partial fulfilment of the requirements for the degree of

Master of Science

In Geology

School of Geography, Environment and Earth Sciences

Victoria University of Wellington 



\section{Acknowledgements}

To obtain and interpret the results presented in this thesis required drawing from a range of different disciplines. This research would not be possible if it were not for the advice and expertise of many throughout the course of this study. To condense my appreciation down to a single page does not feel like I have done these efforts justice.

My gratitude, first and foremost, lies with my co-supervisors - Tim Little and Gillian Turner, both of whom have been integral to the progression of this study. Tim's enthusiasm for this project was almost unmatched and he is thanked greatly for providing useful ideas and insights in the interpretation of the data, and providing useful critiques of the original drafts of this thesis. I thank Gillian for teaching me more than I ever thought I would know about the theoretical background, and standard laboratory techniques, of paleomagnetism. Her help was integral to the results and interpretation obtained in this study. Eliza Piispa is also thanked for conducting a pilot study on these challenging samples. Her efforts kick-started this project, by showing that meaningful results can be obtained from these samples.

Ted Linney is thanked for the endless hours he put into this project helping me saw the samples, and measuring additional samples when more data was required. His insights into potential ways the samples could be strengthened were also helpful. I would also like to thank Ian Schipper, who provided his technical expertise with the microprobe, and Fiona Tuckett for kindly producing grain mounts of the magnetic separates for analysis. I would also like to thank Tony Morris, who was kind enough to provide me with the excel spreadsheets he used to perform his rotation analysis.

Tim's two PhD students (Marcel Mizera and Juergen Oesterle), through all of our collective sighs and frustrations, are also thanked for discussing ideas and providing potential avenues to pursue, and for helping me futilely search for the elusive magnetite. They are also thanked for providing insight into the field sampling in Papua New Guinea.

Last but not least I would like to thank both my friends and family, and my office pals who fought it out with me, for their encouragement and support along this journey. You 
all kept me [mostly] sane throughout the course of this thesis and for that I am immeasurably grateful. 
Dedicated in loving memory to the late Wanda Pauline Horner (née de Vries) Grandmother. Friend. Rock Collector. Inspirer of many.

"manibus date lilia plenis" 


\begin{abstract}
Metamorphic core complexes (MCC) are widespread in extensional tectonic environments. Despite their significant contribution to extension in rifts, little is known about the origin and evolution of metamorphic core complexes. Particular controversy regards the origin of the typically shallowly dipping $\left(<30^{\circ}\right)$ detachment fault that bounds the footwall core of metamorphic rocks. According to Andersonian faulting theory, normal faults should initiate at a dip of $\sim 60^{\circ}$ and frictionally lock up and stop slipping at dips of $<30^{\circ}$. One possible solution to this problem is a rolling hinge evolution for the fault. In this scenario the fault initiates at a steep dip of $\sim 60^{\circ}$ and evolves to a shallower dip during slip due to the rebound of the footwall in response to progressive unloading as the hangingwall is removed (Wernicke \& Axen, 1988; Buck, 1988; Hamilton, 1988). Large rotations of the footwall, indicative of rolling hinge style deformation, may conceivably be measured by comparing the remanent paleomagnetic vector of the footwall rocks with the expected direction of the geomagnetic field at the site where the remanent magnetization was acquired. Using these techniques, large rotations of footwall rocks consistent with rolling hinge style deformation have been demonstrated for the footwalls of oceanic core complexes (Garcés \& Gee, 2006; Zhao \& Tominaga, 2009; Morris et al., 2009; MacLeod et al., 2011), but not for continental MCCs.
\end{abstract}

In this study we attempt to test, using the remanent magnetization of the footwall rocks, whether rolling hinge style rotations have affected the footwall of the Mai'iu fault, Papua New Guinea. The Mai'iu fault, located in the continental Woodlark Rift, is a rapidly slipping ( $\sim 1 \mathrm{~cm} / \mathrm{yr}$ ) (Wallace et al., 2014; Webber et al., 2018), shallowlydipping $\left(<22^{\circ}\right.$ at the surface) normal fault (Spencer, 2010; Little et al., 2019) responsible for the Pliocene-Recent exhumation of the domed Suckling-Dayman MCC, which is comprised mostly of Goropu Metabasalt.

The remanent magnetization of forty-four samples of footwall Goropu Metabasalt were measured for this study. Close to the fault trace $(<1.5 \mathrm{~km})$ a moderately inclined, northerly trending, normal component of magnetic remanence is preserved (Dec: $351.1^{\circ}$, Inc: $-35.7^{\circ}, \alpha_{95}: 6.8^{\circ}, \mathrm{N}=18$ sites). Farther to the south, and up-dip of the fault trace $(>1.5 \mathrm{~km}$ to $10 \mathrm{~km}$ from the fault trace) a normal component is observed in the lower blocking temperature range (Dec: $347.2^{\circ}$, Inc: $-41.7^{\circ}, \alpha_{95}: 9.4^{\circ}, \mathrm{N}=7$ sites) (up to 
$300-400^{\circ} \mathrm{C}$ ) that we interpret to be equivalent to the normal component present in samples closer to the fault trace. The maximum (un)blocking temperature to which the normal component is carried decreases with increasing distance up-dip and away from the fault trace. In the higher blocking temperature range a southerly trending, reversed component of magnetization is preserved that is more steeply inclined than the component mentioned above (Dec: $177.2^{\circ}$, Inc: $57.1^{\circ}, \alpha_{95}: 7.3^{\circ}, \mathrm{N}=8$ sites). We interpret the moderately-inclined normal component in both regions to be a recent component of magnetization to have been acquired during the exhumation of the Goropu Metabasalt over the last 780,000 years (Brunhes chron). The origin of the older, reversed component is less clear; however, we prefer the interpretation that this component is also an exhumational overprint that was acquired between 2,600,000780,000 years ago during the Matuyama chron.

Comparison of the direction of the average normal component of both Group 1 and Group 2 samples (Dec: $350.6^{\circ}$, Inc: $-37.1^{\circ}, \alpha_{95}: 5.4^{\circ}, \mathrm{N}=25$ sites) with the expected direction of the geomagnetic field at the paleomagnetic sampling locality indicates that $23.9 \pm 2.6^{\circ}(1 \sigma)$ of back-rotation about a sub-horizontal axis sub-parallel to fault strike has affected the footwall of the Mai'iu fault. Taking into account the known dip of the fault at the surface of $<20-22^{\circ}$, this rotation value implies an original fault dip at depth of $41.3-48.5^{\circ}$ that is inherited from a paleo-subduction zone. This result is remarkably consistent with other estimates of the original fault dip: for example, geologically observed fault-bedding cut-off angles on an upper plate imbricate (rider) block imply an original fault dip of $\sim 40-49^{\circ}$ (Little et al., 2019). Also, microseismicity between 10-25 $\mathrm{km}$ depth implies a modern dip there of $30-40^{\circ}$ (Eilon et al., 2015; Abers et al., 2016).

This study is the first of its kind to use paleomagnetism to demonstrate that substantial rolling hinge style rotations have affected the footwall of a continental MCC. 


\section{Table of Contents}

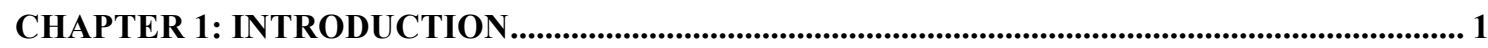

1.1 Metamorphic Core CompleXes and their Detachment Faults............................................... 1

1.2 The Problem of Low Angle Normal Faults and Detachments in the Geological ReCord

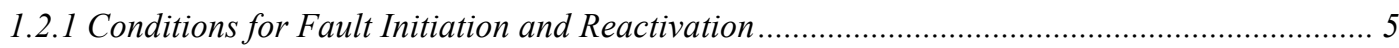

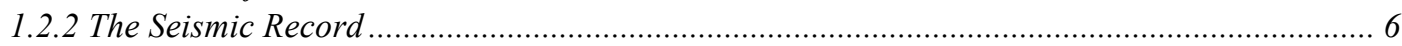

1.2.3 Mechanical Explanations for Slip on LANFs.................................................................. 7

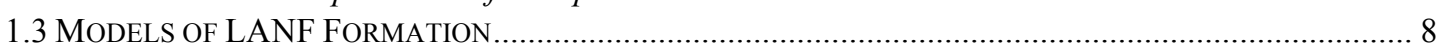

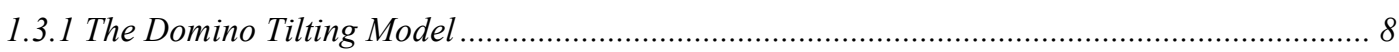

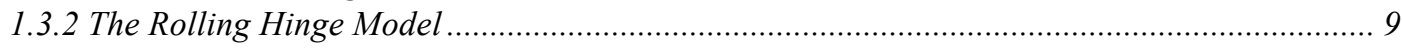

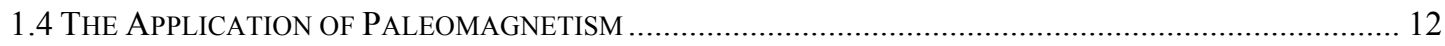

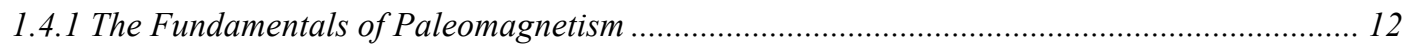

1.4.2 Previous Paleomagnetic Tests of the Rolling Hinge Model.................................................. 15

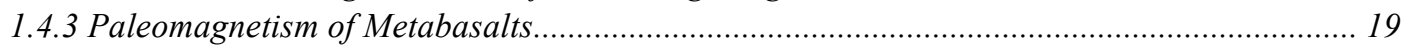

1.4.3.1 Introduction: Metamorphism of Mafic Rocks .............................................................................. 19

1.4.3.2 Thermoviscous Remanent Magnetization of Mafic Metamorphic Rocks .......................................... 20

1.4.3.3 Chemical Remanent Magnetization of Mafic Metamorphic Rocks .................................................. 22

1.4.3.4 Deformation and Paleomagnetism.............................................................................................. 23

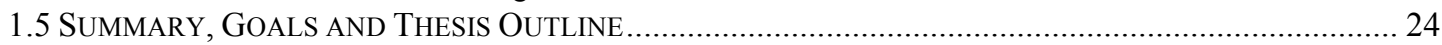

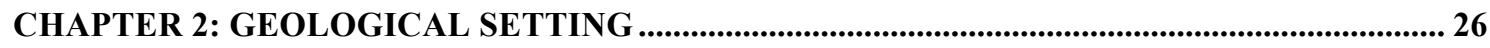

2.1 Regional Tectonic Setting of the Mai'iu Fault and Suckling-Dayman MCC …………..... 26

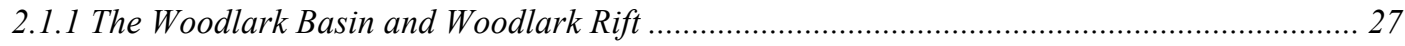

2.2 THE MaI'IU FaUlt AND AsSOCIATED SuCKLING-DAYMan MCC................................................... 31

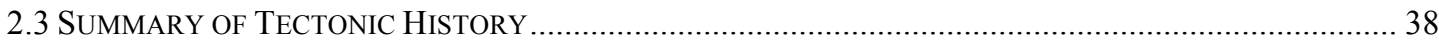

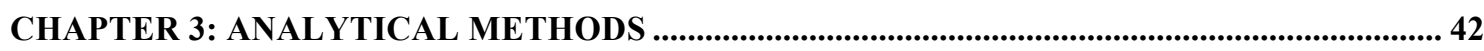

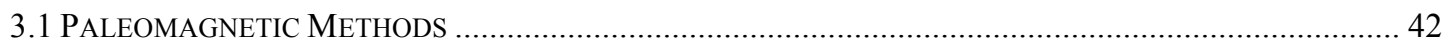

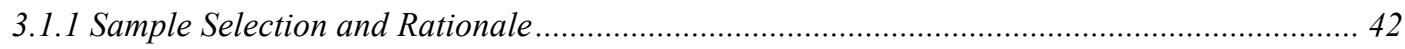

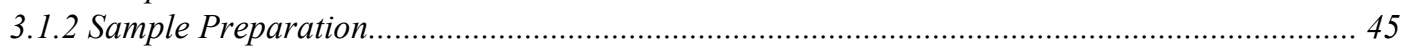

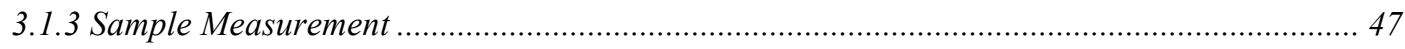

3.1.3.1 Measuring NRM and Progressive Demagnetization Techniques .................................................... 47

3.1.3.2 Temperature-Dependent Susceptibility ……………………………………………………... 49

3.1.3.3 Isothermal Remanent Magnetization Experiments.......................................................................... 49

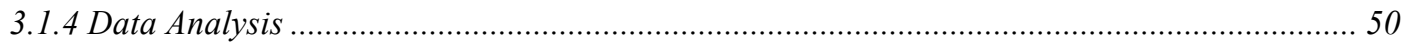

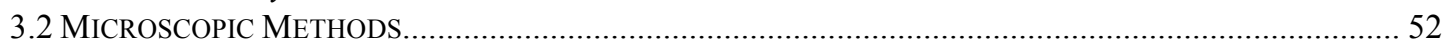

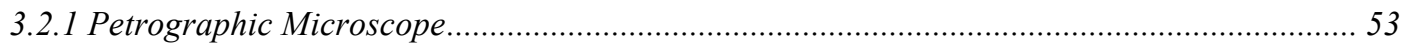

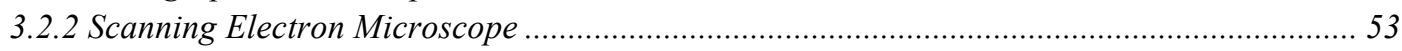

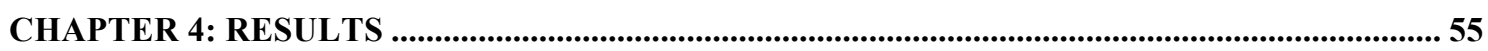

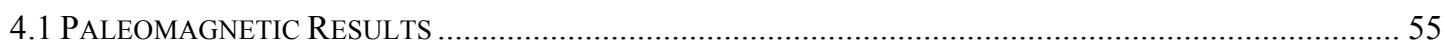

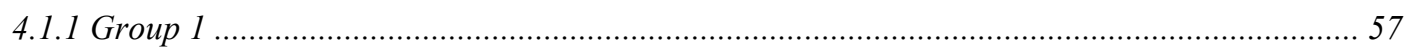

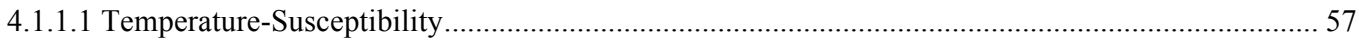

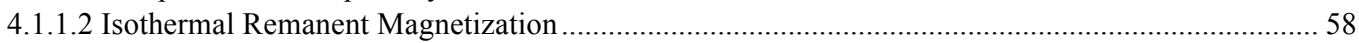

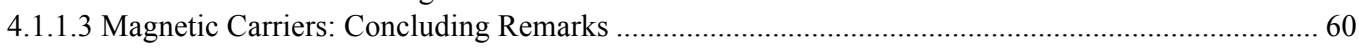

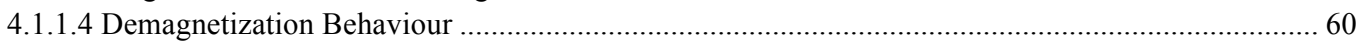

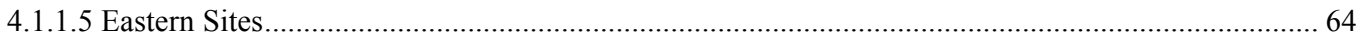

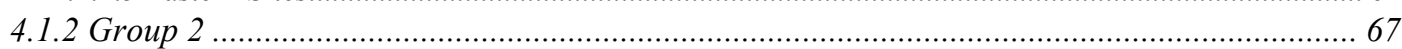

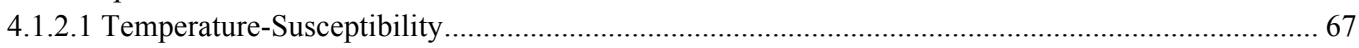

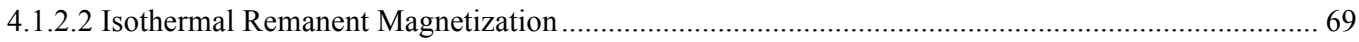

4.1.2.3 Magnetic Carriers: Concluding Remarks ............................................................................... 70

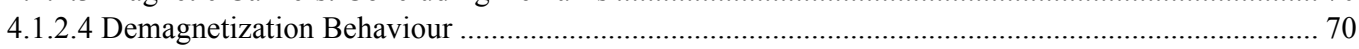

4.2 Microscopic ANalysis of the Magnetic Mineralogy ……………………........................... 76

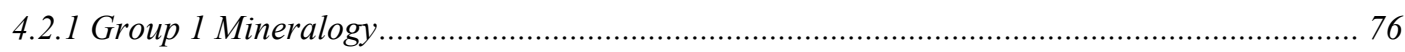

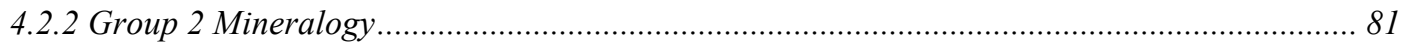

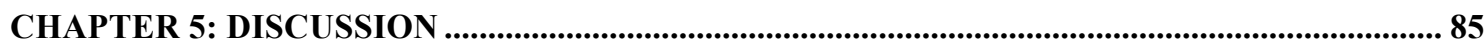




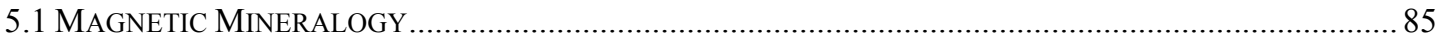

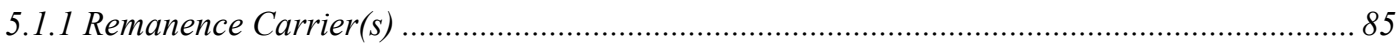

5.1.2 Origin of the Components of Magnetization ………............................................................. 87

5.1.3 Origin of Laboratory-Induced Thermal Alteration ……........................................................ 97

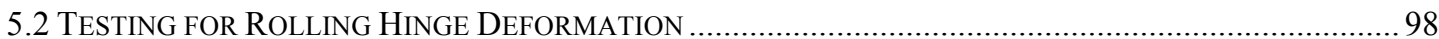

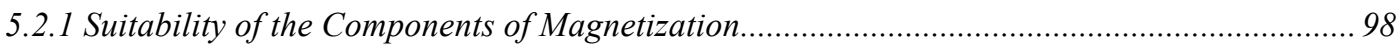

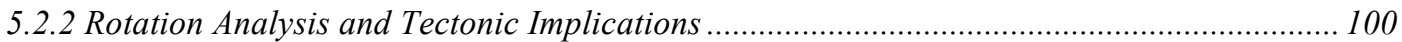

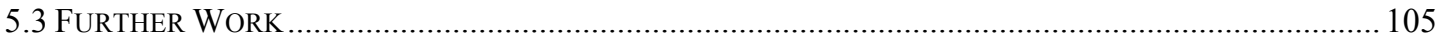

CHAPTER 6: CONCLUSIONS AND SUMMARY …………................................................................... 107

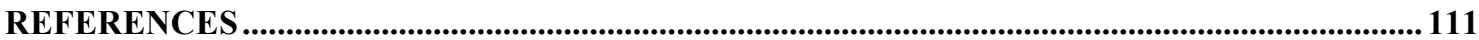

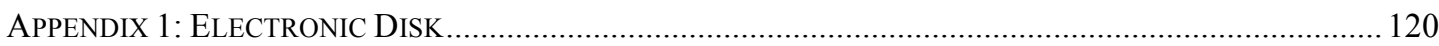

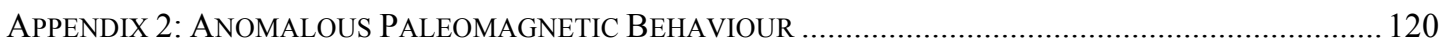

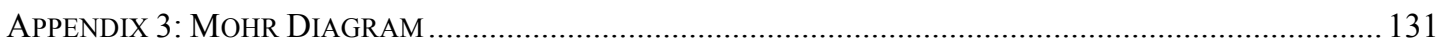




\section{List of Figures}

\section{CHAPTER 1: INTRODUCTION}

Figure 1: Cartoon cross-section of an idealized metamorphic core complex...........................

Figure 2: Global map of metamorphic and oceanic core complexes, known active LANFs and potentially

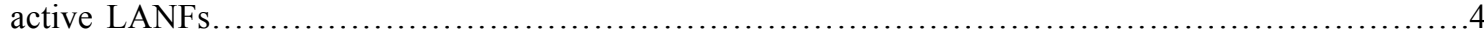

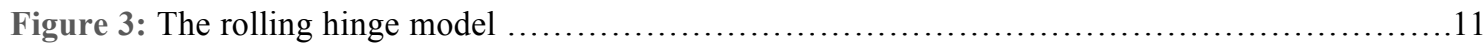

Figure 4: The process of acquisition of thermoremanent magnetization.............................. 14

Figure 5: Schematic blocking temperature spectrum of a rock .................................. 15

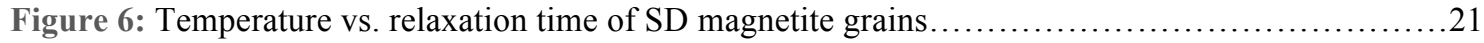

\section{CHAPTER 2: GEOLOGICAL SETTING}

Figure 7: Regional tectonic map of eastern Papua New Guinea................................ 27

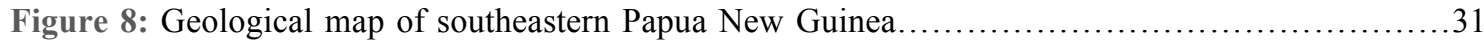

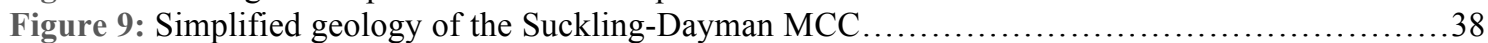

Figure 10: Geological history of the Mai'iu fault and its footwall Goropu Metabasalt...................42

\section{CHAPTER 3: ANALYTICAL METHODS}

Figure 11: Sample suffix scheme for sawn specimens.......................................46

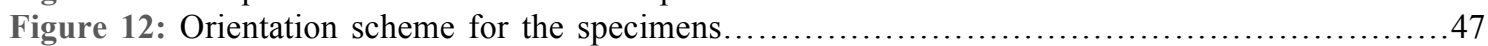

Figure 13: The use of constraints on remagnetization great circles to estimate the direction of an

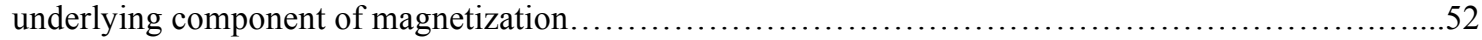

\section{CHAPTER 4: RESULTS}

Figure 14: Suckling-Dayman MCC sample map.......................................... 56

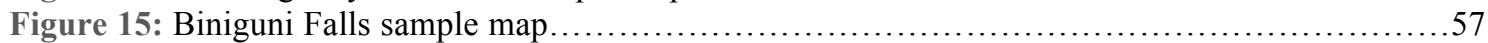

Figure 16: Temperature-susceptibility plots for representative Group 1 samples.....................59

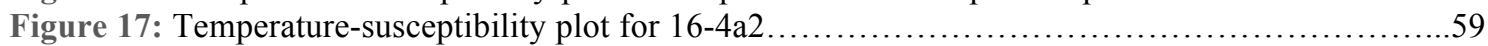

Figure 18: Normalized IRM acquisition curves for an altered and unaltered specimen taken from a

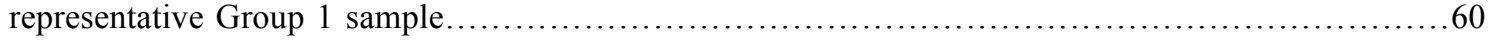

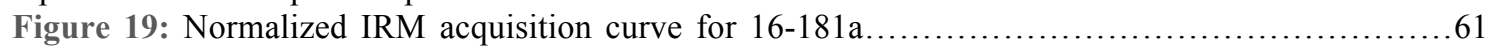

Figure 20: Representative thermal demagnetization plots for Group 1 specimens....................6. 62

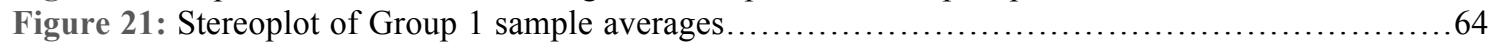

Figure 22: Representative thermal demagnetization plots for $16-119 \mathrm{a}$ and $16-126 \mathrm{~b} \ldots \ldots \ldots \ldots \ldots \ldots \ldots 6$

Figure 23: Stereoplot of the average direction of the normal component in eastern sites..............67

Figure 24: Temperature-susceptibility plot for specimens retrieved from sample 16-172a, obtained during

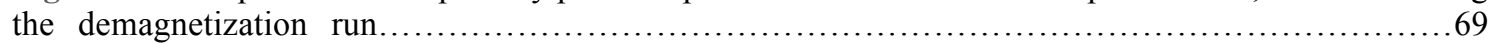

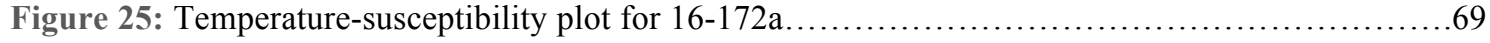

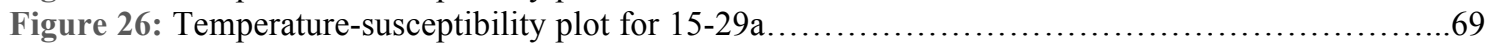

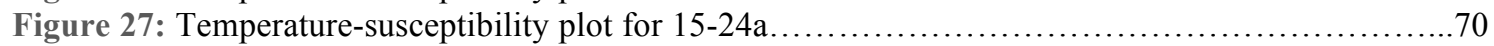

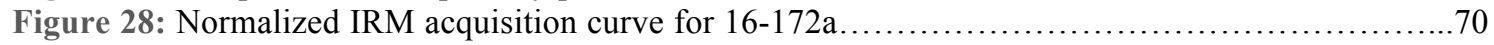

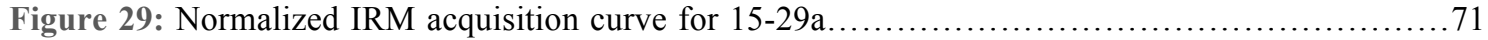

Figure 30: (Un)blocking temperature of the normal component of magnetization vs. distance from the

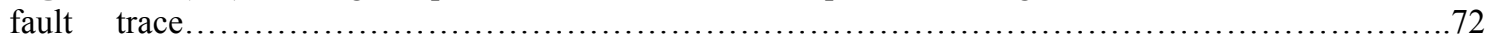
Figure 31: Temperature-susceptibility plots for samples that exhibited two types of thermal alteration

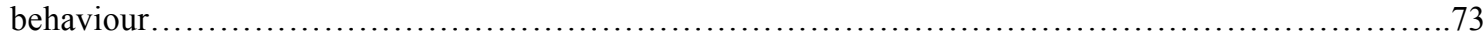

Figure 32: Representative thermal demagnetization plots for Group 2 samples.....................73

Figure 33: Stereoplot of Group 2 sample averages (lower blocking temperature normal component)...75

Figure 34: Stereoplot of Group 2 sample averages (higher blocking temperature reversed component)..75

Figure 35: Representative photomicrographs of a greenschist facies, mylonitic, Group 1 sample of Goropu Metabasalt.................................................................... 77

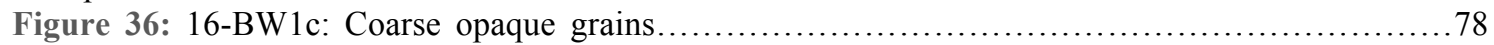

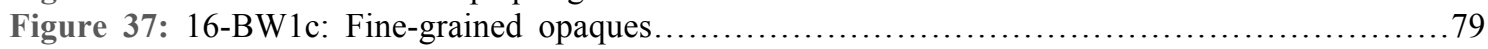

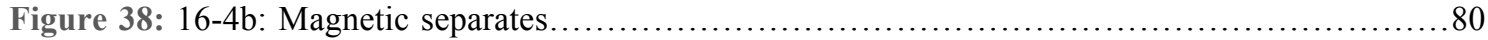

Figure 39: 16-1151a: Magnetic separates................................................. 80

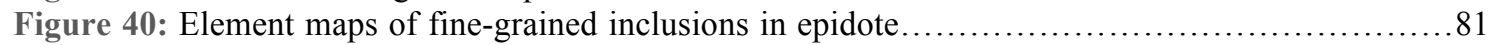

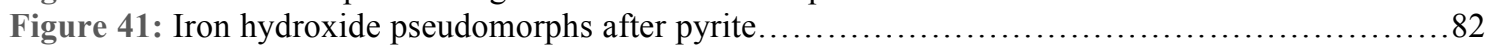

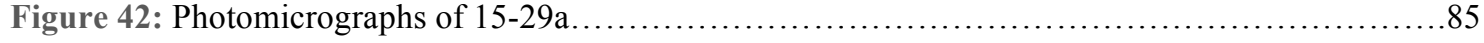

CHAPTER 5: DISCUSSION

Figure 43: Average of the normal component for Group 1 and 2 samples.... 
Figure 44: Stereoplot of Cretaceous expected directions of magnetization and our observed reversed

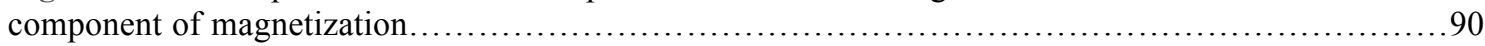
Figure 45: Estimates of metamorphic temperature based on the minimum (un)blocking temperature of

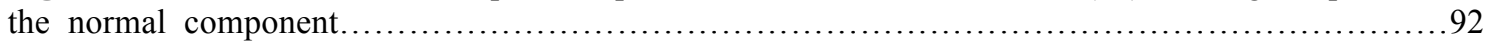
Figure 46: Map of the Suckling-Dayman MCC overlain with estimates of metamorphic

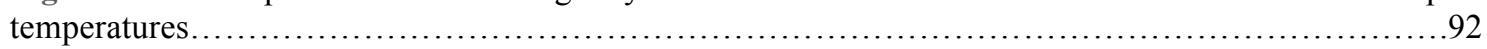
Figure 47: Schematic cross-sections showing the proposed TVRM origin of the reversed

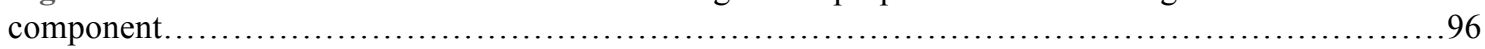
Figure 48: Estimated depth of representative samples of Goropu Metabasalt when the field reversed

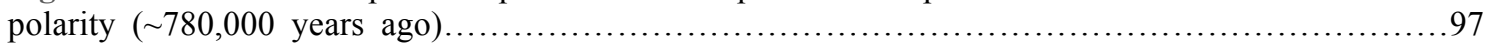

Figure 49: Comparison of the paleomagnetic vector with the foliation plane..............................101 Figure 50: Stereoplot of the observed mean paleomagnetic direction and the expected direction, and

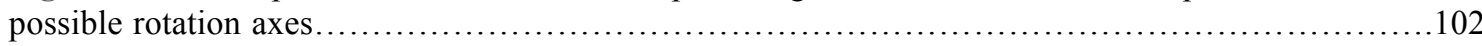

Figure 51: Probability density function of calculated rotation angles.......................... 103

Figure 52: Fault dip vs. inclination for the normal component carried by each sample................106

\section{Chapter 6: CONCLUSIONS AND SUMMARY}

Figure 53: Summary of the geological history of the Mai'iu fault, as partially inferred from paleomagnetic data.

\section{Appendix 2: ANOMALOUS PALEOMAGNETIC BEHAVIOUR}

Figure 54: Representative thermal demagnetization plots for A and B specimens from 16-1151b......121

Figure 55: Representative thermal and alternating field demagnetization plots for $16-1151 \mathrm{c} \ldots \ldots \ldots \ldots 122$

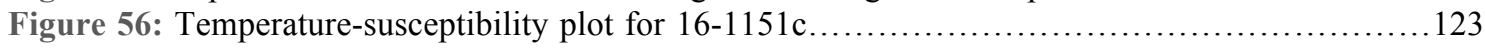

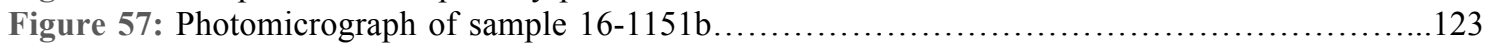

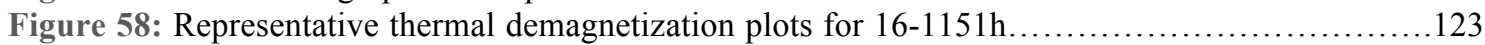

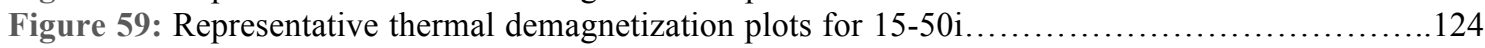

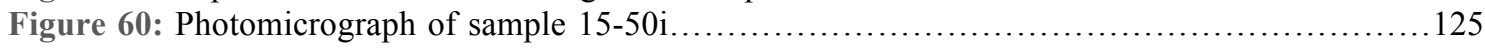

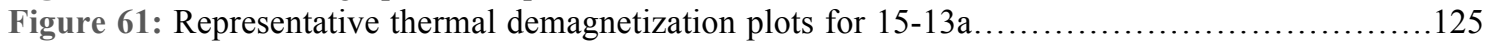

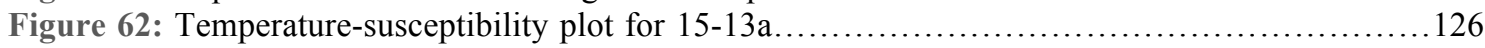

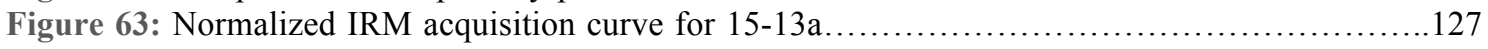

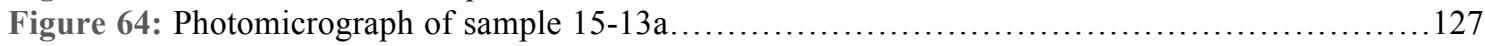

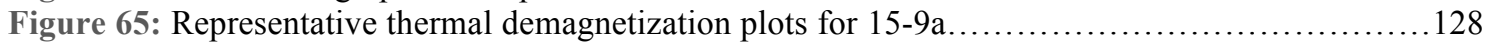

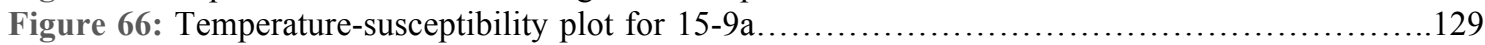

Figure 67: Normalized IRM acquisition curve for 15-9a.................................... 129

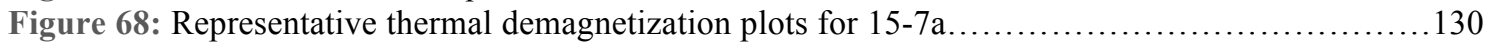

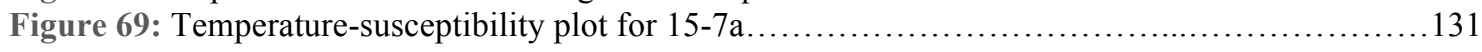

\section{Appendix 3: MOHR DIAGRAM}

Figure 70: Mohr Diagram illustrating a 2D stress state. ...

\section{List of Tables}

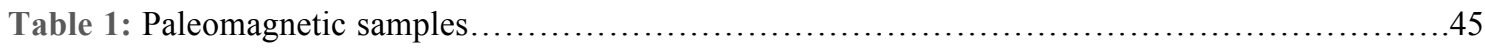

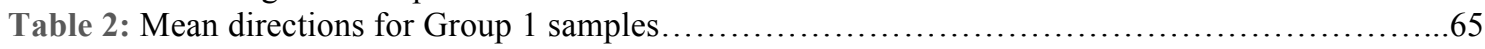

Table 3: Summary of data obtained from Group 2 samples....................................... 76

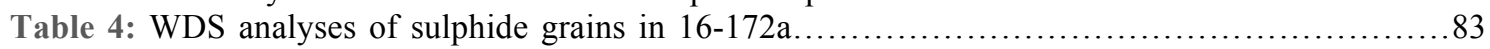

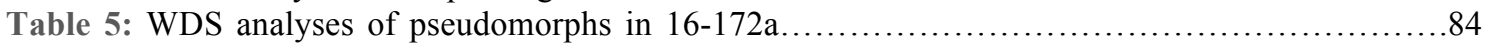

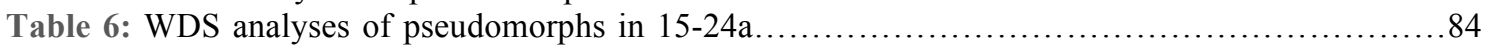

Table 7: Table of mean directions for anomalous paleomagnetic samples.......................... 132 



\section{Chapter 1: Introduction}

Metamorphic core complexes (MCC) are globally widespread in highly extended domains in continental crust. Significant controversy remains regarding the evolution of MCCs, particularly the origin of the gently-dipping $\left(<30^{\circ}\right)$ detachment fault. This is because initiation and slip of normal faults at such shallow angles is mechanically unfavourable (assuming a standard Andersonian stress state for an extensional environment and typical Byerlee values of rock friction). Also, moderate-large earthquakes on normal fault planes dipping $<30^{\circ}$ are rare. Some authors propose that these detachments formed and slipped at shallow angles (Wernicke, 1981, 1995; Spencer, 1984; Davis \& Lister, 1988; Spencer \& Chase, 1989) despite being severely misoriented with respect to the stress field. Others argue that they initiated at a high angle and subsequently rotated to a shallower dip during slip, either through domino rotation (Proffett, 1977) or via a rolling hinge mechanism (Buck, 1988; Hamilton, 1988; Wernicke \& Axen, 1988). Although many authors accept (or assume) the applicability of the rolling hinge model today, compelling evidence to support it has so far only been demonstrated for oceanic core complexes (OCCs) (Garcés \& Gee, 2007; Zhao \& Tominaga, 2009; Morris et al., 2009; MacLeod et al., 2011). Demonstration of the rolling hinge model requires carefully designed studies that can demonstrate substantial back-rotation of the footwall about the fault's strike due to the progressive passage of a rolling hinge during slip and unroofing. A powerful way to document tectonic rotations is through paleomagnetism. Provided footwall rocks preserve a pre/syn-rotation component of magnetization, prior to or during the exhumation of the footwall, comparison between the natural remanent magnetization of the footwall rocks and the time-averaged geomagnetic field at the site where the remanent magnetization was acquired has the potential to demonstrate substantial back-tilting of the footwall rocks about a subhorizontal axis, as is expected for the passage of a rolling hinge.

\subsection{Metamorphic Core Complexes and their Detachment Faults}

Globally MCCs exhibit considerable variability in both their structural form and petrologic characteristics, making it hard to define a MCC. The discussion below is based on several, generally agreed upon features of metamorphic core complexes (Fig. 1).

The footwalls of MCCs generally consist of a regionally extensive (with long axes on 
the order of tens of kilometres in length, and heights of up to 1-2 kilometres [Whitney et al., 2013; Platt et al., 2014]) dome of ductiley deformed low-high grade metamorphic rocks that have been exhumed from the mid-crust or deeper (Fig. 1). Syn-extensional intrusion of granitic magma in the footwalls of MCCs is a common, but not ubiquitous occurrence. The footwall/lower plate of the MCC is juxtaposed against the structurally overlying, typically highly extended upper plate (Fig. 1) across a regionally extensive, typically gently dipping $\left(<30^{\circ}\right)$ detachment fault. Most detachment faults have accumulated enough slip (10's of km) to juxtapose a lower plate derived from midcrustal depths against a hangingwall that is relatively unmetamorphosed. Across the detachment fault, $5-15 \mathrm{~km}$ of structural omission is typically present. The hangingwall, preserved as isolated remnants on top of the domes and around the margins, typically consists of volcanic or sedimentary rocks that are either unmetamorphosed or a significantly lower metamorphic grade than the exhumed footwall rocks in the lower plate of the MCC.

The detachment fault is often deformed into a domal shape above the footwall (Fig. 1). Smaller-scale folds (corrugations or megamullions) parallel to the slip direction commonly occur on the exhumed footwall. The exact mechanism by which the corrugated structure is formed, and timing relative to the formation of the dome, are argued and may be diverse (Davis, 1988; Spencer, 1999; Holm et al., 1994).

The detachment fault is typically underlain by a zone of fault rocks that record a sequence from mylonitic (ductile) to shallower, brittle deformation. This progression reflects passage of the footwall through progressively shallower and cooler conditions as they are exhumed by fault slip (Fig. 1). The oldest fabrics are foliated, lineated mylonites, which vary considerably in thickness (may be hundreds to thousands of metres thick [Whitney et al., 2013; Platt et al., 2014]). Kinematic indicators of shear sense within the mylonites are commonly but not always consistent with sense of motion on the detachment fault; however, the precise temporal and mechanical relationship between the mylonites and the detachment fault remains controversial. Most commonly, ductile deformation of the mylonites predates movement on the detachment fault itself, which is a sharp brittle structure (Lister \& Davis, 1989). Immediately beneath the detachment fault, and above the mylonitic zone, is a zone of brittle fault rocks that may be several metres to tens of metres thick (Fig. 1) (Whitney et al., 2013; Platt et al., 2014). 


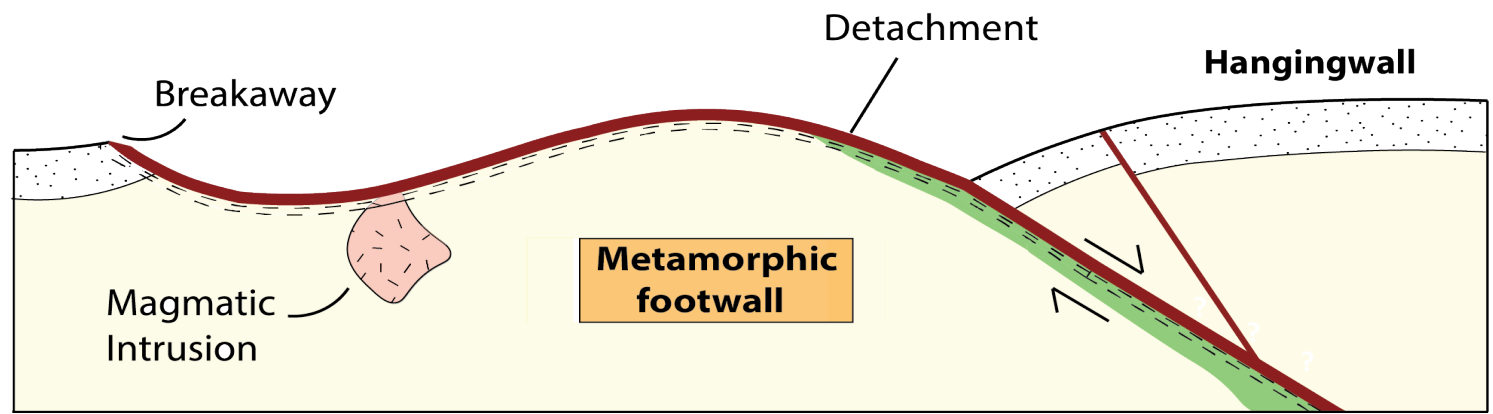

Figure 1: Cartoon cross-section of an idealized metamorphic core complex. Slip on the shallow-dipping detachment at the surface is sufficient to juxtapose medium-high grade, ductiley deformed metamorphic rocks in the footwall against low grade or unmetamorphosed rocks of the brittley extended hangingwall. The breakaway indicates where the detachment originally surfaced. Not to scale.

Not only is there considerable variability between MCCs worldwide, there are many exceptions to the characteristics described above (Platt et al., 2014). MCCs that have been observed to be cored by plutonic igneous rocks (Holder \& Holder, 1988), or with multiple detachments (Parrish et al., 1988), or with no obvious breakaway (MartinezMartinez et al., 2002) are just some of the examples. This serves to emphasize the variability between MCCs globally, and the difficulty in characterizing them.

Metamorphic core complexes were first described in the Cenozoic Basin and Range Province of the North American Cordillera (Davis \& Coney, 1979; Crittenden et al., 1980; Lister \& Davis, 1989). The metamorphic core complexes define a N-S trending semi-continuous belt that stretches from southern Canada to north-western Mexico (Fig. 2). Metamorphic core complexes have since been recognized in a number of continental locations worldwide including the Cyclades archipelago, Aegean Sea, Greece (Lister et al., 1984; Gautier et al., 1993), Mongolia-China where core complexes extend far into Eurasia (Murphy, 2007; Lin et al., 2008), New Zealand (Tulloch \& Kimbrough, 1989) and the Woodlark Rift, Papua New Guinea (Davies \& Warren, 1988; Little et al., 2019) (Fig. 2), where rapid extension and exhumation has led to the world's youngest surficial exposures of ultra-high pressure (eclogite facies) metamorphic rocks (Baldwin et al., 2004, 2008; Little et al., 2011; Gordon et al., 2012). The majority of these MCCs occur in regions of orogenically thickened crust which has subsequently undergone extension. This would seem to suggest that gravitational collapse is an important driving force of continental MCC formation (Whitney et al., 2013). Corrugated domal structures 
bounded by detachment faults similar in geometry and dimension to continental metamorphic core complexes have been observed in seafloor bathymetric images from the Mid-Atlantic ridge (Cann et al., 1997; Tucholke et al., 1998; Blackman et al., 1998; Ranero \& Reston, 1999), the Southwest Indian Ridge (Dick et al., 2000; Baines et al., 2003) and other divergent ridges (Hayman et al., 2011; Christie et al., 1998) (Fig. 2). These have been interpreted as the oceanic equivalent of MCCs - oceanic core complexes (OCCs). The fact that OCCs are common at slow and ultra-slow spreading ridges may be due to the fact that rates of magmatic accretion are insufficient to accommodate plate motion (Tucholke et al., 1998), and the thermal and rheological state of the crust near mid-ocean ridges is conducive to the existence of long-lived detachments.

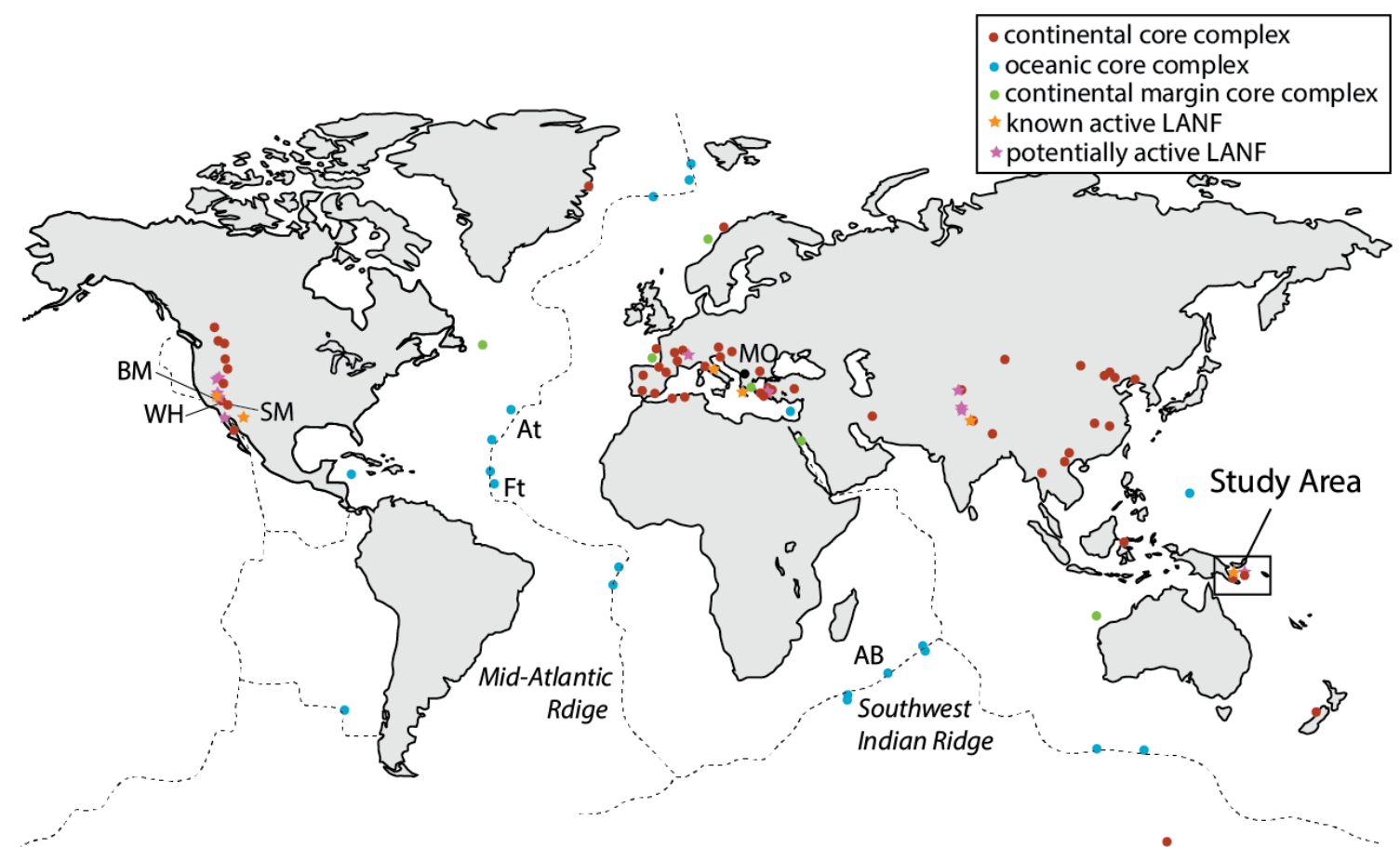

Figure 2: Global map of metamorphic and oceanic core complexes, known active LANFs and potentially active LANFs. Data obtained from compilations of Whitney et al. (2013) and Webber et al. (2018). Locations mentioned in section 1.4.2 are labelled. Atlantis Massif (At); Atlantis Bank (AB); Black Mountain detachment (BM); $15^{\circ} 45^{\prime} \mathrm{N}$ oceanic core complex (Ft); Mirdita Ophiolite (MO); South Mountains (SM); MCCs of the Whipple-Harcuvar extended terrane (WH).

\subsection{The Problem of Low Angle Normal Faults and Detachments in the Geological Record}

Low angle detachment faults that have accrued large amounts of slip, some of which have exhumed MCCs, are common in the geological record. A small number of these detachments (that dip less than $30^{\circ}$ at the surface) are active today (Hayman et al., 2003; Webber et al., 2018) (Fig. 2) or can be shown to have been active in the past at these shallow angles (John, 1987; Lister \& Davis, 1989; Wernicke, 1995). These are known 
as Low Angle Normal Faults (LANFs). Such structures have attracted considerable debate owing to their seemingly infeasible orientations and rarity of large earthquakes on normal fault planes dipping less than $30^{\circ}$. Is slip on such fault planes accommodated principally seismically (Abers, 1991; Abers et al., 1997; Reitbrock et al., 1996; Caskey et al., 1996; Rigo et al., 1996; Bernard et al., 1997; Abbott et al., 2001; Hayman et al., 2003) or by aseismic creep (Boncio et al., 2000; Chiaraluce et al., 2007; Abers et al., 2016)? And how did these structures form? Did they initiate at a shallow angle due to the existence of special boundary conditions, or did they initiate at a high angle and subsequently rotate to shallower dips?

This section discusses why low angle normal faults represent a mechanical problem, why the existence of LANFs appears to contradict the seismic record, and hypotheses that allow for slip on LANFs consistent with our understanding of fault mechanics. Section 1.3 deals independently with the formation of LANFs.

\subsubsection{Conditions for Fault Initiation and Reactivation}

For intact, isotropic, homogeneous crust, brittle faults should form in accordance with the coulomb criterion for shear failure:

$\tau=\mathrm{C}+\mu_{\mathrm{i}}^{*}\left(\sigma_{\mathrm{n}}-\mathrm{P}_{\mathrm{f}}\right)$

Where $\mathrm{C}$ is the initial cohesion, $\mu_{\mathrm{i}}$ is the coefficient of internal friction, and $\tau$ and $\sigma_{\mathrm{n}}$ are, respectively, the resolved components of shear and normal stress on the failure plane. The resolved components of shear and normal stresses on a plane containing the intermediate compressive stress $\sigma_{2}$ at a given angle $(\theta)$ to the maximum compressive stress $\sigma_{1}$ are given by the equations:

$\tau=\left(\left(\sigma_{1}+\sigma_{3}\right) / 2\right) * \sin 2 \theta$

$\left.\sigma_{\mathrm{n}}{ }^{\prime}=\left(\sigma_{\mathrm{n}}-\mathrm{P}_{\mathrm{f}}\right)=\left(\left(\left(\sigma^{\prime}{ }_{1}+\sigma^{\prime}{ }_{3}\right) / 2\right)-\left(\left(\sigma^{\prime}{ }_{1}-\sigma^{\prime}{ }_{3}\right) / 2\right)\right)\right) * \cos 2 \theta$

Where $\tau$ and $\sigma_{\mathrm{n}}$ ' are the shear and effective normal stresses, respectively. $\sigma_{1}$ and $\sigma_{3}$ are the maximum and minimum principal compressive stresses, respectively, and $\sigma_{1}{ }^{\prime}$ and $\sigma_{3}$ ' are the maximum and minimum effective principal compressive stresses. $\mathrm{P}_{\mathrm{f}}$ is the pore fluid pressure, which has the effect of reducing the effective normal stress. 
By substituting equations 2 and 3 into equation 1 it can be shown that, for typical values of $\mu_{\mathrm{i}}\left(0.5-1.0\left[\right.\right.$ Jaeger \& Cook, 1979]) brittle faults should ideally nucleate at $22-32^{\circ}\left(\theta_{\mathrm{i}}\right)$ to $\sigma_{1}$, where the shear stress on the plane is maximized relative to the effective normal stress. This is illustrated graphically in Appendix 3. For extensional environments characterized by a vertical $\sigma_{1}$ (Anderson, 1951) this corresponds to ideal initiation dips of $58-68^{\circ}$ for normal faults.

Re-shear of existing cohesionless faults (i.e. a pre-existing discontinuity such as a preexisting brittle fault or exhumed mylonitic fabric) is governed by the equation:

$\tau=\mu *\left(\sigma_{\mathrm{n}}-\mathrm{P}_{\mathrm{f}}\right)$

For fault planes containing $\sigma_{2}$, oriented at a reactivation angle $\left(\theta_{\mathrm{r}}\right)$ to $\sigma_{1}$ equation four can be rewritten in terms of the ratio of effective principal compressive stresses:

$\sigma^{\prime}{ }_{1} / \sigma^{\prime}{ }_{3}=\left(\sigma_{1}-\mathrm{P}_{\mathrm{f}}\right) /\left(\sigma_{3}-\mathrm{P}_{\mathrm{f}}\right)=\left(1+\mu_{\mathrm{s}} \cot \theta_{\mathrm{r}}\right) /\left(1-\mu_{\mathrm{s}} \tan \theta_{\mathrm{r}}\right)$

For the middle of Byerlee's static coefficient of friction range (0.6-0.85[Byerlee, 1978]) this equation shows a positive minimum at $27^{\circ}$ to $\sigma_{1}$ (corresponds to a dip of $63^{\circ}$ for normal faults) which is the optimal angle for reactivation. As $\theta_{\mathrm{r}}$ increases or decreases away from this optimal angle the stress ratio required for slip on the fault increases (i.e. less favourable orientation for slip), reaching infinity at $54^{\circ}$ to $\sigma_{1}$ (normal fault dips of $36^{\circ}$ ) where the fault frictionally locks-up. Below this dip conditions where $\mathrm{P}_{\mathrm{f}}>\sigma_{3}$ are required for frictional reactivation.

\subsubsection{The Seismic Record}

The idea that normal faults ideally form at $\sim 60^{\circ}$ and frictionally lock up at $\sim 30^{\circ}$ seems difficult to reconcile with the widespread observation of detachment faults in the geological record and the lack of earthquakes attributable to LANFs in the seismic record. Jackson \& White (1989), Thatcher \& Hill (1991) and Collettini \& Sibson (2001) have compiled fault dips for normal fault earthquakes where $M>5.5$ (earthquakes that rupture a large portion of the upper brittle crust). For these compilations, only events where the rupture plane could be unambiguously identified were included. These studies show that large earthquakes generally occur on fault planes with dips between 
$70^{\circ}$ and $30^{\circ}$, with the largest number of events occurring on normal fault planes dipping around $45^{\circ}$. Assuming the regional $\sigma_{1}$ is vertical in the brittle crust then this is consistent with frictional lock-up of normal faults at $30^{\circ}$ at the bottom of the Byerlee friction range $(\sim 0.6)$. However, low dip $\left(<35^{\circ}\right)$ normal fault earthquakes have been argued to have occurred in the Woodlark Rift near the transition from rifting to sea floor spreading in the Woodlark Basin, Papua New Guinea (Abers, 1991; Abers et al., 1997), and potentially in the Gulf of Corinth, Greece (Rigo et al., 1996).

The apparent lack of low angle normal fault earthquakes, and seemingly low coupling coefficients of modelled faults in GPS studies in rifts including the Woodlark Rift, may be due to the fact that these structures are slipping aseismically (Collettini, 2011; Wallace et al., 2014). Others argue that LANFs are capable of seismic slip, at least in part, and the relative absence of LANF earthquakes in the seismic record may be explained by the fact that these faults have unusually long recurrence intervals (Wernicke, 1995). If this is the case then this has substantial implications for seismic hazard in extensional environments where LANFs are common (Wernicke, 1995; Styron \& Hetland, 2014).

\subsubsection{Mechanical Explanations for Slip on LANFs}

I distinguish here between models which seek to explain normal slip on pre-existing low angle faults and ones which seek to explain the initiation of LANFs as primary structures, the latter being much harder to explain. Evidence for slip on geologically active LANFs indicates that these do occur (e.g. Chiaraluce et al., 2007; Wallace et al., 2014), at least at the surface.

Ignoring the problem of LANF nucleation for the moment, models that explain slip on low angle normal faults are divided into those that invoke a non-Andersonian stress state, typically characterized by an inclined $\sigma_{1}$ (Spencer \& Chase, 1989; Lister \& Davis, 1989; Yin, 1989; Westaway, 2005) and those that advocate slip in an Andersonian stress regime as a result of a frictionally weak fault plane, due to either high pore fluid pressure (Axen, 1992) or fault rocks characterized by coefficients of friction lower than the typical Byerlee range (Wintsch et al., 1995; Numelin et al., 2007; Collettini, 2009; Vadacca et al., 2016). The latter condition, if it is caused by smectitic clays, may explain the apparent aseismic behaviour exhibited by some LANFs as many minerals with low coefficients of friction typically exhibit velocity strengthening behaviour which facilitates aseismic creep (Collettini, 2011). 


\subsection{Models of LANF Formation}

LANFs that initiate at a shallow dip are problematic to explain using Mohr-Coulomb theory. Currently there exists no satisfactory general model that explains how LANFs form as primary structures in intact, isotropic crust (Axen, 2004). This is especially troubling given that many geological and thermochronological studies have been used to argue for a shallow initiation dip (e.g., documentation of the cut-off angle between upper plate strata and the detachment, or thermal history profiles parallel to fault dip derived from thermochronological data) (Howard \& John, 1987; Lister \& Davis, 1989; John \& Foster, 1993; Axen, 2004) - even in cases where $\sigma_{1}$ has been shown to be vertical (Axen \& Selverstone, 1994; Lister \& Davis, 1989; John \& Foster, 1993). Alternatively, LANFs may initiate by reactivating pre-existing weak shallow-dipping faults (Jolivet et al., 2010; Lecomte et al., 2010) such as thrust faults. Explaining the existence of apparent primary LANFs remains a significant problem in tectonics. Conversely many now shallow-dipping normal faults may have initiated at a high angle, consistent with Andersonian faulting theory, and later rotated to a shallow dip, potentially becoming inactive once highly misoriented. This can be achieved through either rigid-body rotation of closely bounded faults (Proffett, 1977) or non-rigid deformation of the footwall in response to tectonic unloading (Buck, 1988; Hamilton, 1988; Wernicke \& Axen, 1988).

\subsubsection{The Domino Tilting Model}

In the domino tilting model, normal faults initiate at a high angle and rotate to shallower dips through rigid body, domino-like rotation of high-angle, fault-bounded blocks. Once the faults frictionally lock-up $\left(<30^{\circ}\right)$, due to a diminishing resolved shear stress relative to normal stress on the fault planes, they are cut by a series of younger high-angle normal faults which can rotate the old generation of faults into even shallower dips, despite this generation of faults no longer being active. Proffett (1977) demonstrated this process for the Yerington district, Nevada. In this region, the oldest faults are the most shallowly dipping, and the youngest faults are the most steeply dipping. In instances where one fault cut another it was observed that the more steeply dipping faults cross-cut the more shallowly dipping ones. The domino tilting model provides an explanation for the formation of what are today shallowly dipping normal faults, and it is consistent with both Mohr-Coulomb theory and the seismic record. Furthermore, if one such block is rotated to such an extent that the base of the block is now exposed at the surface, it might look very much like an MCC (Gans \& Gentry, 2017). Although the 
domino model may be applicable to a number of LANFs that are exposed over areas less than tens of square kilometres (Proffett, 1977) many shallowly dipping detachments as large as tens of kilometres in the direction of motion are observed, that may not be crosscut by younger, steeply dipping faults (Lister \& Davis, 1989), suggesting that the domino tilting model may be limited in its application.

\subsubsection{The Rolling Hinge Model}

In the rolling hinge model, the fault initiates at a moderate or steep dip with the upper part of the fault later becoming strongly back-rotated to shallower dips due to the isostatic and flexural response of the footwall to unloading of the hangingwall during progressive slip (Fig. 3). The shallow, back-rotated section, which is inactive, and the steep section down-dip of it, which is active, are separated by an antiformal hinge (Fig. 3). This hinge moves up-dip through the footwall as the footwall is progressively unroofed as a result of fault slip. The axis about which the footwall rotates is horizontal and sub-parallel to the strike of the detachment fault (Fig. 3). The most deformed, shallow and/or exhumed parts of the fault surface are highly misoriented and become abandoned (Fig. 3c). New, more steeply-dipping splay faults may cut into the former hangingwall to bound rider blocks that are captured by and uplifted on the footwall (Fig. $3 \mathrm{c})$.

The rolling hinge model was suggested by Buck (1988), Hamilton (1988) and Wernicke \& Axen (1988), and expanded on the idea originally presented by Spencer (1984) that rotation of the footwall and corresponding detachment can be caused by isostatic rebound in response to unloading of the footwall during exhumation, a process that can explain the occurrence of shallow-dipping normal faults at the surface. The models are broadly similar but differ in the inferred macroscopic footwall deformational mechanism responsible for detachment rotation (e.g., Airy isostasy \& sub vertical simple shear, Wernicke \& Axen, 1988; regional flexure \& flexural failure in which the footwall behaves as a flexed elastic beam, Buck, 1988). These can be thought of as endmember models for rolling hinge deformation that are not mutually exclusive (Manning $\&$ Bartley, 1994). The passage of a rolling hinge does not necessarily require an originally steeply dipping fault (Manning \& Bartley, 1994), as footwall rocks of a detachment that originally formed at shallow angles could also experience near-surface back-tilting in response to tectonic unloading (Spencer, 1984). In order to reconcile the problem of initial dip it must be demonstrated that the footwalls of these detachments 
have experienced substantial tectonic rotations around a horizontal axis parallel to the strike of the fault.

Several authors have proposed that the deeper ductile portions of detachments are subhorizontal at depth (Davis \& Lister, 1988; Cooper et al., 2010). This is based on the observation that many MCCs do not show a significant change of metamorphic grade of the footwall rocks in the direction of upper plate transport (Cooper et al., 2010). This implies the existence of a second hinge at the base of the ramp portion of the detachment. In this instance the footwall rocks are tilted at the base of the ramp and then untilted again at the top of the ramp as they move through a second, upper hinge. This has important consequences for paleomagnetic studies that seek to demonstrate largescale footwall rotations because, depending on when the footwall remanent magnetization was acquired, the footwall paleomagnetic vector may record zero net tilting despite significant tilting at the surface.

In addition to explaining shallow fault dips in the near surface, a strength of the rolling hinge model is that it potentially could explain the rapid uplift of footwall rocks that are commonly inferred using geochronological and thermochronological studies (Davis, 1988). By contrast rapid uplift along primary low angle detachments would require extremely high slip rates. Furthermore, the rolling hinge model can explain the convexupward domal geometry of metamorphic core complexes because progressive backrotation of the exhumed footwall would generate a domiform geometry. The rolling hinge model also has the appealing property that it is consistent with Andersonian faulting theory because it invokes the initiation of normal faults at a high dip angle, with later abandoning of the exhumed upper parts of these faults once they are rotated below $\sim 30^{\circ}$.

Despite widespread discussion of this model it has only been conclusively demonstrated for OCCs. Such studies employed the use of paleomagnetism to demonstrate substantial back-tilting of the footwall relative to the horizontal. The fundamental aspect of paleomagnetism is that rocks are capable of acquiring a component of magnetization parallel to Earth's magnetic field that is stable over geological timescales. Provided footwall rocks acquire a NRM at depth this provides us with a potential passive marker that could be capable of recording any finite rotations of the fault and its footwall (Fig. 3). The orientation of the NRM can be compared to the expected Geocentric Axial 
Dipole (GAD) field at the site where the NRM was acquired to gauge any potential rotation (Fig. 3).

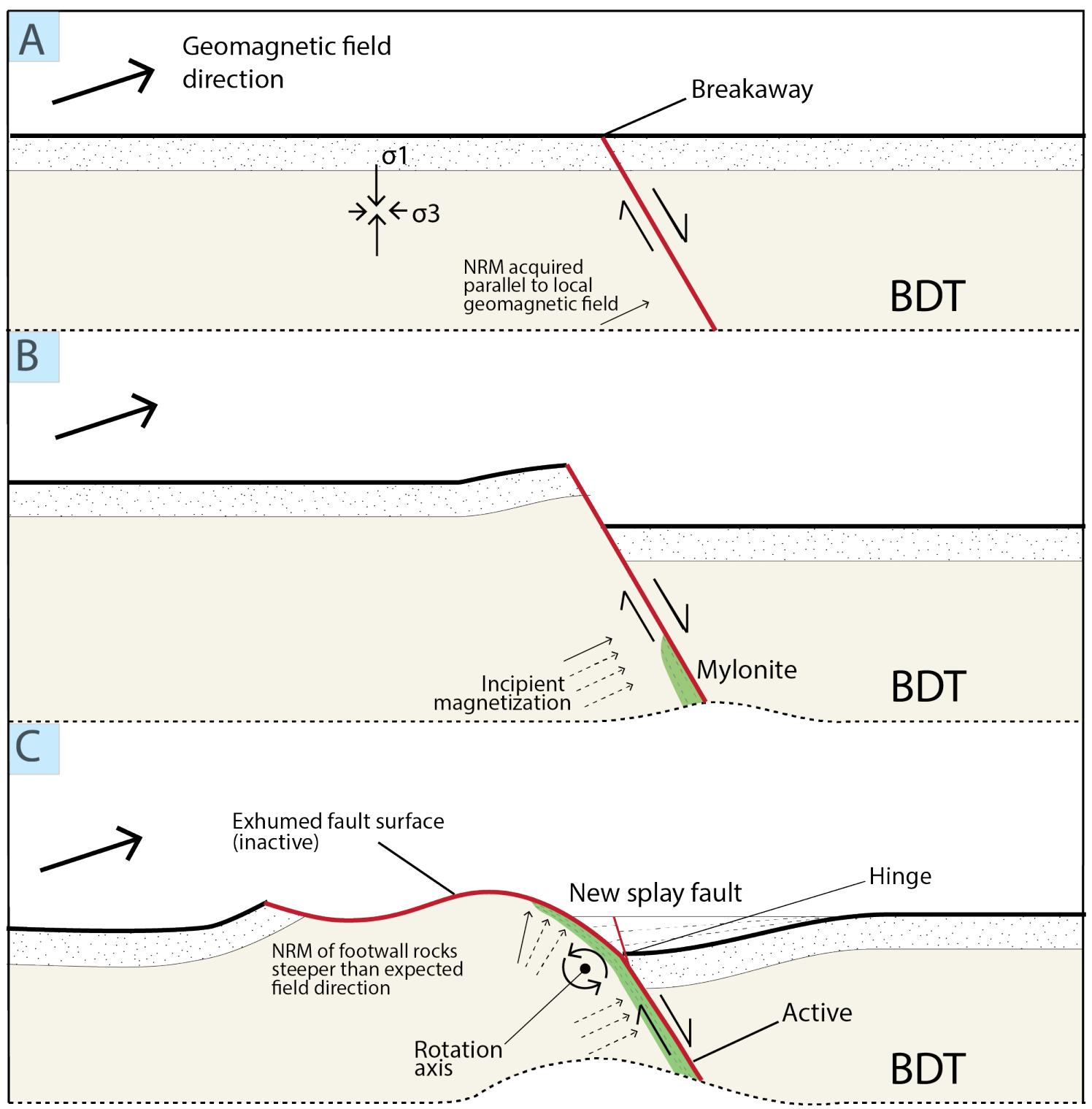

Figure 3: The rolling hinge model. Cartoon illustrating the proposed rolling hinge model for the formation of shallowly-dipping detachment faults. A) Initiation of a high angle normal fault in accordance with Coulomb failure criteria. Footwall rocks cooling through the blocking temperature(s) of their magnetic grains acquire a component of magnetization that is parallel to the local geomagnetic field. Note that for the ease of demonstration this figure depicts a simple scenario where the footwall rocks contain grains with a single blocking temperature (here equivalent to the temperature of the BDT [brittle-ductile transition]). Realistically rocks contain grains with a spectrum of blocking temperatures. B) Slip on the fault and isostatic rebound of the footwall in response to unloading of the hangingwall. C) Continued slip has produced a shallowly-dipping detachment at the surface and a broad dome of ductiley deformed metamorphic rocks. The exhumed fault surface has been abandoned in favour of a new steeper-dipping splay fault which has cut part of the former hangingwall and is now uplifting with the footwall. Rolling hinge deformation is accompanied by a progressive back-rotation of natural remanent magnetization (NRM) that the footwall rocks may carry. Comparison to a time-averaged geocentric axial dipole field at the site of NRM acquisition can therefore be used to test the rolling hinge hypothesis. 


\subsection{The Application of Paleomagnetism}

The primary goal of this thesis is to use paleomagnetic techniques to test whether the footwall of the Mai'iu fault has experienced a large finite back-rotation about the strike of the fault. This section begins with a brief discussion of the physical processes leading to the acquisition and stability of remanent magnetization in rocks containing ferromagnetic/ferrimagnetic minerals. Previous studies that have attempted to demonstrate rotation of shallowly dipping detachments using paleomagnetism are then discussed, followed by a discussion on the paleomagnetism of metamorphic rocks. The samples considered in this study are variably metamorphosed (up to greenschist facies) seafloor basaltic rocks. Fundamental to the interpretation of this study is an understanding of how competing metamorphic (and other) processes may alter or change the primary thermoremanent magnetization (TRM) of the samples that would have been acquired during eruption on the seafloor.

\subsubsection{The Fundamentals of Paleomagnetism}

Magnetic properties of natural materials such as rocks arises from the atomic magnetic moments of constituent atoms, which are produced by the spin and orbit of electrons around the atomic nucleus. In ferromagnetic/ferrimagnetic materials (e.g., some titanomagnetites and titanohaematites) the interaction between atomic magnetic moments produces spontaneous alignment of magnetic moments over a single domain volume. Ferromagnetic/ferrimagnetic grains can consist of one or many (single domain [SD] or multiple domains [MD]) domains of uniform magnetization. Above a threshold grain size $(\sim 0.01 \mu \mathrm{m}$ for magnetite), the formation of multiple domains, each with different magnetization directions, is energetically favourable. In MD grains, the domains are separated by a domain wall over which magnetization direction changes rapidly. Rocks with a high proportion of MD grains are less well suited for paleomagnetism because domain walls shift easily in response to changes in the geomagnetic field making MD grains less stable carriers of remanent magnetization. The boundary between coarse MD grains and fine grained SD grains is not sharp. The transition also depends on mineralogy and grain shape. Pseudo-single domain (PSD) grains are grains of intermediate size which consist of few domains and may carry a strong and stable magnetization due to the existence of crystal imperfections.

Rocks that contain a natural remanent magnetization (NRM) can be thought of as an assemblage of SD ferromagnetic/ferrimagnetic grains that are dispersed within a matrix 
of nonmagnetic minerals. The vector sum of the grain magnetic moments results in an overall natural remanent magnetization of the rock. Remanent magnetization can consist of one or more components typically comprising 1) the primary component acquired during formation of the rock, and 2) secondary component(s) acquired after formation of the rock.

Many different physical processes can lead to the acquisition of a primary remanent magnetization during the formation of a rock, including 1) thermoremanent magnetization, 2) detrital remanent magnetization and 3) chemical remanent magnetization. Here I focus on the acquisition of thermoremanent magnetization, the means by which the exhumed, metamorphosed samples considered in this study would have acquired a primary magnetization. Such a discussion also introduces fundamental paleomagnetic concepts, such as blocking temperature and relaxation time, that aid in understanding how secondary processes may affect the primary magnetization of a rock. Such processes are considered in more detail in section 1.4.3.

The basic theory of thermoremanent magnetization asserts that rocks consisting of an assemblage of identical single domain grains cooling below the Curie temperature(s) of their respective magnetic mineral(s) acquire a component of remanent magnetization that is parallel to the ambient magnetic field at that time. Each mineral has a characteristic Curie temperature (e.g. $580^{\circ} \mathrm{C}$ for magnetite, $680^{\circ} \mathrm{C}$ for haematite). Above the Curie temperature $\left(T_{c}\right)$ of the minerals, spontaneous interaction and alignment of atomic magnetic moments does not occur, therefore the grains cannot sustain a magnetic moment (Fig. 4a). The minerals are said to behave paramagnetically.

When the rock cools below the Curie temperature spontaneous alignment of atomic magnetic moments occur, resulting in ferromagnetic/ferrimagnetic grains that have magnetic moments (Fig. 4b). However, just below the Curie temperature grain moments are unstable due to thermal fluctuations and the overall magnetization decays rapidly (Fig. 4b). In such a rock, the action of the geomagnetic field does result in a bias of grain magnetizations parallel to the magnetic field that counters the randomizing influence of thermal energy fluctuations. This bias is captured as the rock cools below the blocking temperature $\left(\mathrm{T}_{\mathrm{b}}\right)$ of the grains (defined as the temperature below which the magnetization of a rock is considered stable on geological timescales), resulting in a net 
magnetization parallel to Earth's magnetic field that is stable over geological timescales (Fig. 4c).

This stability arises from the random distribution of "easy axes" of the ferromagnetic/ferrimagnetic grains. Easy axes are axes along which it is energetically favourable for the magnetization of a grain to lie. Such axes arise from shape and magnetocrystalline anisotropies of the grains, i.e., it is energetically favourable for the magnetization of an elongate ferromagnetic/ferrimagnetic grain to be parallel to the long axis. If an ambient magnetic field is removed, the grain magnetic moments that were previously aligned with the ambient field slowly relax back towards the closest easy axis. The random distribution of easy axes of ferromagnetic/ferrimagnetic minerals within the rock results in a net remanent magnetization that is parallel to Earth's magnetic field.

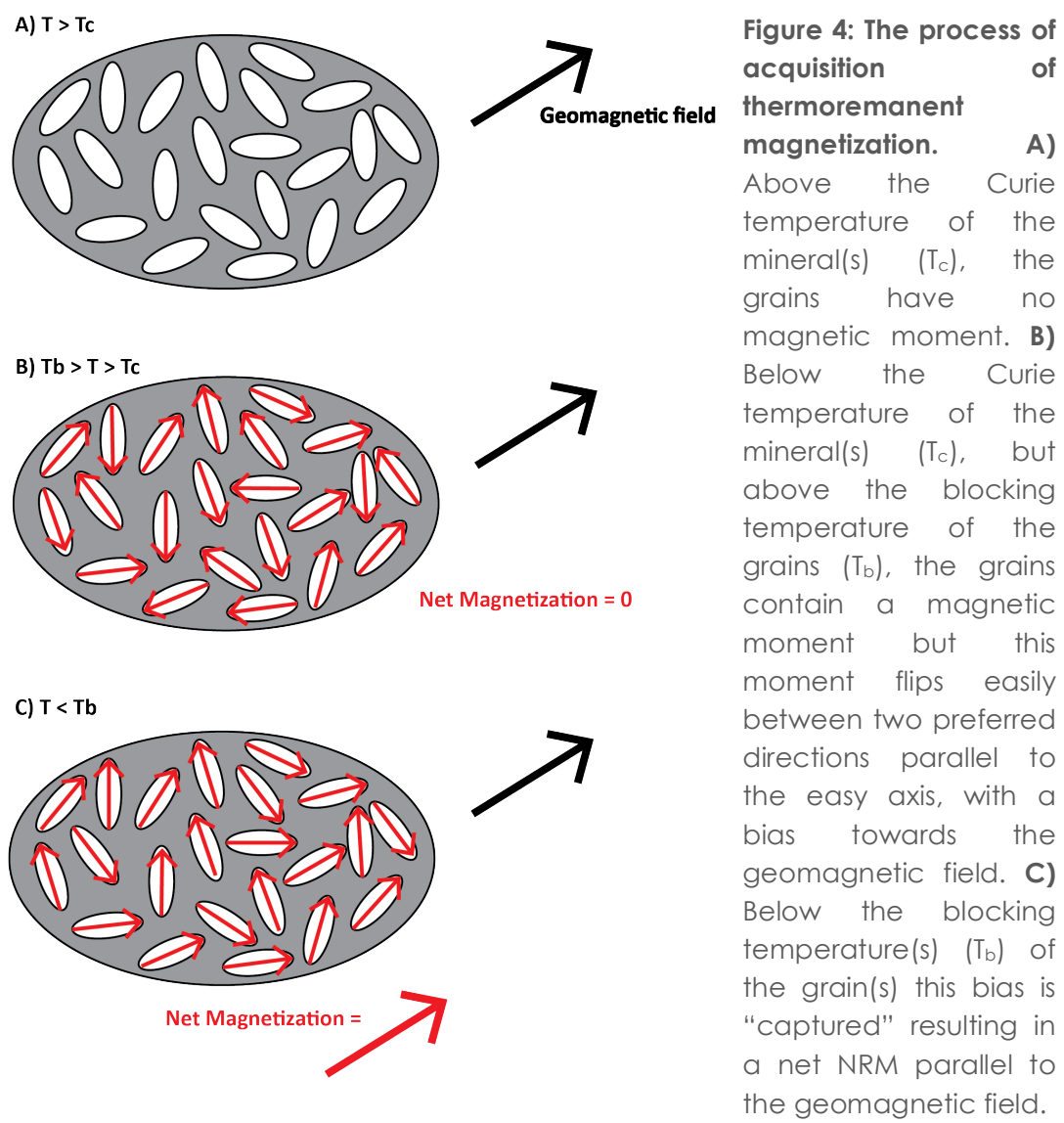

The above analysis of thermoremanent magnetization acquisition assumed that rocks feature a single, fixed blocking temperature for their constituent ferromagnetic/ferrimagnetic grains. Realistically rocks are heterogeneous and are composed of grains that exhibit a spectrum of blocking temperatures ranging between 
the Curie temperature(s) of the ferrimagnetic/ferromagnetic minerals to ambient room temperature (Fig. 5). This is due to both heterogeneities in grain shape and size, and mineralogy.

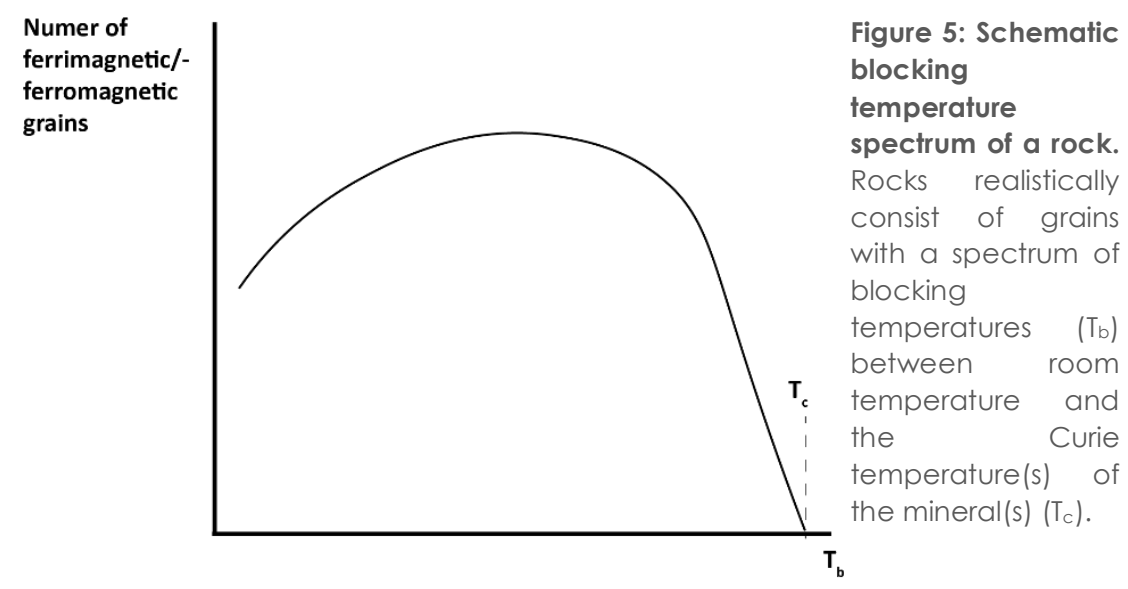

The existence of a spectrum of blocking temperatures also explains how secondary processes such as viscous relaxation of unstable grains, weathering, lightning strikes and metamorphism may partially or completely overprint the primary magnetization of a rock. This concept is expanded on further in section 1.4.3. This is the basis for stepwise thermal or alternating field demagnetization, which allows us to isolate different components of remanent magnetization that were acquired through different processes and inhabit different parts of the blocking temperature or coercivity spectra. The coercivity of a grain is the resistance of a grain to changes in magnetization. Like blocking temperature, rocks consist of grains with a spectrum of coercivities due to differing grain volume, shape and mineralogy.

\subsubsection{Previous Paleomagnetic Tests of the Rolling Hinge Model}

Using paleomagnetic methods, shallow-dipping detachments bounding oceanic core complexes have been demonstrated to have rotated back from originally higher dips. Garcés \& Gee (2007) and Zhao \& Tominaga (2009) demonstrated large-scale backrotations of $50-80^{\circ}$ and $50^{\circ}$ of footwall rocks (upper mantle peridotite and lower crustal gabbro) drilled near the Fifteen-Twenty Fracture Zone near the mid-Atlantic ridge, and the Atlantis Massif, respectively (Fig. 2). Because ODP and IODP cores are not oriented azimuthally these authors relied on inclination data alone, preventing a more comprehensive demonstration of tilting. Morris et al. (2009) overcame this problem by correlating core structures with those observed in the borehole wall, therefore allowing 
an azimuthal orientation to be assigned to the core. They demonstrated a minimum of $\sim 46^{\circ}$ of back rotation of the footwall of the Atlantis Massif from their paleomagnetic data. MacLeod et al. (2011) were able to collect precisely oriented cores and provided much tighter constraints on the potential rotation axes, by reference to the full $3 \mathrm{D}$ paleomagnetic vector, and kinematic data from the detachment fault shear zone. They demonstrated $\sim 64^{\circ}$ of back rotation had affected the footwall of the $15^{\circ} 45^{\prime} \mathrm{N}$ oceanic core complex near the Fifteen-Twenty Fracture Zone. Other studies, sampling similar footwall lithologies, have documented lesser degrees of footwall back rotation $\left(17-20^{\circ}\right)$ for Atlantis Bank OCC on the SW Indian ridge (Fig. 2) (Pariso et al., 1991; Pettigrew et al., 1999; Dick et al., 2000; Allerton and Tivey, 2001). MacLeod et al. (2011) argued that some rotation may have occurred prior to the footwall rocks cooling through the Curie temperatures of the constituent ferro/ferrimagnetic minerals and thus that a portion of the finite rotation would not have been recorded, therefore such rotation angle estimates may be considered a minimum. Paleomagnetic sampling of the footwall of a detachment fault preserved in the Jurassic age Mirdita Ophiolite (Fig. 2) indicates rolling hinge-style deformation was present in the ancient lithosphere (Maffione et al., 2013).

Paleomagnetic studies in oceanic settings are, in general, much more straightforward than the continents because the oceanic crust near a mid-ocean ridge generally has a much less complicated thermal and deformational history than continental rocks. The application of paleomagnetism to the footwalls of metamorphic core complexes in the continents requires careful consideration of the magnetic carriers in the metamorphosed footwall rocks, and evaluation of when and how they acquired any magnetization relative to exhumation of the footwall.

Paleomagnetic data from the footwalls of detachment faults in continental MCCs have so far been generally inconclusive. Livaccari et al. (1995) sampled syn-kinematic footwall intrusives (granite and granodiorite plutons and mafic and felsic dykes) and Proterozoic host rocks (gneiss) of the footwall of the South Mountains MCC, North American Cordillera (Fig. 2). The paleomagnetic data suggest the 'back-dipping' side of the MCC has rotated by $\sim 10^{\circ}$ about the strike of the fault, and an initially low dip for the bounding detachment $\left(<15^{\circ}\right)$. The South Mountains detachment fault is believed to have formed at comparatively shallow crustal levels (5 to $10 \mathrm{~km})$ and therefore may not be representative of fault geometry at greater depths (Livaccari \& Geissman, 2001). 
Livaccari \& Geissman (2001) sampled footwall rocks including Miocene intrusions (dykes and plutons), Late Cretaceous granite intrusions, and Proterozoic host rocks (gneisses and granites with ages ranging from 1.7 to $1.4 \mathrm{Ga}$ ) from the Harquahala, Harcuvar, Buckskin, and Whipple MCCs (together forming the Whipple-Harcuvar extended terrane) (Fig. 2) of western Arizona and south-eastern California, which are a product of Miocene extension. The authors found evidence for back-rotation of the footwalls, but only modest amounts of $<15^{\circ}$. This is generally consistent with geological field studies which indicate a low initiation angle for the Whipple Mountains detachment (Lister \& Davis, 1989). Other studies that use other data such as tilted mafic dykes are permissive of a rolling hinge evolution for the Whipple and Buckskin MCCs (Axen \& Selverstone, 1994; Dorsey \& Becker, 1995; Spencer \& Reynolds, 1989; Gans $\&$ Gentry, 2017). Assuming vertical emplacement of the dykes indicates up to $35^{\circ}$ of tilting of the footwall about the strike of the detachment fault bounding the Whipple Mountains MCC (Gans \& Gentry, 2017). Thermochronological data, within the uncertainty, from the Harcuvar mountains may support a higher initiation angle (Axen \& Bartley, 1997). We suggest that the paleomagnetic data reported by Livaccari et al. (2001) may only be indicative of the minimum amount of rotation that has affected the footwalls of these MCCs because considerable rotation may have occurred above the blocking temperatures of the grains carrying the stable, isolated component of magnetization.

Holm et al. (1993) sampled 11.5Ma (gabbro-diorite) and 8.7Ma (granite and quartz monzonite) intrusions and host Precambrian gneiss and diabase in the footwall of the Black Mountains detachment, California (Fig. 2). Their paleomagnetic data record a complex deformational history of which no net tilt can be confidently attributed to a rolling hinge. A component of magnetization present in the older plutons varies in inclination as a function of site locality and this is interpreted to be due to folding of the intrusion following remanence acquisition. Sampling of the younger ( $8 \mathrm{Ma}$ ) plutons yields a remanence that does not deviate from the expected Miocene direction. Thermochronological (Holm \& Dokka, 1993) and geological (Holm \& Wernicke, 1992; Holm, 1995) data are, however, consistent with the passage of a rolling hinge. Axen \& Bartley (1997) argued that the lack of a recorded net tilt may be because the detachment is sub horizontal at depth. In this case the footwall rocks may have been tilted when they moved through the lower hinge and then untilted again as they moved through the 
upper hinge at the top of the ramp, thus recording no net tilt. This may also be the case for the South Mountains MCC (Axen \& Bartley, 1997).

The above summarized paleomagnetic studies of continental MCCs have generally been hindered by the footwall rocks being old with respect to the initiation of extension, and that fault slip and exhumation have long been inactive. This means the footwall remanent paleomagnetic vector may be affected by pre- and post- exhumation deformation that is difficult to evaluate or quantify (such as pre-extension large-scale continental translation), and the timing of magnetization and the orientation of the geomagnetic field, with which to compare the remanent magnetization of the footwall rocks, at such time and location can be difficult to constrain.

Rolling hinge behaviour on the continents has also been investigated through geological field studies (i.e., documenting the cut-off angle of upper plate strata and the detachment, reconstructed cross-sections) and the careful application of thermochronologic studies to estimate pre-extension initial fault dip angles. Although there is tantalizing evidence for rolling hinge behaviour (Bartley \& Wernicke, 1984; Bartley et al., 1990; Dokka, 1993; Manning \& Bartley, 1994; McGrew \& Snee, 1994; Fletcher et al., 1995; Lee, 1995; Selverstone et al., 1995; Hoisch et al., 1997) so far most are merely permissive of rather than unambiguously indicative of a rolling hinge that caused substantial tectonic rotation.

This study is concerned with the Mai'iu fault, located on the mountainous Papuan Peninsula in the southern margin of the Woodlark Rift (Fig. 2). The normal-sense Mai'iu fault is active today, dips $<20-22^{\circ}$ at the surface and is slipping at a dip slip rate of $\sim 1 \mathrm{~cm} / \mathrm{yr}$ (Wallace et al., 2014; Webber et al., 2018). This low angle normal fault has exhumed the well-exposed Suckling-Dayman MCC in its footwall, which is composed chiefly of the Late Cretaceous age Goropu Metabasalt. Because this fault is wellexposed and active today this provides a rare "natural laboratory" in which to assess whether or not the Mai'iu fault has evolved through a rolling hinge process. Rapid slip on the Mai'iu fault has led to the rapid and ongoing exhumation of the Goropu Metabasalt. Therefore, the footwall rocks may have acquired a recent component of magnetization during rapid exhumation in an ambient magnetic field that is approximately the present-day one. Any rotation analysis is therefore unhindered by uncertainties in the reference geomagnetic field, as is the case for MCCs that are the 
result of Miocene and older extension. Metabasalts typically carry a relatively high proportion of ferrimagnetic minerals in the single to pseudo-single domain grain size range, which are efficient carriers of remanent magnetization. Because the footwall is comprised chiefly of Goropu Metabasalt this may present an opportunity to analyse whether rolling-hinge style rotations have affected this MCC. Furthermore, unlike drilling studies at mid-ocean ridges, outcrops are widespread in the footwall of this MCC, allowing comprehensive sampling both up-dip and along strike of the fault trace.

\subsubsection{Paleomagnetism of Metabasalts}

\subsubsection{Introduction: Metamorphism of Mafic Rocks}

Metabasalts are basaltic rocks which have experienced mineralogical changes in response to elevated temperature and pressure. Such reactions show wholesale changes in mineralogy even at low grades of metamorphism. Due to the anhydrous nature of minerals in a primary basaltic lava, the presence of fluids is essential to produce the typical hydrous phases we see in metamorphosed basalt. Furthermore, what phases develop at low pressures and temperatures are strongly dependent on both the fluid composition and bulk composition of the precursor rock (Winter, 2001).

The typical low grade $\left(<150^{\circ} \mathrm{C}\right)$ (zeolite facies) assemblage in a metabasalt consists of albite, chlorite, calcite, quartz and one or more zeolites. At slightly higher grade the zeolites disappear and prehnite, pumpellyite, and eventually actinolite, appear across a temperature range of $150-300^{\circ} \mathrm{C}$ that spans the prehnite-pumpellyite to pumpellyiteactinolite facies. The metastable nature of Low-T hydration reactions that replace primary igneous phases means low-grade metabasalts commonly exhibit disequilibrium assemblages, with unreacted High-T assemblages occurring alongside Low-T assemblages, and relict igneous grains and textural relations are commonly preserved. Furthermore, the heterogeneous distribution of fluid and hydration in a rock results in the irregular replacement of primary phases by Low-T phases, with preferential development of Low-T phases in fluid-rich vesicles and veins. These very low-grade metamorphic facies are collectively termed the subgreenschist facies. The transition to greenschist facies $\left(\mathrm{T}=300-450^{\circ} \mathrm{C}\right)$ is typically marked by the disappearance of pumpellyite and the growth of epidote minerals. The typical stable mineral assemblage for a greenschist facies metabasalt is chlorite + epidote + actinolite + albite and quartz. Greenschist facies (and above) rocks are commonly pervasively recrystallized and 
primary igneous textures may be obliterated.

During metamorphism rocks are subjected to elevated temperatures and complex mineralogical and chemical changes, therefore secondary processes such as chemical remanent magnetization or thermoviscous remanent magnetization may overprint the primary magnetization of a metabasalt. As an additional complexity, the basaltic protolith may have been altered by seafloor processes soon after eruption. Seafloor basalts are commonly subjected to hydrothermal alteration, seafloor metamorphism and weathering on the ocean floor. Recognition of these processes is important from a paleomagnetist's perspective because these processes can act to alter the assemblage of magnetic minerals present in the rock, produce new magnetic minerals (e.g. oxidation of magnetite to maghemite during interaction with hydrothermal fluids) or it may change the bulk composition of the rock. Distinguishing between competing processes that may produce the observed remanent magnetization in the Goropu Metabasalt is the motivation for section 4.2 in this study. Metamorphic rocks are generally regarded as poor recorders of primary magnetization, but are generally excellent recorders of secondary, more recent component(s) of magnetization. This may be advantageous for our study if the Goropu Metabasalt acquired a more recent, secondary component of magnetization prior to or during uplift and exhumation of the Suckling-Dayman MCC.

\subsubsection{Thermoviscous Remanent Magnetization of Mafic Metamorphic} Rocks

When subject to elevated temperatures for a prolonged time, previously magnetized grains may unblock and progressively remagnetize in the direction of the ambient geomagnetic field. On cooling they may retain this new magnetization. This process is known as thermoviscous remanent magnetization (TVRM). Any partial TVRM overprint may be isolated by thermal demagnetization experiments. Laboratory temperatures required to remove a TVRM metamorphic overprint are generally much higher than the maximum metamorphic temperatures that the rock has seen. This is due to the temperature dependence of relaxation times of ferromagnetic/ferrimagnetic grains. For a large number of identical, single-domain grains this relation can be expressed in terms of the equation:

$\tau=(1 / \mathrm{j}) \exp \left(\mathrm{M}_{\mathrm{s}} \mathrm{B}_{\mathrm{c}} \mathrm{v} / \mathrm{kT}\right)$ 
Where:

$\tau=$ Relaxation time

$\mathrm{B}_{\mathrm{c}}=$ The microscopic coercivity of a single-domain grain (a function of grain shape and temperature)

$\mathrm{M}_{\mathrm{s}}=$ Saturation magnetization (temperature-dependent)

$\mathrm{V}=$ Single-domain grain volume

$\mathrm{j}=$ Frequency factor $\left(10^{8}-10^{10} \mathrm{~s}^{-1}\right)$

$\mathrm{k}=$ Boltzmann's constant

$\mathrm{T}=$ Absolute temperature

Figure 6 shows relaxation time vs. temperature for different populations of grains of single-domain magnetite. This figure shows that an assemblage of identical singledomain magnetite grains heated for 10 million years at $520^{\circ} \mathrm{C}$ (Point 1 ) requires $550^{\circ} \mathrm{C}$ to unblock the acquired magnetization (heating in the lab for 30 minutes) (Point 2). Néel's (1955) theory of single domain grains thus predicts that for a rock comprised of single domain magnetite or haematite, primary magnetizations may survive heating to greenschist facies, but not amphibolite facies (Pullaiah et al., 1975). Numerous studies have demonstrated that temperatures required to remove thermoviscous remanent magnetization are generally higher than those predicted by Néel theory (Butler, 1992). This is inferred to reflect the existence of PSD or MD grains in natural samples and perhaps chemical alteration of existing ferro/ferri- magnetic phases or growth of new ferro/ferri- magnetic phases during metamorphism in such rocks.

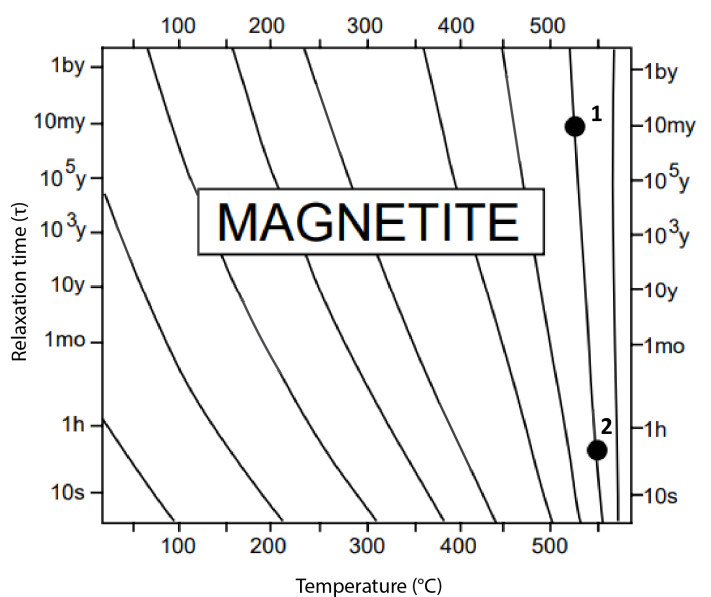

Figure 6: Temperature vs.

relaxation time of SD magnetite grains, for which the temperaturedependence of $M_{s}$ is well constrained. The contours represent relaxation time vs. temperature for an assemblage of identical SD magnetite grains (assembages of differing size and shape). Based on Néel's single domain theory. From Butler (1992), redrawn after Pullaiah et al. (1975). 


\subsubsection{Chemical Remanent Magnetization of Mafic Metamorphic Rocks}

During metamorphism existing ferromagnetic/ferrimagnetic phases may be consumed and new ferromagnetic/ferrimagnetic phases may be produced. These processes can result in the acquisition of a new chemical remanent magnetization (Butler, 1992). As can be seen from the equation in section 1.4.3.2, relaxation time is strongly dependent on grain volume. Holding temperature fixed, grains with a smaller volume have a shorter relaxation time and therefore magnetization decays away quickly. However, because the mineral growth is occurring at temperatures below its Curie temperature, bias in magnetizations of the grains parallel to the local geomagnetic field is produced. We can define a volume above which the relaxation time is long and the grain considered stable on geological timescales (the blocking volume). As the grain grows through this blocking volume this bias is captured and the rock acquires a component of magnetization parallel to the local geomagnetic field.

During low to high grade metamorphism of basaltic rocks primary igneous iron oxides and iron-titanium oxides, and their alteration products, are generally consumed by the growth of other paramagnetic phases, accompanied by a progressive decrease in magnetization (Dunlop \& Özdemir, 1997). In the subgreenschist facies primary igneous phases commonly remain unaffected by metamorphism unless exposed to circulating fluids (Clark, 1997). Hydrothermal alteration may result in haematite pseudomorphing magnetite (at high $f \mathrm{O}_{2}$ ) or the production of paramagnetic phases from ferromagnetic/ferrimagnetic ones (Ade-Hall et al., 1971). Secondary magnetite may be produced at low grades in these haematitic rocks (Grant, 1984). At greenschist and amphibolite facies magnetite breaks down and the ferric iron and titanium is distributed into paramagnetic phases such as epidote, chlorite and sphene at greenschist facies, and biotite, amphibole and ilmenite at amphibolite facies (Clark, 1997). Gabbro is comparatively more resistant to demagnetization during metamorphism due to the presence of fine-grained magnetite inclusions in phases such as plagioclase and clinopyroxene that are protected during metamorphic breakdown (Hargraves \& Young, 1969; Evans \& Wayman, 1970; Wu et al., 1974; Murphy et al., 1981).

Stable assemblages at greenschist facies are reported to be titanite \pm haematite or magnetite (Laird, 1980; Cassidy \& Groves, 1988). At greenschist facies the formation of sphene is preferred over ilmenite due to the presence of significant amounts of calcite or other carbonates that are typically produced during seafloor alteration (Cassidy \& 
Groves, 1988). Further magnetite growth at grades up to amphibolite facies is uncommon in rocks that have undergone carbonate alteration because the presence of carbon reduces the stability field of magnetite (Grant, 1984). Hattori \& Hirooka (1979) in their study of metamorphosed mafic to intermediate igneous rocks demonstrated that the strength of magnetization progressively decreased with increasing metamorphic grade. This matched petrographic observations that suggested the amount of magnetite present in the samples decreased with increasing metamorphic grade. A corresponding lack of increase in magnetization suggested that no new ferro/ferri- magnetic minerals were grown during metamorphism up to greenschist facies (Hattori \& Hirooka, 1979). Burzyński et al. (2017) demonstrated growth of metamorphic magnetite in greenschist facies metabasites. These phases were coarse-grained, euhedral and intergrown with albite-chlorite-actinolite. Relict phenocrysts of magmatic magnetite were also observed up to $0.5 \mathrm{~mm}$ but were strongly replaced by titanite and anatase (Burzyński et al., 2017).

\subsubsection{Deformation and Paleomagnetism}

Deeply buried metamorphic rocks may be subjected to high differential stress and large finite strains, the possible effect of which on the primary and secondary NRM must be considered.

In rocks subjected to a large finite strain, the remanence vector is thought to systematically deflect away from the tectonic shortening axis and towards the stretching axis as a result of flow - this is known as the passive line model (Lowrie et al., 1986). Laboratory studies on rocks that simulate ductile flow have confirmed that the passive line model is a reasonable approximation in homogeneously strained rocks (Borradaile, 1993), although actual mechanisms of rotation of remanence at the microscopic level are complex due to both heterogeneity in the stress field at the grain level and thus heterogeneous rotation of individual magnetic moments of grains, and also the nonpassive behaviour of ferromagnetic inclusions in grains that do not change shape passively (Borradaile, 1997). This analysis is for a single component NRM, rocks containing a multicomponent NRM react more complexly to finite strain (Borradaile, 1997). This may present a significant problem for the interpretation of a primary remanence but may not matter for a secondary remanence acquired following fabric development in metamorphic rocks. Metamorphic fabric development during regional metamorphism may, however, produce a rock that is strongly anisotropic for the acquisition of remanence. We consider this potential in Chapter 5. 
The analysis described above does not take into account the possible rotation of remanence relative to the grains. Large differential stresses can be effective at reducing the anisotropy of SD grains or the barriers to domain wall motion in MD grains. The applied field can then rotate magnetic domains or displace domain walls that were previously fixed - this process is known as Piezoremanent Magnetization (PRM). Laboratory experiments have demonstrated that PRM forms approximately parallel to the magnetizing field, however PRM usually forms in low coercivity grains (Borradaile, 1997), that are generally susceptible to VRM and are removed in laboratory cleaning experiments.

Concerns have also arisen that the NRM of highly stressed rocks may be deflected away from the geomagnetic field in response to tectonic unloading (Graham, 1956); however, laboratory experiments indicate that this seems unlikely in reasonably isotropic rocks (with respect to the distribution of crystallographic axes of the magnetic phases) (Kern, 1961).

\subsection{Summary, Goals and Thesis Outline}

Shallow-dipping detachment faults are common in the geological record and present a significant challenge for Earth scientists in terms of explaining their existence. Andersonian faulting and Mohr-Coulomb theory dictate that normal faults should form at high angles and subsequently lock up at shallow angles. Furthermore, seismic activity on such structures appears to be rare. Numerous authors have proposed that these faults may indeed form at a high angle and subsequently rotate to a shallower dip as the footwall rebounds in response to unloading of the hangingwall during movement along the fault (Buck, 1988; Hamilton, 1988; Wernicke \& Axen, 1988). Studies employing paleomagnetism have conclusively demonstrated that substantial rotation has indeed affected the footwalls of many oceanic detachments (Garcés \& Gee, 2007; Zhao \& Tominaga, 2009; Morris et al., 2009; MacLeod et al., 2011), however such studies of continental detachments have failed to demonstrate any such rotations, although paleomagnetic studies on MCCs are uncommon, and none have been undertaken on an active example. Shallow-dipping detachment faults are common in ancient extensional environments and a small number are demonstrably active in the present day, including the Mai'iu fault (Wallace et al., 204; Webber et al., 2018). Understanding the processes responsible for their origin and evolution therefore has important implications for 
understanding the evolution of extensional environments and seismic hazard in such environments.

The Mai'iu fault occurs at the southern margin of the Woodlark Rift, Papua New Guinea. This fault is a rapidly slipping, continental low angle normal fault responsible for the rapid exhumation of the Suckling-Dayman metamorphic core complex in its footwall. The primary goal of this thesis is to test, using the remanent magnetization of footwall rocks, whether any horizontal-axis rotations have affected the footwall MCC of the Mai'iu fault. A component of magnetization must be recently acquired (pre/synrotation) in order for any variation from a time-averaged geocentric axial dipole (GAD) field to be interpretable in terms of horizontal-axis rotation caused by a migrating hinge. To this end, various microscopic and paleomagnetic techniques are employed in order to identify the phase(s) carrying the component(s) of magnetization and when these component(s) of magnetization were acquired.

In chapter 2 I will outline the geological setting of the Mai'iu fault and SucklingDayman MCC. Knowledge of the local and regional geological setting and geological history are vital to the interpretation of any results from paleomagnetic and microscopic analyses. Particularly due to the complexities of interpreting remanent paleomagnetism of old rocks which have undergone previous phases of metamorphism and deformation.

In chapters 3 and $4 \mathrm{I}$ will outline the methods employed in paleomagnetic and microscopic/petrological data collection and the subsequent analysis and interpretation of these data.

Chapter 5 integrates the results of paleomagnetic and microscopic analyses to address which minerals are responsible for the component(s) of magnetization and when these magnetization component(s) may have been acquired. Subsequent rotation analyses are employed to rigorously test whether any component of remanent magnetization can be interpreted in terms of a rolling hinge evolution for the Mai'iu fault, and if so, the magnitude of rotation and original fault dip implied by the paleomagnetic data.

Chapter 6 presents a summary of the conclusions of this study. 


\section{Chapter 2: Geological Setting}

\subsection{Regional Tectonic Setting of the Mai'iu Fault and Suckling- Dayman MCC}

The tectonic setting in southeast Papua New Guinea is complex and today dominated by the rapid $(10-11 \mathrm{~cm} / \mathrm{yr})$, oblique convergence of the Pacific and Australian plates. This rapid convergence has led to the formation of a number of intervening microplates in the zone of convergence between the Pacific and Australian Plates (North and South Bismarck, New Guinea Highlands, Solomon Sea and Woodlark microplates), all rotating about nearby Euler poles (Fig. 7) (Tregoning et al., 1998; Wallace et al., 2004, 2014). In some cases, these microplates can be further subdivided into smaller, rotating tectonic blocks (Trobriand block, D’Entrecasteaux block, Papuan Peninsula block, Goodenough Bay block and Normanby block) (Fig. 8) (Wallace et al., 2014; Cairns et al., 2015). Rapid and complex interaction between these rotating microplates has led to an array of different tectonic environments and types of active plate boundaries (Wallace et al., 2014).

Presently most of the convergence between the Pacific and Australian Plates is accommodated at the New Britain and San Cristobal trenches where the WoodlarkSolomon Sea microplate is subducting to the NE beneath the South and North Bismarck microplates at rates which increase eastward from $55 \mathrm{~mm} / \mathrm{yr}$ along the New Britain trench in the west to $130 \mathrm{~mm} / \mathrm{yr}$ along the San Cristobal trench in the east (Fig. 7) (Tregoning et al., 1998; Wallace et al., 2014). The Solomon Sea Plate has been subducted northward to $600 \mathrm{~km}$ depth (Hayes et al., 2012). The New Britain trench transitions to the west into the Ramu-Markham fault (Fig. 7) - a trench which is now inactive following the collision between the Finisterre arc terrane to the north and the northern margin of PNG (Jaques \& Robinson, 1977; Abbott et al., 1994; Woodhead et al., 2010).

Figure 7: Regional tectonic map of eastern Papua New Guinea, overlain with Woodlark relative to Australian Plate GPS best-fit velocities of Wallace et al. (2014). Figure modified after Little et al. (2019). 


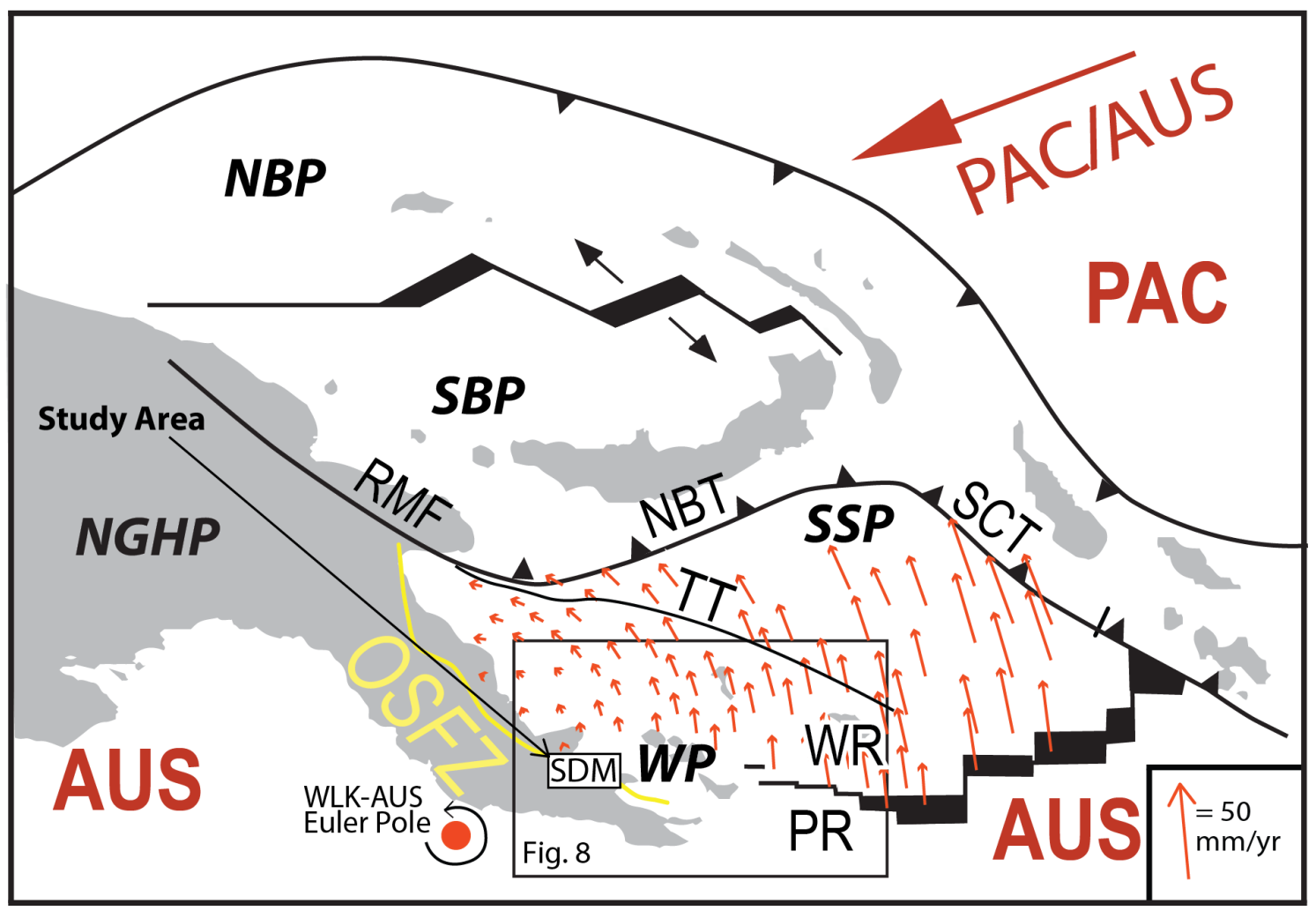

Differential slab pull forces exerted along the northern margin of the Woodlark microplate, along which there is rapid subduction at the New Britain trench (Wallace et al., 2014), has led to a $2^{\circ} / \mathrm{Myr}$ anticlockwise rotation of the Woodlark-Solomon Sea microplate relative to the Australian Plate about an Euler pole, located south of the Papuan Peninsula (Fig. 7) (Taylor et al., 1999; Tregoning et al., 1998; Wallace et al., 2004, 2014). This has resulted in roughly north-south seafloor spreading in the Woodlark Basin and extension in the Woodlark Rift, which separate the Woodlark and Australian plates (Fig. 7) (Weissel et al., 1982; Wallace et al., 2004, 2014). The oceanic crust produced by this seafloor spreading at the eastern end of the Woodlark Basin, which is as old as $\sim 6 \mathrm{Ma}$, is being subducted to the north at San Cristobal trench (Mann et al., 1998).

\subsubsection{The Woodlark Basin and Woodlark Rift}

Today active seafloor spreading is occurring in the Woodlark Basin at contemporary rates that vary from $21 \mathrm{~mm} / \mathrm{yr}$ in the west to $40 \mathrm{~mm} / \mathrm{yr}$ in the east, a gradient that reflects the nearby position of the Euler pole to the west (Wallace et al., 2014). To the west of the rift active seafloor spreading gives way to continental rifting of orogenically thickened continental crust of the Papuan Peninsula (Benes et al., 1994; Taylor et al., 1999), and is one of several places in the world where active seafloor spreading 
transitions into continental rifting. Today the transition between seafloor spreading and continental rifting is located at $151.7^{\circ} \mathrm{E}$, near the Moresby Seamount (Taylor et al., 1995; Mutter et al., 1996).

Based on preserved seafloor magnetic anomalies that are as old as magnetic anomaly $3 \mathrm{~A}$, seafloor spreading in the Woodlark Basin is inferred to have initiated at $>6 \mathrm{Ma}$ (Taylor et al., 1999) in response to rapid, anticlockwise rotation of the Woodlark microplate relative to Australia (Weissel et al., 1982; Wallace et al., 2004, 2014). This is a minimum estimate because some oceanic crust produced by this spreading has been consumed by subduction at the New Britain trench (Benes et al., 1994; Taylor et al., 1999). Woodlark Basin spreading initiated in the east and since then the spreading centre has propagated $500 \mathrm{~km}$ westward, at a rate of $14 \mathrm{~cm} / \mathrm{yr}$ (Taylor et al., 1995, 1999), propagating through oceanic crust of the Solomon Sea before separating orogenically thickened continental rocks of the Papuan Peninsula into the conjugate Woodlark and Pocklington rises (Taylor et al., 1995, 1999). The timing of initiation and evolution of extension in the Woodlark Rift is comparatively less well constrained. Horizon "A", a widespread marine unconformity observed in seismic reflection surveys and correlated with exploration wells in Goodenough Bay (Fig. 8) is interpreted to represent widespread marine inundation that has been interpreted as marking the onset of rifting (Taylor \& Huchon, 2002) though there may be a eustatic component. Horizon " $\mathrm{A}$ " is located between the first and last occurrences of Minylitha convallis, between 9.3 and 7.8 Ma. Direct extrapolation assuming constant sedimentation rates indicates an age of 8.4 Ma for the onset of rifting in the Woodlark Rift. Conversely Petersen \& Buck (2015) argue for initiation $4 \mathrm{Ma}$ based on initiation at $6 \mathrm{Ma}$ requiring more extension than what is observed at the D'Entrecasteaux Islands and further east, and the timing of cessation of ultrahigh pressure metamorphism in the D'Entrecasteaux Islands (3.6 \pm 0.1 Ma).

Contemporary extension in the Woodlark Rift is occurring at rapid rates of $10-20 \mathrm{~mm} / \mathrm{yr}$ (Tregoning et al., 1998; Wallace et al., 2014). Extension in much of the Woodlark Rift is distributed across a $100 \mathrm{~km}$ wide zone, but it localizes to the east where rifting transitions to seafloor spreading (Wallace et al., 2014). West of this transition, the crust of the Papuan Peninsula on mainland Papua New Guinea has an overall bulk composition that is felsic to intermediate (Ferris et al., 2016) and varies in thickness 
from $17-20 \mathrm{~km}$ along the rift axis to $28-32 \mathrm{~km}$ beneath the Suckling-Dayman MCC to 35-40 km beneath the outer margins of the rift (Abers, 2001; Abers et al., 2016).

The Woodlark Rift is one of the few extensional environments on the planet where potential seismic activity on low angle normal faults $\left(<35^{\circ}\right)$ has been documented. Abers (1991) and Abers et al. (1997) compiled focal mechanisms from the Woodlark Rift and identified several shallowly dipping nodal planes. Although the conjugate highangle nodal plane cannot be ruled out as the slip surface, compelling geological constraints favour the shallow dipping nodal plane $\left(\sim 25^{\circ}\right.$ and $\left.\sim 35^{\circ}\right)$ for at least two large-magnitude events. These apparent LANF earthquakes both occurred near the rift tip (further east from the Mai'iu fault), where rifting transitions to seafloor spreading (Fig. 8), suggesting that high strain rates may promote slip on LANFs (Abers et al., 1997). Collettini (2011) hypothesize that this documented seismic slip may be explained by the fact that the fault surfaces are weak, due to either the presence of minerals in altered fault rocks that have a low coefficient of friction and/or high pore fluid pressure - a hypothesis that is supported by talc-chlorite-serpentine fault gouge and high pore fluid pressures that have been documented on faults in the Woodlark Rift (Floyd et al., 2001; Taylor \& Huchon, 2002).

Extension in the Woodlark Rift is accommodated by slip on high-angle normal faults that bound submarine grabens and some shallowly-dipping normal faults that have rapidly exhumed footwall metamorphic rocks. The fact that rifting is occurring in previously orogenically thickened continental lithosphere (Mutter et al., 1996) makes the Woodlark Rift a favourable location for MCC formation. West of the rift tip an EW trending belt of metamorphic core complexes is observed from the D'Entrecasteaux Islands in the Solomon Sea to the Suckling-Dayman MCC in the east located on the Papuan Peninsula (Fig. 8). Based on GPS geodesy roughly half of the overall extension in the Woodlark Rift is accommodated by slip on the $30-40^{\circ}$ dipping normal faults that bound the gneiss domes of the D'Entrecasteaux Islands (Little et al., 2011; Wallace et al., 2014). The D'Entrecasteaux Islands consist of high grade (e.g. eclogite- and amphibolite- facies), subaerially exhumed, metamorphic domes overlain by a cover of ultramafic rocks and alluvial and marine sediments and volcanics intruded by granodiorite bodies, that are bounded on the northern coasts by shallowly dipping normal faults that dip $30-40^{\circ}$, mostly to the north (Little et al., 2007; Little et al., 2011). These rocks have been rapidly exhumed from $90 \mathrm{~km}$ depth and temperatures of 700 - 
$900^{\circ} \mathrm{C}$, at rates of $\sim 2-3 \mathrm{~cm} / \mathrm{yr}$ (Baldwin \& Hill, 1993; Baldwin et al., 2008; DesOrmeau et al., 2017).

Deformation east of the D'Entrecasteaux Islands is being accommodated offshore to the north of Normanby island, in Dawson Strait, and further east in the area of Moresby Seamount (Wallace et al., 2014). Near the seamount, external strain becomes highly localized on the Moresby normal fault This fast-slipping normal fault (dip $30^{\circ}$ ) has accommodated $8 \mathrm{~km}$ of normal slip since the Pliocene (Taylor \& Huchon, 2002; Speckbacher et al., 2011). West of $149^{\circ} 30^{\prime}$ nearly all of the extension in the Woodlark Rift is localized on the shallowly dipping Mai'iu fault, which bounds the southern margin of the Woodlark Rift (Wallace et al., 2014; Cairns et al., 2015; Little et al., 2019).

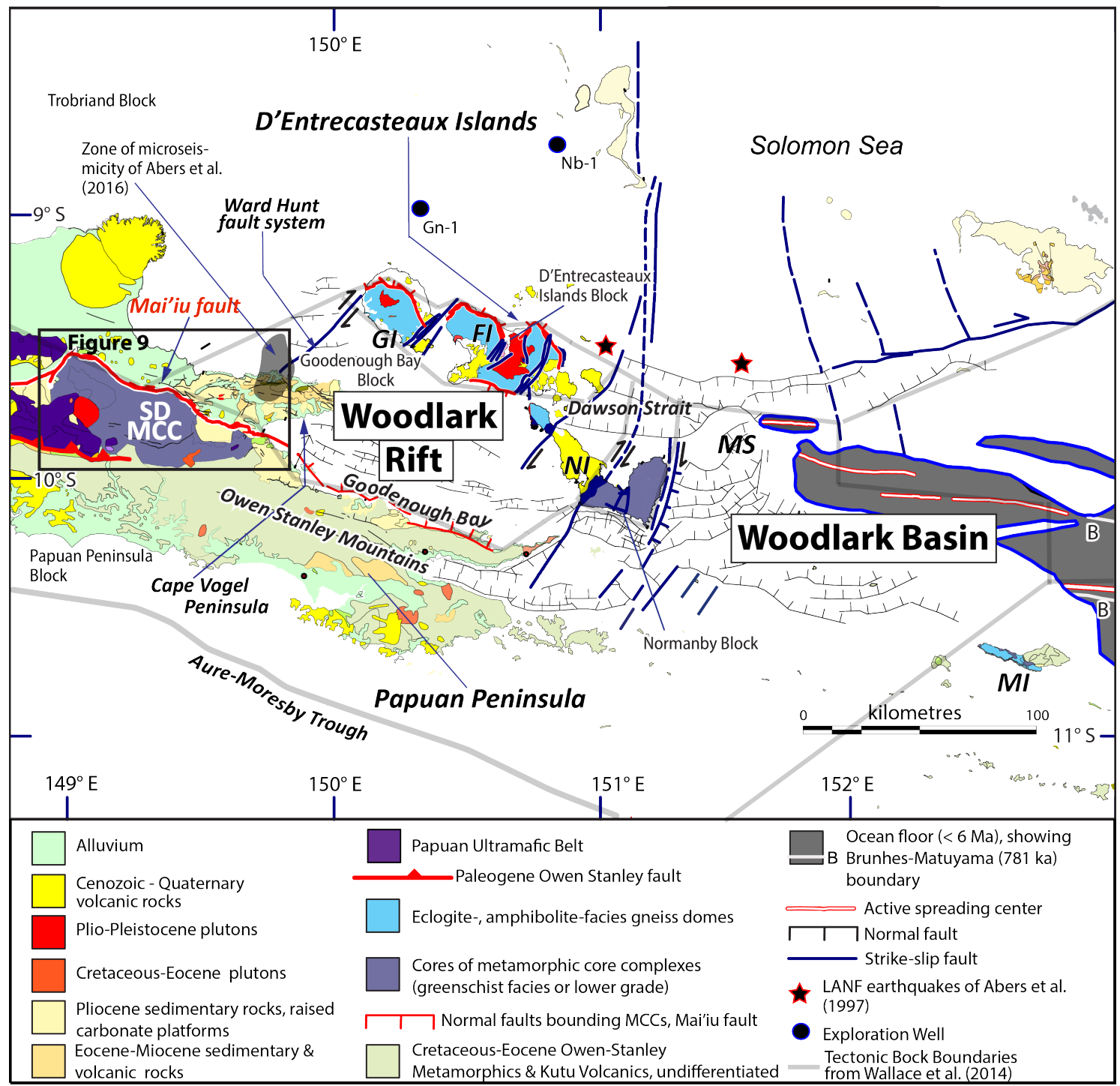


Figure 8: Geological map of southeastern Papua New Guinea, showing the Woodlark Basin and Woodlark Rift, and local tectonic features and geological units. Figure modified after Little et al. (2019).

Fergusson Island (FI); Goodenough Island (GI); Goodenough-1 Well (Gn-1); Nubiam-1 Well (Nb-1); Normanby Island (NI); Misima Island (MI); Moresby Seamount (MS); Suckling-Dayman Metamorphic Core Complex (SD $\mathrm{MCC})$.

\subsection{The Mai'iu Fault and Associated Suckling-Dayman MCC}

The Mai'iu fault lies approximately $220 \mathrm{~km}$ west of the transition between Woodlark Basin seafloor spreading and continental extension in the Woodlark Rift (Fig. 8). Along much of its trace the Mai'iu fault dips northward into the ground at 20-22 ${ }^{\circ}$ (Spencer, 2010) but its dip increases to $30-40^{\circ}$ between $10-25 \mathrm{~km}$ beneath the surface as revealed by a band of microseismicity, mapped offshore near Cape Vogel Peninsula (Fig. 8) that projects directly down-dip from the mapped fault trace (Abers et al., 2016; Eilon et al., 2015). Above the ground, a wide exhumed part of the fault that has been abandoned decreases in dip to the south to become near sub-horizontal over the main divide of the dome, $\sim 20 \mathrm{~km}$ south of the fault trace, before gradually reversing in dip direction to $12^{\circ}$ south (Fig. 9b). This convex-upward shaped exhumed fault surface defines the $60 \mathrm{~km}$ long, 30 km wide Suckling-Dayman metamorphic core complex (Fig. 9) (Davies, 1980; Spencer, 2010; Daczko et al., 2011). The active Mai'iu fault trace bounds the northern flank of the dome and extends more than $100 \mathrm{~km}$ along strike to the southeast before becoming submerged along the south side of Goodenough Bay (Fig. 8). The location of the Mai'iu fault west of the Suckling-Dayman MCC is uncertain, though it is believed that it transitions into a NNE striking zone of strike-slip transfer faulting to the west of Mt Suckling (Little et al., 2019).

The Mai'iu fault is commonly interpreted as part of the geodetically defined, presentday Owen Stanley Fault Zone (OSFZ), which separates the Woodlark Plate to the north and the Australian Plate to the south (Fig. 7). In the Woodlark Rift the OSFZ is accommodating extension (the Mai'iu normal fault). Beyond the western tip of the Woodlark rift the greater OSFZ is believed to be a left-lateral strike slip fault, before transitioning in the northwest to contraction (Wallace et al., 2014). The Mai'iu fault has been interpreted as reactivating a portion of a pre-existing Paleogene Owen Stanley thrust in response to Miocene - Recent extension in the Woodlark Rift (Davies, 1980; Davies \& Jacques, 1984; Webb et al., 2008; Daczko et al., 2011). The Paleogene Owen Stanley thrust is a suture that separates the Owen Stanley Metamorphics (comprised of the Goropu Metabasalt and the Kagi Metamorphics) of the Australian Plate, in the 
footwall, from the Papuan Ultramafic Body and Dabi Volcanics (and their sedimentary and volcanic cover) of the Woodlark Plate to the north, in the hangingwall.

The Mai'iu fault is still active today, inverting the Paleogene Owen Stanley thrust and rapidly exhuming the Suckling-Dayman MCC in its footwall. Modelling of campaign GPS velocities suggests a dip slip rate of 7.5-9.6mm/yr (assuming a dip of $21^{\circ}$ at the surface) (Wallace et al., 2014). This is consistent (at $1 \sigma$ ) to the longer term slip rate obtained by recent cosmogenic nuclide exposure dating of the Mai'iu fault scarp. The latter study indicates a dip slip rate of $11.7 \pm 3.5 \mathrm{~mm} / \mathrm{yr}$ over the last $5.5 \mathrm{ky}$ (Webber et al., 2018), making the Mai'iu fault one of the world's fastest slipping active normal faults. The Mai'iu fault is possibly creeping at the surface and is interpreted to be slipping through mixed seismic-aseismic behaviour at depths of $10-12 \mathrm{~km}$ on the frictionally strong, moderately dipping ramp (Little et al., 2019). In the near surface the Mai' iu fault is misoriented for slip (dipping $<30^{\circ}$ ) and is inferred to be frictionally very weak due to the presence of minerals with low coefficients of friction, such as saponite, in highly altered fault gouges, that both allow slip and exhibit velocity strengthening behaviour which promotes stable fault sliding (Ikari et al., 2012; Moore et al., 2016).

Slip direction of the Mai'iu fault (Fig. 9a) is indicated from the NNE trend of megacorrugation hingelines on the surface of the Suckling-Dayman MCC (Spencer, 2010; Daczko et al., 2011), slickenline data (Little et al., 2019) and a mineral elongation lineation trend in the mylonitic footwall Goropu Metabasalt (Little et al., 2019). These geological data show striking similarity with the inferred Australia-Woodlark Plate extension direction from 3.6 to $0.5 \mathrm{Ma}$ (Daczko et al., 2011) and the slip direction for the Mai'iu fault as inferred from campaign GPS data (Wallace et al., 2014).

A minimum of $30 \mathrm{~km}$ of total slip can be estimated based on the total width of the exhumed fault surface measured parallel to the slip direction (Mizera et al., in review). Further constraints on the total amount of slip come from metamorphic conditions of the footwall Goropu Metabasalt. Pseudosection analysis of Greenschist facies Goropu Metabasalt taken from near the base of the scarp in the mylonitic zone indicate peak pressures of 5.9-7.2kbar (Daczko et al., 2009) indicating exhumation from depths of 20$25 \mathrm{~km}$. Assuming that slip along the convex-upward shaped Mai'iu fault is solely responsible for the exhumation of these metabasalts then this equates to dip-slip magnitudes of 35-45 km (Little et al., 2019). Timing constraints on the initiation of the 
Mai'iu fault are poor. To exhume the $>30 \mathrm{~km}$ width of footwall at an estimated slip rate of $10 \mathrm{~mm} / \mathrm{yr}$ indicates that the Mai'iu fault initiated at least 3 million years ago (Little et al., 2019). This is consistent with the inferred Pliocene age of the Gwoira Conglomerate (Smith \& Davies, 1976), a syn-tectonic sedimentary formation deposited during exhumation of the footwall Suckling-Dayman MCC, and U-Pb ages (3.3 Ma) obtained from zircon from the syn-extensional Suckling Granite (Caffi, 2008; Little et al., 2019).

The footwall of the Suckling-Dayman MCC consists chiefly ( $>90 \%)$ of Goropu Metabasalt (Fig. 9a). This 3-4 km thick unit is composed of metamorphosed mid-ocean ridge basalt (MORB) and younger associated gabbroic intrusives (Yau Gabbro) with interbeds of pelagic limestone that contain latest Cretaceous (Maastrichtian) foraminifera (Davies \& Smith, 1971; Smith \& Davies, 1976; Davies, 1980). The Goropu Metabasalt is structurally overlain by the Papuan Ultramafic Belt (PUB) tectonite, an ophiolite interpreted to have been emplaced on the Owen Stanley Thrust during Paleogene collision. The ophiolitic upper plate includes arc-related basement rocks of Eocene age (Fig. 9a) (Davies \& Jacques, 1981; Davies, 1980). A small flap of PUB tectonite rests in the footwall of the Mai'iu fault south of Mt Suckling above the Goropu Metabasalt (Davies \& Smith, 1974). The base of the PUB in this location is interpreted as the Paleogene Owen Stanley thrust which has been cross cut by the younger Mai'iu normal fault due to imperfect extensional reactivation along the Paleogene Owen Stanley thrust (Davies \& Smith, 1974; Little et al., 2019). To the south and southeast of Mount Suckling the footwall Goropu Metabasalt is intruded by two felsic igneous bodies (Fig. 9a) - the Suckling Granite and Mai'iu Monzonite (Smith \& Davies, 1976). The Goropu Metabasalt is locally hornfelsed near the intrusions. Davies \& Warren (1988) report a gravity low beneath the Suckling-Dayman MCC that reflects the presence of felsic continental crust there.

The Suckling-Dayman MCC rises from near sea level at the fault trace to a maximum height of $3.7 \mathrm{~km}$ along the crest of the Owen Stanley Mountains, defined by the convexup Mai'iu fault surface. The northern slopes reveal a smooth, corrugated surface that is being rapidly exhumed in the footwall of the Mai'iu fault. In detail the fault surface is dissected by NNE trending stream channels that trend subparallel to the slip direction. Across the main divide the stream channels drain in the opposite direction to the south and are separated by many abandoned stream channels, known as windgaps (Spencer, 2010, Mizera et al., in review). This is interpreted to reflect bending associated with 
tectonic unroofing, consistent with a rolling hinge evolution for the fault (Spencer, 2010; Mizera et al., in review).

The footwall Goropu Metabasalt contains multiple foliations. The dominant foliation, comprising most of the dome, is a non-mylonitic foliation interpreted to have been derived from Paleogene underthrusting (top-to-the-south) of the Goropu Metabasalt beneath the PUB (Little et al., 2019) along the Paleogene Owen Stanley thrust. Within 1-2 $\mathrm{km}$ of the fault trace this is overprinted by a mylonitic foliation developed during Neogene extensional (top-to-the-north) shearing at depth (Little et al., 2019). The mylonitic and non-mylonitic foliation of the footwall Goropu Metabasalt are folded into a broad antiform that is arched in concert with the exhumed fault surface, whereby progressive shallowing of the foliation corresponds to a progressive shallowing of the fault surface (Fig. 9b). This progressive arching of the footwall foliation provides further evidence for back-tilting of the Mai'iu fault surface (Little et al., 2019; Mizera et al., in review).

The axial traces of several major NNE-trending antiforms that deform the exhumed fault plane extend from the summits of Mt Dayman, Mt Suckling and Mt Masasoru (Fig. 9a). To the east of Mt Dayman the Gwoira depression is a corresponding synformal fold (Fig. 9a). In this depression, back-tilting of the fault to shallow $\left(<20^{\circ}\right)$ dips is inferred to have caused the local abandonment of the Mai'iu fault and formation of a new steeper-dipping splay fault - the Gwoira fault. This splay dips $40-50^{\circ} \mathrm{N}$ and cuts through the former hangingwall of the synclinally deformed Gwoira Conglomerate to bound the Gwoira rider block (Fig. 9a). The Gwoira fault is inferred to merge with the Mai'iu fault at depth based on the local presence of a shallow-dipping band of microseismicity east of the Gwoira fault (Abers et al., 2016). The Gwoira rider block is bounded underneath by a now inactive section of the Mai'iu fault and is actively uplifting in the footwall of the Gwoira splay fault. Bedding within the Gwoira Conglomerate displays increasing southward dip with age (Webber, 2017). The major NNE-trending folds are interpreted to be amplifying today as folds in the near surface as inferred from patterns of stream piracy and deflected stream patterns on either side of the synformal Gwoira depression (Little et al., 2019).

The domal, convex-up shape of the Mai'iu fault is evidenced by the domal nature of the topography, arching of the footwall foliation, outcrop exposures of the Mai'iu fault and 
the steeper dip of microseismicity at depth (Spencer, 2010; Daczko et al., 2011; Little et al., 2019; Mizera et al., in review). This continuous convex-upward shape of this active to inactive fault surface suggests progressive bending of a single fault, consistent with the rolling hinge model (Mizera et al., in review). Backward-tilting of fluvial terraces on the footwall also indicate this (Mizera et al., in review), and the progressive steepening of bedding in the footwall Gwoira Conglomerate (Webber, 2017). Mizera et al. (in review) hypothesize that unbending stresses related to the uplift and flexure of the footwall was in-part accommodated by slip on the numerous antithetic-sense normal faults that cross-cut the dome. Un-bending strains in the outer arc of the flexed footwall beam in response to a rolling hinge requires structures to accommodate small magnitudes of slip-parallel shortening. A widespread late-stage crenulation foliation observed in the Goropu Metabasalt and folding of sedimentary beds in Gwoira Conglomerate are hypothesized as such structures and provide strong evidence for rolling hinge evolution for the Mai'iu fault (Mizera et al., in review). Although these lines of evidence are all consistent with a rolling hinge model none of them demonstrate that the footwall rocks have undergone substantial back-rotation about the strike of the Mai'iu fault which is the most important prediction of the rolling hinge model.

The footwall Goropu Metabasalt is characterized by progressively southward decreasing metamorphic grade from greenschist facies near the Mai'iu fault trace to pumpellyiteactinolite and prehnite-pumpellyite facies on the northern flanks of the MCC, grading to unmetamorphosed equivalents (the Kutu Volcanics) to the south of the MCC (Fig. 9a) (Davies, 1980; Smith \& Davies, 1976; Smith, 2013). This metamorphic gradient is interpreted as representing an exhumed crustal section that was previously underthrust beneath the Papuan Ultramafic Belt along the Paleogene Owen Stanley thrust and then inverted and exhumed by slip on the Mai'iu fault.

The prehnite-pumpellyite facies metabasalts are massive and commonly preserve their primary igneous structures (Davies, 1980). Farther north, more schistose metabasalt characterized by the minerals albite, actinolite \pm pumpellyite \pm epidote (pumpellyiteactinolite facies) is present (Davies, 1980). This mineral assemblage characterizes much of the northern flank of the Suckling-Dayman MCC and is estimated to have formed at depths of 20-30 km (Daczko et al., 2009). Farther north, a pumpellyite-out isograd has been mapped approximately 10-12 km north of the fault trace (below which pumpellyite 
does not occur in thin section) (Fig. 9a) (Little et al., 2019). This is estimated to correspond to temperature conditions of $350-375^{\circ} \mathrm{C}$ (Beiersdofer \& Day, 1995).

Close to the Mai'iu fault the Goropu Metabasalts have been exhumed from their greatest original depth. A greenschist facies assemblage consists of actinolite-chloriteepidote-albite-quartz-calcite-titanite. These rocks are pervasively recrystallized and preserve few, if any, relict volcanic structures or minerals. Pseudosection modelling indicates the conditions associated with this metamorphism are temperatures of $425 \pm$ $50^{\circ} \mathrm{C}$ and pressures of 6-9.5kbar (Daczko et al., 2009). Outside of the narrow northern mylonite zone, the older non-mylonitic foliation $\left(\mathrm{S}_{\mathrm{d}}\right)$ is generally defined by a shapepreferred orientation of actinolite and in some rocks layers that are variably enriched in epidote and albite (Little et al., 2019). The non-mylonitic lineation $\left(\mathrm{L}_{\mathrm{d}}\right)$ is defined by the shape preferred orientation of actinolite needles and by elongate strain shadows (actinolite, albite, chlorite, quartz) that are attached to porphyroclasts of epidote, albite, or relict clinopyroxene, and trends NNW (Little et al., 2019). Shear fabrics associated with the non-mylonitic Goropu Metabasalt record a top-to-the-south (thrust) sense of shear inferred to have formed during Paleogene underthrusting of the Goropu Metabasalt beneath the PUB along the Owen Stanley thrust (Little et al., 2019). The dip of the non-mylonitic foliation is discordant with the exhumed Mai'iu fault surface, consistently dipping $\sim 15^{\circ}$ more steeply, a relationship that may be explained by the fact the observed thrust fabrics were developed during Paleogene underthrusting (Little et al., 2019).

Within 1-2 km of the Mai'iu fault trace the metabasalts were mylonitized during late Neogene extensional shearing, and remain greenschist facies (Little et al., 2019). Mafic mineral assemblages in the Goropu Metabasalt do not change across this boundary, and are interpreted to have originally crystallized in the non-mylonitic Goropu Metabasalt and remained stable during overprinting of extensional ductile deformation (Little et al., 2019).

Near the fault trace a mylonitic lineation $\left(\mathrm{L}_{\mathrm{m}}\right)$ is defined by a smear of albite grains and strain shadows infilled with chlorite, albite and actinolite, and is parallel to the inferred slip direction (NNE) (Little et al., 2019). The shear fabrics within the mylonitic Goropu Metabasalt record normal sense motion (Little et al., 2019). Little et al. (2019) inferred that the mylonitic extensional deformation are Pliocene and younger and post-date the 
timing of peak metamorphism, which dates back to the Paleogene thrusting event on the Owen Stanley thrust. The exhumed Mai'iu fault surface is consistently subparallel to the mylonitic foliation $\left(\mathrm{S}_{\mathrm{m}}\right)$. The mylonite zone is overprinted by a 1.5-3 $\mathrm{m}$ thick layer of brittle fault rocks that progressively cannibalise each other and record increasingly localized deformation at lower temperatures as the footwall rocks were exhumed and cooled through the brittle crust (Daczko et al., 2011; Little et al., 2019).

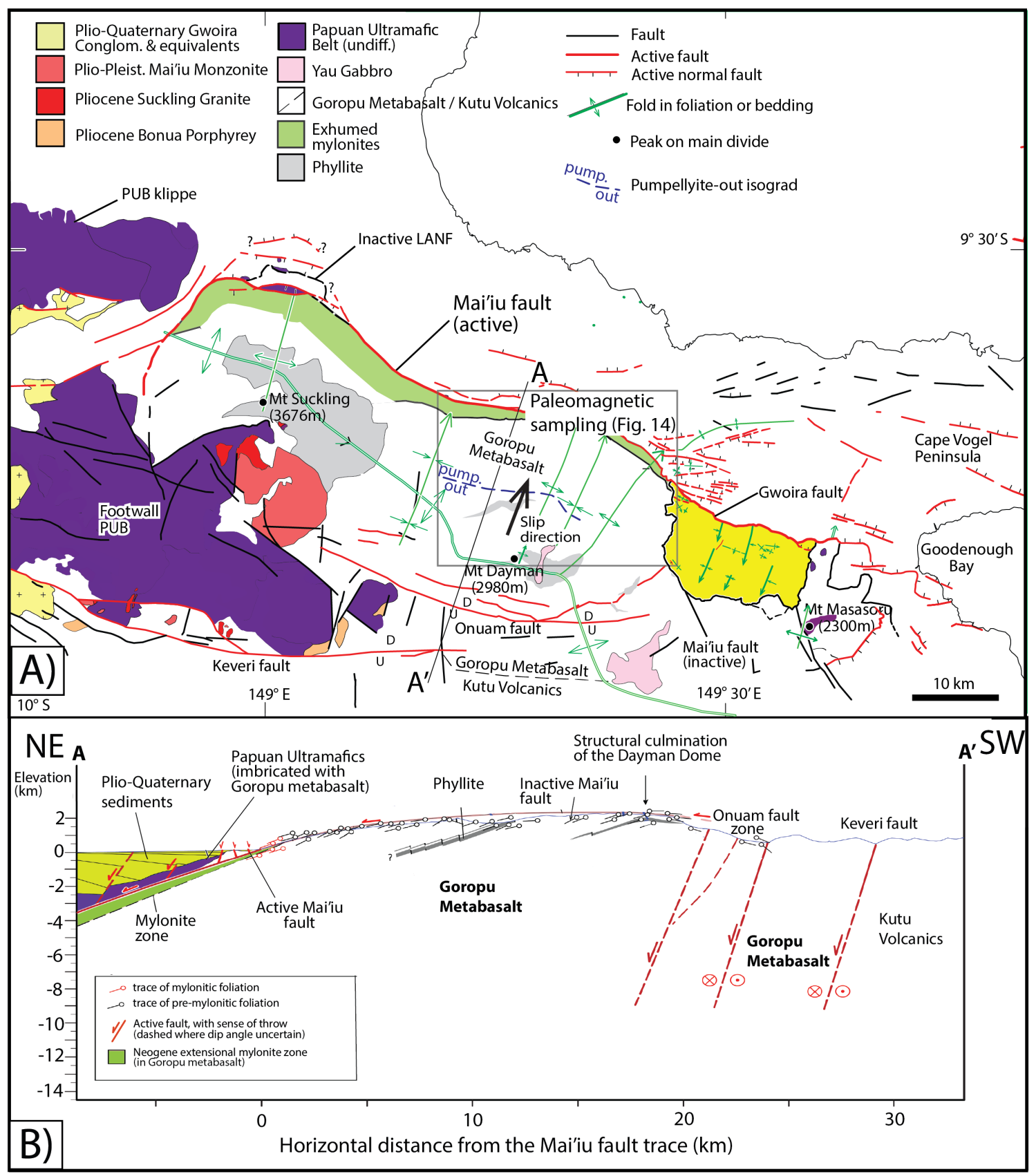

Figure 9: Simplified Geology of the Suckling-Dayman MCC. Figure modified after Little et al. (2019).

A) Map of the Suckling-Dayman MCC. The Suckling-Dayman MCC is bounded in the northwest by the active Mai'iu fault. To the east the Mai'iu fault is synformally deformed and has been abandoned and cross-cut by the Gwoira fault to form the Gwoira rider block (yellow). B) Cross-section through Mt Dayman. The Goropu Metabasalt is structurally overlain by the Papuan Ultramafic Belt and Plio-Quaternary sediments. The Mai'iu fault generally occupies the contact between the Goropu Metabasalt and Papuan Ultramafic Belt (the Paleogene Owen Stanley thrust). To the south of Mt Suckling the PUB is locally cross-cut by the Mai'iu fault, the base of which is interpreted to be the Paleogene Owen Stanley thrust (see map). 


\subsection{Summary of Tectonic History}

The footwall rocks sampled in this study, the Goropu Metabasalt, have experienced a multi-stage tectonic history culminating with rapid exhumation beneath the Mai'iu fault. Knowledge of the history of the Goropu Metabasalt is relevant to understanding the origin of any isolated component(s) of magnetization of the Goropu Metabasalt. To this end I will briefly outline the Cenozoic tectonic history of the Papuan Peninsula, particularly as such a history relates to the history of the Goropu Metabasalt.

In the Late Cretaceous the Goropu Metabasalt was erupted on an ocean floor marginal basin that existed to the north of a rifted fragment of the Australian continent. This rifted fragment was to become the Papuan Peninsula. The oceanic crust to the north of the Goropu Metabasalt included the Lokanu Volcanics and the Papuan Ultramafic Body. In the Paleogene NW-SE rifting in the Coral Sea Basin occurred at the same time that the PUB was obducted (Weissel \& Watts, 1979; Davies et al., 1984; 1987; Gaina et al., 1999; Zirakparvar et al., 2012).

The obduction event marked the collision of the Dabi Island arc to the NE over the thinned Australian continental margin to the SW of the Papuan Peninsula, and it resulted in the Papuan Orogeny. This orogeny produced the $30-45 \mathrm{~km}$ thick core of the Papuan Peninsula (Davies \& Smith, 1971; Taylor \& Huchon, 2002). The collision led to the emplacement of the Papuan Ultramafic Belt and the Dabi Island arc to the southwest over the Goropu Metabasalt along this NE dipping subduction zone - the Owen Stanley thrust (Fig. 10a) (Davies \& Smith, 1971; Jaques, 1981; Davies \& Jaques, 1984; Hall, 2002). The $58.3 \pm 0.4 \mathrm{Ma}$ age for the metamorphic sole of the PUB suggests that obduction had begun by this time (Lus et al., 2004), only shortly after formation of the PUB. Obduction continued into the Eocene based on the age of volcanic and intrusive rocks of the Dabi Arc in the upper plate (Smith \& Davies, 1976; Walker \& MacDougall, 1982; Rogerson et al., 1993). Subduction along the Owen Stanley fault resulted in the metamorphism of the Goropu Metabasalt to temperatures of $\sim 425^{\circ} \mathrm{C}$ and $5.2-7.9 \mathrm{Kbar}$ (Daczko et al., 2009) and the development of thrust fabrics in the non-mylonitic Goropu Metabasalt (Little et al., 2019). Smith \& Davies (1976) noted that several lines of evidence are consistent with the interpretation of the Goropu Metabasalt as a metamorphosed thrust sheet. This includes the synkinematic nature of the regional metamorphism, the south-north increase in metamorphic grade reflecting increasing 
depth of burial along this subduction zone, and the local occurrence of high $\mathrm{P} / \mathrm{T}$, blueschist-facies minerals (lawsonite, glauconite, aragonite) observed in the northern and central parts of the MCC (Smith \& Davies, 1976; Davies, 1980).

The subduction system was eventually jammed when continental crust of the Australian Plate entered the system (Davies \& Smith, 1971; Davies \& Jaques, 1984). Davies \& Jaques (1984) proposed that underthrusting of the Goropu Metabasalt and Kutu Volcanics beneath the PUB was followed by underthrusting of the continental Australian margin derived Kagi Metamorphics beneath the Goropu Metabasalt and the Kutu Volcanics, probably in the Miocene (Little et al., 2019) (Fig. 10b). This would explain both the pronounced gravity low beneath the Suckling-Dayman MCC and presence of granitoid plutons that intrude the dome.

External slip on the Mai'iu fault began approximately 3 million years ago in response to extension in the Woodlark Rift inverting the Owen Stanley thrust (Little et al., 2019). Although, as noted in section 2.2, timing constraints are poor and based largely on observations of slip rate and total offset. Progressive brittle overprinting of ductile structures records an evolution of the fault rocks from ductile shear to brittle slip and a progressive slip localization on the Mai'iu fault as it was exhumed to shallower crustal depths and lower temperatures (Daczko et al., 2009, 2011; Little et al., 2019) as is typical of MCCs globally. Mineral equilibria modelling, using pseudosection analysis, suggests that mylonitic deformation occurred at depths of $20 \mathrm{~km}$ (Daczko et al., 2009). Neogene ductile deformation at depth is inferred to have produced the observed mylonitic fabrics. The locally ductiley deformed Suckling Granite in the Mt Suckling area yields an LA-ICP-MS age of 3.3Ma $\pm 0.1 \mathrm{Ma}$ (Caffi, 2008) which indicates ductile shearing at this time.

Clast petrology of the Gwoira Conglomerate (almost 100\% Goropu Metabasalt derived) suggests the Gwoira Conglomerate was derived by erosion from the nearby subaerially exposed Suckling-Dayman MCC (Caffi, 2008). Unpublished cosmogenic nuclide burial ages and $\mathrm{U}-\mathrm{Pb}$ and $\mathrm{U}(\mathrm{He})$ thermochronology indicate the syn-tectonic Gwoira Conglomerate is Plio-Pleistocene indicating slip on the Mai'iu fault had begun by this time (Oesterle et al., 2018). Melting of continental crust at depth led to the buoyant ascent of felsic intrusives that migrated up the Mai'iu fault and were intruded in the footwall (the Mai'iu Monzonite and Suckling Granite) at $<12 \mathrm{~km}$ depth (based on 
andalusite-bearing contact metamorphic assemblages in the Goropu Metabasalt). Melting of the continental crust may have been caused by removal of the lithospheric mantle down-dip of the fault and by consequence caused rising asthenosphere, which is also interpreted, at least in part, as supporting the high elevation of the dome (Abers et al., 2002; Little et al., 2019)

Geological and geomorphic data suggest, but do not prove, that the Mai'iu fault has been domally warped and back-tilted as a result of a rolling hinge isostatic process, producing the convex-up geometry of the fault as observed today (Fig. 10d) (Spencer, 2010; Daczko et al., 2011; Little et al., 2019; Mizera et al., in review). Continuous flexure and back-tilting is evidenced by the presence of windgaps, back-tilting of the dominant foliation of the Goropu Metabasalt and tilting of bedding in the Gwoira Conglomerate (Mizera et al., in review). Bending stresses associated with this flexure may have been accommodated by the numerous steep, antithetic-sense (up-to-the-north) faults that cross-cut the Mai'iu fault surface and affects its modern drainage pattern (Mizera et al., in review). Cut-off angles of bedding in the footwall Gwoira Conglomerate (in the Gwoira rider block in the Gwoira depression) with the Mai'iu fault constrain the original dip of the fault at the surface to have been at least $\sim 40-49^{\circ}$, which presumably would have reflected the inherited dip of the Paleogene Owen Stanley thrust at the surface. Such a moderate dip on the active part of the Mai'iu fault at depth is implied by the alignment of microseismicity, down-dip of the Mai'iu fault trace at $30-40^{\circ}$ from 10-25 km depth (Eilon et al., 2015; Abers et al., 2016). During the exhumation process the shallow, rotated, upper parts of the fault were strongly tilted by footwall warping (Fig. 10d). In the Gwoira embayment the locally shallowly dipping Mai'iu fault has been abandoned and cross-cut by the Gwoira fault (Fig. 10d). 


\section{A) Eocene}

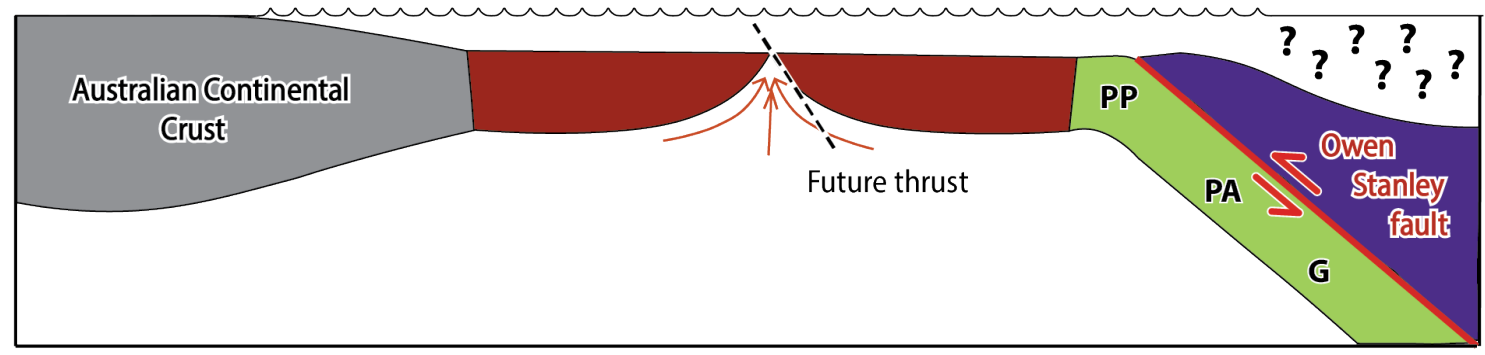

B) Late Miocene (?)

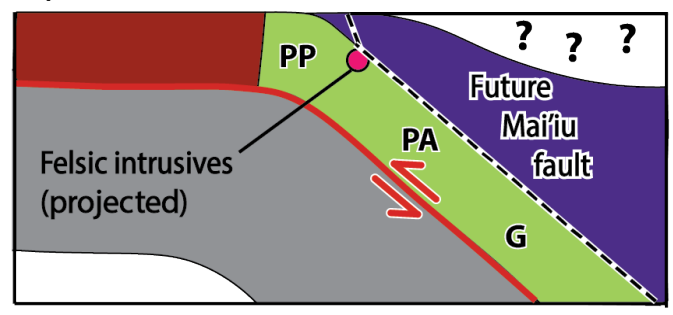

\section{C) Pliocene}

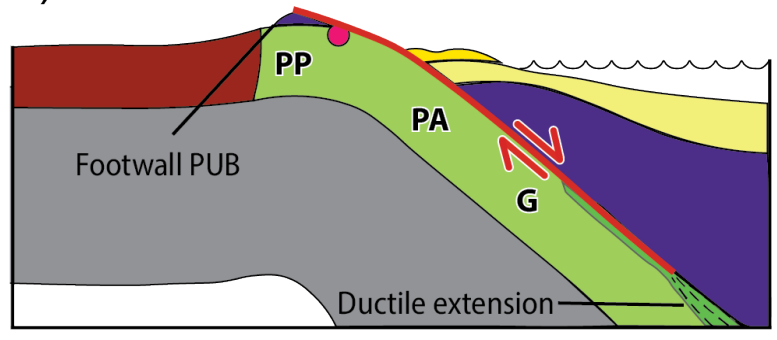

\section{Key}

Kagi Metamorphics

Kutu Volcanics

Goropu Metabasalt

$$
\begin{array}{|l|l}
\hline \text { PP } & \text { Prehnite-pumpellyite facies } \\
\hline \text { PA } & \text { Pumpellyite-actinolite facies } \\
\hline \text { G } & \text { Greenschist facies } \\
\hline & \text { Mylonite } \\
\hline
\end{array}
$$

Papuan Ultramafic Belt (undifferentiated)

Gwoira Conglomerate

Cenozoic Sedimentary Rocks

$1 / 2$ Active fault (showing slip sense)

' Future fault

' Inactive fault

\section{D) Present day}

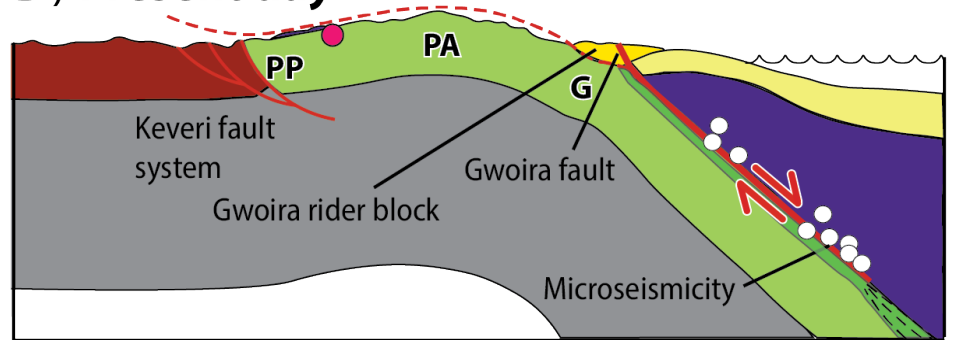

Figure 10: Geological history of the Mai'iu fault and its footwall Goropu Metabasalt after Daczko et al. (2011): Little et al. (2019). A) Subduction of the Goropu Metabasalt and emplacement of the Papuan Ultramafic Belt along the Owen Stanley thrust. B) Thrusting of the Kagi Metamorphics beneath a separate thrust sheet comprised of Goropu Metabasalt and Kutu Volcanics. C) Extensional reactivation of the Owen Stanley thrust in response to extension in the Woodlark Rift. The Gwoira Conglomerate is deposited in the hangingwall of the Mai'iu fault as the Suckling-Dayman Dome is exhumed. D) Inferred rolling hinge evolution for the Mai'iu fault producing the observed convex-up shape we see today at the surface. Microseismicity constrains the dip of the fault at depth. The Mai'iu fault is locally abandoned and cross-cut by the Gwoira fault to isolate the Gwoira rider block on the current footwall. 


\section{Chapter 3: Analytical Methods}

Oriented samples were collected by Tim Little, Marcel Mizera, Sam Webber and Juergen Oesterle during four campaigns to Papua New Guinea. Some of the samples collected in 2014 were subjected to progressive demagnetization experiments in a pilot study by VUW postdoctoral student Eliza Piispa to test whether the samples of Goropu Metabasalt contained consistent, measurable component(s) of magnetization that would be appropriate for a paleomagnetic study. Samples that were collected in 2015, 2016 and 2018 are the main subject of this study (Table 1). Samples were oriented using the mylonitic or metamorphic foliation as a reference surface (Table 1) using geological compasses corrected for local magnetic declination $\left(6.5^{\circ} \mathrm{E}\right)$, before removal from the outcrop and transportation back to Victoria University of Wellington.

A subset of the samples collected during these campaigns were selected for use in this study. The rationale behind sample selection, and the subsequent treatment of the samples, is outlined below. This chapter is divided into two main sections: 1) Paleomagnetic methods, with the objective of measuring and isolating any components of magnetization in the selected samples; and 2) microscopic methods with the objective of identifying the magnetic carrier(s) that are present in the rock and to evaluate how the measured component(s) of magnetization were acquired.

\subsection{Paleomagnetic Methods}

\subsubsection{Sample Selection and Rationale}

Initial sampling covered a large $\left(>500 \mathrm{~km}^{2}\right)$ area of the Suckling-Dayman MCC. Sample selection was made chiefly on the basis of spanning this available spatial coverage (Table 1; Fig. 14). Samples at the base of the scarp near the fault trace cover more than $30 \mathrm{~km}$ along strike. Sampling at this level is dominated by the Biniguni Falls locality, which is a spectacular, continuous exposure of the exhumed fault surface at the base of the scarp (Fig. 15). Sampling up-dip of the fault trace covers more than $18 \mathrm{~km}$ in the upper plate transport direction, subparallel to the slip direction. This breadth of sampling allows us to assess whether any differing paleomagnetic signatures/processes and/or differential rotation has affected the remanent magnetization of the samples up the scarp, given the domal shape of the fault surface. A key prediction of the rolling hinge model is that samples further up the scarp should have experienced, and potentially recorded, progressively larger degrees of back rotation to the south about the 
$\sim$ EW fault strike direction. This breadth of sampling also permits us to assess any potential changes in the components of magnetization across the scarp in terms of the number of components and the blocking temperature and coercivity range that these component(s) inhabit. Such changes might be expected in that the exhumed footwall represents a tilted crustal section of differing original burial and metamorphic grade.

Table 1: Paleomagnetic Samples. The rock type and orientation information, in addition to the number of specimens retrieved from each sample are presented. Longitude, latitude (WGS 84 Datum) and slip-parallel distance from the fault trace are also presented. *orientation of the top surface of the sample(and parallel to the dominant foliation) unless otherwise specified. NB: In 2015 sampling was undertaken by two separate teams. A '2' has been added preceding the year of sample collection for samples that were collected by team two in order to differentiate between the two sample suites. 


\begin{tabular}{|c|c|c|c|c|c|c|}
\hline Sample & Rock Type & Longitude & Latitude & \begin{tabular}{|l} 
Distance \\
from fault \\
trace $(\mathrm{m})$ \\
\end{tabular} & $\begin{array}{l}\text { Orientation } \\
\text { wrt folia- } \\
\text { tion* }\end{array}$ & $\begin{array}{l}\text { Number } \\
\text { of speci- } \\
\text { mens }\end{array}$ \\
\hline 16-BW1b & Metabasalt (mylonitic) & \multicolumn{3}{|c|}{ Biniguni Falls - not specified } & $269 / 18 / \mathrm{N}$ & 6 \\
\hline 16-BW1c & Metabasalt (mylonitic) & \multicolumn{3}{|c|}{ Biniguni Falls - not specified } & $301 / 20 / \mathrm{NE}$ & 7 \\
\hline $16-1151 b$ & Metabasalt (mylonitic) & \multicolumn{3}{|c|}{ Biniguni Falls - not specified } & $258 / 11 / \mathrm{NW}$ & 7 \\
\hline $16-1151 c$ & Metabasalt (mylonitic) & \multicolumn{3}{|c|}{ Biniguni Falls - not specified } & $283 / 14 / \mathrm{NE}$ & 6 \\
\hline $16-1151 \mathrm{~g}$ & Metabasalt (mylonitic) & \multicolumn{3}{|c|}{ Biniguni Falls - not specified } & $329 / 18 / \mathrm{NE}$ & 6 \\
\hline $16-1151 \mathrm{~h}$ & Metabasalt (mylonitic) & \multicolumn{3}{|c|}{ Biniguni Falls - not specified } & $294 / 23 / \mathrm{NE}$ & 6 \\
\hline $16-1151 j$ & Metabasalt (mylonitic) & \multicolumn{3}{|c|}{ Biniguni Falls - not specified } & $303 / 20 / \mathrm{NE}$ & 4 \\
\hline $16-1151 \mathrm{k}$ & Metabasalt (mylonitic) & \multicolumn{3}{|c|}{ Biniguni Falls - not specified } & $292 / 25 / \mathrm{NE}$ & 6 \\
\hline $16-4 a 2$ & Metabasalt (greenschist) & 149.17222 & -9.64699 & Within $100 \mathrm{~m}$ & $312 / 46 / \mathrm{NE}$ & 6 \\
\hline $16-131 a$ & Metabasalt (mylonitic) & 149.39861 & -9.70859 & Within $100 \mathrm{~m}$ & $348 / 23 / \mathrm{NE}$ & 7 \\
\hline $16-181 a$ & Metabasalt (greenschist) & 149.26772 & -9.68624 & 1400 & 299/12/NE & 7 \\
\hline $16-126 a$ & Metabasalt (greenschist) & 149.44896 & -9.76100 & Within $100 \mathrm{~m}$ & 178/19/NE & 4 \\
\hline $16-119 a$ & Metabasalt (mylonitic) & 149.44413 & -9.75318 & Within $100 \mathrm{~m}$ & $004 / 35 / \mathrm{SE}$ & 7 \\
\hline $16-169 a$ & Metagabbro (greenschist) & 149.25309 & -9.72372 & 5800 & 280/25/NE & 4 \\
\hline $16-170 a$ & Metabasalt (greenschist) & 149.24987 & -9.71663 & 5100 & $256 / 20 / \mathrm{NW}$ & 6 \\
\hline $16-172 a$ & Metabasalt (greenschist) & 149.25046 & -9.70764 & 4100 & $279 / 25 / \mathrm{NE}$ & 6 \\
\hline $16-176 a$ & Metabasalt (greenschist) & 149.25177 & -9.71040 & 4500 & $259 / 31 / \mathrm{NW}$ & 6 \\
\hline $16-177 b$ & Mafic Psammitic (greenschist) & 149.25953 & -9.70074 & 3200 & $271 / 22 / N$ & 6 \\
\hline (2)15-3a & Metabasalt (mylonitic) & 149.26958 & -9.67573 & Within $100 \mathrm{~m}$ & $330 / 10 / \mathrm{NE}$ & 4 \\
\hline (2)15-6a & Metabasalt (mylonitic) & 149.26954 & -9.67539 & Within $100 \mathrm{~m}$ & $005 / 38 / E$ & 5 \\
\hline (2)15-8a & Metabasalt (mylonitic) & 149.26964 & -9.67530 & Within $100 \mathrm{~m}$ & $304 / 23 / \mathrm{NE}$ & 6 \\
\hline (2)15-9a & Metabasalt (mylontic) & 149.26978 & -9.67528 & Within $100 \mathrm{~m}$ & $087 / 38 / \mathrm{S}$ & 4 \\
\hline (2)15-11a & Metabasalt (mylonitic) & 149.26981 & -9.67512 & Within 100m & $316 / 14 / \mathrm{NE}$ & 6 \\
\hline (2) $15-15 a$ & Metabasalt (mylonitic) & 149.27042 & -9.67489 & Within $100 \mathrm{~m}$ & $288 / 17 / \mathrm{N}$ & 4 \\
\hline $15-41 a$ & Metabasalt (greenschist) & 149.29052 & -9.69012 & 1400 & $255 / 17 / \mathrm{NW}$ & 5 \\
\hline $15-43 a$ & Metabasalt (mylonitic) & 149.28851 & -9.68281 & 600 & $130 / 25 / \mathrm{SW}$ & 5 \\
\hline $15-50 i$ & Metabasalt (mylonitic) & 149.28669 & -9.67778 & Within $100 \mathrm{~m}$ & $225 / 23 / \mathrm{NW}$ & 6 \\
\hline $15-52 a$ & $\begin{array}{l}\text { Metabasalt (mylonitic) limestone } \\
\text { layer (avoided) }\end{array}$ & 149.29029 & -9.67831 & Within $100 \mathrm{~m}$ & 275/19/NNE & 4 \\
\hline $15-59 a$ & Metabasalt (mylonitic) & 149.26938 & -9.67500 & Within $100 \mathrm{~m}$ & 298/14/NE & 6 \\
\hline $15-20 d$ & Metabasalt (pumpellyite-bearing) & 149.26642 & -9.77924 & 11,800 & $235 / 24 / \mathrm{NW}$ & 5 \\
\hline $15-23 a$ & Metabasalt (pumpellyite-bearing) & 149.26455 & -9.77136 & 10,700 & 267/25/NW o.t. & 6 \\
\hline $15-24 a$ & Metabasalt (pumpellyite-bearing) & 149.26485 & -9.77110 & 10,800 & $282 / 26 / \mathrm{NE}$ & 6 \\
\hline $15-29 a$ & Metabasalt (greenschist) & 149.27163 & -9.74858 & 8200 & $245 / 13 / \mathrm{NW}$ & 4 \\
\hline $15-30 a$ & Metabasalt (greenschist) & 149.27841 & -9.73380 & 6400 & $272 / 14 / \mathrm{N}$ & 8 \\
\hline $15-32 a$ & Metabasalt (greenschist) & 149.28318 & -9.71937 & 4700 & $228 / 19 / \mathrm{NW}$ & 5 \\
\hline $15-33 a$ & Metabasalt (greenschist) & 149.28262 & -9.71599 & 4400 & $035 / 23 / \mathrm{SE}$ & 7 \\
\hline $15-37 a$ & Metabasalt (greenschist) & 149.28417 & -9.70841 & 3500 & 274/24/NE & 6 \\
\hline $15-39 a$ & Metabasalt (greenschist) & 149.28647 & -9.70399 & 3000 & 287/29/NE & 6 \\
\hline $15-13 a$ & Metabasalt & 149.28437 & -9.82733 & 18,100 & $228 / 36 / \mathrm{NW}$ & 4 \\
\hline $15-9 a$ & Metabasalt & 149.28352 & -9.83714 & 19,400 & 222/24/NW o.t. & 6 \\
\hline $15-7 a$ & Metabasalt & 149.28724 & -9.83596 & 19,000 & 263/24/NW o.t. & 5 \\
\hline $18-1 a$ & Metabasalt (mylonitic) & Biniguni Falls - I & not specified & & $127 / 29 / \mathrm{NE}$ & 2 \\
\hline $18-2 a$ & Metabasalt (mylonitic) & Biniguni Falls - I & not specified & & $114 / 20 / \mathrm{NE}$ & 4 \\
\hline $18-3 a$ & Metabasalt (mylonitic) & Biniguni Falls -1 & not specified & & $140 / 57 / N E$ & 5 \\
\hline
\end{tabular}




\subsubsection{Sample Preparation}

Samples were sawed into $22 \mathrm{~mm}$ x $22 \mathrm{~mm}$ x $20 \mathrm{~mm}$ (volume of $9.68 \mathrm{ccm}$ ) cubes (specimens) appropriate to fit the cube sample holder in the AGICO JR6 spinner

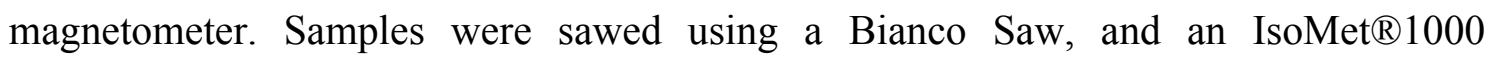
Precision Saw for more delicate samples. Specimens were sanded down to the appropriate size and shape where necessary using a diamond cup-wheel lap. Between 4 and 6 specimens were recovered from each oriented hand sample depending on the available material. Specimens that broke during sawing were restored using UHU glue. Pervasive fracturing of the samples was a significant problem when sawing. Samples were treated with Wacker Silres fluid or sodium silicate solution but this did not work. Using a gentler, high-precision saw proved to be the most effective method, in addition to the use of non-magnetic cement in a selected few samples. Where possible, these specimens were not selected for thermal demagnetization steps. Except during measuring, sawn specimens remained stored in mu metal shielding in order to prevent acquisition of VRM in the laboratory.

Sample nomenclature follows a traditional format adopted during earlier field seasons. The locality (PNG) is denoted followed by the year of sample collection $(14,15,16$, 18). This is followed by a field station number $(1,2,3,4,5, \ldots)$, which corresponds to a unique outcrop with associated GPS coordinates that can be mapped. An additional sample suffix ( $a, b$, c etc.) differentiates between duplicate but different samples retrieved from the same station (outcrop). To differentiate between the specimens retrieved from each sample for this study a final numerical suffix was added to the sample name in order to denote the relative position of specimens taken from the sample (Fig. 11). 'PNG' was dropped from the sample name to aid in simplicity.

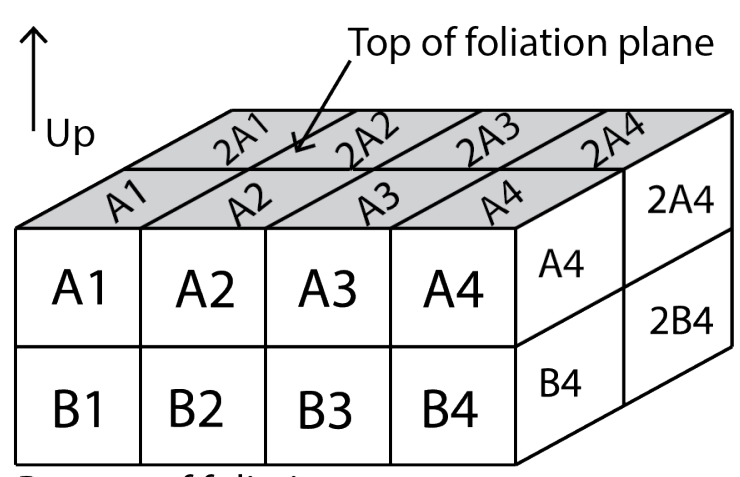

Bottom of foliation
Figure 11: Sample suffix scheme for sawn specimens.

This scheme is used to differentiate between specimens taken from a single sample and denote their position relative to each other, where $A$ to $Z$ corresponds to increasing distance from the top surface, prefix 1, 2, 3,... etc. corresponds to increasing distance from the arbitrarily defined front side of the sample, and suffix 1, 2, 3,..., etc. corresponds to increasing distance from the arbitrarily defined left side of the sample.

For example, a specimen taken from the top, leftmost, front corner of sample PNG14-01 a will subsequently be labelled 14-01aAl. 
A right-handed Cartesian coordinate system of 3 orthogonal axes $(\mathrm{X}, \mathrm{Y}$ and $\mathrm{Z})$ is used as an orientation scheme for the cubed specimens (Fig. 12). For a cube sawn such that the top surface is parallel to the foliation, and two of the four vertical faces are sawn parallel to strike, $+\mathrm{X}$ will point in the up dip direction, $+\mathrm{Y}$ will coincide with the strike of the foliation and $+\mathrm{Z}$ is the downward pole to the foliation (Fig. 12). The spinner magnetometer calculates the declination and inclination of the NRM relative to these "specimen coordinates." In order to convert this vector into geographic coordinates information must be known about the azimuth (from geographic north) of the Y axis and the plunge of the $\mathrm{Z}$ axis from horizontal (Fig. 12). Because $\mathrm{Z}$ is perpendicular to the top surface, which is inclined at some specified angle from the horizontal (foliation dip), the plunge of $\mathrm{Z}$ will be 90 - Dip. The azimuth of the $\mathrm{Y}$ axis will be either the quoted foliation strike value or $180^{\circ}$ to the quoted strike value, depending on which end of strike was specified in the field. In the interest of preservation of material, many instances occurred where two vertical faces were not able to be sawn parallel to strike (i.e., the y axis is no longer parallel to strike). This difference in geometry was corrected for using a stereonet. In rare instances where the bottom or dominant facing surface of the foliation was marked, procedure for orienting remained the same, with the exception that $+\mathrm{Y}$ is anticlockwise to the $+\mathrm{X}$ axis. An artificial top surface was cut and marked for these samples.

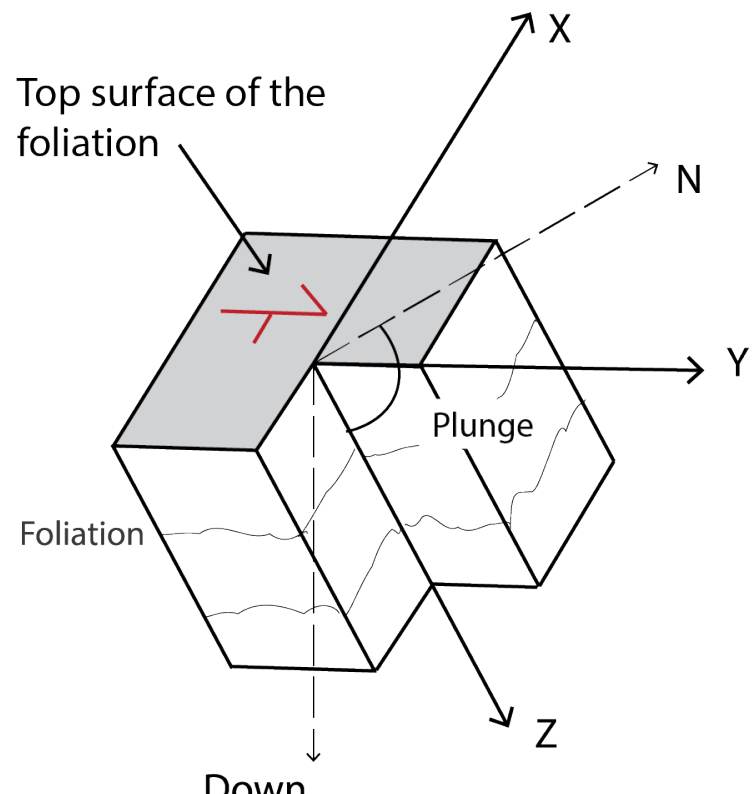

Figure 12: Orientation scheme for the specimens, showing the XYZ axes for a cubed specimen with an $Y$ inclined top surface. The oriented top surface is marked in the field with a strike and dip symbol (red). The half arrow denotes the north end of strike and the tick indicates the dip direction. The $Z$ axis is perpendicular to the foliation. $+Y$ is $90^{\circ}$ clockwise from $+X$. The plunge of the $Z$ axis is the angle from horizontal. The trend of the $Y$ axis is the angle from north, in a horizontal plane.

It is acknowledged that errors in the paleomagnetic vector can be acquired during the process of sawing (and orienting) the specimens however these errors are small $\left(<10^{\circ}\right)$ 
and randomized across a sample, and between samples, and are therefore not a detriment to the overall goals of this study.

\subsubsection{Sample Measurement}

\subsubsection{Measuring NRM and Progressive Demagnetization Techniques}

All of the samples considered in this study were measured in the AGICO JR6 spinner magnetometer, operated by the Rema6W software (Chadima \& Hrouda, 2006) at the paleomagnetic laboratory at Victoria University of Wellington. Cubes were placed inside a manual cube holder and rotated on a slow speed (16.7 rev/s) and for a normal acquisition time. The sample holder is covered by a mu metal shield to eliminate any influence of an external magnetic field. Once the magnetization of the samples dropped below a cut-off point of $2.0 \times 10^{-04} \mathrm{~A} / \mathrm{m}$ the acquisition time was increased. Measurements were calibrated using a cube standard with a volume of $13 \mathrm{ccm}$ and a magnetization of $5.79 \mathrm{~A} / \mathrm{m}$ along the $\mathrm{Z}$ axis. The sample holder rotates the specimen at a constant angular velocity of $16.7 \mathrm{rev} / \mathrm{s}$. This acts to induce a current in a pair of coils surrounding the specimen. The amplitude and phase of this current depends on the strength and direction of the remanent magnetization vector perpendicular to the vertical rotation axis of the specimen. This will correspond to two of the three orthogonal axes of the specimen. By progressively changing the orientation of the cube inside the sample holder between measurements, multiple estimates can be made for the component of magnetization along each axis, allowing for the calculation of a best-fit direction of NRM (in specimen coordinates). This can be translated to geographic coordinates using the input orientation parameters of the specimen (section 3.1.2.).

As discussed in section 1.4.1 rocks carrying an NRM can be conceptualized as an assemblage of ferromagnetic/ferrimagnetic grains interspersed within a nonmagnetic matrix. These grains generally exhibit a spectrum of blocking temperatures or coercivities relating to differences in both grain shape and volume. Though a primary magnetization is acquired following the formation of a rock, secondary processes such as heating may partially or completely overprint a part of (or the entire) blocking temperature or coercivity spectra. Thermal and alternating field demagnetization techniques are designed to isolate different components of magnetization that inhabit different parts of the blocking temperature or coercivity spectra. Because the NRM is a vector sum of the components of magnetization present in a specimen, progressive 
demagnetization is integral to the interpretation of any paleomagnetic study.

Thermal demagnetization was the primary means of demagnetizing specimens considered in this study. A subset of specimens from each sample were chosen for thermal demagnetization -3 or 4 depending on the consistency of NRM directions and strength of magnetization. Specimens that had the strongest magnetization and best shape were preferred for these experiments. Thermal demagnetization is designed to isolate different components of magnetization that inhabit different parts of the blocking temperature spectra. Specimens are heated in an oven, and subsequently cooled in a zero magnetic field, causing the magnetic moments of grains with blocking temperatures below the peak applied temperature to randomize and cancel out (Butler, 1992). NRM was measured after each demagnetization step to assess the changes in strength and direction of magnetization after each thermal step. Thermal steps were generally $80,150,200,250,300,350,400,450,500,550,580^{\circ} \mathrm{C}$. The specimens were kept at peak temperature for 25 minutes in order to equilibrate. Magnetic susceptibility was monitored after each step in order to test for any thermally induced mineral alterations. All thermal demagnetization was undertaken at the paleomagnetic laboratory at Victoria University of Wellington.

A comparatively smaller number of specimens (3) were demagnetized via alternating field. This was done to gain important information that could not be gained from thermal demagnetization. The alternating field technique is designed to separate out components of magnetization that inhabit different parts of the coercivity spectra. An oscillating field is applied to the specimens. After reaching a pre-set peak intensity the field starts to decay linearly. Grains with coercivities lower than the peak applied field will have their magnetic moments oscillate with the applied field until the amplitude of the field decreases below their coercivity. Because the field is oscillating between two antipodal directions these reset magnetic moments should cancel out, leaving only the NRM of grains with coercivities higher than the peak applied field (Butler, 1992). Because demagnetization only occurs parallel to the direction of the applied field, specimens are rotated between each demagnetization treatment so that they are demagnetized along the $\mathrm{X}, \mathrm{Y}$ and $\mathrm{Z}$ axes. Peak fields were 2.5, 5, 10, 15, 20, 25, 50, $100,200,300,400,500,700,900 \mathrm{mT}$. Specimens were measured after each step, as for thermal demagnetization. 


\subsubsection{Temperature-Dependent Susceptibility}

Temperature-dependent susceptibility experiments were undertaken on the Bartington MS2 furnace system at the paleomagnetic laboratory at Victoria University of Wellington. Selected samples were crushed to fit $\sim 3-5 \mathrm{~g}$ of material in the sample holder. Samples were heated and cooled and their susceptibility was monitored throughout this process. The experiment is designed to start measuring susceptibility once samples reach $40^{\circ} \mathrm{C}$, with measurements taken every $10^{\circ} \mathrm{C}$. Experiments reach a set peak temperature up to $700^{\circ} \mathrm{C}$ before cooling back to $40^{\circ} \mathrm{C}$.

Temperature dependent susceptibility experiments can be used to determine the Curie temperature of the magnetic mineral(s) present in the sample and therefore infer the magnetic mineralogy, and to test for thermally induced mineral alterations at temperatures where the ferro/ferrimagnetic or paramagnetic phase(s) present may become unstable. As samples are heated past the Curie temperature(s) of their constituent ferro/ferri magnetic mineral(s) a significant drop in magnetic susceptibility occurs as the grain(s) can no longer sustain a magnetization. As the sample is cooled the magnetic susceptibility increases again. Because each magnetic mineral has a characteristic Curie temperature, observation of susceptibility with temperature should be indicative of which magnetic mineral(s) are present in the sample contributing to the NRM. Curie temperature is also very sensitive to Fe-Ti oxide composition (Lattard et al., 2006) allowing for constraints on composition. If the heating and cooling curves differ then this indicates that irreversible changes to the magnetic mineralogy have occurred in response to heating.

\subsubsection{Isothermal Remanent Magnetization Experiments}

Progressive isothermal remanent magnetization (IRM) experiments were undertaken on the molspin pulse magnetizer at the paleomagnetic laboratory at Victoria University of Wellington. Representative specimens were demagnetized in an alternating field then remagnetized along the $\mathrm{Z}$ axis by applying a strong magnetic field in incremental steps. The increments were generally $5 \mathrm{mT}$ up to $100 \mathrm{mT}$, followed by $20 \mathrm{mT}$ increments up to $200 \mathrm{mT}$ and then $100 \mathrm{mT}$ increments above $800 \mathrm{mT}$. Magnetization was measured in the Agico JR6 Spinner magnetometer after each applied field in order to monitor the growth of IRM with increasing field. Once the specimens saturated the direction of the field was reversed in 3-10 $\mathrm{mT}$ increments until the magnetization of the specimens changed sign, in order to determine the coercivity of remanence. How the magnetization 
of a specimen grows with increasing applied field and the coercivity of remanence of a specimen is generally indicative of magnetic mineralogy. For example, Fe-rich titanomagnetite saturates much more quickly and has a lower coercivity of remanence than minerals such as goethite or haematite. The gradient of this curve can also be used as a proxy for the coercivity distribution. Additionally, the coercivity of remanence is an extremely sensitive grain size indicator.

\subsubsection{Data Analysis}

Data analysis was performed in Remasoft 3.0 (Chadima \& Hrouda, 2006). The components of magnetization were primarily calculated using principal component analysis (PCA) (Kirschvink, 1980) where consistent components could be identified on Zjiderveld diagrams. Zjiderveld diagrams display directional and intensity information by projecting the end point of the NRM vector after each demagnetization step on to two orthogonal (horizontal and vertical) planes. PCA determines the line of best-fit through a series of directionally consistent, often scattered data points plotted on a Zjiderveld diagram. Maximum angular deviation (MAD) can also be calculated and provides a numerical estimate of the precision with which the best-fit line has been determined. The points through which the line was fitted were selected to achieve the lowest MAD, and fitted to the origin and/or anchored to the last point where appropriate.

In many instances two components of magnetization of opposite polarity was carried by a sample in which a stable endpoint of magnetization was not reached due to the presence of substantial thermal alteration that appeared to have an effect on the magnetization. In this instance we used remagnetization great circles to estimate a stable end point (Fig. 13). Remagnetization great circles were fitted to the data for each specimen using the PMGSC42 software (McFadden \& McElhinny, 1988) (Fig. 13a). We were then able to place possible constraints on the remagnetization great circles. During the demagnetization of a sample that carries two components of magnetization of different magnitude and opposing direction, the measured NRM after each demagnetization step will lie on a great circle path between the directions of the two components (Fig. 13b). Because a stable endpoint is not reached we know that the underlying component must lie beyond the last measurement used to constrain the great circle, and must lie within the antipodal direction of the lower blocking temperature component (Fig. 13a,b). An example of this procedure is shown below for 15-30a (Fig. 
13). The intersection point of the constrained great circles provides an estimate for the direction of the higher blocking temperature component (Fig. 13c).

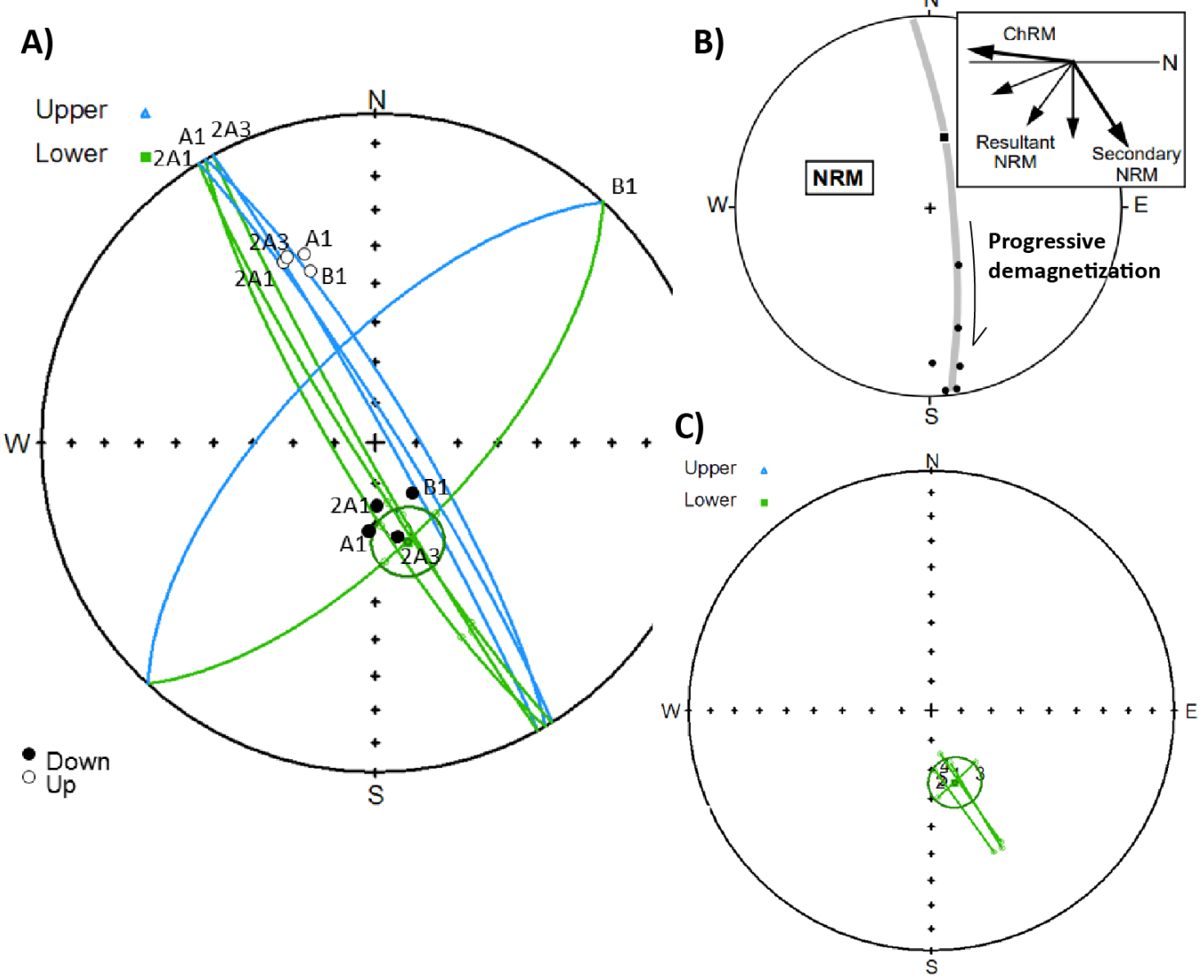

Figure 13: The use of constraints on remagnetization great circles to estimate the direction of an underlying component of magnetization where a stable end point was not reached (15-30a). A) Remagnetization great circles are produced for each individual specimen from a sample. The possible intersection point of each great circle is constrained to lie within the antipodal direction of the estimated lower blocking temperature normal component (open circles) and beyond the last point used to constrain the great circle (closed circles). B) Schematic example showing how, for a sample carrying two components of opposite polarity, the resultant NRM after each demagnetization step will lie along a great circle. For this example, a characteristic remanent magnetization (ChRM) is overprinted by a secondary NRM of opposite polarity (Butler, 1992). C) The intersection point of the constrained great circles (15-30a) provides an estimate for the direction of the higher blocking temperature component.

Fisher means (Fisher, 1953) were employed to estimate components in instances where the magnetization grouped and remained stable across a large blocking temperature range.

Fisher (1953) statistical procedures were then used to calculate sample means with an associated uncertainty envelope $\left(\alpha_{95}\right)$ and $\delta$ value. $\delta$ is a measure of the angular dispersion between data points used in calculating the mean. Because $\alpha_{95}$ is dependent on the number of directional estimates that are used to compute the average we consider 
the $\delta$ value to be a better estimate of our confidence in a sample, where only 2-4 specimens were used to calculate a mean.

Fisher (1953) statistical procedures were then used to combine sample means into overall group means. Samples were excluded from the calculation of a group mean if its mean direction was more than two circular standard deviations from the mean of the population of samples. This is considered a reliable method where $\mathrm{N}<20$.

\subsection{Microscopic Methods}

A hypothesis of this research is that the samples may carry a recently acquired component of remanent magnetization that can be used to document the rolling hinge hypothesis. A component of magnetization acquired prior to subduction and exhumation of the Goropu Metabasalt may potentially be uninterpretable in terms of a rolling hinge due to the complex deformational and chemical history of the Goropu Metabasalt, the effect of which on the primary NRM may be difficult to evaluate. This section is designed to investigate how and/or when the components of magnetization were acquired relative to the events discussed in section 2.3. To this end I document the textural relations of opaque grains under the petrographic microscope and use reflected light microscopy, and energy dispersive spectroscopy (EDS) and wavelength dispersive spectroscopy (WDS) analysis of opaque grains to aid in the identification of these phases. Samples analysed were selected in order to assess the petrological differences between representative samples from different sample localities that displayed differing demagnetization behaviour. These results are then integrated with the results from magnetic experiments to determine the dominant carriers of magnetization. The polished sections considered in this section were prepared by Rob Spiers at Canterbury University.

Magnetic separates of Goropu Metabasalt were prepared by VUW PhD student Juergen Oesterle, as a by-product of mineral separation for thermochronology work. The larger samples of Goropu Metabasalt were initially broken down with a sledge hammer or cut into smaller pieces with the diamond blade saw. The samples were placed in a Boyd crusher, and a disk mill was used to further break down the rock to grain sizes of 1$2 \mathrm{~mm}$. Coarse $(>250 \mu \mathrm{m})$ and fine $(60 \mu \mathrm{m})$ fractions were separated out using a nylon mesh sieve. A Frantz isodynamic separator was used to separate out the ferromagnetic/ferrimagnetic portion of the $60-250 \mu \mathrm{m}$ mineral separates. Four of these 
magnetic separates were prepared as grain mounts by Fiona Tuckett (VUW petrology lab technician). Analysis of these grain mounts has the added advantage of easily locating and identifying magnetic grains, however the textural relations of these grains are lost. Although magnetic separates were not prepared for samples that were measured directly in this study, they were taken from samples retrieved at the same stations as samples measured in this study, and are therefore assumed to be representative.

I acknowledge that there are two major inherent assumptions in the microscopic analysis. First, the stable component of remanent magnetization is typically carried by very fine grained SD grains, which may be optically irresolvable. Magnetic carriers are identified on the assumption that coarser grained MD grains can be used as a proxy for smaller, magnetically stable grains. Secondly, it is assumed that a single polished section is generally representative of the sample as a whole. Measurements of the magnetization of the specimens indicated substantial heterogeneity with respect to the distribution of ferrimagnetic/ferromagnetic grains at both the specimen and sample level for many samples. In this respect, grain mounts of magnetic separates may be advantageous.

\subsubsection{Petrographic Microscope}

On a first order, polished sections and grain mounts were evaluated under the petrographic microscope. I documented the overall mineralogy, the presence of opaque grains and their textural relations, in order to determine any mineralogical and/or textural differences/similarities between samples that exhibited different paleomagnetic behaviour. A considerable advantage to this analysis is that the samples considered represent an exhumed crustal section of varying degrees of metamorphism, allowing comprehensive documentation of the evolution and changes in opaque grain occurrences as a function of metamorphic mineral assemblage in the samples. Opaque grains were identified and selected for analysis under the electron microprobe.

\subsubsection{Scanning Electron Microscope}

Polished section and grain mounts of interest were analysed in the JEOL 8230 superprobe at the School of Geography, Environment and Earth Sciences, Victoria University of Wellington, in instances where opaque grains could not be identified with the petrographic microscope alone. Polished sections and grain mounts were carbon coated prior to analysis. Grains of interest were identified using backscattered electron 
maps. Semi-quantitative (energy dispersive spectroscopy [EDS]) and quantitative (wavelength dispersive spectroscopy[WDS]) spot analyses were used to determine the mineral chemical composition in order to identify the phase. WDS analyses were performed with an accelerating voltage of $15 \mathrm{KV}$ and beam current of $12 \mathrm{nA}$. All elements were analysed for peak/background times of 30/15 seconds. The primary standards for analysed iron oxides were ilmenite (USNM 96819) (Ti), wollastonite (Ca), pure synthetic oxides ( $\mathrm{Si}, \mathrm{Al}, \mathrm{Mg}, \mathrm{Cr}, \mathrm{Mn}$ ), magnetite (USNM 114887) (Fe) and elba pyrite (S) (Jarosewich et al., 1980). Primary standards for analysed sulphides were elba pyrite (Fe, S) and pure synthetic oxides (Ti, Cu, Mg, Cr, Mn) (Jarosewich et al., 1980). 


\section{Chapter 4: Results}

\subsection{Paleomagnetic Results}

This section presents the paleomagnetic results of the 44 samples (240 specimens) measured for this study. The locations of the samples considered in this study are shown on the map below (Fig. 14). The results of the demagnetization experiments are divided into two groups, based on the number and polarity of the paleomagnetic components observed, which correlate with increasing distance from the fault trace. First we discuss the potential magnetic carriers for each group, as indicated by temperature-susceptibility and isothermal remanent magnetization experiments, before discussing the component(s) of magnetization and directions of those component(s) obtained by progressive demagnetization experiments on these samples. The results of our microscopic analyses of the potential magnetic mineralogy of the samples is presented separately in Section 4.2.

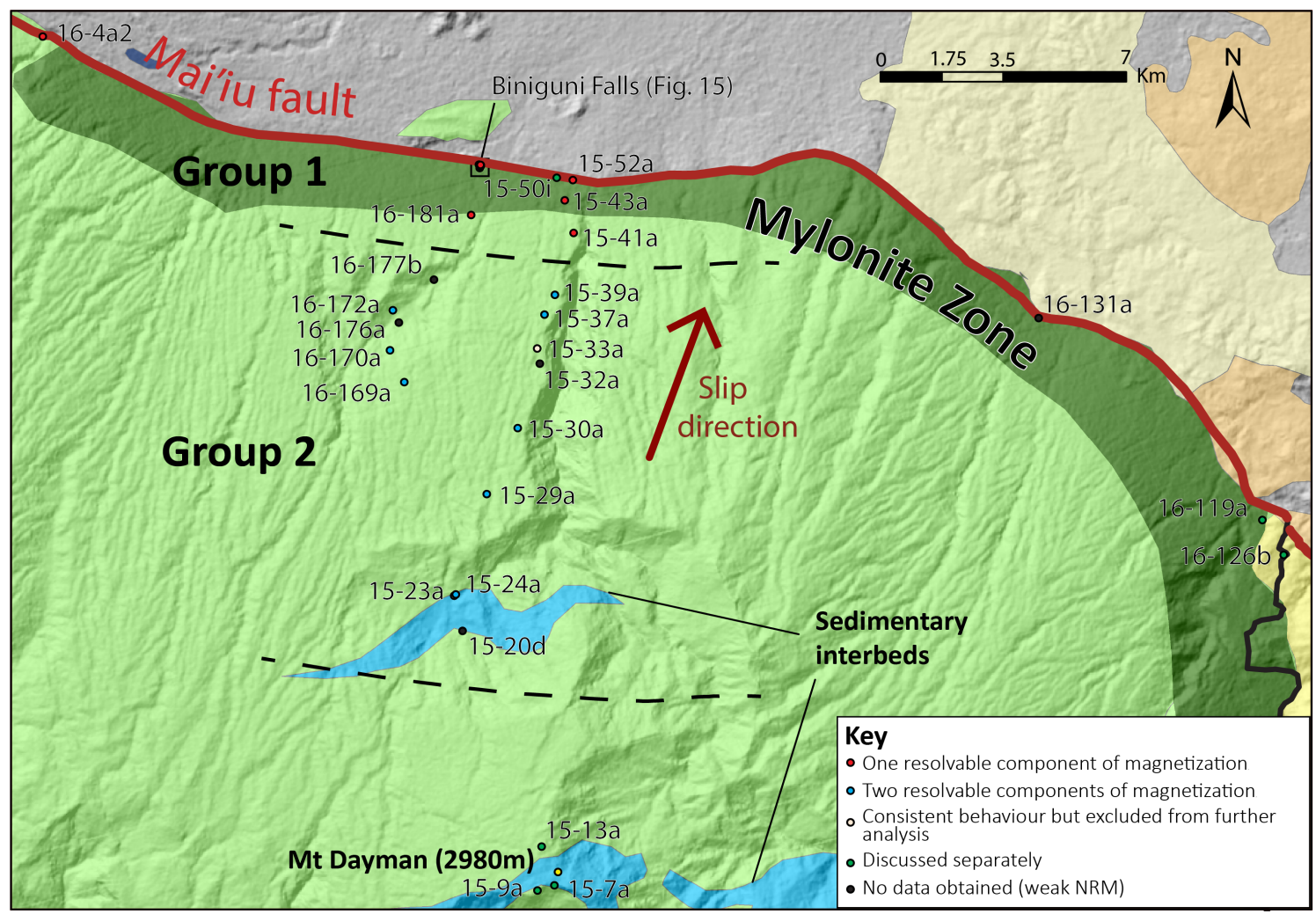

Figure 14: Suckling-Dayman MCC sample map. The samples considered in this section are plotted, along with the boundaries between the two groups of paleomagnetic behaviour. See text for further discussion. 


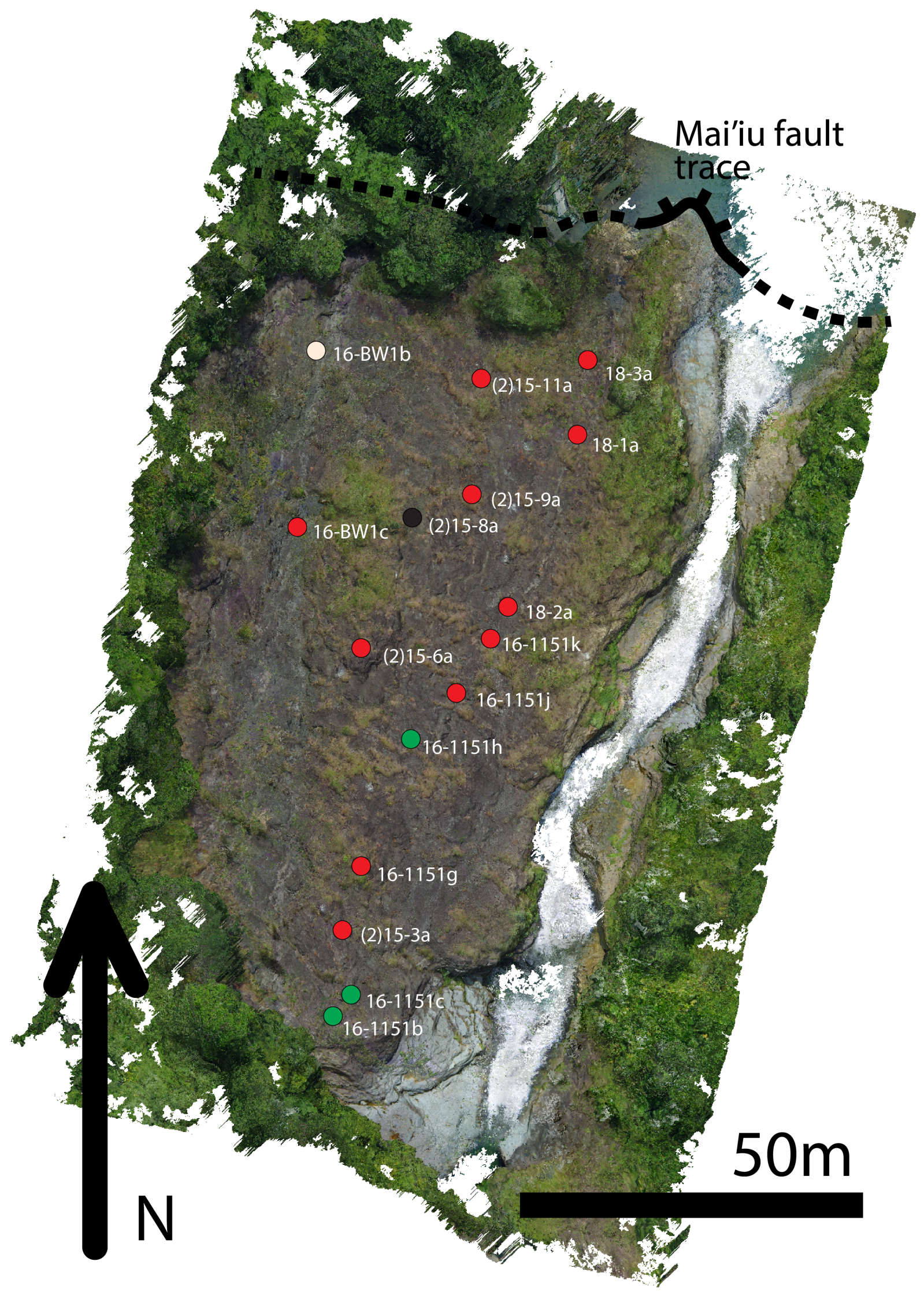

Figure 15: Biniguni Falls sample map. See Figure 14 for key. Samples were retrieved from a continuous, smooth exposure of the fault surface. See text for discussion. Note: Samples retrieved in 2016 and 2018 do not have associated GPS positions. A rough location was estimated from field notes. 


\subsubsection{Group 1}

Group 1 is comprised of greenschist facies mylonitic and nonmylonitic metabasalts located within $1.5 \mathrm{~km}$ of the fault trace. Twenty-five samples (109 specimens) were measured in this group. These samples, closest to the fault trace, are freshly exhumed in response to slip along the Mai'iu fault, and have experienced the highest temperatures $\left(425 \pm 50^{\circ} \mathrm{C}\right)$ and pressures (5.9-7.2 kbar) (Daczko et al., 2009), during burial, of the rocks studied. The most heavily sampled locality of this group was Biniguni Falls, near the trace of the Mai'iu fault (Fig. 15). Eighteen samples were measured from this locality, spanning an up-dip distance of $\sim 100 \mathrm{~m}$ parallel to the slip direction of the Mai'iu fault. This corresponds to $\sim 10,000$ years of exhumation and remanence acquisition with the known $\sim 1 \mathrm{~cm} / \mathrm{yr}$ slip rate of the fault, which is sufficient to average out secular variation. The dip of the fault at this locality is well constrained from bedrock exposures of the fault plane to be $<20-22^{\circ}$ to the north

\subsubsection{Temperature-Susceptibility}

Temperature-susceptibility data were obtained for two representative samples from Group 1 (16-BW1c and 15-43a) in order to investigate the magnetic mineralogy of Group 1 samples. A 1/T dependence of susceptibility is observed up to $400^{\circ} \mathrm{C}$ (Fig. 16). This $1 / T$ dependence of susceptibility is indicative of the dominance of the contribution of paramagnetic phases to the susceptibility of these samples. A gradual increase in susceptibility is followed by a pronounced peak in susceptibility at $\sim 510-550^{\circ} \mathrm{C}$ (Fig. 16). This is strongly indicative of the growth of new ferromagnetic/ferrimagnetic phases from paramagnetic ones upon heating. This is followed by a pronounced drop in susceptibility at $580^{\circ} \mathrm{C}$ (Fig. 16). A much smaller drop in susceptibility at $660^{\circ} \mathrm{C}$ may be observed in sample 16-BW1c (Fig. 16). These results are indicative of the presence of both Fe-rich magnetite and very minor haematite or maghemite in Group 1 samples. The heating and cooling curves are irreversible (Fig. 16), indicating substantial thermal alteration, therefore it is impossible to distinguish whether these phases were present in the sample prior to laboratory heating or were grown in the lab following heating, using this data alone. The presence of phases with Curie temperatures below $400^{\circ} \mathrm{C}$ can effectively be ruled out, however. A small increase $\sim 250^{\circ} \mathrm{C}$ characteristic of the $\lambda$ transition in hexagonal pyrrhotite (Rochette et al., 1990) was also not observed. Additional material from 16-BW1c was treated to maximum heating temperatures of $400^{\circ} \mathrm{C}$ and $500^{\circ} \mathrm{C}$. The heating and cooling curves become irreversible when heated to temperatures of $450^{\circ} \mathrm{C}$ (Fig. 16), indicating the onset of thermal alteration between 400 - 

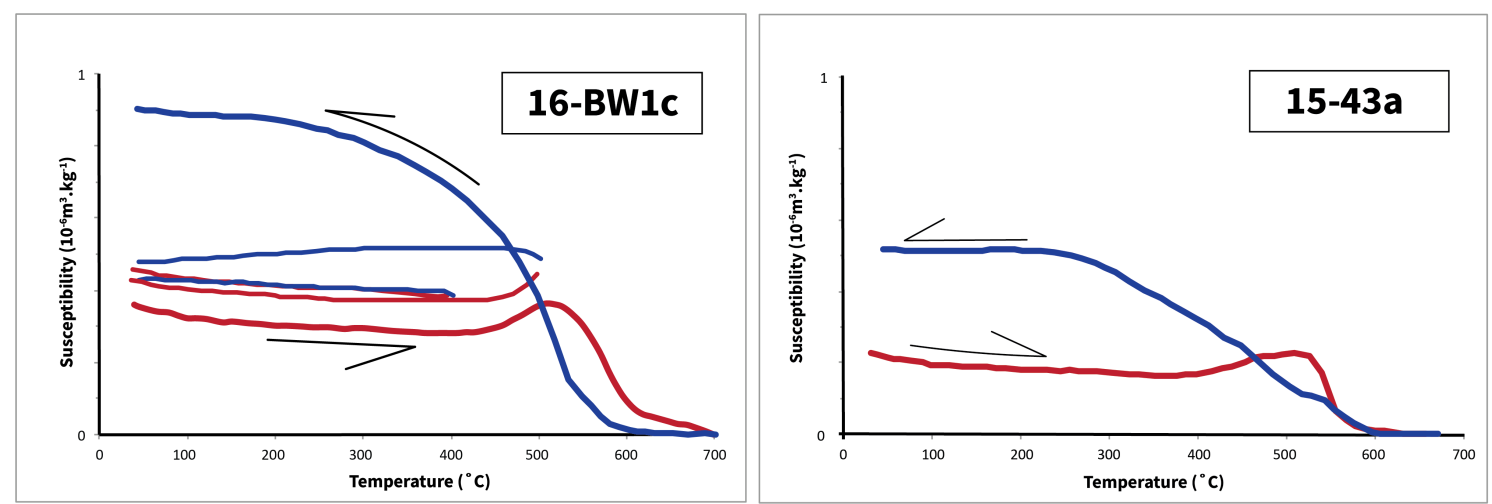

Figure 16: Temperature-susceptibility plots for representative Group 1 samples. The heating and cooling curves are reversible below $400^{\circ} \mathrm{C}$ but are irreversible above $450^{\circ} \mathrm{C}$ indicating the onset of thermal alteration between $400-450^{\circ} \mathrm{C}$. Susceptibility drops at $580^{\circ} \mathrm{C}$ and $660^{\circ} \mathrm{C}$ indicate the presence of Fe-rich magnetite and haematite or maghemite, respectively, though it is impossible to distinguish what phases were present prior to thermal alteration using this data alone. Note: Temperature-Susceptibility curves to maximum temperatures of $400^{\circ} \mathrm{C}$ and $500^{\circ} \mathrm{C}$ were undertaken on duplicate samples.

Sample 16-4a2 differed from the behaviour of all other Group 1 samples during the later demagnetization run, because the absence of a pronounced susceptibility increase indicated thermal alteration was only very minor (Fig. 17). Pronounced drops in susceptibility are observed at $\sim 580^{\circ} \mathrm{C}$ and $\sim 650^{\circ} \mathrm{C}$ upon heating, indicating the presence of Fe-rich magnetite, and haematite or maghemite in this sample (Fig. 17). Because this sample exhibits the same paleomagnetic behaviour as the 16-BW1c and 15-43a (section 4.1.1.3) we suggest that the susceptibility drops observed in 16-BW1c and 15-43a are at least partially attributable to the presence of these phases in these samples prior to thermal alteration.

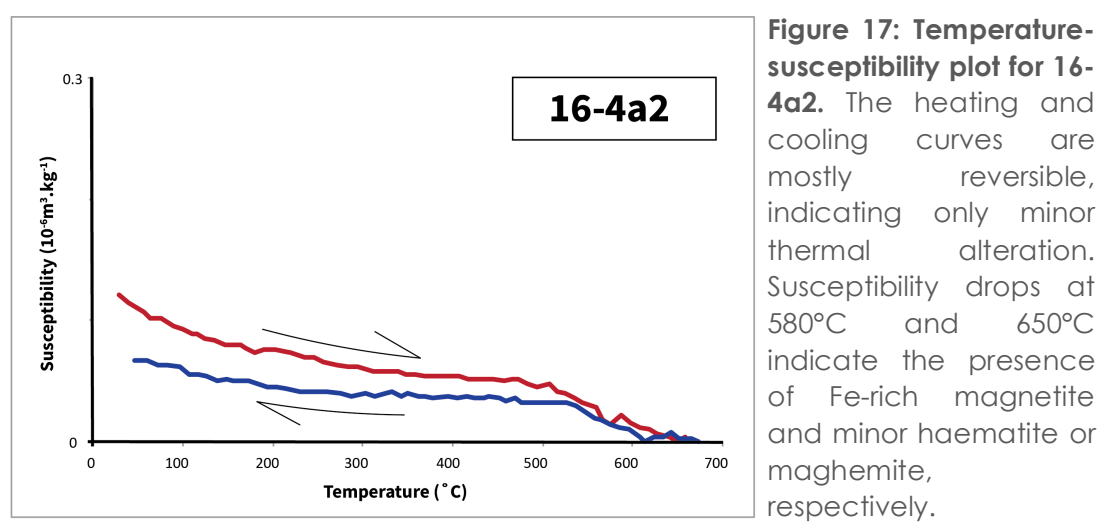

\subsubsection{Isothermal Remanent Magnetization}

Isothermal remanent magnetization (IRM) experiments were undertaken on three representative specimens from Group 1 samples. This technique has the advantage that the results are unaffected by thermal alteration. 16-BW1cA2 (fresh, unaltered) and 16BW1cB1 (after being subjected to thermal alteration during thermal demagnetization 
experiments) were measured in order to compare and contrast the magnetic mineralogy of these specimens. This was done in order to infer the chemical changes that are occurring in these specimens in response to laboratory heating. 16-BW1cA2 (a proxy for the magnetic mineralogy of Group 1 samples prior to thermal alteration) saturates quickly $\left(\mathrm{B}_{95}=179 \mathrm{mT}\right)$ and has a low coercivity of remanence of $20.8 \mathrm{mT}\left(\mathrm{B}_{\mathrm{cr}}\right)$ (Fig. 18). A pronounced peak in the $\mathrm{dIRM} / \mathrm{dB}$ vs. applied field curve between 10-20 $\mathrm{mT}$ is evident (Fig. 18). This behaviour is consistent with fine-grained titanomagnetite as the dominant carrier of magnetization in Group 1 samples, and is consistent with temperature-susceptibility experiments that indicate the presence of Fe-rich titanomagnetite in Group 1 samples (section 4.1.1.1). The low saturation remanence (SIRM) $\left(5.67 * 10^{-2} \mathrm{~A} / \mathrm{m}\right)$ is interpreted to be due to the low concentration of titanomagnetite in these samples. The corresponding thermally altered specimen does not saturate and has a higher coercivity of remanence $\left(\mathrm{B}_{\mathrm{cr}}=63.8 \mathrm{mT}\right)$ (Fig. 18) suggesting the growth of a higher coercivity phase (most likely haematite) in response to laboratory heating.
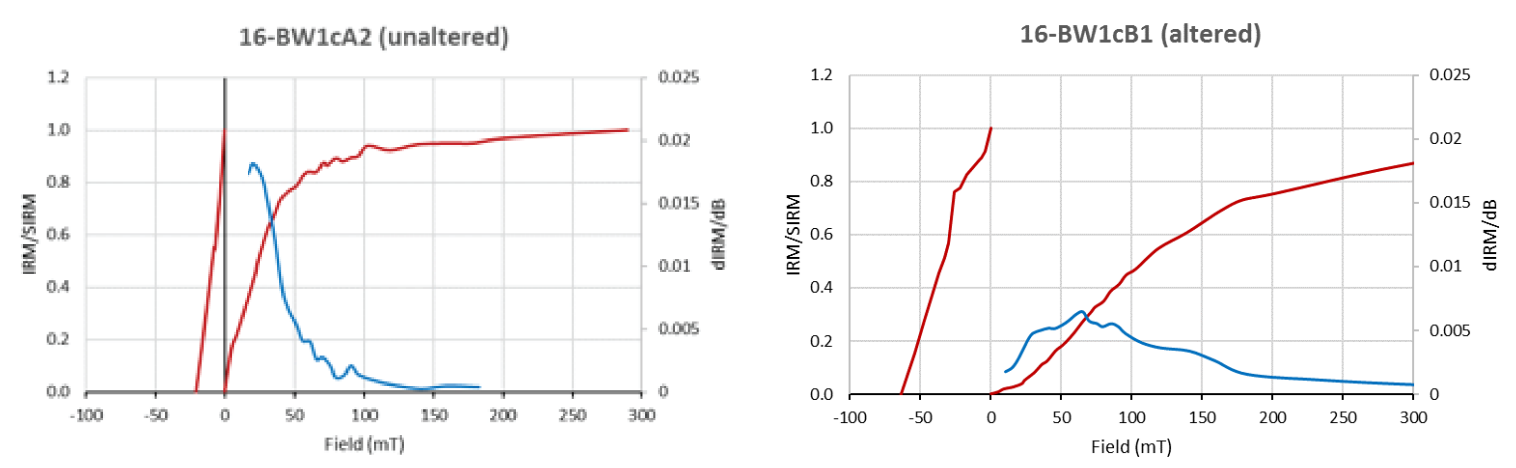

Figure 18: Normalized IRM acquisition curves for an unaltered (left) and altered (right) specimen taken from a representative Group 1 sample. Red: IRM/SIRM vs. Field (mT). Blve: dIRM/dB vs. Field (mT) (a proxy for the coercivity spectrum). 16-BW1cA2: Peak in coercivity spectrum $\left(B_{\text {peak }}\right)=10-20 \mathrm{mT}$, Saturating field $\left(B_{95}\right)=179 \mathrm{mT}$, Saturation remanence $(S I R M)=5.67 * 10-02 \mathrm{~A} / \mathrm{m}$, Coercivity of Remanence $\left(B_{c r}\right)=20.8 \mathrm{mT}$. 16-BW1CB1: Peak in coercivity spectrum $\left(B_{\text {peak }}\right)=60-70 \mathrm{mT}$, Coercivity of Remanence $\left(B_{c r}\right)=63.8 \mathrm{mT}$, Remanence at $800 \mathrm{mT}=3.07 \mathrm{~A} / \mathrm{m}$.

16-181a (a fresh nonmylonitic Group 1 sample) also saturated very quickly $\left(\mathrm{B}_{95}=200\right.$ $\mathrm{mT}$ ) and had a low coercivity of remanence of $35.7 \mathrm{mT}$ (Fig. 19). A peak in the coercivity spectrum is observed $\sim 40 \mathrm{mT}$ (Fig. 19). This result is similarly consistent with titanomagnetite as the dominant carrier of magnetization. Slight differences in magnetic parameters between samples are attributed to either slight grain size or compositional differences. 


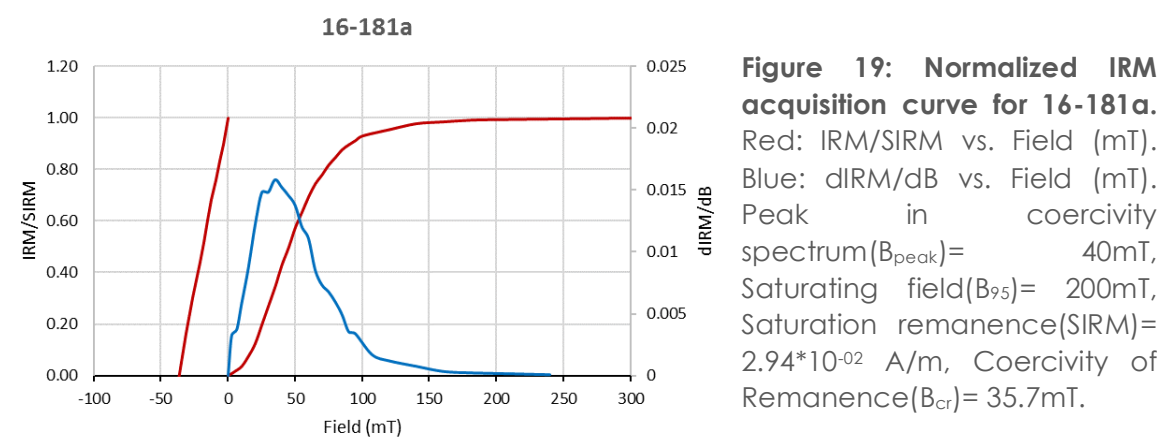

\subsubsection{Magnetic Carriers: Concluding Remarks}

Temperature-susceptibility experiments and isothermal remanent magnetization experiments undertaken on samples that have not thermally altered during the thermal demagnetization experiments indicate that fine-grained, Fe-rich titanomagnetite is the dominant carrier of magnetization in both the mylonitic and nonmylonitic Group 1 samples. Minor amounts of haematite or maghemite may also be present in these samples, however the susceptibility drops are small and often difficult to distinguish from background noise. The experiments also indicate that haematite \pm magnetite is produced by thermal alteration during heating.

\subsubsection{Demagnetization Behaviour}

Samples from Group 1 generally had weak NRM intensities that ranged from $10^{-5}$ and $10^{-3} \mathrm{~A} / \mathrm{m}$ (Appendix 1). Magnetization generally reached less than $10 \%$ of its initial value at demagnetization steps above $350-500^{\circ} \mathrm{C}$ (Fig. 20). The majority of these samples (nineteen) appeared to carry a single, normal polarity component of remanence throughout this blocking temperature range (Table 2; Fig. 20). Persistent thermal alteration above $400-450^{\circ} \mathrm{C}$ (as evidenced by increases in susceptibility during the demagnetization run) and the weak strength of NRM made it difficult to determine whether an underlying component of magnetization was present beyond unblocking temperatures of $400-500^{\circ} \mathrm{C}$, and if so, estimate its direction. The origin-bound nature of the magnetization of the Zjiderveld plots does, however, indicate that this normal component is carried to the highest blocking temperatures $\left(400-550^{\circ} \mathrm{C}\right)$ in most, if not all, of the samples (Fig. 20; Appendix 1).

There were two exceptions to the thermal alteration behaviour described above. Thermal alteration is minimal in 16-4a2 (as evidenced by the lack of a pronounced susceptibility increase during the demagnetization run and in temperature-susceptibility experiments, as mentioned above) (Appendix 1), and thermal alteration was inferred at 
temperatures above $300^{\circ} \mathrm{C}$ in some specimens in sample $15-41 \mathrm{a}$ as evidenced by the pronounced susceptibility increase above those temperatures (Appendix 1).
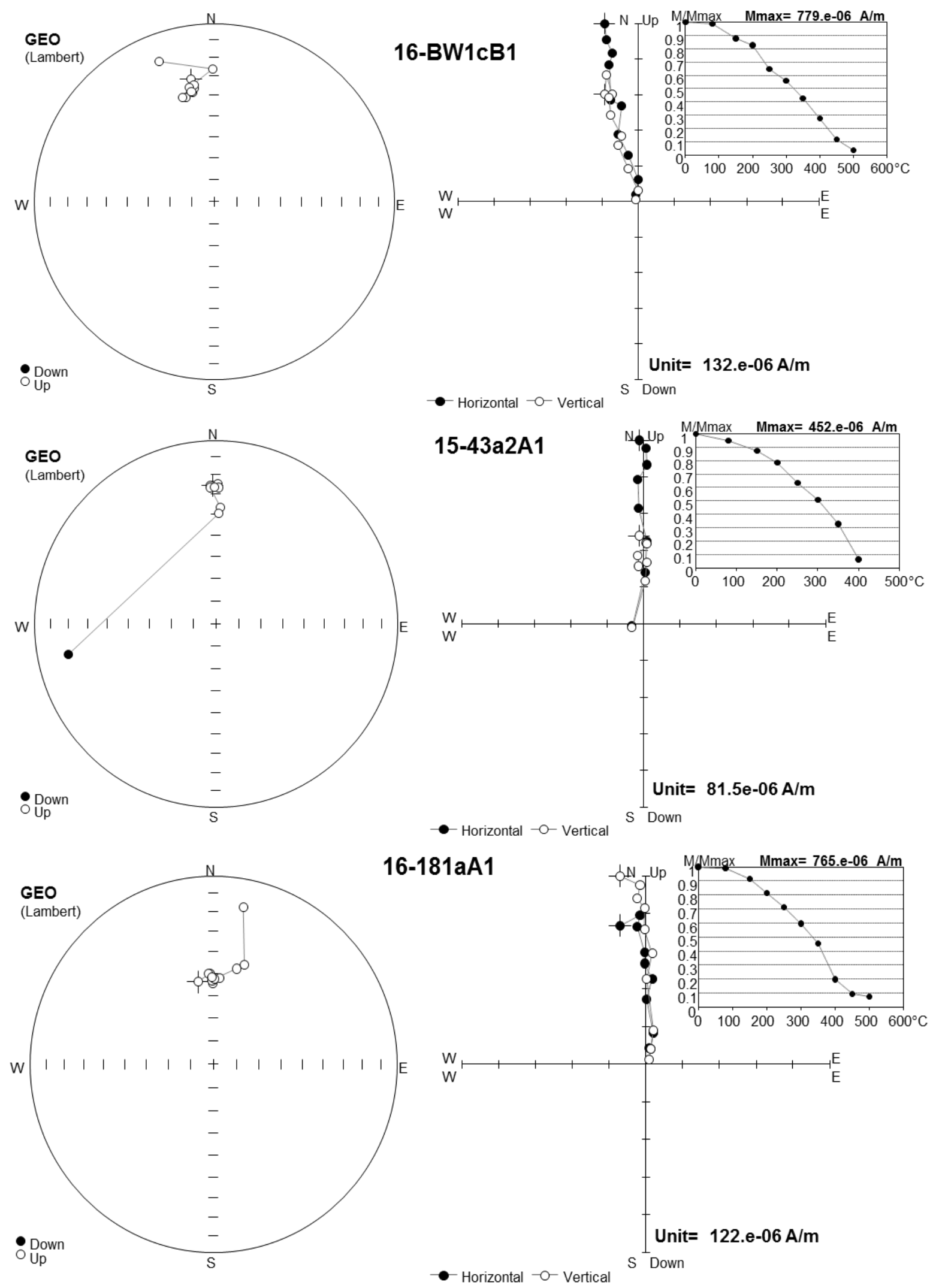

Figure 20: Representative thermal demagnetization plots for Group 1 specimens. The specimens carried a single resolvable component of magnetization that is normal-polarity and appears to be present to (un)blocking temperatures of at least $400-550^{\circ} \mathrm{C}$. 
The direction of the normal component of remanence for each specimen was estimated using Principal Component Analysis (PCA) between temperatures NRM- $80^{\circ} \mathrm{C}$ and $350^{\circ} \mathrm{C} \pm 150^{\circ} \mathrm{C}$, fitted to the origin and/or anchored to the last point where a lower MAD was achieved. Generally, above $350^{\circ} \mathrm{C}$ magnetization dropped below strengths that are sufficient for accurate measurement in the JR6 spinner magnetometer. As a consequence, the data obtained from demagnetization temperatures above $350^{\circ} \mathrm{C}$ generally had large errors and were therefore excluded from PCA estimates. Excluding these data points also excludes any effect laboratory thermal alteration above $400^{\circ} \mathrm{C}$ may have on the magnetization.

Sample remanence directions were calculated by averaging the PCA estimates of 3-4 individual specimens retrieved from a sample. The sample averages cluster around north at a moderate inclination (Fig. 21). The slight variation between sample averages is attributed to secular variation and slight orientation errors that may have resulted from sawing of the hand samples. The combined mean $(\mathrm{N}=18$ specimens $)$ of this component in the Group 1 samples has a declination of $351.1^{\circ}$, inclination of $-35.7^{\circ}$ and an $\alpha_{95}$ of $6.8^{\circ}$ (Fig. 21). 16-BW1b was excluded from the average because its direction was more than two circular standard deviations $\left(\theta_{63}\right)$ from the mean (Fig. 21).

Two samples measured from this group yielded data that were too noisy to estimate a reliable component of magnetization that was consistent between specimens (Table 2; Appendix 1).

Of the 25 samples measured from this group, four displayed paleomagnetic behaviour that differed from the average behaviour described above. These samples are discussed in Appendix 2. 


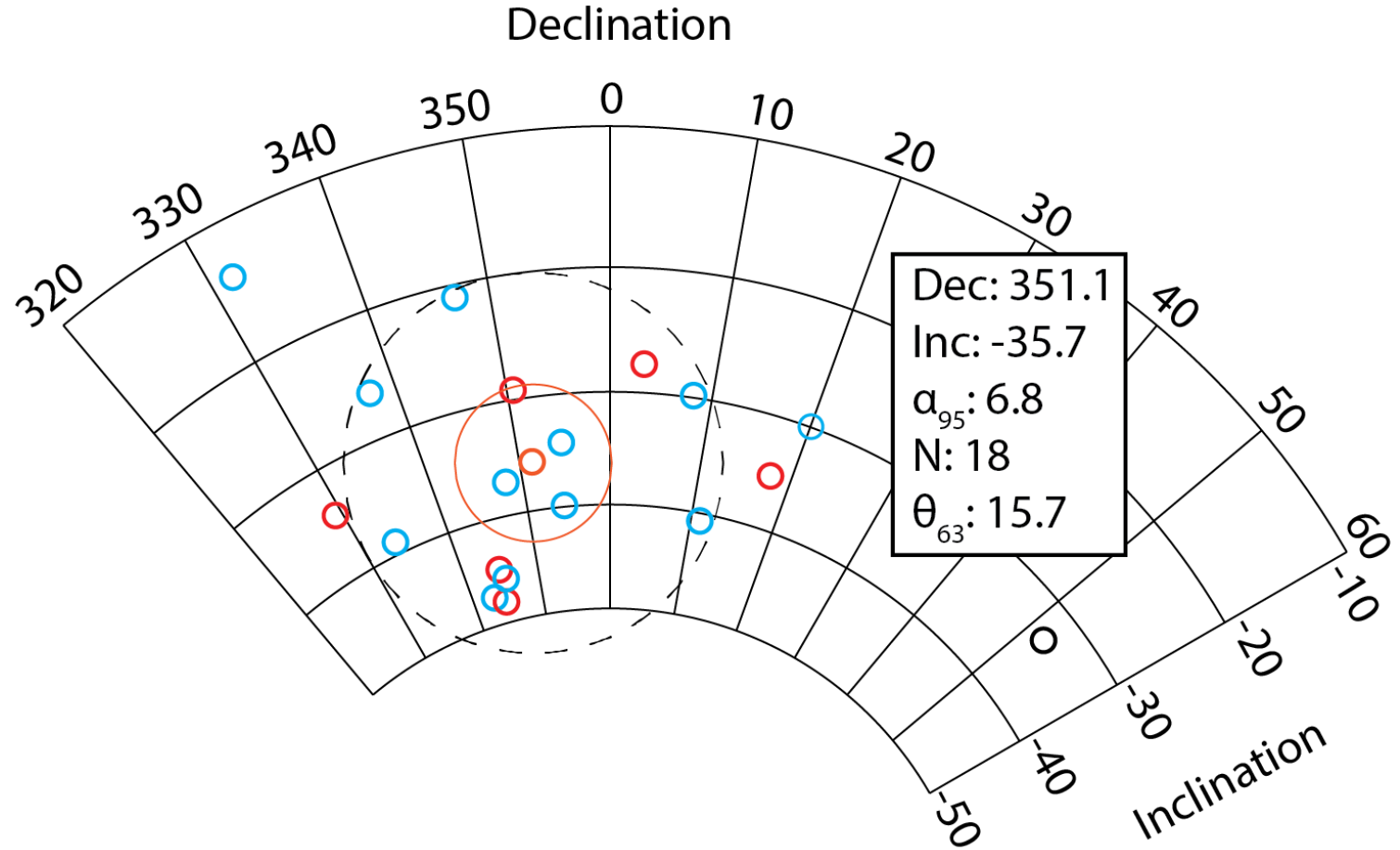

Figure 21: Stereoplot of Group 1 sample averages. Blve: Biniguni Falls samples. Red: Samples from other sites. Orange: Mean direction. Black-dashed: Circular standard deviation of the population of samples. Samples that lie more than two circular standard deviations from the mean (black) are not included in the overall mean. 


\begin{tabular}{|c|c|c|c|c|c|c|c|c|}
\hline \multirow[t]{2}{*}{ Sample } & \multirow[t]{2}{*}{$N(n)$} & \multicolumn{7}{|c|}{ Component 1} \\
\hline & & Declination $\left({ }^{\circ}\right)$ & Inclination $\left({ }^{\circ}\right)$ & $\alpha_{95}$ & $\delta$ & $n_{\text {specimen }}$ & PCA limits $\left({ }^{\circ} \mathrm{C}\right)$ & Maximum $\mathrm{T}\left({ }^{\circ} \mathrm{C}\right)$ \\
\hline 16-BW1b*t & 6(3) & 52.3 & -33.1 & 22.6 & 12 & 3 & NRM-500 F & $>500$ \\
\hline 16-BW1c*t & $7(3)$ & 348.2 & -37.1 & 1.6 & 0.9 & 3 & $80-500$ OA & $>500$ \\
\hline $16-1151 b^{* t}$ & $7(6)$ & \multicolumn{7}{|l|}{ See Appendix } \\
\hline $16-1151 c^{*+}$ & $6(5)$ & \multicolumn{7}{|l|}{ See Appendix } \\
\hline $16-1151 \mathrm{~g}^{*+}$ & $6(5)$ & 354.9 & -34.3 & 15 & 14 & 5 & NRM-450 OA/A & $>450$ \\
\hline $16-1151 h^{* t}$ & $6(3)$ & \multicolumn{7}{|l|}{ See Appendix } \\
\hline $16-1151 j^{*+}$ & $4(3)$ & 343.2 & -47.4 & 9.3 & 5 & 3 & NRM-450 OA & $>500$ \\
\hline $16-1151 k^{*+}$ & $6(3)$ & 354.6 & -40.0 & 6.8 & 3.6 & 3 & NRM-400 OA & $>500$ \\
\hline $16-4 a 2^{*+}$ & $6(4)$ & 17.9 & $\mid-35.2$ & 11.7 & 8.9 & 4 & NRM-400 OA & 580 \\
\hline $16-131 \mathrm{a}^{+}$ & $7(4)$ & \multicolumn{7}{|l|}{ N/A } \\
\hline 16-181a & $7(4)$ & 344.7 & -48.1 & 11.5 & 8.7 & 4 & NRM-400 OA & $>500$ \\
\hline (2)15-3a*t & $4(3)$ & 20.2 & -30.0 & 45.0 & 10.0 & 3 & NRM-450 OA & $>450$ \\
\hline (2)15-6a*t & $5(3)$ & 347.2 & -21.1 & 21.2 & 11.2 & 3 & NRM-350 OA & $>500$ \\
\hline (2)15-8a*t & 6 & \multicolumn{7}{|l|}{ N/A } \\
\hline (2)15-9a*t & $4(3)$ & 11.3 & -40.8 & 8.2 & 4.4 & 3 & NRM-400 OA & $>450$ \\
\hline (2)15-11a*+ & $6(4)$ & 331.7 & -13.9 & \begin{tabular}{|l|}
24.4 \\
\end{tabular} & 18.1 & 4 & NRM-400 OA & $>500$ \\
\hline (2)15-15a*t & $4(3)$ & 8.3 & -29.9 & 7.8 & 4.2 & 3 & NRM-350 OA & $>450$ \\
\hline $15-41 a$ & $5(4)$ & 344.9 & -44.9 & 12.0 & 9.1 & 4 & NRM-300 OA & $>400$ \\
\hline $15-43 a^{+}$ & $5(3)$ & 3.3 & $\mid-27.7$ & 7.0 & 3.7 & 3 & NRM-350 OA & $>500$ \\
\hline $15-50 \mathrm{i}^{+}$ & $6(3)$ & \multicolumn{7}{|l|}{ See Appendix } \\
\hline $15-52 a^{+}$ & $4(3)$ & \begin{tabular}{|l}
329.3 \\
\end{tabular} & -34.3 & 9 & 4.8 & 3 & $80-300$ OA & $>550$ \\
\hline 15-59a $a^{*+}$ & $6(4)$ & 350.7 & -29.3 & 3.7 & 2.8 & 4 & NRM-350 OA & $>400$ \\
\hline $18-1 a^{*+}$ & $2(2)$ & 337.7 & -26.3 & 44.1 & 9.8 & 2 & 80-250 OA & $>500$ \\
\hline $18-2 a^{*+}$ & $4(3)$ & 333.8 & -39.0 & 66.5 & 14.2 & 2 & NRM-350 OA & $>400$ \\
\hline $18-3 a^{*+}$ & $5(4)$ & 345.5 & -45.9 & 6.1 & 4.6 & 4 & NRM-350 OA & $>400$ \\
\hline 16-119a (e) & $7(4)$ & 347.4 & -20.7 & 15.7 & 11.8 & 4 & NRM-500 OA & $>500$ \\
\hline $16-126 b(e)$ & $4(3)$ & 351.2 & -22.2 & 30.6 & 16.0 & 3 & NRM-450 & $>450$ \\
\hline \multicolumn{2}{|c|}{ Average $(\mathrm{N}=18$ ) } & 351.1 & -35.7 & 6.8 & & & & \\
\hline
\end{tabular}

Iabie 2: Mean aırecrions ior Group I sampies. N(n) Number or specimens retrievea (number or specimens measured), $\alpha_{95}$ uncertainty envelope on the mean estimate ( $95 \%$ confidence), $\delta$ angular dispersion of data points considered in the sample mean, $n_{\text {specimen }}$ number of specimens that were used in the sample mean, PCA Principal Component Analysis, F Fisher mean, O Fitted to the origin, A Anchored to the last point, $T$ Maximum unblocking temperature. *Biniguni Falls samples. † Mylonitic Goropu Metabasalt. (e) Eastern sites. $\delta$ is considered to be a much better estimate of the confidence in a sample, where $<7$ specimens were used in a sample mean.

\subsubsection{Eastern Sites}

In addition to the Group 1 (base of the scarp) samples measured at and around Biniguni Falls, two other samples (16-119a and 12-126b) from low on the scarp were measured $\sim 22 \mathrm{~km}$ further east on the western limb of the Gwoira synform (Fig. 9; Fig. 14). The Gwoira Synform is a synformal corrugation in the surface of the Mai'iu fault that is interpreted to still be amplifying today (Little et al., 2019). Care must be taken when interpreting paleomagnetic directions from sites near this corrugation because a deviation between the expected and observed paleomagnetic direction might be influenced by an additional rotation about the NE trending fold hinge of the synform that might not be present farther west near Biniguni Falls. This would produce a 
shallowing of the paleomagnetic vector and a deflection of an upward-direction towards the west, relative to the bulk of the Group 1 samples at Biniguni Falls.

16-119a carried two resolvable components of magnetization. In the lower blocking temperature range $\left(\mathrm{NRM}-200^{\circ} \mathrm{C}\right)$ a reversed, north-northwesterly trending, steeply inclined component of unknown origin is carried (Fig. 22; blue). Two of the measured specimens do not carry this component of magnetization. In the higher blocking temperature range $\left(200^{\circ} \mathrm{C}\right.$ to at least $\left.450^{\circ} \mathrm{C}\right)$ a normal, northwesterly trending, shallowly inclined component of magnetization is preserved (Table 2; Fig. 22; red). Laboratory thermal alteration made it impossible to determine if any other components of magnetization were present at blocking temperatures above $450^{\circ} \mathrm{C}$; however, the trend of the demagnetization plots may indicate that a reversed component is present in the highest blocking temperature range (Fig. 22).

16-126b carried two resolvable components of magnetization. Similarly to $16-119 \mathrm{a}$ a reversed component of magnetization was present in the lower blocking temperature range (NRM-200 ${ }^{\circ} \mathrm{C}$ ), however this component was more shallowly inclined (Fig. 22). This component was not present in one of the measured specimens. In the higher blocking temperature range a normal, northwesterly, shallowly inclined component of magnetization is present (Table 2; Fig. 22).

The average direction of the normal component estimated in these two eastern samples is Dec: $349.3^{\circ}$, Inc: $-21.5^{\circ}, \alpha_{95}: 8.4^{\circ}(\mathrm{N}=2)$ (Fig. 23). The results indicate that the remanence vector in these samples has not been significantly westerly deflected relative to other Group 1 samples and therefore has not obviously been affected by synformal deformation. The Gwoira Synform is still amplifying today therefore this implies that the normal component in these samples was acquired very recently and may post-date the acquisition of the normal component in Group 1 samples. However, there are too few data points to draw a strong conclusion. Paleomagnetic analysis of more samples from this region, and investigations into the magnetic mineralogy of these samples is desired to test whether this behaviour is representative of the area, and if so, if differing mineralogy, or other mechanisms, are responsible. 

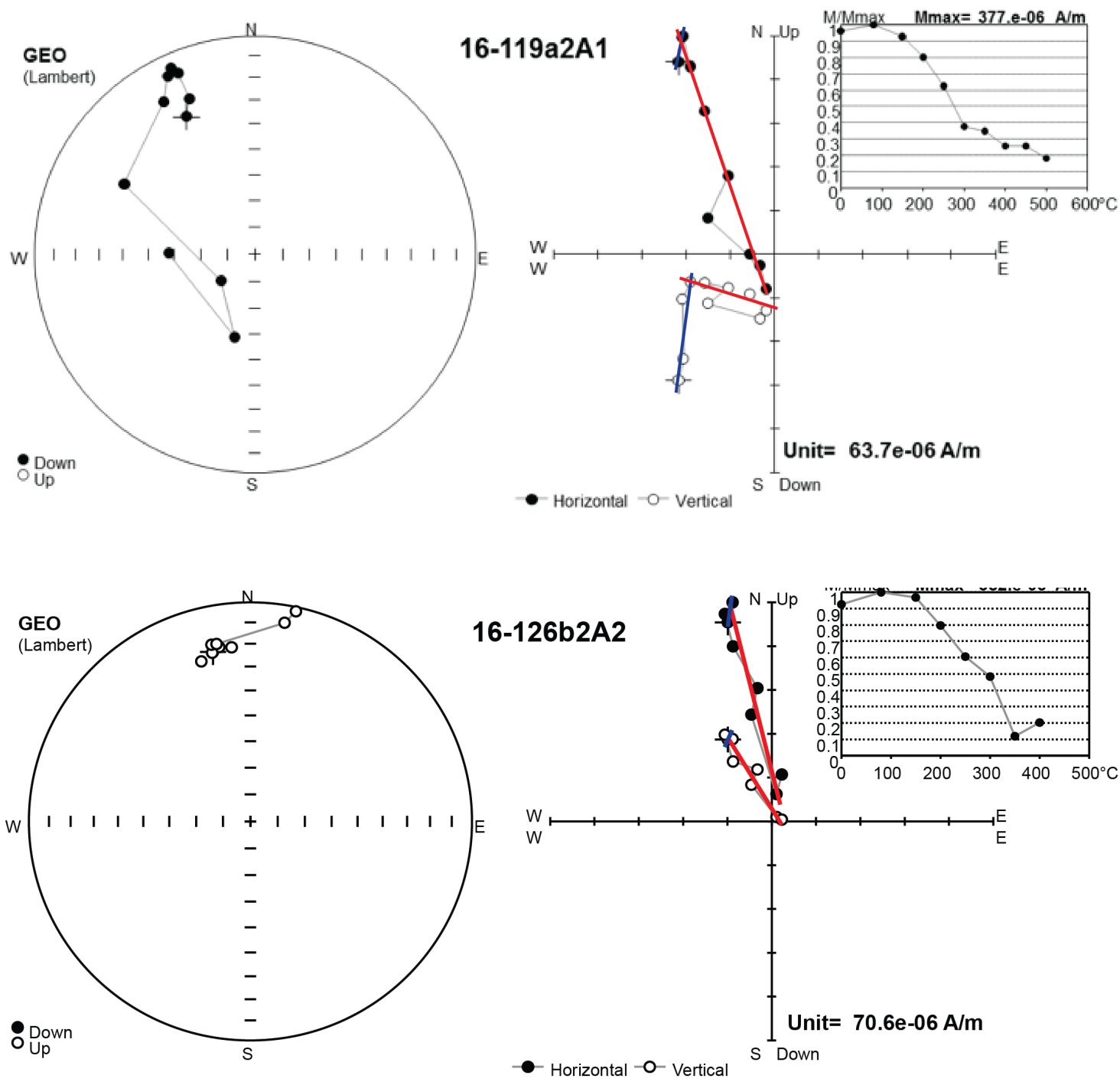

Figure 22: Representative thermal demagnetization plots for 16-119a and 16-126b. Two resolvable components of magnetization were observed; In the lower blocking temperature range a reversed polarity, northerly trending component is observed (blue), in the higher blocking temperature range a normal polarity, northwesterly trending, shallowly inclined component of magnetization is preserved (red).

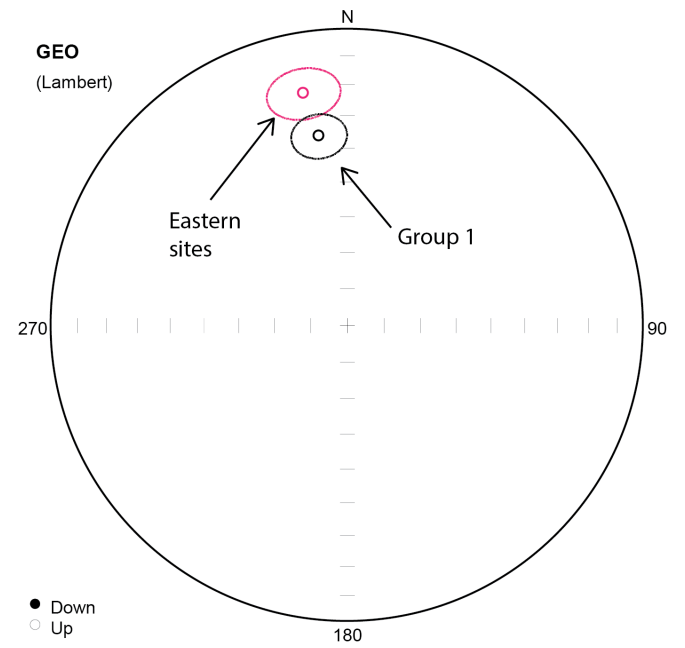

Figure 23:

Stereoplot of

the average

direction of the normal component in the eastern sites. The direction is shallower than other Group 1 samples. 


\subsubsection{Group 2}

Group 2 is comprised of greenschist to locally pumpellyite-actinolite facies metabasalts located between $>1.5 \mathrm{~km}$ and $10 \mathrm{~km}$ from the fault trace (Fig. 14). Fourteen samples were measured from this group. Of these samples, five were either abandoned during the demagnetization run, due to the possession of very weak NRMs, or the complete data set was too noisy to estimate any components of magnetization. These samples are included in Table 3 but are not discussed any further. Located further from the fault trace, Group 2 samples were subducted to lower maximum metamorphic temperatures and were exhumed prior to Group 1 samples, however their maximum paleotemperatures are not constrained precisely.

\subsubsection{Temperature-Susceptibility}

Temperature-susceptibility experiments were undertaken on representative Group 2 samples that exhibited alteration at different temperatures (above 250 and $400^{\circ} \mathrm{C}$ ), or only minor alteration.

Sample 16-172a begins to alter above $400^{\circ} \mathrm{C}$ based on observations of increases in susceptibility and magnetization during the demagnetization run (Fig. 24). The observed $1 / \mathrm{T}$ dependence of susceptibility at lower temperatures (Fig. 25) is indicative of the dominance of paramagnetic materials in this sample. A major drop in susceptibility is observed $\sim 525^{\circ} \mathrm{C}$ (Fig. 25) indicating the presence of Fe-rich titanomagnetite with minor titanium incorporation $(\mathrm{x}<0.1)\left(\mathrm{Fe}_{3-\mathrm{x}} \mathrm{Ti}_{\mathrm{x}} \mathrm{O}_{4}\right)$. Another, smaller drop in susceptibility occurs at $\sim 650^{\circ} \mathrm{C}$ (Fig. 25) which may be indicative of the presence of minor amounts of haematite or maghemite in this sample. Although an increase in susceptibility above $400^{\circ} \mathrm{C}$ is not observed in the temperature-susceptibility data, the heating and cooling curves are irreversible (Fig. 25) indicating thermal alteration has taken place. We are therefore unable to determine if these phases were present prior to thermal alteration using this data alone. This temperature-susceptibility behaviour is similar to that observed in Group 1 samples. 


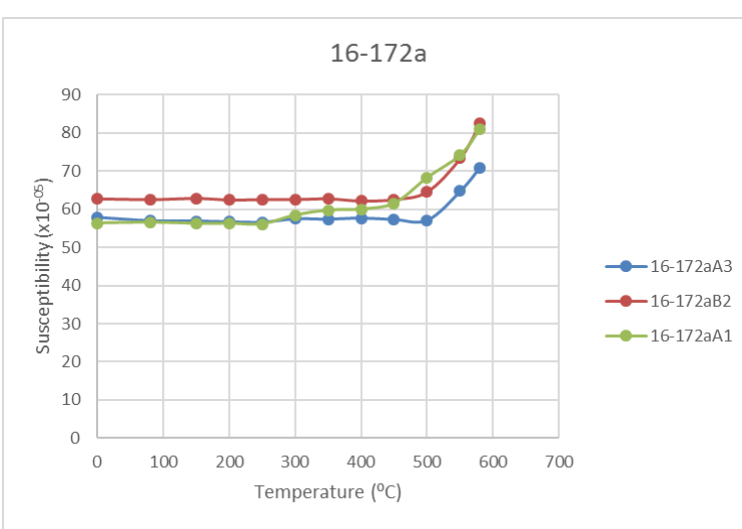

Figure 24: Temperature-
susceptibility plot for
specimens obtained from
sample 16-172a, obtained
during the demagnetization
run. Although not observed
in the temperature-
susceptibility experiment,
pronounced thermal
alteration above $400^{\circ} \mathrm{C}$ is
observed in the
susceptibility data here.

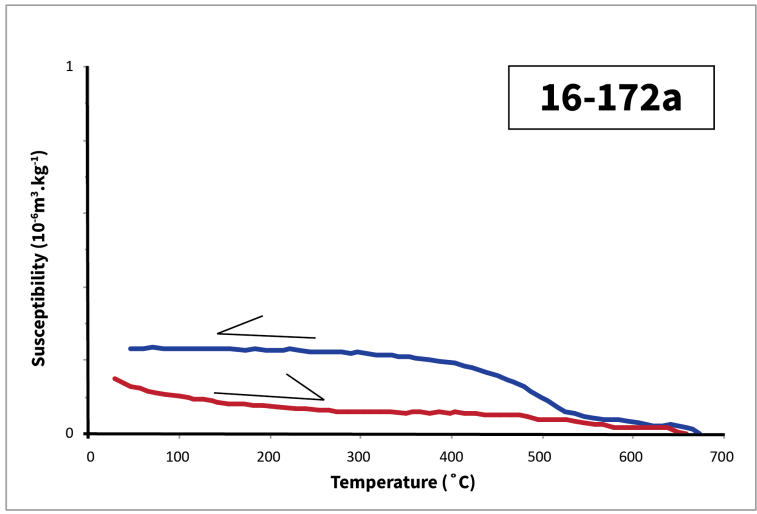

Figure 25: Temperaturesusceptibility plot for 16172a. Pronounced susceptibility drops at $525^{\circ} \mathrm{C}$ and $650^{\circ} \mathrm{C}$ are indicative of the presence of titanomagnetite $(x<0.1)$ and minor amounts of haematite or maghemite, respectively. The heating and cooling curves are irreversible, indicating thermal alteration has

Sample $15-29$ a differs from $16-172$ a as alteration is more pronounced and begins to occur at lower temperatures above $250-300^{\circ} \mathrm{C}$ (Fig. 26). A substantial susceptibility drop occurs $\sim 530^{\circ} \mathrm{C}$ (Fig. 26) indicating the presence of titanomagnetite $(\mathrm{x}<0.1)$ in this sample. However, it is impossible to determine whether this phase was present prior to thermal alteration. A similar $1 / \mathrm{T}$ relationship is observed up to a temperature of $250^{\circ} \mathrm{C}$ (Fig. 26) indicating the dominance of paramagnetic phases in this sample.

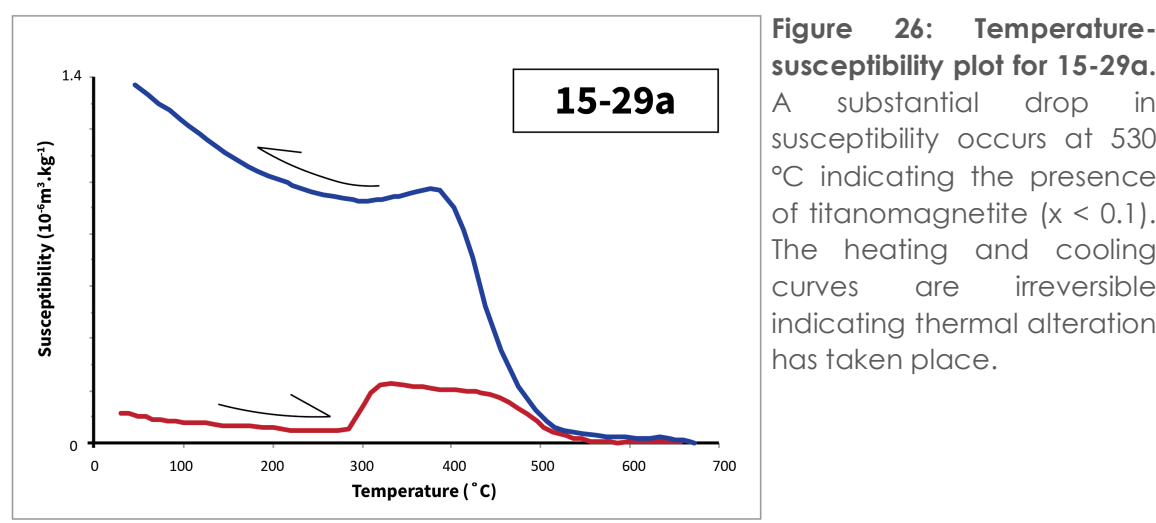

Comparatively, alteration in sample 15-24a was only minor (Fig. 27). 15-24a displays the same decreasing trend in susceptibility with increasing temperature as the other samples (Fig. 27), indicating the dominance of paramagnetic phases to the contribution of the susceptibility in this sample. A substantial drop in susceptibility occurs at $550^{\circ} \mathrm{C}$ 
(Fig. 27) indicating the presence of titanomagnetite $(\mathrm{x}<0.1)$ in this sample. We therefore interpret that the susceptibility drops between $525-530^{\circ} \mathrm{C}$ observed in samples 16-172 $\mathrm{a}$ and $15-29 \mathrm{a}$ are at least in part attributable to titanomagnetite $(\mathrm{x}<0.1)$ present prior to thermal alteration and therefore that titanomagnetite $(\mathrm{x}<0.1)$ is a major carrier of remanence in the Group 2 samples.

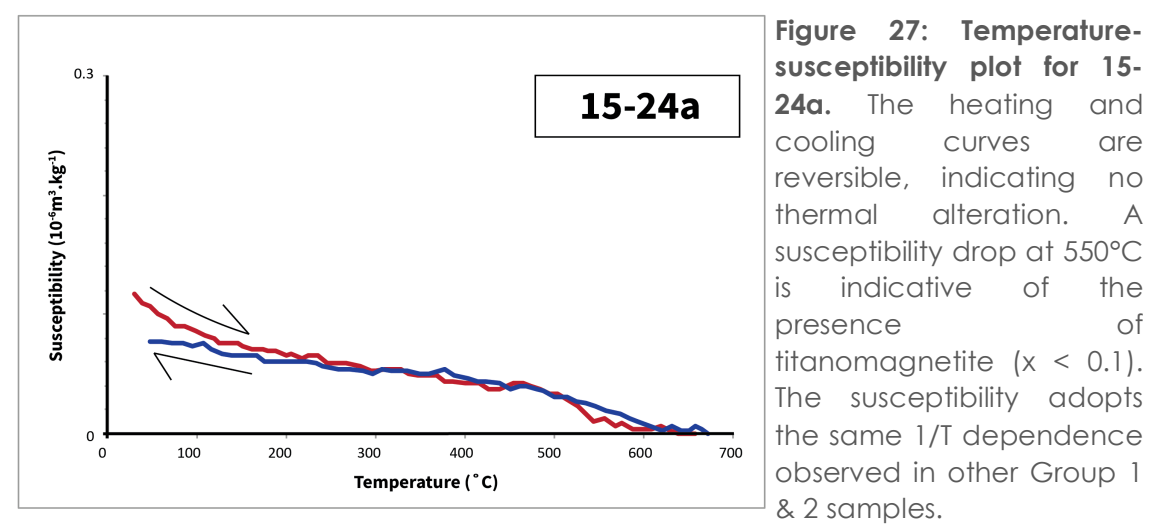

\subsubsection{Isothermal Remanent Magnetization}

Isothermal remanent magnetization experiments were carried out on two representative Group 2 specimens. The measured Group 2 specimens both exhibit a low coercivity peak between 20-30 mT and a low coercivity of remanence (28-35 mT) (Fig. 28, 29). This behaviour is consistent with fine-grained titanomagnetite as the dominant carrier of magnetization in these samples, and is consistent with temperature-susceptibility experiments which also indicate titanomagnetite $(\mathrm{x}<0.1)$. However, neither sample completely saturates (Fig. 28, 29). This is due to the presence of a very high coercivity phase (or phases) in these samples - goethite and/or haematite. This is consistent with temperature-susceptibility experiments which indicate minor amounts of haematite and is consistent with optical observations that may suggest the presence of goethite in Group 2 samples (section 4.1.2.1; 4.2.2), although there is no indication of the low Curie temperature of goethite in the temperature-susceptibility data.

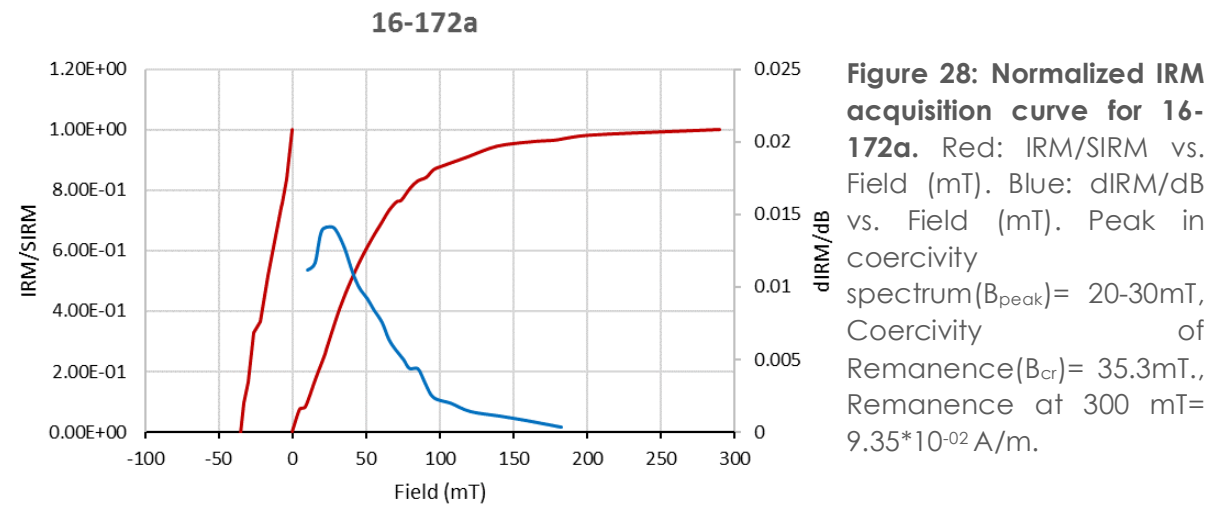




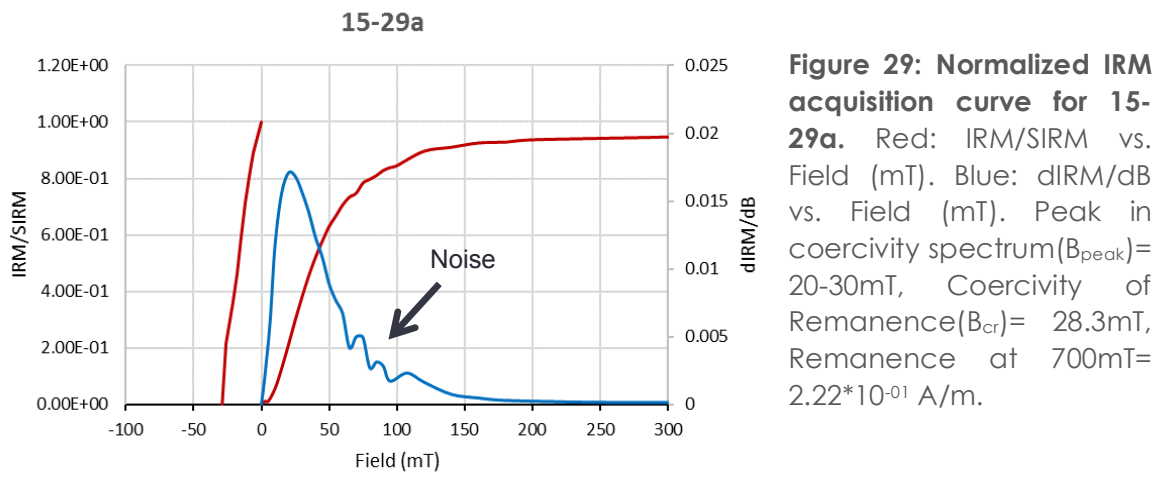

\subsubsection{Magnetic Carriers: Concluding Remarks}

We conclude based on temperature-susceptibility and IRM experiments that magnetite with minor Ti incorporation $(x<0.1)$ is the dominant carrier of magnetization in Group 2 samples. Susceptibility does not completely drop to zero above $580^{\circ} \mathrm{C}$ indicating the presence of minor amounts of haematite or maghemite. The presence of a high coercivity phase is inferred from IRM experiments that may either be the haematite suggested by temperature-susceptibility experiments and/or the goethite suggested by microscopy.

\subsubsection{Demagnetization Behaviour}

Samples in this group carried generally weak NRM intensities, ranging from $10^{-5}$ and $10^{-3} \mathrm{~A} / \mathrm{m}$. Of the nine samples that were strong enough to be measured in the JR6 spinner magnetometer all contained two resolvable components of magnetization (Table $3)$.

In the lower blocking temperature range a normal polarity component of magnetization is preserved (Fig. 32) The maximum (un)blocking temperature that the normal component is carried to, as estimated from Zjiderveld plots, decreases with increasing distance from the fault trace $\left(300-400^{\circ} \mathrm{C}\right)($ Fig. 30$)$.

The samples from Group 2 also carry a reversed polarity, southerly trending, moderately inclined component of magnetization in the higher blocking temperature range (Fig. 32). Thermal alteration made it difficult to determine whether this component was carried to the highest blocking temperatures in these samples; however, a third underlying component can be effectively ruled out for at least one of the samples due to the origin-bound nature of the magnetization on the Zjiderveld plot (Sample 1530a) (Fig. 32), so is unlikely to be carried by other Group 2 samples. 


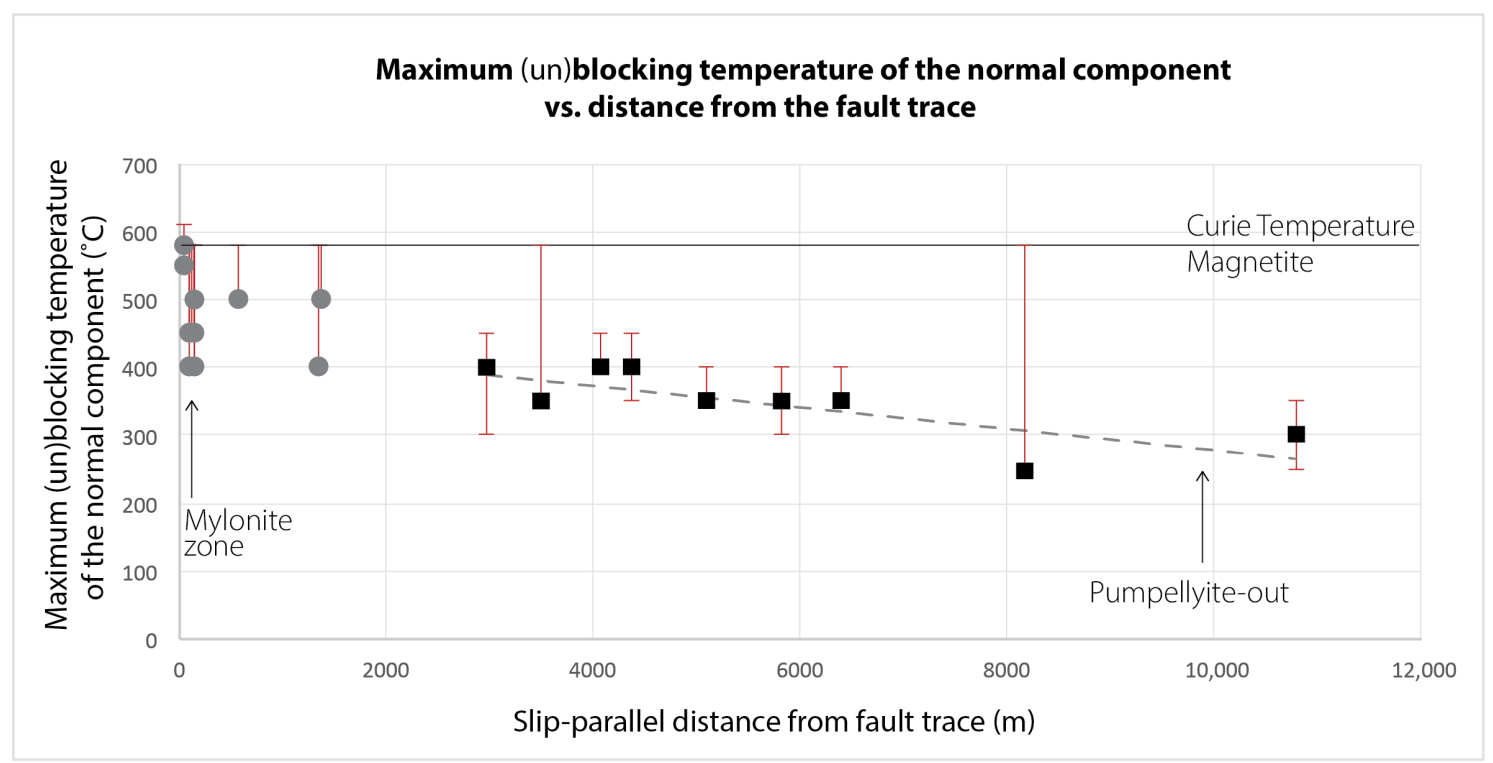

Figure 30: (Un)blocking temperature of the normal component of magnetization vs. distance from the fault trace. Plot showing changes in (un)blocking temperature of the normal component of magnetization with increasing distance from the fault trace. (Un)blocking temperature decreases steadily with increasing distance from the fault trace. Grey circles: Group 1 samples. Black squares: Group 2 samples.

Thermal alteration behaviour was pervasive within the Group 2 samples and may be divided into 2 types. Increases in magnetization and susceptibility above $400^{\circ} \mathrm{C}$ is evident in most samples $(\mathrm{n}=9)$. This thermal alteration observed in Group 1 samples is still present, however not to the same extent. Many samples $(n=6)$ also begin to alter above $250-300^{\circ} \mathrm{C}$. These alteration behaviours are different and can clearly be seen coexisting together in a single sample (Fig. 31).
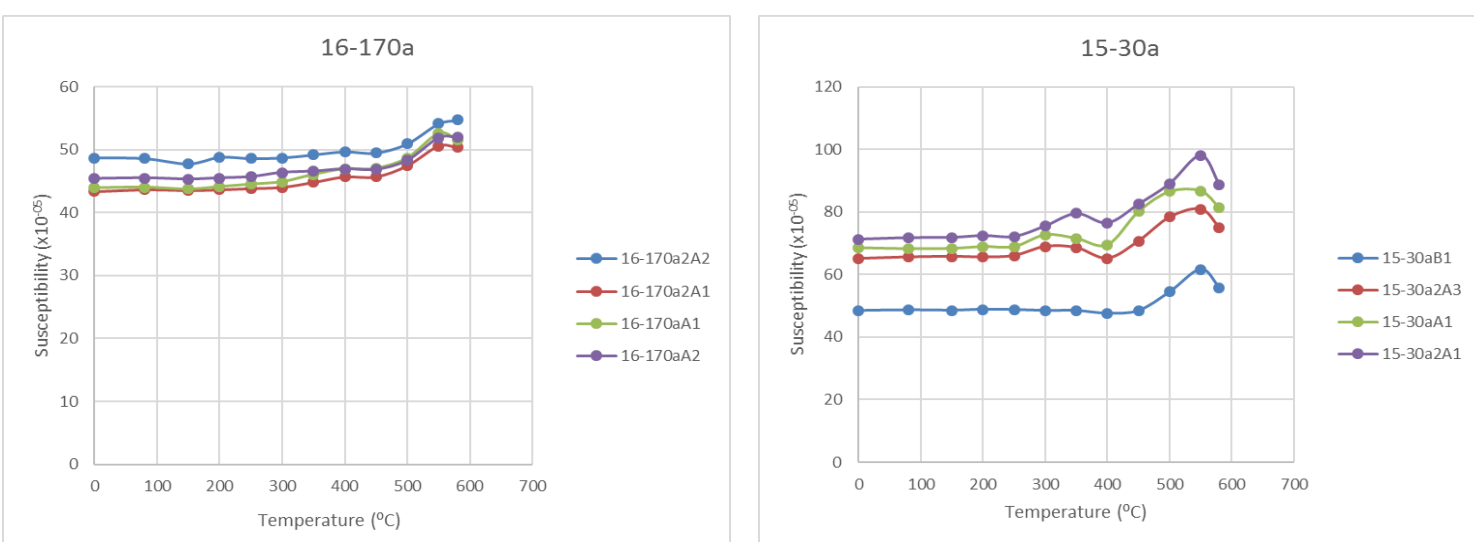

Figure 31: Temperature-susceptibility plots for samples that exhibited two types of thermal alteration behaviour. Increases in susceptibility were observed at temperatures of $250^{\circ} \mathrm{C}$ and $400^{\circ} \mathrm{C}$. We postulate that this is due to the presence of two types of thermal alteration behaviour in these samples. Data was obtained during the demagnetization run. 

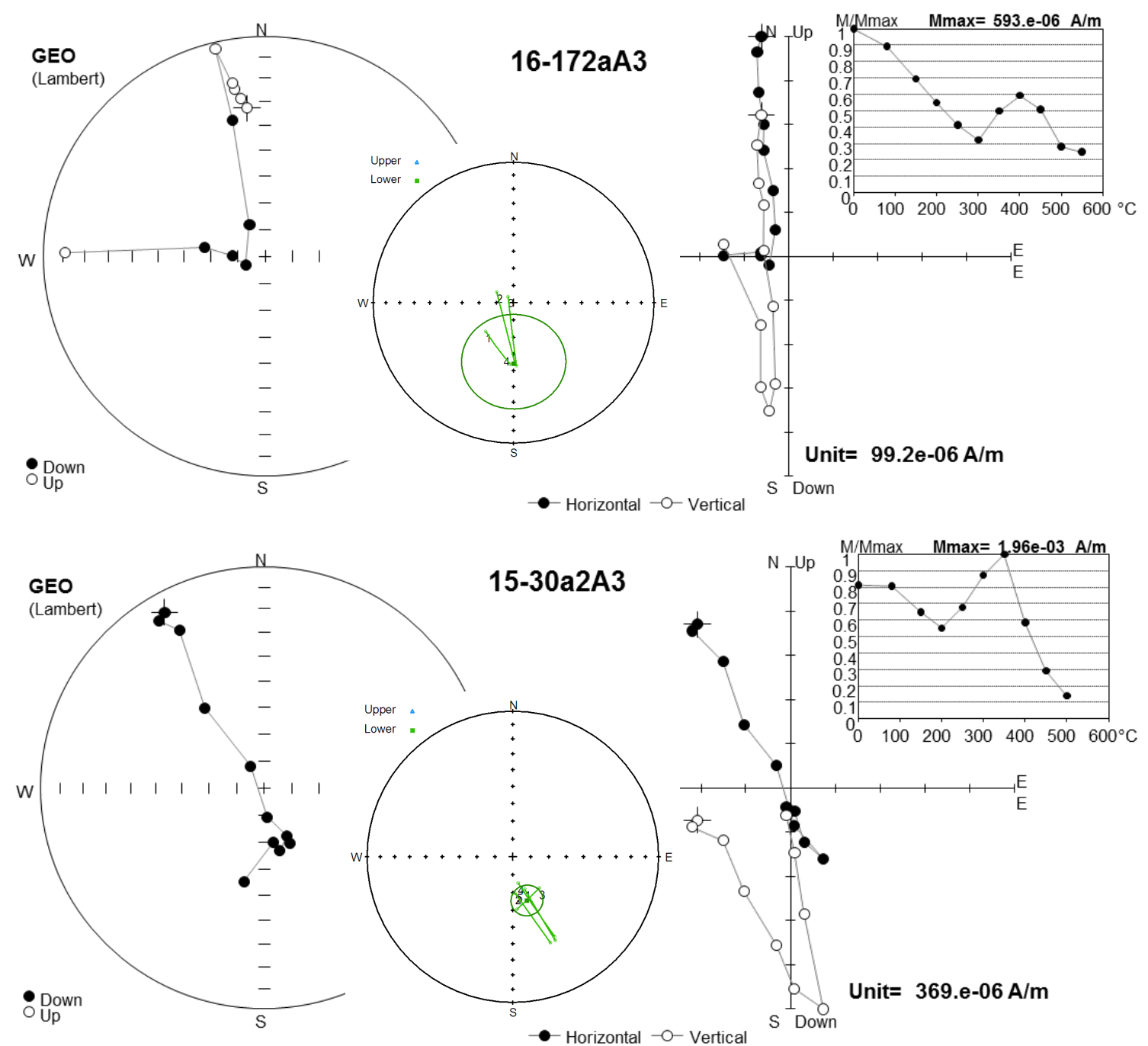

Figure 32: Representative thermal demagnetization plots for Group 2 specimens. A normal polarity, moderately-inclined, northerly-northwesterly component is removed at (un)blocking temperatures above 300$400^{\circ} \mathrm{C}$, depending on the distance of the sample from the fault trace. In the higher blocking temperature range a reversed-polarity, moderately-inclined, southerly trending component is observed. Figure inset: Stereoplot showing the intersection point of constrained remagnetization great circles, which was used as a means of estimating the direction of the reversed component for each sample.

The direction of the normal component in each individual specimen was estimated using PCA between temperatures NRM- $150^{\circ} \mathrm{C}$ and $200-400^{\circ} \mathrm{C}$ (Table 3). Estimates from each individual specimen were averaged to get a sample mean (Table 3). The sample means had a northwesterly trend and moderate inclination (Fig. 33). The slight variation between samples is attributed to secular variation and small orientation errors during the process of sawing the samples. These sample averages are combined into a grand mean: Dec: $347.2^{\circ}$, Inc: $-41.7^{\circ}$, $\alpha_{95}: 9.4^{\circ}(\mathrm{N}=7)$ (Fig. 33). Sample 15-33a was excluded from this average because its direction was more than two circular standard deviations from the mean (Fig. 33). 
The direction of the reversed component was generally difficult to estimate due to the inferred presence of thermal alteration at temperatures above $300-400^{\circ} \mathrm{C}$ that appeared to have a pronounced effect on the magnetization of the samples, and due to the weak strength of NRM at these temperatures. Using principal component analysis this direction was only able to be estimated for four of the samples (Table 3), however the end point of magnetization was not reached in these samples. The direction of this component for each sample was also estimated using the intersection of remagnetization great circles (Table 3). Possible solutions/end point directions along a great circle for each specimen were constrained to lie beyond the last measured reversed point used to constrain the great circle and within the antipodal point of the estimated normal component (McFadden \& McElhinny, 1988). These end point estimates for each sample were combined to get an overall average: Dec:177.2 ${ }^{\circ}$, Inc: $57.1^{\circ}, \alpha_{95}: 7.3^{\circ}(\mathrm{N}=8)($ Fig. 34). Sample 15-24a was excluded from this average using the same criteria discussed in section 4.1.1.4 (Fig. 34).

The two components present in Group 2 samples are not antipodal. The higher blocking temperature reversed component is more steeply inclined than the normal component. This difference is statistically significant (the $\alpha_{95}$ envelopes do not overlap). 


\section{Declination}

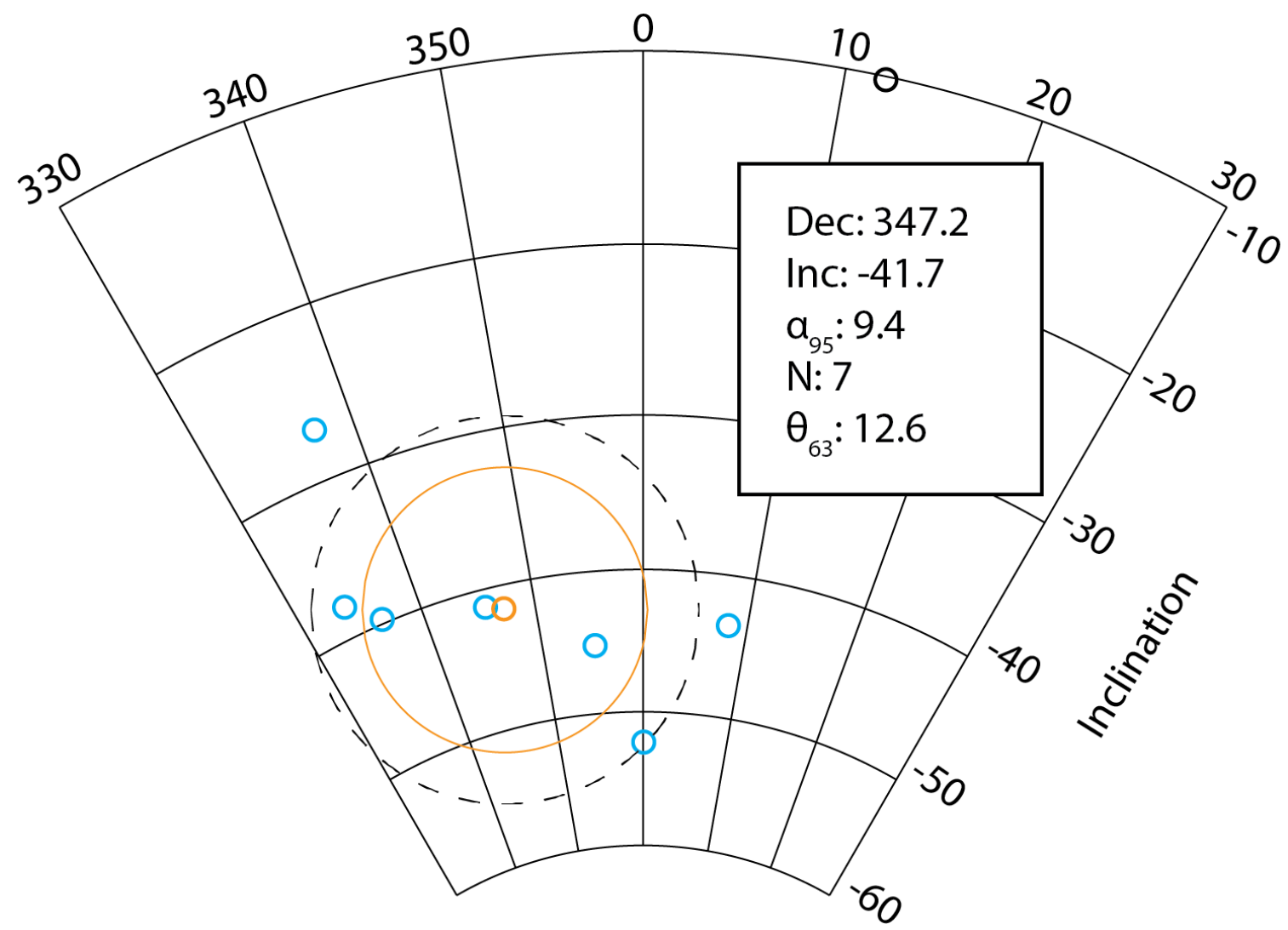

Figure 33: Stereoplot of Group 2 sample averages (lower blocking temperature normal component). Orange: Overall mean. Black-dashed: Circular standard deviation. Samples more than two circular standard deviations from the mean are excluded from calculation of the overall mean.

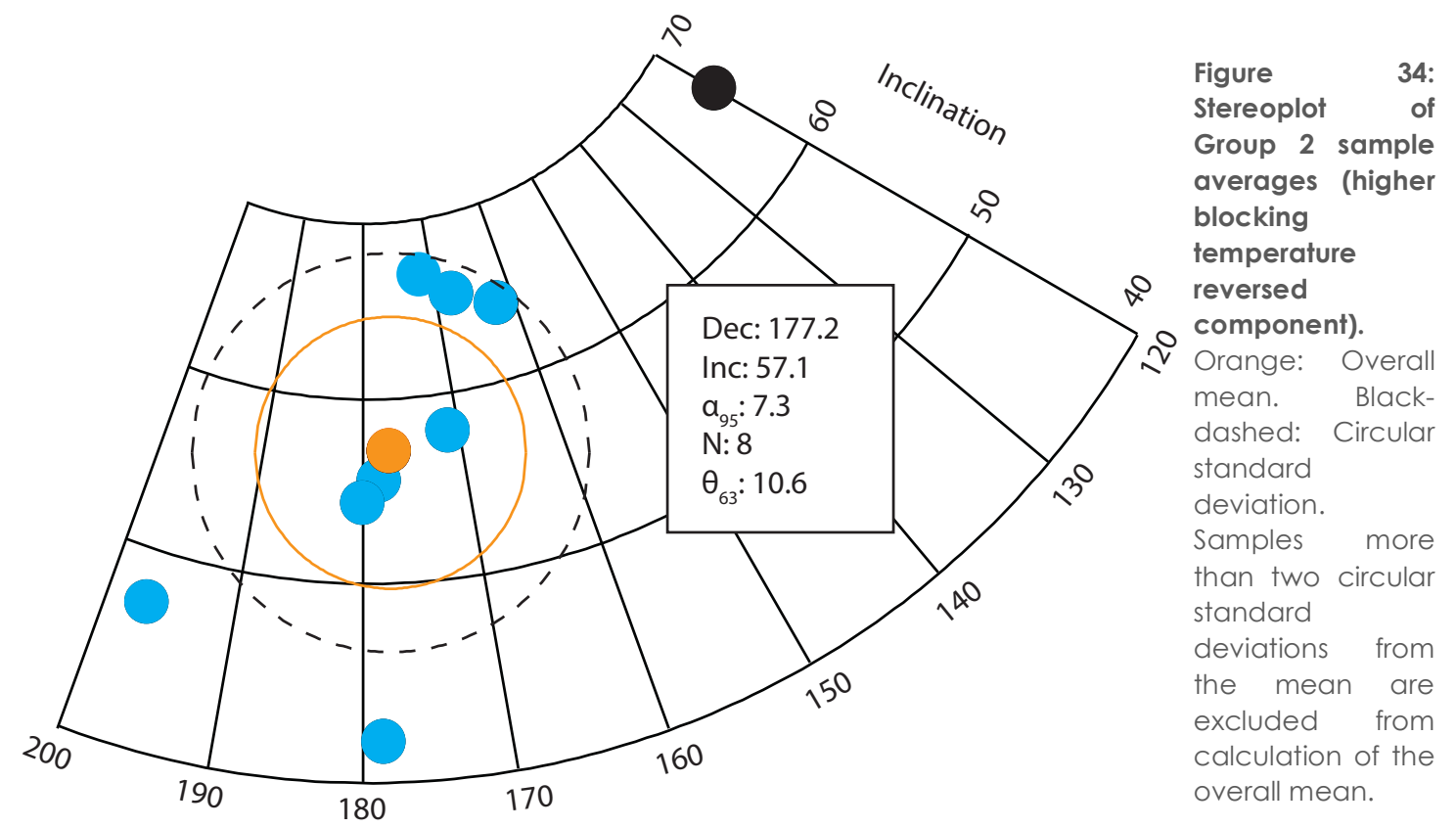

Declination 


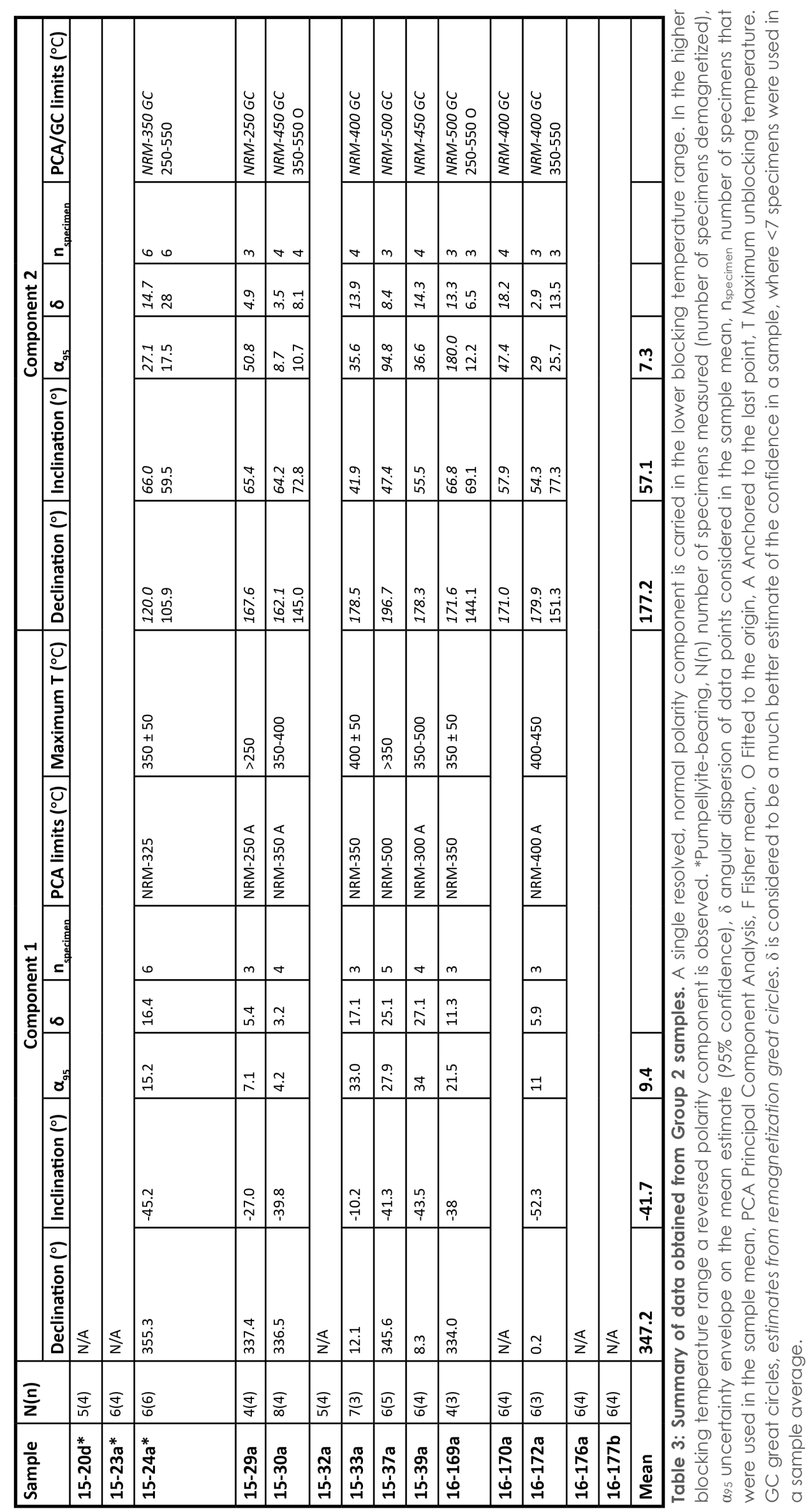




\subsection{Microscopic Analysis of the Magnetic Mineralogy}

In this section I present, and integrate, the results of reflected and transmitted light microscopy and scanning electron microprobe analyses on representative polished sections and mineral (magnetic) separates. Below I briefly summarize the petrology of the Goropu Metabasalt, before presenting a more detailed analysis of the opaque grain mineralogy.

The metabasaltic samples analysed in this study generally consisted of fine-grained and well dispersed epidote, albite, actinolite, titanite/sphene, chlorite, quartz and opaques (Fig. 35) \pm minor amounts of white mica, calcite, stilpnomelane, apatite and relict clinopyroxene. The foliation is chiefly defined by a shape preferred orientation (SPO) of actinolite grains (Fig. 35). Up to $700 \mu \mathrm{m}$ thick epidote-enriched layers are common in the samples, in addition to minor $\mu$ m-scale folding of the dominant foliation. In the mylonites (of Group 1 samples) quartz and calcite veins are present that are either aligned with or cross-cut the foliation. Samples vary in both average and maximum grain size $(\mu \mathrm{m}-\mathrm{mm})$, and relative abundance of main-assemblage minerals.
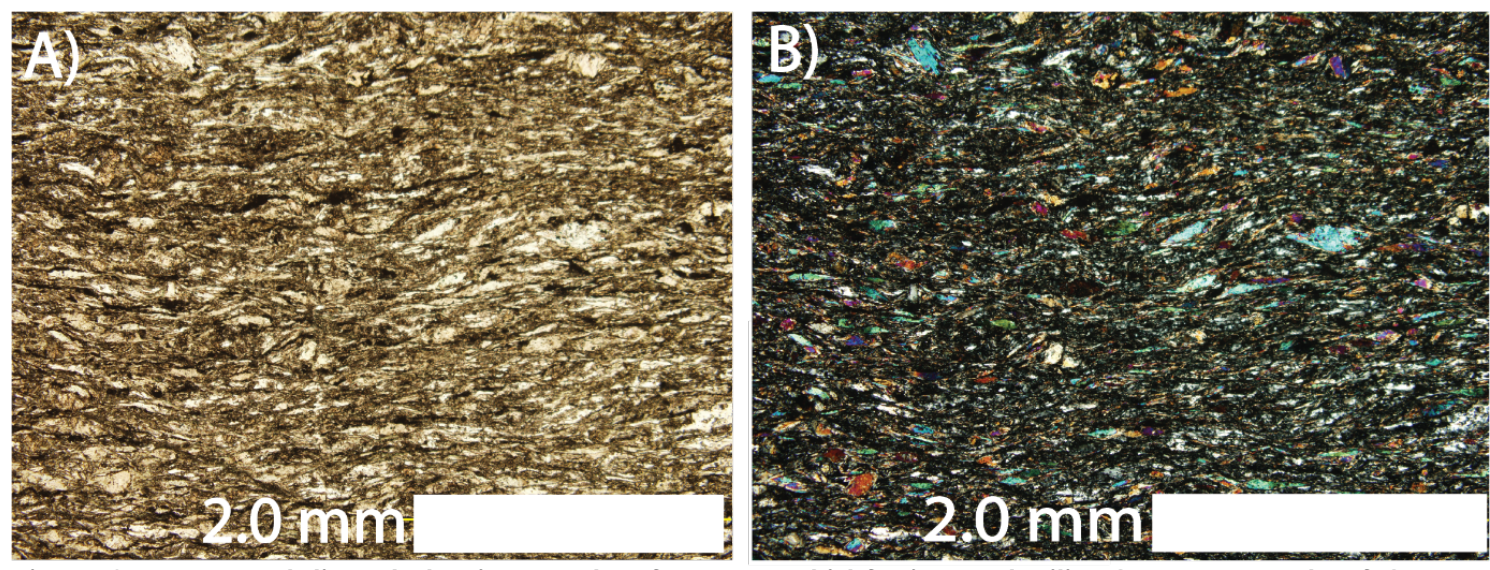

Figure 35: Representative photomicrographs of a greenschist facies, mylonitic, Group 1 sample of Goropu Metabasalt (16-BW1C). The foliation, defined by a shape preferred orientation of actinolite grains, is evident. The samples consist of actinolite, epidote, albite, sphene/titanite, chlorite, quartz and opaque grains. A) Plane polarized transmitted light, B) Cross polarized transmitted light.

\subsubsection{Group 1 Mineralogy}

Samples 16-BW1b and 16-BW1c were selected as representative Group 1 samples that carried relatively weak $\left(10^{-05} \mathrm{~A} / \mathrm{m}\right)$ and strong $\left(10^{-03} \mathrm{~A} / \mathrm{m}\right) \mathrm{NRMs}$, respectively.

\section{6-BW1c}

16-BW1c is characterized by both coarse and fine-grained opaques. Coarser grained 
opaques (up to $300 \mu \mathrm{m}$ in diameter) are fragmented and concentrated in bands aligned parallel to the foliation (Fig. 36), and contain inclusions of the main assemblage silicate minerals. In some cases, these opaque grains have been broken apart, with the gaps infilled with chlorite. Finer-grained $(10-50 \mu \mathrm{m})$ opaques generally have a SPO parallel to the foliation defined by an alignment in their longest dimension. A reddening of some of the grain rims indicates minor oxidation occurring at the rims of these coarse opaque grains. Reflected light microscopy and semi-quantitative chemical compositions, as determined from EDS analysis, indicate that these grains are the non-magnetic sulphides pyrite with minor chalcopyrite (Fig. 36). This is consistent with the lack of a low-temperature $\left(\sim 300^{\circ} \mathrm{C}\right)$ susceptibility drop in temperature-susceptibility experiments that would be indicative of magnetic sulphides (pyrrhotite and greigite) (see section 4.1.1.1).

Very fine-grained opaques $(<10 \mu \mathrm{m})$ are associated with the fine-grained, disseminated sphene and exist as minor inclusions in metamorphic silicate minerals (predominantly epidote, which also has inclusions of titanite) (Fig. 37). These grains have a much higher reflectance, and BSE brightness, than surrounding silicate minerals (Fig. 37) suggesting they may be iron oxides, however, these grains are too fine-grained to identify in reflected light or with the microprobe.
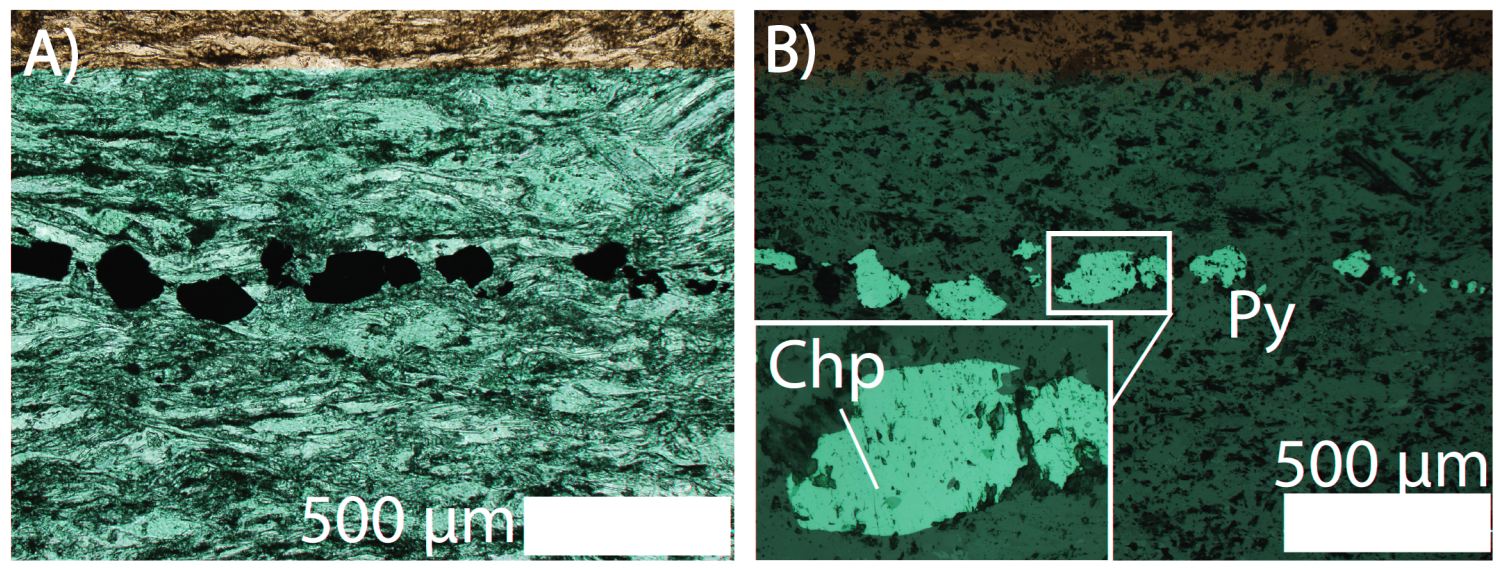

Figure 36: 16-BW1c: Coarse opaque grains. A) Plane polarized transmitted light. B) Plane polarized reflected light. Reflected light microscopy indicates the presence of at least two sulphide phases. EDS analysis on these sulphide grains confirmed that the light-yellow grains observed in reflected light are pyrite(py), whereas the darker coloured sulphide is chalcopyrite(chp). Both are nonmagnetic and therefore cannot account for the magnetization of the Goropu Metabasalt. 

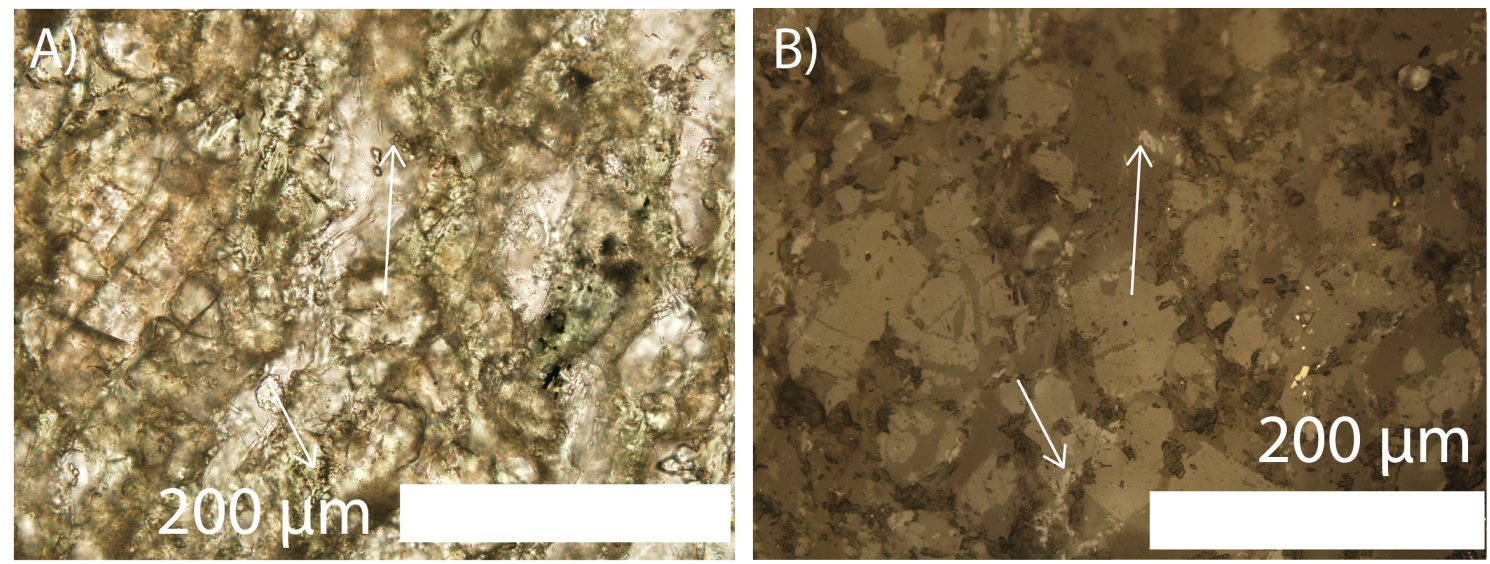

Figure 37: 16-BW1c: Fine-grained opaques. A) Plane polarized transmitted light. B) Plane polarized reflected light. Fine-grained opaques in the matrix are commonly associated with sphene/titanite. These grains are too fine-grained to conclusively identify, but their brightness in reflected light suggest they may be iron oxides. This fine grained bright 'dust' was common in this sample.

\section{6-BW1b}

Opaques of all occurrences are less common than in 16-BW1c. The sample is dominated by calcite veins (up to $2 \mathrm{~cm}$ thick) that cross-cut and are aligned with the foliation, and contain up to $2 \mathrm{~mm}$ thick rotated clasts of host rock. Reflected light microscopy confirms that the coarse opaque grains present in this sample are pyrite with minor chalcopyrite, as in 16-BW1c. Finer grained opaques were also present $(<10 \mu \mathrm{m})$, however were too small to be conclusively identified.

\section{Magnetic Separates: 16-4b \& 15-1151a}

The magnetization of Group 1 samples was revealed to be weak, therefore it is unlikely that the magnetic carrier of the Goropu Metabasalt is volumetrically significant. Grain mounts of magnetic separates were also prepared in order to ensure that the magnetic carriers were not missed by the polished sections that were studied. The magnetic separates are dominated by the paramagnetic phases epidote and sphene (Fig. 38). Opaque grains with reddish rims were also common that we interpret to be iron hydroxides (potentially the magnetic goethite) based on the optical similarities with grains probed in samples 16-172a and 15-24a (section 4.2.2) (Fig. 38). The magnetic character of these grains may suggest submicroscopic magnetic particles as inclusions in these otherwise paramagnetic phases. These were potentially imaged (see below). Sulphide grains were also picked up in these separates (Fig. 39). EDS analysis confirms these are pyrite. In all cases this pyrite is partially altered at the rim (Fig. 39) by an iron hydroxide (potentially to the magnetic goethite). Iron filings, a potential artefact from the rock crushing process, were a common contaminant in the magnetic separates. These were distinguished from potential iron oxides by their extremely high BSE 
brightness, presence of heavy metals such as chromium, vanadium and molybdenum and absence of oxygen.
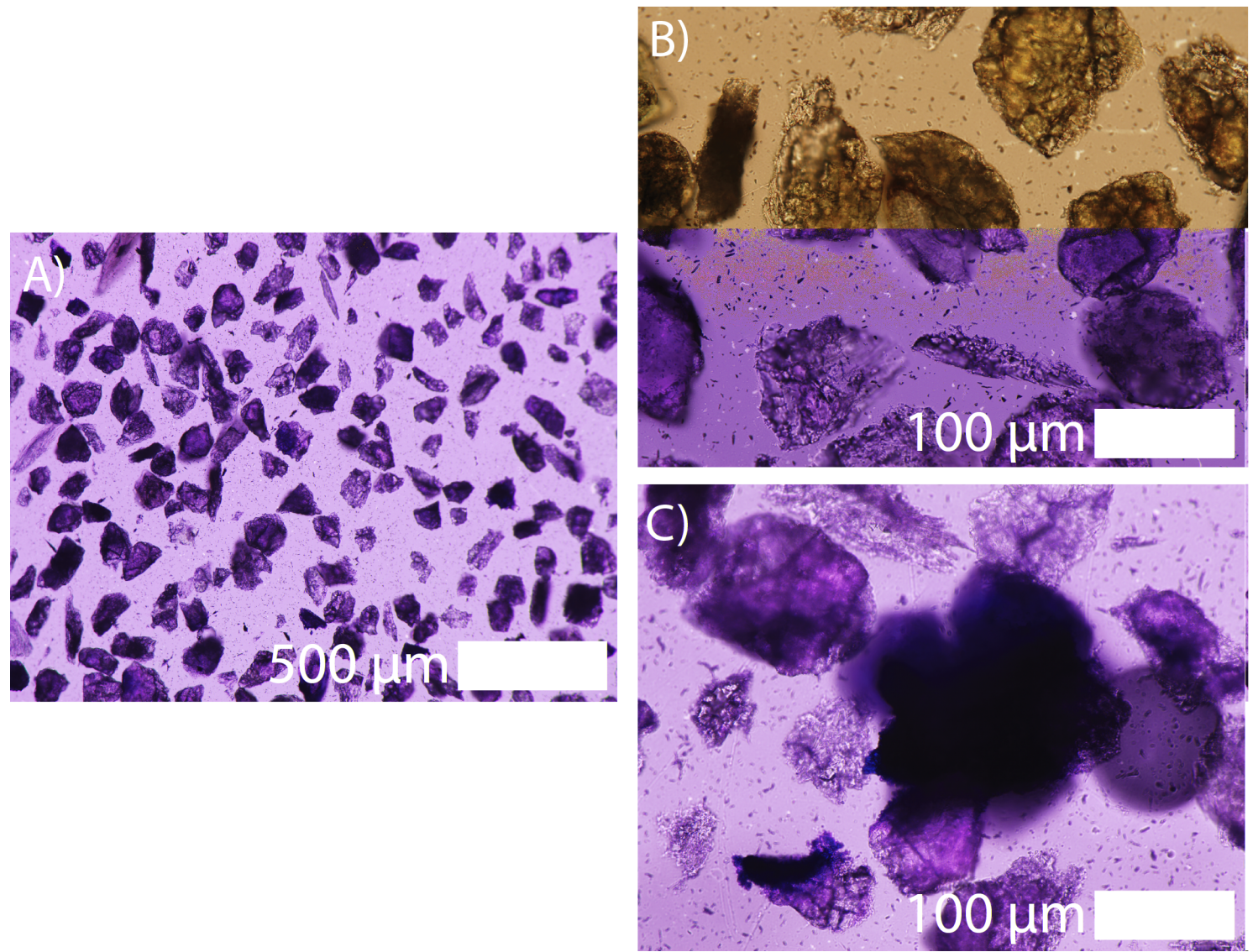

Figure 38: 16-4b: Magnetic separates. A) Plane polarized transmitted light photomicrograph of a typical magnetic separate. B) Plane polarized transmitted light photomicrograph of epidote grains in a magnetic separate. C) Plane polarized transmitted light photomicrograph of an iron hydroxide (potentially goethite). Magnetic separates appeared to be dominated by epidote and sphene (and goethite?).
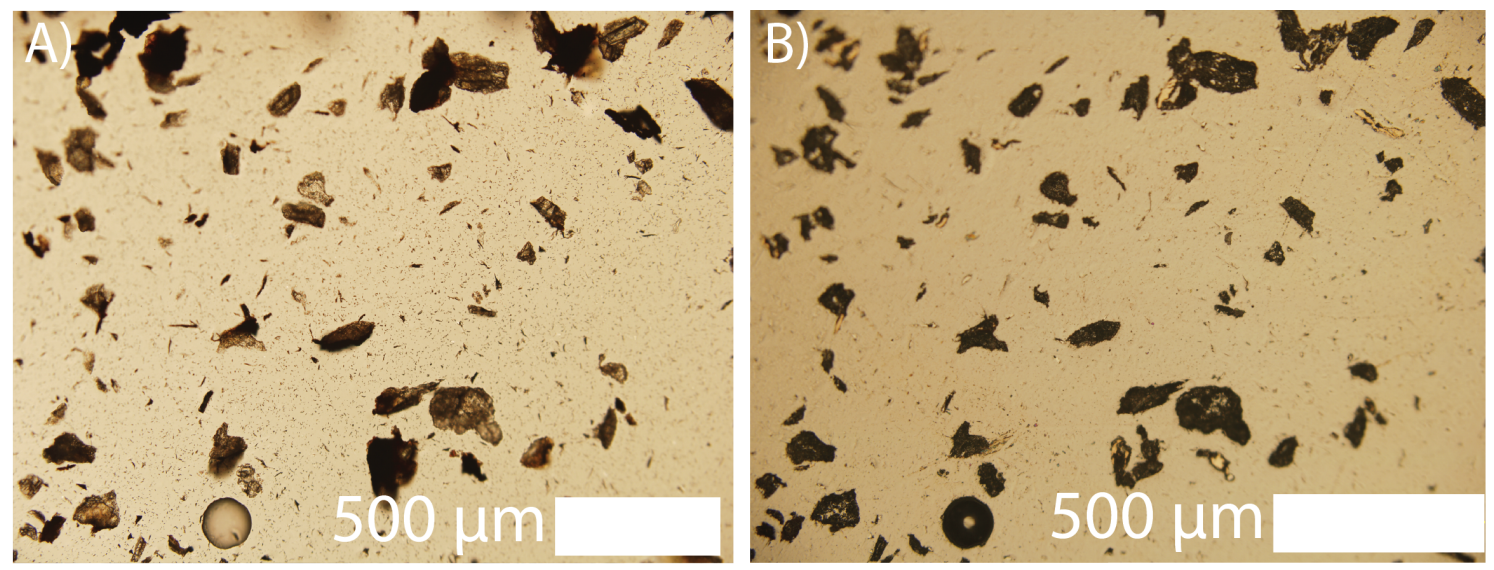

Figure 39: 16-1151a: Magnetic separates. A) Plane polarized transmitted light photomicrograph of sulphide grains in 16-1151a. B) Plane polarized reflected light photomicrograph of sulphide grains in 16-1151a. This sample was almost identical to 16-4b with the exception that sulphides were much more common.

Very fine-grained, high BSE brightness grains were commonly observed as inclusions in epidote (Fig. 40). These phases were too fine-grained to probe. We therefore used element maps as a means of estimating a rough composition of these grains. The 
element maps indicate these grains are rich in iron and oxygen and comparatively poor in all other elements (pictured here is silicon, calcium, aluminium) (Fig. 40). We therefore suggest that these grains are iron oxides, and may be the magnetite suggested by magnetic experiments.
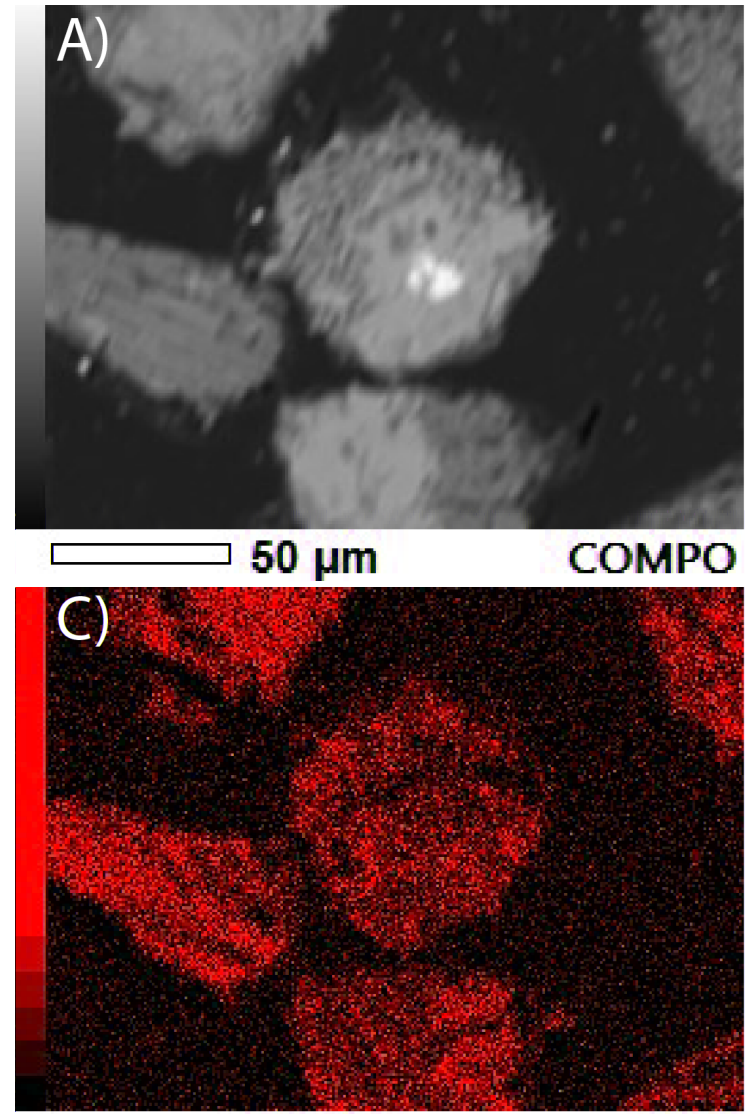

$$
50 \mu \mathrm{m}
$$

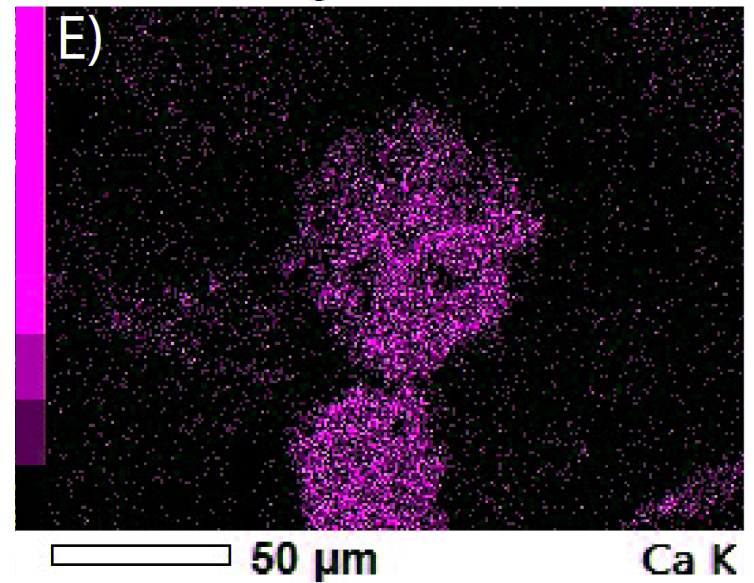

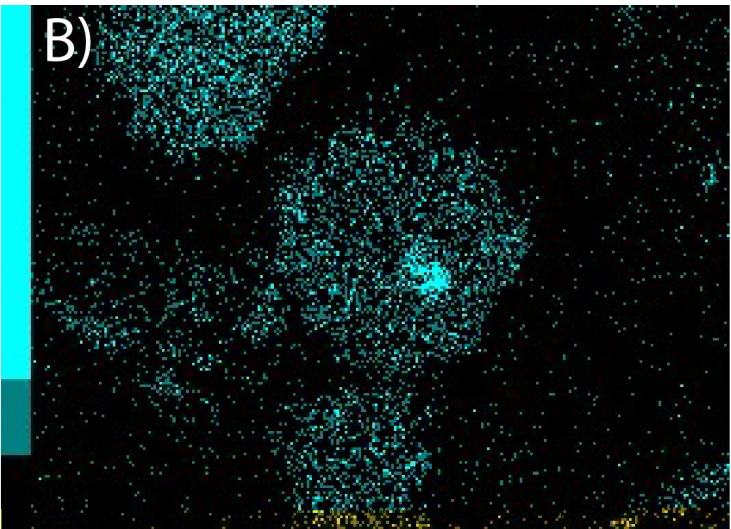

$50 \mathrm{\mu m}$

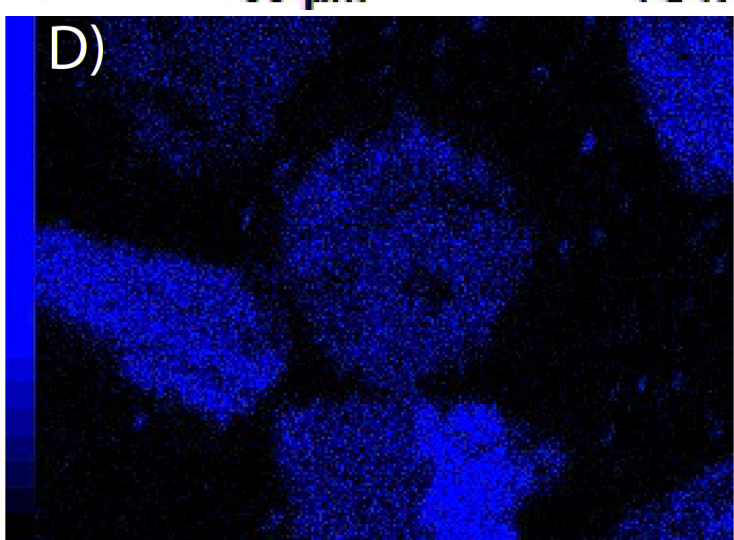

\section{$50 \mu \mathrm{m}$}

Si K

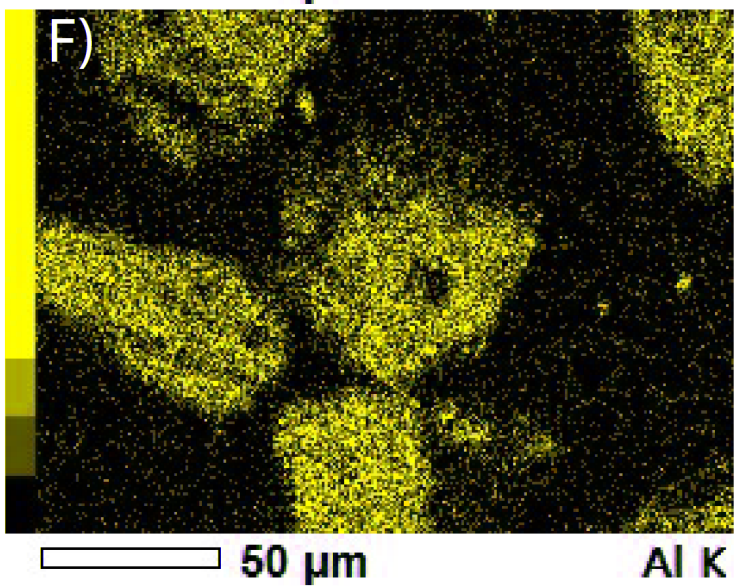

Figure 40: Element maps of fine-grained inclusions in epidote (16-4b). A) BSE image. B) Fe composition. C) $O$ composition. D) Si composition. E) Ca composition. F) Al composition. The fine-grained phases are rich in iron and oxygen, and contain no silicon, calcium or aluminium, or other elements (not pictured). 


\subsubsection{Group 2 Mineralogy}

Samples 16-172a and 15-24a were selected as representative two component samples that carried a strong and weak NRM, respectively.

\section{6-172a}

All phases present in the sample are generally fine-grained $(<200 \mu \mathrm{m})$. Sphene occurs in coarse aggregates up to $150 \mu \mathrm{m}$ thick, which differs from the disseminated nature of the sphene further down the scarp in Group 1 mylonites. Coarse opaque grains (up to 400 $\mu \mathrm{m})$ are less common than in 16-BW1c and b. These grains are generally less wellformed than those in 16-BW1b and c, exhibiting sieve textures, and red rims (Fig. 41c). WDS analyses confirmed that these grains are predominantly pyrite (Table 4) with minor chalcopyrite. They have been partially or completely pseudomorphed by an unknown, high-BSE brightness phase (Fig. 41 a, b). Fine-grained opaques observed in the matrix associated with sphene and observed as inclusions in epidote that were too small to conclusively identify were also observed in this sample.

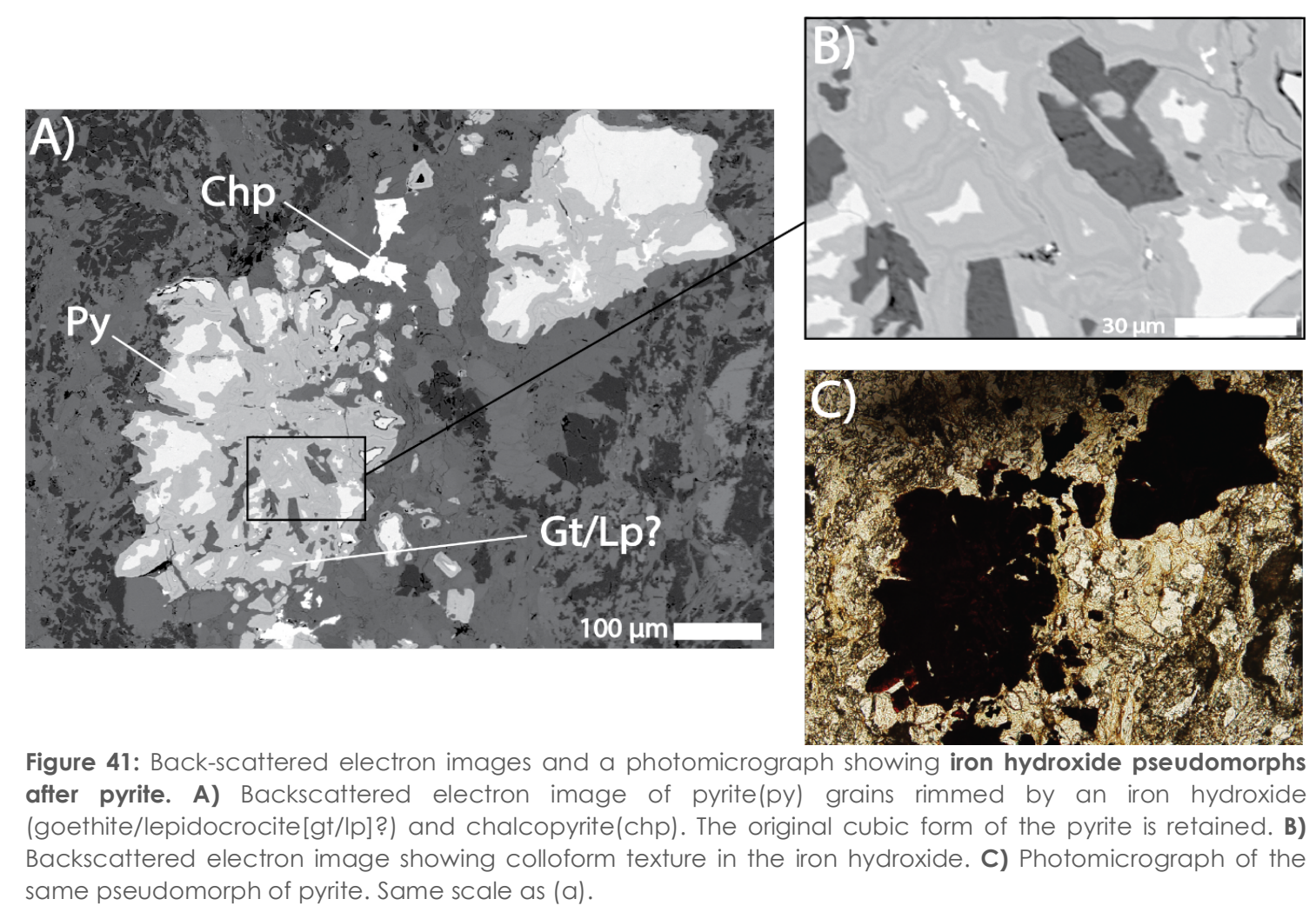




\begin{tabular}{|l|l|l|l|l|l|l|l|l|}
\hline Point & Ti(mass\%) & Cu(mass\%) & Mg(mass\%) & Fe(mass\%) & Cr(mass\%) & S(mass\%) & Mn(mass\%) & Total(mass\%) \\
\hline $\mathbf{1}^{*}$ & 0 & 0.24 & 0.004 & 46.455 & 0 & 53.224 & 0.14 & 100.063 \\
\hline $\mathbf{2}^{*}$ & 0.002 & 0.236 & 0.019 & 46.797 & 0.04 & 53.426 & 0.231 & 100.751 \\
\hline $\mathbf{3}$ & 0.011 & 0.047 & 0.009 & 47.206 & 0.011 & 52.986 & 0.003 & 100.273 \\
\hline $\mathbf{4}$ & 0 & 0.09 & 0 & 46.038 & 0.004 & 52.681 & 0 & 98.813 \\
\hline $\mathbf{5}$ & 0.004 & 0.085 & 0.009 & 46.997 & 0 & 52.792 & 0 & 99.887 \\
\hline $\mathbf{6}$ & 0.003 & 0.063 & 0 & 46.711 & 0.014 & 52.705 & 0.013 & 99.509 \\
\hline $\mathbf{7}$ & 0 & 0.073 & 0 & 46.547 & 0.016 & 52.534 & 0.014 & 99.184 \\
\hline $\mathbf{8}$ & 0 & 0.066 & 0.002 & 46.654 & 0 & 52.483 & 0 & 99.205 \\
\hline $\mathbf{9}$ & 0 & 0.045 & 0.001 & 46.734 & 0 & 52.555 & 0 & 99.335 \\
\hline $\mathbf{1 0}$ & 0 & 0.054 & 0.002 & 46.152 & 0 & 52.453 & 0.011 & 98.672 \\
\hline $\mathbf{1 1 *}$ & 0 & 0.216 & 0.004 & 46.964 & 0 & 53.041 & 0.293 & 100.518 \\
\hline $\mathbf{1 2 *}$ & 0 & 0.212 & 0 & 46.666 & 0.036 & 52.969 & 0.274 & 100.157 \\
\hline
\end{tabular}

Table 4: WDS analyses of sulphide grains in sample 16-172a. *Secondary pyrite standard

WDS analyses on this unknown, high-BSE brightness phase are presented in Table 5. With all ferrous iron converted to ferric iron the results total $88-92 \%$. This was done by multiplying $\mathrm{FeO}$ mass\% by $1.1113\left(\left[\mathrm{Fe}_{\text {mass }} \times 2\right]+[\operatorname{mass} \times 3] /\left[\mathrm{Fe}_{\text {mass }}+\mathrm{O}_{\text {mass }}\right]\right.$ x 2). This data is most consistent with this phase being either goethite $(\alpha-\mathrm{Fe}(\mathrm{III}) \mathrm{O}(\mathrm{OH}))$ or the less stable polymorph lepidocrocite $(\gamma-\mathrm{Fe}(\mathrm{III}) \mathrm{O}(\mathrm{OH}))$, which contain $\sim 10$ mass $\% \mathrm{H}_{2} \mathrm{O}$. Minor (3-5 mass\%) silica is also present. The results are remarkably repeatable and no other elements are picked up in significant concentrations therefore it is unlikely that the reported silica content is due to the beam missing these grains or sampling submicroscopic inclusions (other than quartz). It is instead likely due to appreciable incorporation of silica in the crystal structure. Previous analyses have reported up to 5 mass \% incorporation of silica (Klein \& Hurlbut, 1985). This has been reported to slow the transformation of lepidocrocite to goethite, and reduce the magnetic ordering and Curie temperature of goethite as the replacement of $\mathrm{Fe}^{3+}$ ions by $\mathrm{Si}^{4+}$ ions distort the crystal structure (Murad, 1979; Quin et al., 1988).

Fine-grained inclusions in epidote that are rich in iron and oxygen and comparatively depleted in all other elements that were observed in the magnetic separates in $16-4 \mathrm{~b}$ were also observed in this sample. 


\begin{tabular}{|c|c|c|c|c|c|c|c|c|c|c|}
\hline Point & $\mathrm{TiO}_{2}$ (mass $\%$ ) & $\mathrm{CaO}$ (mass\%) & $\mathrm{MgO}$ (mass\%) & $\mathrm{SiO}_{2}$ (mass\%) & $\mathrm{Al}_{2} \mathrm{O}_{3}$ (mass $\left.\%\right)$ & $\mathrm{Fe}_{2} \mathrm{O}_{3}$ (mass $\left.\%\right)$ & $\mathrm{Cr}_{2} \mathrm{O}_{3}$ (mass $\left.\%\right)$ & $\mathrm{SO}_{3}($ mass $\%)$ & $\mathrm{MnO}$ (mass\%) & Total(mass\%) \\
\hline 1 & 0 & 0.186 & 0.059 & \begin{tabular}{|l|l|}
4.644 \\
\end{tabular} & 0 & 83.829 & 0.013 & 0.102 & 0.009 & \begin{tabular}{|l}
88.841 \\
\end{tabular} \\
\hline 2 & 0.02 & 0.204 & 0.337 & 4.075 & 0.015 & 83.745 & 0 & 0.178 & 0.014 & 88.589 \\
\hline 3 & 0.001 & 0.145 & 0.299 & \begin{tabular}{|l|}
4.021 \\
\end{tabular} & 0.033 & 83.755 & 0 & 0.095 & 0.015 & 88.364 \\
\hline 4 & 0 & 0.064 & 0.153 & 4.375 & 0.008 & 84.159 & 0 & 0.068 & \begin{tabular}{|l|}
0.032 \\
\end{tabular} & 88.859 \\
\hline 5 & 0.023 & 0.132 & 0.113 & \begin{tabular}{|l|}
4.977 \\
\end{tabular} & 0.013 & 84.640 & 0 & 0.086 & 0.013 & 89.9966 \\
\hline 6 & 0.04 & 0.43 & 0.352 & 4.412 & 0.026 & 83.172 & 0 & 0.104 & 0.008 & 88.544 \\
\hline 7 & 0.028 & 0.445 & 0.354 & \begin{tabular}{|l|l|}
4.028 \\
\end{tabular} & 0.017 & 83.456 & 0 & 0.097 & 0.009 & 88.434 \\
\hline 8 & 0.026 & 0.446 & 0.37 & 4.303 & 0.004 & 83.730 & 0 & 0.09 & 0.043 & 89.012 \\
\hline 9 & 0 & 0.693 & 0.21 & 5.117 & 0.607 & 81.204 & 0.029 & 0.26 & 0 & 88.120 \\
\hline 10 & 0 & 0.083 & 0.05 & 4.448 & 0.001 & 86.587 & 0.007 & 0.189 & 0.047 & 91.412 \\
\hline 11 & 0 & 0.079 & 0.099 & 4.272 & 0 & 85.221 & 0.02 & 0.176 & 0.002 & 89.870 \\
\hline
\end{tabular}

Table 5: WDS analyses of pseudomorphs in sample 16-172a. The results are reported as all Fe ${ }^{2+}$ converted to $\mathrm{Fe}^{3+}$. Totals exclude the inferred $\sim 10 \mathrm{wt} \% \mathrm{H}_{2} \mathrm{O}$.

\section{5-24a}

Opaque grains of all occurrences are less common in this sample than in 16-172a. Opaque grain mineralogy is identical to sample 16-172a with the exception that sulphides are almost completely oxidized to an iron hydroxide (Table 6). Minor layers containing $600 \mu \mathrm{m}$ thick pumpellyite grains are observed in this sample.

\begin{tabular}{|c|c|c|c|c|c|c|c|c|c|c|}
\hline Point & $\mathrm{TiO}_{2}$ (mass\%) & $\mathrm{CaO}$ (mass\%) & $\mathrm{MgO}($ mass $\%)$ & $\mathrm{SiO}_{2}$ (mass\%) & $\mathrm{Al}_{2} \mathrm{O}_{3}$ (mass $\left.\%\right)$ & $\mathrm{Fe}_{2} \mathrm{O}_{3}$ (mass $\left.\%\right)$ & $\mathrm{Cr}_{2} \mathrm{O}_{3}$ (mass $\left.\%\right)$ & $\mathrm{SO}_{3}$ (mass $\left.\%\right)$ & $\mathrm{MnO}$ (mass\%) & Total(mass\%) \\
\hline 1 & \begin{tabular}{|l|l|} 
\\
\end{tabular} & 0.237 & \begin{tabular}{|l|l|} 
\\
\end{tabular} & 4.203 & \begin{tabular}{|l|l|}
0.297 \\
\end{tabular} & \begin{tabular}{|l|l|}
85.677 \\
\end{tabular} & 0.029 & \begin{tabular}{|l|}
0.111 \\
\end{tabular} & 0 & \begin{tabular}{|l|}
90.938 \\
\end{tabular} \\
\hline 2 & 0 & 0.181 & 0.859 & 3.513 & 0.011 & 85.282 & 0.038 & 0.163 & 0 & 90.047 \\
\hline 3 & \begin{tabular}{|l}
0.008 \\
\end{tabular} & \begin{tabular}{|l}
0.277 \\
\end{tabular} & \begin{tabular}{|l|l|}
0.538 \\
\end{tabular} & 4.145 & \begin{tabular}{|l|l|}
0.114 \\
\end{tabular} & \begin{tabular}{|l|l|}
83.480 \\
\end{tabular} & 0.042 & 0.092 & 0.023 & \begin{tabular}{|l|}
88.719 \\
\end{tabular} \\
\hline 4 & 0.004 & 0.211 & 0.685 & 4.024 & 0.021 & 84.312 & 0.009 & \begin{tabular}{|l|l|}
0.116 \\
\end{tabular} & 0 & 89.382 \\
\hline 5 & \begin{tabular}{|l|l|}
0.014 \\
\end{tabular} & 0.231 & 0.531 & 3.436 & \begin{tabular}{|l|l|}
0.077 \\
\end{tabular} & \begin{tabular}{|l|l}
85.504 \\
\end{tabular} & 0 & 0.083 & 0.016 & 89.893 \\
\hline 6 & 0 & 0.269 & 0.46 & 4.098 & \begin{tabular}{|l|l|}
0.04 \\
\end{tabular} & 85.117 & 0.013 & \begin{tabular}{|l|}
0.064 \\
\end{tabular} & 0.015 & \begin{tabular}{|l|}
90.076 \\
\end{tabular} \\
\hline 7 & 0 & \begin{tabular}{|l}
0.387 \\
\end{tabular} & 0.233 & 4.282 & 0.002 & \begin{tabular}{|l|l|}
86.973 \\
\end{tabular} & \begin{tabular}{|l|l|} 
\\
\end{tabular} & \begin{tabular}{|l|}
0.057 \\
\end{tabular} & 0 & \begin{tabular}{|l}
91.943 \\
\end{tabular} \\
\hline
\end{tabular}

Table 6: WDS analyses of pseudomorphs in sample 15-24a. The results are reported as all $\mathrm{Fe}^{2+}$ converted to $\mathrm{Fe}^{3+}$. The totals exclude the inferred $\sim 10 \mathrm{w}+\% \mathrm{H}_{2} \mathrm{O}$.

\section{5-29a}

Sample 15-29a displayed the same paleomagnetic behaviour as samples 15-24a and 16172a; however, pronounced alteration began to occur above $250^{\circ} \mathrm{C}$ (section 4.1.2.1). A strong crenulation foliation was observed in this sample (Fig. 42). This sample was highly oxidized, with almost all of the pyrite replaced by an iron hydroxide (Fig. 42). These pseudomorphs were up to $700 \mu \mathrm{m}$ thick. Fine $(<100 \mu \mathrm{m}$ thick) ribbons of these opaque grains were aligned with the foliation (Fig. 42). The presence of yellow-red internal reflections observed in reflected light (Fig. 42b) indicate that at least some of these iron hydroxide grains are goethite. 

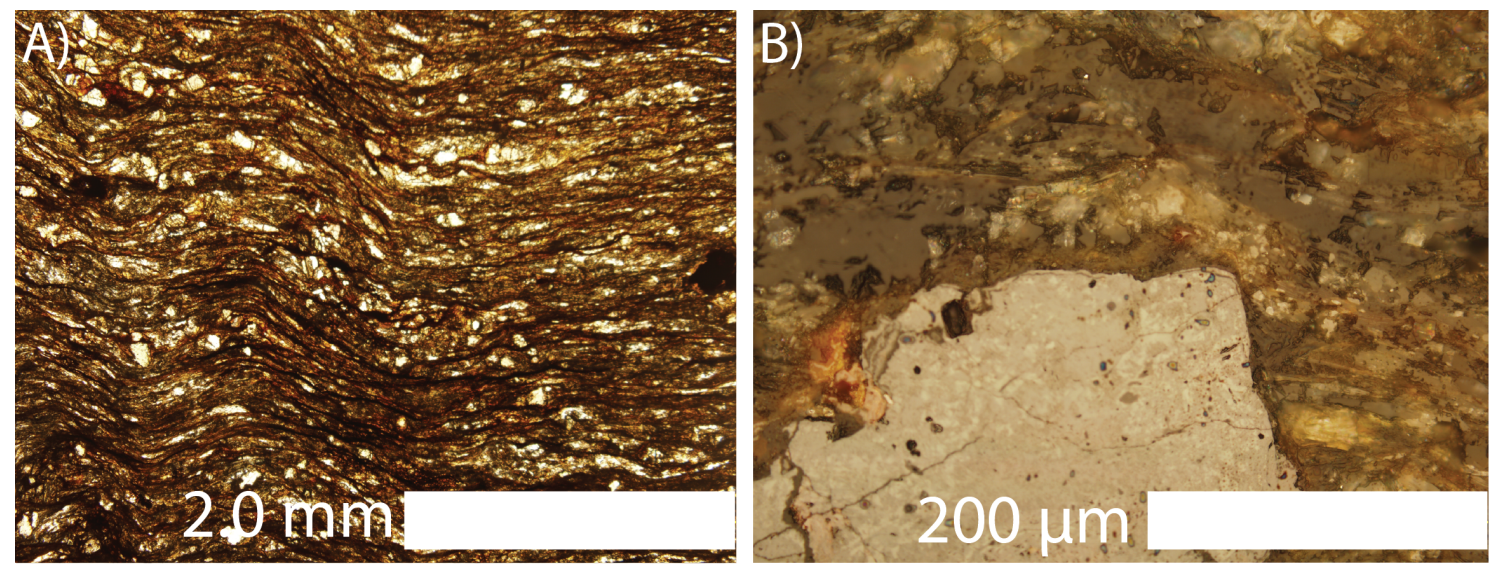

Figure 42: Photomicrographs of 15-29a. A) Plane Polarized transmitted light photomicrograph showing the crenulation foliation. The sample is highly oxidized, with thin ribbons of opaque grains concentrated along the foliation. B) Plane polarized reflected light photomicrograph of a pseudomorph of pyrite. The characteristic red-yellow internal reflections indicate the presence of goethite in this sample.

\section{Magnetic Separate: 16-169c}

A magnetic separate of sample 16-169c was analysed as a representative sample for Group 2 samples. The magnetic separate did not differ significantly from those of Group 1 with the exception that iron hydroxides (potentially goethite) were much more abundant. 


\section{Chapter 5: Discussion}

\subsection{Magnetic Mineralogy}

\subsubsection{Remanence Carrier(s)}

A thorough microscopic analysis of opaque grain mineralogy of the Goropu Metabasalt revealed that the dominant opaque grains present in the samples considered in this study are pyrite with minor chalcopyrite, both of which are paramagnetic and cannot account for the observed remanent magnetization of the Goropu Metabasalt. In samples further from the trace of the fault, these sulphides are pseudomorphed by an iron hydroxide (goethite [ferromagnetic] or lepidocrocite[paramagnetic]). This difference in oxidation state is consistent with an increasing duration of subaerial exposure with increasing distance from the fault trace. Although these two phases cannot be distinguished from each other using the microprobe, the observation of a high coercivity phase during IRM experiments, the presence of these grains in magnetic separates and the observation of yellow-red (Craig \& Vaughan, 1981) internal reflections indicate at least some of these grains are goethite. Despite this, characteristic susceptibility drops at the Curie temperature of goethite $\left(120^{\circ} \mathrm{C}\right)$ were not observed during any of the temperaturesusceptibility experiments. We suggest that the susceptibility of Group 1 and 2 samples is therefore dominated by other phases. Furthermore, the magnetization of the Goropu Metabasalt is carried to blocking temperatures (at least $400^{\circ} \mathrm{C}$ ) in excess of the Curie temperature of goethite. A different phase must therefore be carrying the remanence observed in the Goropu Metabasalt (both Group 1 and 2 samples).

Magnetic experiments conducted on Group 1 and 2 samples indicate no significant difference in the magnetic mineralogy and are strongly indicative of Fe-rich titanomagnetite $\left(\mathrm{Fe}_{3-\mathrm{x}} \mathrm{Ti}_{\mathrm{x}} \mathrm{O}_{4}\right.$ where $\left.\mathrm{x}<0.1\right)$ as the dominant carrier of magnetization in the Goropu Metabasalt, however no magnetite grains were conclusively identified by our microscopic analysis. We therefore suggest that the magnetization of the Goropu Metabasalt is carried by very fine-grained magnetite crystals that are optically irresolvable. These crystals may exist in the matrix or as submicroscopic inclusions in main assemblage minerals. This is a reasonable interpretation because magnetite has a very high saturation magnetization compared to other magnetic minerals so only small concentrations of magnetite are required to produce the weak magnetizations observed in this study (Evans \& Wayman, 1970; Stacey \& Banerjee, 1974). This result is similar 
to that obtained in Eneroth (2002) in their magnetic petrology study of diabase dikes metamorphosed to amphibolite facies. No individual magnetite grains were observed during microscopy but magnetic experiments indicated that the dominant carrier of magnetization was magnetite. Also, numerous studies have reported very fine-grained exsolved magnetite inclusions as the dominant carrier of magnetization in gabbros and metagabbros (Hargraves \& Young 1969; Evans \& Wayman 1970; Wu et al.1974; Murphy et al. 1981) so this result is not uncommon. This interpretation is also consistent with the relatively high $\mathrm{B}_{\mathrm{cr}}(\sim 20-40 \mathrm{mT})$ for titanomagnetite grains observed in these samples which indicate grain sizes of $<1 \mu \mathrm{m}$ (Thompson \& Oldfield, 1986). We note that the fine-grained, opaque, high reflectance 'dust' observed in the matrix associated with sphene, and opaque inclusions in epidote, that are too small to be conclusively identified, may be the magnetite suggested by magnetic experiments.

Because titanomagnetite was not directly observed during microscopic experiments it cannot be distinguished whether that phase is primary or secondary; however, we suggest that it is likely to be primary, magmatic magnetite. Secondary magnetite growth is not common in metamorphism at grades up to greenschist facies (Clark, 1997), furthermore metamorphic magnetite tends to be coarse-grained and compositionally pure with no titanium (Clark, 1997). Additionally, we observed no significant increase in magnetic intensity with metamorphic grade (decreasing distance from the fault trace), suggesting the absence of growth of magnetic minerals during metamorphism to these metamorphic grades. This interpretation is also consistent with the fact that primary magnetite is commonly reported to survive up to greenschist facies (Dunlop \& Özdemir, 1997).

Ti-bearing, fine-grained magnetite is inferred to be present further from the fault trace in Group 2 samples based on temperature-susceptibility experiments. This titanomagnetite is most likely primary. Closer to the fault trace, the titanomagnetite present in Group 1 samples is near the pure magnetite endmember. This may reflect some loss of titanium from the titanomagnetite during progressive metamorphism, or recrystallization or exsolution processes affecting primary titanomagnetite (Dunlop \& Özdemir, 1997). The weak magnetization of these samples is attributed to the loss of much of the original titanomagnetite content during prograde metamorphism by reaction to form iron and titanium-bearing phases such as epidote, sphene and chlorite. The range in magnetizations observed in the samples may be attributable to different amounts of 
relict magnetite being preserved in the SD-PSD range. Also the protolith basalt may have been magnetite-poor (a function of melt composition and conditions of melt crystallization and seafloor processes). In the mylonite zone, weak samples tend to contain abundant calcite veins, suggesting the weak magnetization is likely due to the small concentrations of ferrimagnetic/ferromagnetic minerals because of the dominance of paramagnetic phases.

\subsubsection{Origin of the Components of Magnetization}

Progressive demagnetization experiments on the Goropu Metabasalt revealed two major components of magnetization. Closer to the fault trace $(<1.5 \mathrm{~km}$; Group 1), a moderately inclined, northerly trending, normal polarity component of magnetization is observed (Dec: $351.1^{\circ}$, Inc: $-35.7^{\circ}, \alpha_{95}: 6.8^{\circ}, \mathrm{N}=18$ sites). Further from the fault trace $(<1.5 \mathrm{~km}$ to $10 \mathrm{~km}$; Group 2) a normal component is present in the lower blocking temperature range of the samples (up to $300-400^{\circ} \mathrm{C}$ ) (Dec: $347.2^{\circ}$, Inc: $-41.7^{\circ}, \alpha_{95}: 9.4^{\circ}$, $\mathrm{N}=7$ sites). The direction of these normal components are not significantly different and therefore they are interpreted to be equivalent. We have accordingly averaged them together into a single, grand mean (Fig. 43).

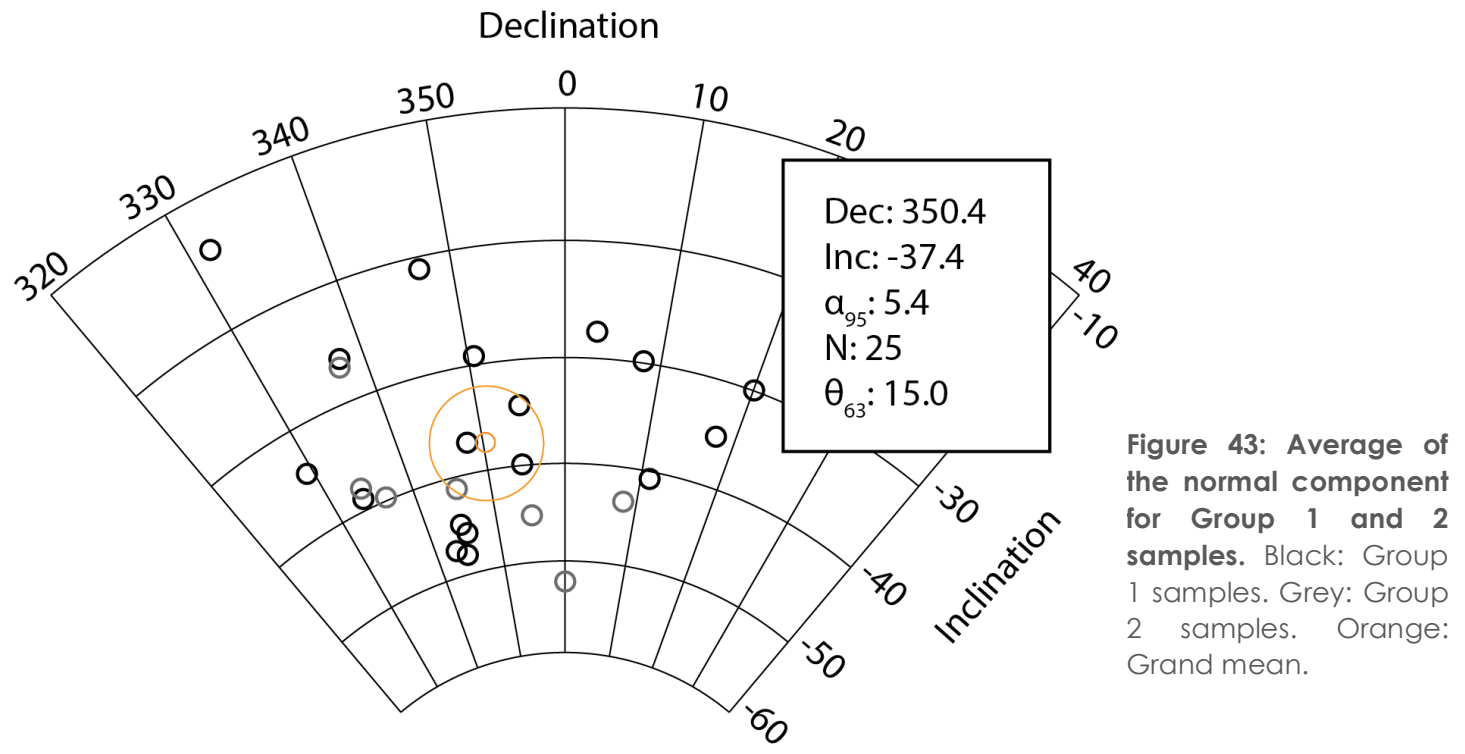

In the higher blocking temperature range of the more fault-distant Group 2 samples a more steeply inclined, southerly trending, reversed component of magnetization is observed (Dec: $177.2^{\circ}$, Inc: $57.1^{\circ}, \alpha_{95}: 7.3^{\circ}, \mathrm{N}=8$ ).

Due to the apparent primary nature of the magnetite in these samples and the absence of 
any other ferromagnetic/ferrimagnetic phases in significant abundances that may conceivably contribute to a chemical remanent magnetization we interpret the lower blocking temperature normal component to be a thermoviscous overprint that was acquired during exhumation and cooling of the Goropu Metabasalt during the Brunhes chron. This interpretation is strongly supported by the observation that the maximum blocking temperature that the normal component is carried to decreases with increasing distance from the fault trace (i.e., it decreases with decreasing grade of metamorphism and lower maximum burial depths) (Fig. 30). This component is unlikely to represent an earlier, normal polarity chron or subchron because the Goropu Metabasalt is still being exhumed today, at rapid rates of $>1 \mathrm{~cm} / \mathrm{yr}$. This component is therefore ideal to use to test the possibility of footwall rotations of the Mai'iu fault, because it was acquired recently, at a latitude approximately equal to the present day latitude of the site. Though we cannot rule out the possibility that the magnetite in these samples is secondary or affected by recrystallization or exsolution processes, this does not change the suitability of the normal component to test the rolling hinge hypothesis, because, a) magnetite grown prior to metamorphism would still have its magnetization in the lower blocking temperature range reset during peak metamorphic conditions (temperatures up to $\sim 425^{\circ} \mathrm{C}$ ) and b) magnetite grown during retrograde metamorphism would be younger than 2-3 Ma.

We consider two alternative hypotheses for the origin of the underlying, reversed component. We may confidently conclude that it is older than the normal component and unlikely to be a chemical remanent magnetization due to the absence of significant contributions of secondary magnetic minerals to the magnetization of these samples. This implies either a TRM or TVRM origin for the reversed component.

The first hypothesis is that the reversed component is a primary thermoremanent magnetization (TRM) acquired during Cretaceous eruption on the seafloor and subsequently overprinted during regional metamorphism. Erupted in the Late Cretaceous (Maastrichtian) the Goropu Metabasalt would have acquired a primary, thermoremanent magnetization. Age constraints are based on the presence of Cretaceous-age foraminifera present in metamorphosed sedimentary interbeds. As the Goropu Metabasalt was subducted in the Eocene a portion of this magnetization (in the lower blocking temperature range) would have become unblocked and remagnetized during exhumation of the Goropu Metabasalt (the lower blocking temperature normal 
component). If this is the case then a) the reversed paleomagnetic vector (if unaffected by any deformation) should be consistent with a Late Cretaceous paleopole for the Australian Plate and b) the maximum unblocking temperature that the normal polarity component is carried to should be consistent with independent estimates of footwall paleotemperatures.

We used the data from Torsvik et al. (2012) to calculate the expected declination, inclination and $\alpha_{95}$ for the field site on the Australian Plate at 10 million year intervals. This shows that our observed, reversed remanence direction is steeper and more westerly than the expected direction (angle $12.2^{\circ} \pm 10^{\circ}$ ) when the Goropu Metabasalt was erupted (60-80 Ma) (Fig. 44). For the reversed component to be primary it implies eruption of the Goropu Metabasalt $>90$ million years ago (Fig. 44), which does not agree with independent age constraints. Although this comparison excludes the effects of rolling hinge deformation, this deformation would have produced a remanence vector that is shallower than the expected direction. Therefore, the difference between the two directions is unlikely to be explained by rolling hinge deformation. This comparison does not consider the effects that fabric development may have on the primary remanence acquired prior to fabric development. But if so, deformation and mineral realignment related to development of the foliation would also be expected to produce a remanence that is shallower than expected, assuming a simple scenario in which a single, primary component of magnetization is deflected away from the tectonic shortening axis. This only matters for a component of magnetization acquired prior to the development of the metamorphic foliation.

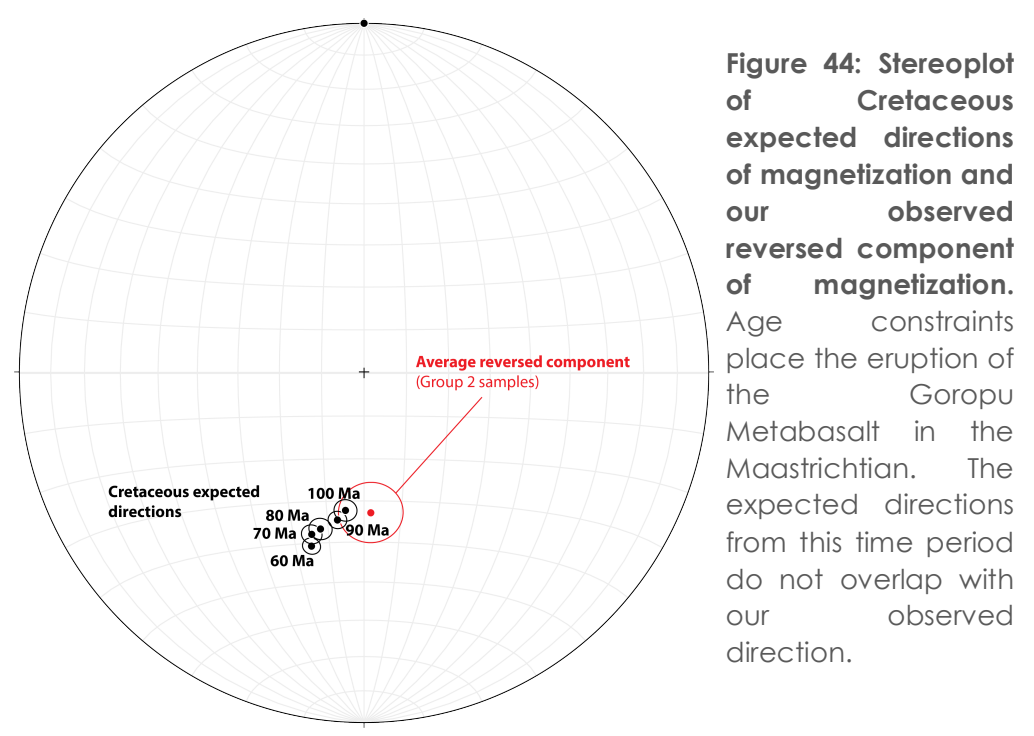


The maximum metamorphic temperature that the mylonitic Goropu Metabasalt has been subducted to is estimated to be $425 \pm 50^{\circ} \mathrm{C}$ (Daczko et al., 2009). Temperature estimates from further from the fault trace are less well constrained but must be lower than the temperatures estimated at the base of the scarp. In sample 15-18c both zircon fission track ages and zircon helium ages are completely reset (Oesterle et al., 2018). To the south, in sample 16-1153a zircon fission track and zircon helium ages are only partially reset (Oesterle et al., 2018). This implies that the base of the partial annealing and partial retention zones of zircon fission tracks and helium in zircon lies between these two samples. This gives temperature constraints of $120-390^{\circ} \mathrm{C}$ (Fig. 46) (Oesterle et al., 2018). However, in a rapidly cooled setting such as the Mai'iu fault footwall the base of the zircon fission track partial annealing zone is likely to be $\sim 300^{\circ} \mathrm{C}$ (Oesterle et al., 2018).

We compare these temperatures to our estimates of metamorphic temperature based on the maximum unblocking temperature that the normal component is carried to. Our conversions use the curves of Pullaiah et al. (1970) for magnetite (Fig. 45). This shows that the maximum blocking temperature that the normal component is carried to in Group 2 samples is lower than expected based on the known metamorphic temperatures that the samples have been to (Fig. 46). Although the curves of Pullaiah et al. (1975) are based on pure magnetite, we do not expect that the temperature discrepancy can be explained by minor titanium incorporation $(x<0.1)$. Based on estimates of the slip rate and total offset along the fault, exhumation would have taken place over 2-3 million years (Little et al., 2019). This time period spans at least 1 normal (Brunhes) and 1 reversed chron (Matuyama). Therefore, we should expect to see one younger, normal polarity and one older, reversed polarity metamorphic overprint carried by the footwall Goropu Metabasalt. In our scenario the observation of only a single polarity metamorphic overprint implies exhumation from temperatures in excess of $400^{\circ} \mathrm{C}$ over the last $\sim 780,000$ years. This implies slip rates in excess of $50 \mathrm{~mm} / \mathrm{yr}$ (assuming exhumation from $25 \mathrm{~km}$ and a mean dip below the surface of $45^{\circ}$ ), and is inconsistent with geological evidence that suggest exhumation began earlier.

The caveats discussed here are the basis for theory 2 . 


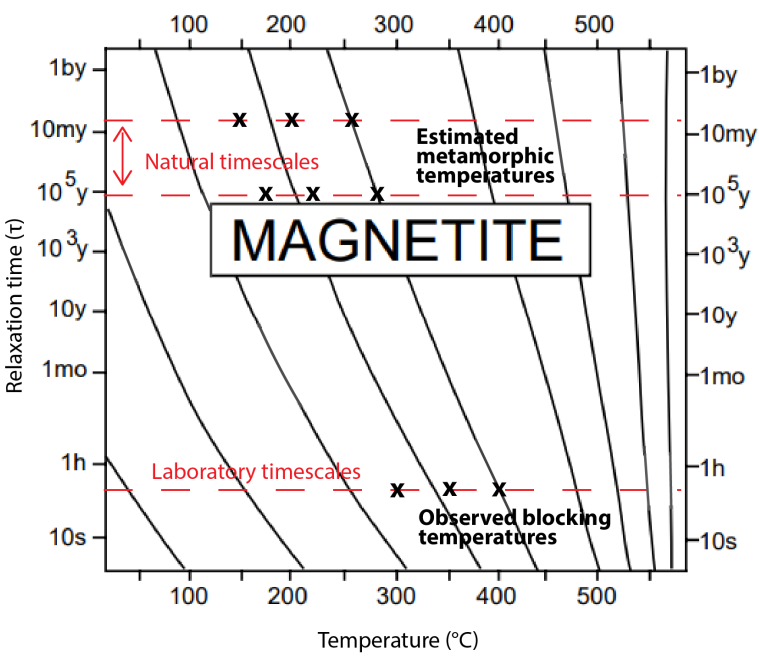

Figure 45: Estimates of metamorphic temperature based on the minimum (un)blocking temperature of the normal component. Temperature estimates for each site take into account our uncertainty in the length of time samples were at maximum metamorphic temperatures, and our uncertainty in estimated laboratory unblocking temperature. Unblocking temperature estimates are a minimum and can be up to $50^{\circ} \mathrm{C}$ higher for a given site (based on the step sizes). Modified after Butler (1992).

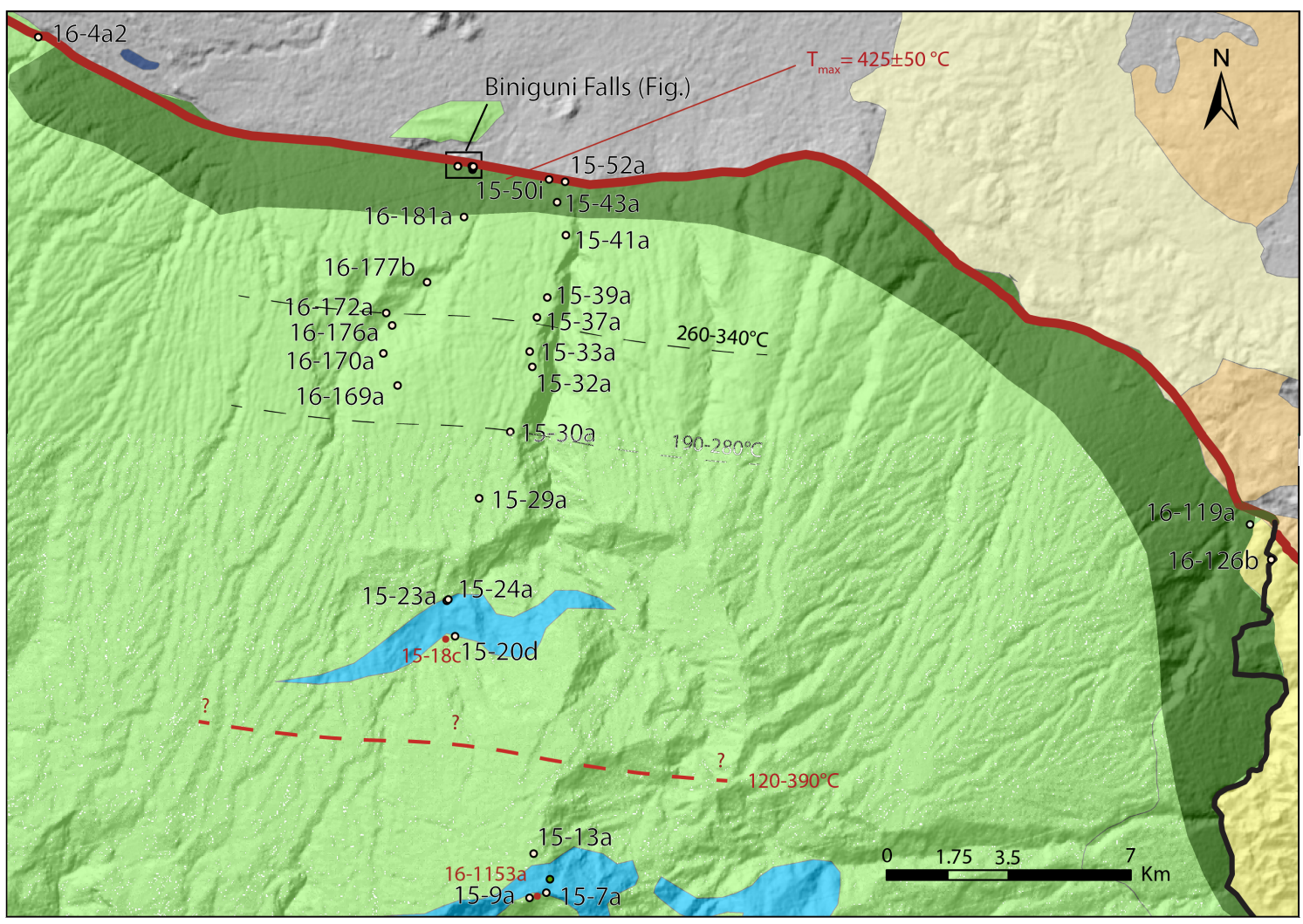

Figure 46: Map of the Suckling-Dayman MCC overlain with estimates of metamorphic temperatures. Red: Independent temperature constraints. Isograds (black) are placed at the first site where a lower (un)blocking temperature for the normal component of magnetization is observed. For example, unblocking temperatures between $400-450^{\circ} \mathrm{C}$ are first unambiguously observed at site 16-172a. This is indicative of temperatures between $260-340^{\circ} \mathrm{C}$. Assuming that the reversed component is a Cretaceous-age magnetization the temperature estimates are reflective of maximum metamorphic temperatures. For a scenario where the reversed component is also a metamorphic overprint the estimated temperatures are temperatures the samples were at when the polarity of the field reversed $\sim 780,000$ years ago. 
An alternative hypothesis is that the reversed component is a thermoviscous overprint that was acquired during an earlier reversed polarity period (Matuyama Chron) than the normal component observed further down the scarp, and both formed during the progressive exhumation of the Goropu Metabasalt. Fig. 47 illustrates how samples exhumed continuously over the last polarity reversal will carry two components of magnetization of opposite polarity. The temperature to which the lower blocking temperature component is carried will depend on the distance of the sample from the fault trace; i.e., maximum depth and temperature they were at during the last polarity reversal (these decrease up-dip of the exhumed fault plane). This is true also for the first hypothesis.

Samples furthest up-dip from the fault trace, such as 15-13a had been subducted to reach temperatures of $<\mathrm{T}_{1}$ for these rocks. These structurally higher rocks were the first to be cooled and exhumed during the later normal-slip on the Mai'iu fault, and was during the Matuyama chron (Fig. 47a, b). The expected result would be a reversed polarity component present in the lower blocking temperature range $\left(<\mathrm{T}_{1}\right)$ and potentially an underlying, primary component of magnetization in the higher blocking temperature range (Fig. 47a, b). Samples farther down the fault and nearer to its trace, such as 16-BW1c, had been subducted to temperatures of $<\mathrm{T}_{4}$. During the Matuyama chron the samples are exhumed and cool to $<\mathrm{T}_{2}$ acquiring a reversed component in that blocking temperature range (Fig. 47a, b). During the Brunhes chron the samples are exhumed to the surface, retaining a reversed component of magnetization in the higher blocking temperature range $\left(<\mathrm{T}_{2}\right)$, and acquiring a normal component of magnetization in the lower blocking temperature range (Fig. $47 \mathrm{c}, \mathrm{d})$. This interpretation is consistent with the estimated length of time of the exhumation of the Goropu Metabasalt and might explain why the direction of this component does not match the Australian Plate paleopole for the Late Cretaceous.

This scenario predicts that samples more than $10 \mathrm{~km}$ up-dip and southward of the fault trace do not carry a normal component of magnetization because they were exhumed prior to the last (Brunhes-Matuyama) polarity reversal (Fig. 47). Samples closer to the fault trace carry a normal component in their lower blocking temperature range and a reversed component in their higher blocking temperature range (Fig. 47). Two problems are obvious with this hypothesis. 
If this second interpretation is correct this implies a complete metamorphic overprint (to unblocking temperatures of $580^{\circ} \mathrm{C}$ ) is carried by all samples, which have only been subducted to temperatures of $300-425^{\circ} \mathrm{C}$ (i.e., no primary component of magnetization is observed where it would be expected).

Furthermore, in this scenario the estimated metamorphic temperatures in Fig. 46 (based on the unblocking temperature of the normal component of magnetization) are interpreted to be the maximum temperature the samples were at when the field reversed polarity $\sim 780,000$ years ago. Fig. 48 plots the estimated depth of representative samples during this polarity reversal, as calculated using the known slip-rate of the Mai'iu fault (6-15 mm/yr) and time duration of Brunhes chron ( 780,000 years) together with possible range of dips for the fault (section 5.2.2). This is overlain with the estimated metamorphic temperatures from Fig. 46, estimated using the temperature that the normal component is carried to and assuming residence times between $\sim 1,000,000$ $10,000,000$ years. To explain the observed laboratory unblocking temperatures our reconstructed depths and metamorphic temperatures at the time of polarity reversal imply that there was an extremely high geothermal gradient (in excess of $50^{\circ} \mathrm{C} / \mathrm{km}$ ) along the Mai'iu fault in the past. A high geothermal gradient is not unexpected, given the high total slip (at least $30 \mathrm{~km})$ and rapid slip rate $(\sim 1 \mathrm{~cm} / \mathrm{yr})$ on the Mai'iu fault. This is because the geothermal gradient is expected to be elevated near the fault as a result of rapid advection of hot rocks in its footwall as a result of slip (e.g., Koons, 1987) - a prediction borne out by the presence of hot springs along the fault today (Little et al., 2019). Moreover, the presence of dm-thick mafic dikes intruding the footwall directly adjacent to the Mai'iu fault, including at Biniguni Falls (Little et al., 2019) suggest the possibility of short-lived pulses of elevated geothermal gradient near the fault in the past.

Nonetheless, we infer that the reconstructed paleotemperatures in Fig. 46 are likely to be overestimates. Numerous studies have reported temperatures required to remove TVRM are higher than that predicted by Néel theory (Butler, 1992). Differences of $>150^{\circ} \mathrm{C}$ have previously been reported (Kent, 1985). This may be due to the effects of stress on the blocking temperature of the ferromagnetic/ferrimagnetic grains at deep burial depths. It has been reported that stress annealing of dislocations in crystals that previously contained pinned domain walls reduces blocking temperature (Dunlop \& Özdemir, 1997). Additionally, our metamorphic temperature estimates ignore the 
possibility that chemical changes have taken place, and the effects of the contribution of pseudo-single domain or multidomain grains, both of which have been reported to produce laboratory blocking temperatures that are higher than expected. Since the titanomagnetite present in these samples was too fine-grained to be observed directly, this remains a possibility. Furthermore, the effect of relaxation time-temperature relationships for magnetite with minor Ti incorporation is unknown. Though laboratory experiments appear to confirm the predictions of Pullaiah et al. (1975), they have not taken into account geological timescales (Dunlop \& Özdemir, 1993).

In summary, if this theory is correct, then both components of magnetization in all samples are carried to higher blocking temperatures than would be predicted by Néel theory. We have outlined a number of reasons why that may be.

The average $1 \mathrm{~cm} / \mathrm{yr}$ slip rate of the Mai'iu fault implies that samples around site $15-24 \mathrm{a}$ (currently more than $8 \mathrm{~km}$ from the fault trace) were exhumed approximately 1 million years ago, prior to the last reversal of the geomagnetic field (Fig. 48). These samples, however do carry a normal component. This may imply that slip rates were higher along the Mai'iu fault in the past (Fig. 48).

We suggest that it is reasonable to assume that the footwall rocks failed to record any normal polarity subchrons (such as the Olduvai or Jaramillo) that occurred during the Matuyama chron because the timescale of these periods of normal polarity are short relative to the exhumation timescale of the Suckling-Dayman MCC. The footwall rocks may have preserved these normal polarity subchrons, however, these subchrons would have been promptly overprinted in the rocks because they were sitting at length at elevated temperatures in a prevailing reversed polarity field (Matuyama chron).

The average reversed component carried by Group 2 samples is $\sim 10^{\circ}$ steeper than the average normal component carried by Group 2 samples. We suggest that because this component is representative of fault dips, at the position of the corresponding samples, prior to 780,000, years this paleomagnetic vector may record shallowing of the fault dip prior to the polarity reversal. 


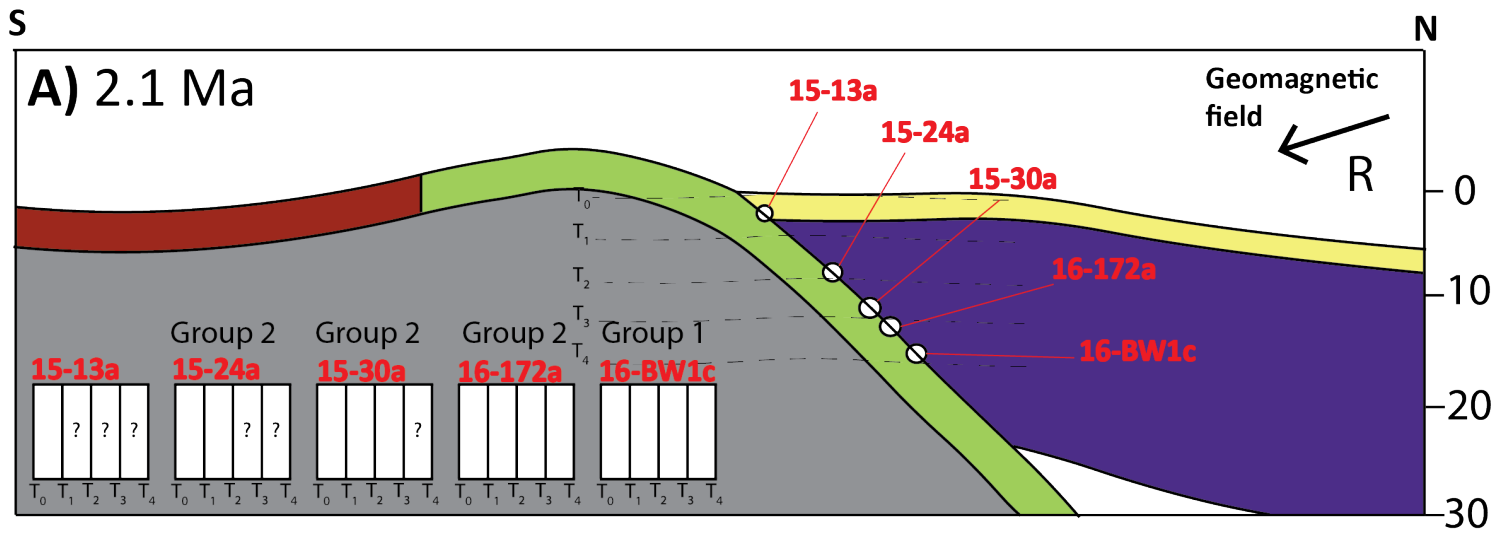

S

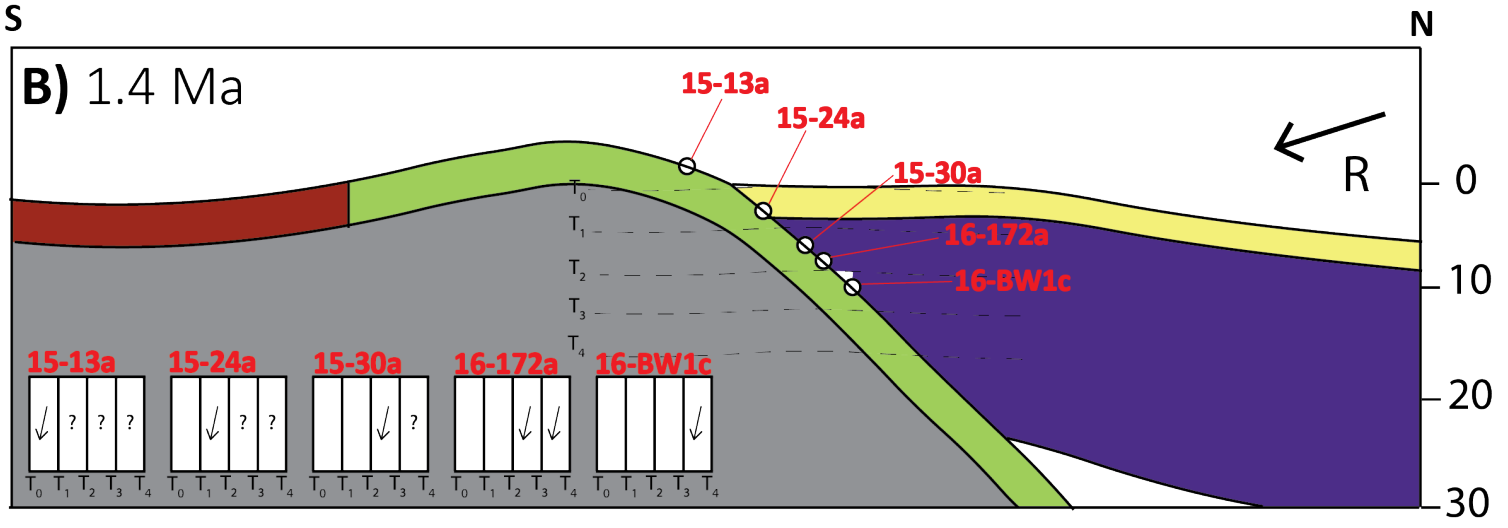

$S$

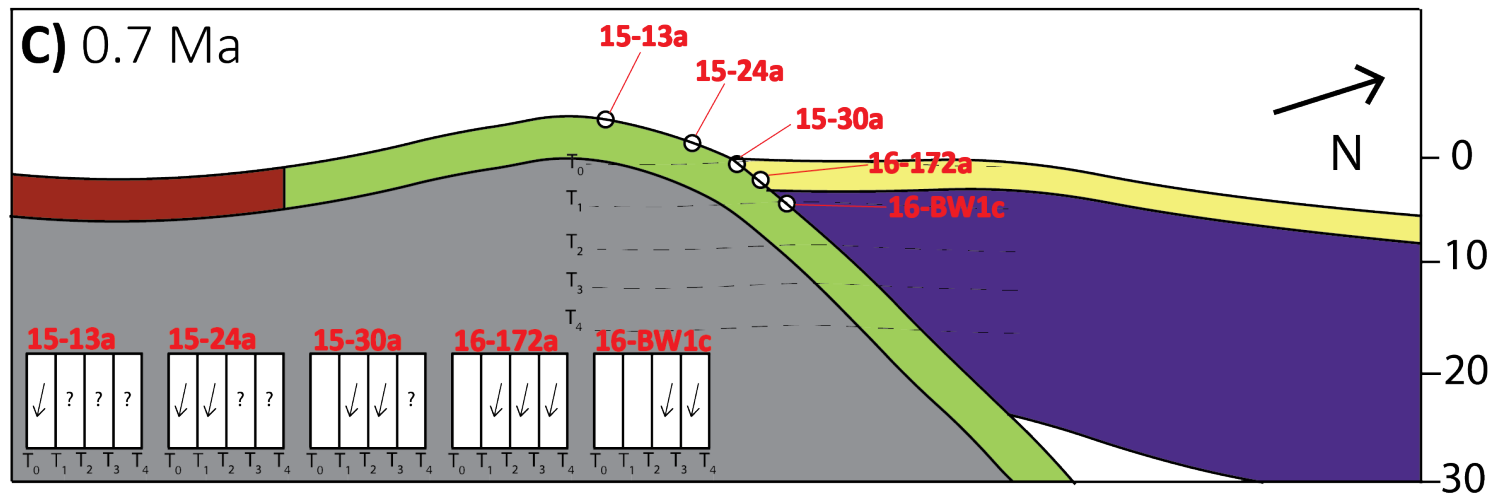

S

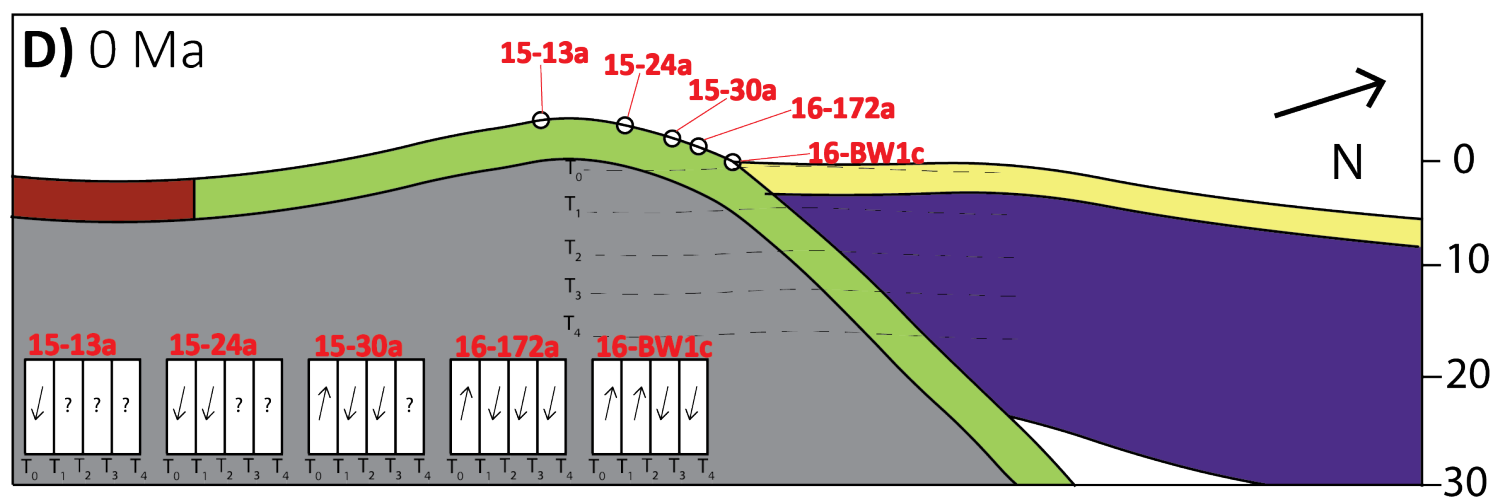


Figure 47: Schematic cross-sections showing the proposed TVRM origin of the reversed component. Representative samples are plotted, in addition to the estimated blocking temperature spectrum of each representative sample at a given time (A-D; Assuming a constant slip rate of $1 \mathrm{~cm} / \mathrm{yr}$ ). When cooling between each blocking temperature interval (e.g. $T_{4}$ to $T_{3}$ ) the sample acquires a component of magnetization in that blocking temperature range that is parallel to the Earth's magnetic field at the time. This figure demonstrates how this process produces, in the footwall samples, a normal component in the lower blocking temperature range and a reversed component in the higher blocking temperature range. Note: Only relative temperatures are plotted because very few constraints exist on the paleotemperature and paleo-geothermal gradient of the footwall. This illustration, for simplicity, assumes 1:1 correlation between natural and laboratory blocking temperatures.? symbol: component of magnetization acquired prior to the metamorphic overprint. Blank space: no stable component. This illustration starts at 2.1 Ma but exhumation likely began prior.

Depth $(\mathrm{km})$

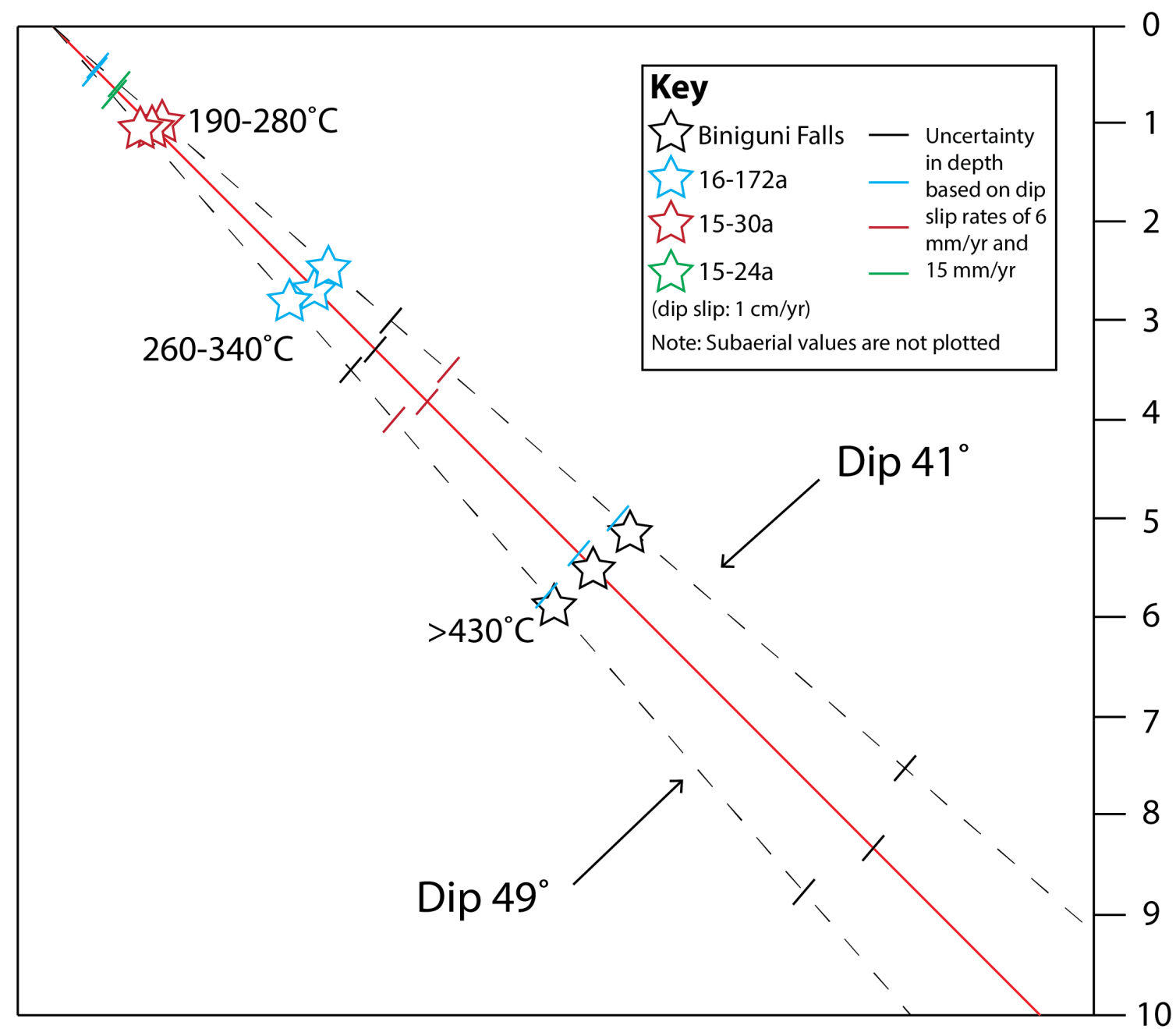

Figure 48: Estimated depth of representative samples of Goropu Metabasalt when the field reversed polarity ( $\sim 780,000$ years ago). Depth is estimated assuming a constant slip rate between $6-15 \mathrm{~mm} / \mathrm{yr}$ and a constant dip of $41-49^{\circ}$ (section 5.2.2).

With our current data we prefer the interpretation that the reversed component is a thermoviscous overprint acquired during the Matuyama chron. Comprehensive examination of the two theories presented here is limited by the fact that knowledge of paleotemperatures and the paleo-geothermal gradient of the footwall rocks is poorly constrained, in addition to past slip rates along the Mai'iu fault and the beginning of onset of exhumation of the Goropu Metabasalt. In addition, the titanomagnetite present 
in these samples was not observed directly. Lasar Raman Spectroscopy on carbonaceous material in the Goropu Metabasalt is ongoing and may provide tighter constraints on past footwall temperatures, which may place further constraints on the two theories presented here. Furthermore, comparison of the magnetic properties of the Goropu Metabasalt with the magnetic properties of the unmetamorphosed protolith (Kutu Volcanics) may shed further light on the origin of the reversed component. Though the origin of the reversed component remains uncertain we emphasize that this does not affect the overall goals of this study.

\subsubsection{Origin of Laboratory-Induced Thermal Alteration}

Laboratory thermal alteration was inferred in almost all of the specimens subjected to thermal demagnetization based on substantial, irreversible increases in susceptibility during the demagnetization run. Generally, thermal alteration is produced by the breakdown of ferromagnetic/ferrimagnetic phases into other ferromagnetic/ferrimagnetic phases or paramagnetic ones, or the growth of ferromagnetic/ferrimagnetic minerals from paramagnetic ones.

Thermal alteration in samples closer to the fault trace, inferred to occur at temperatures above $400^{\circ} \mathrm{C}$, is likely due to the oxidation of pyrite into magnetite and then haematite. This alteration behaviour correlates with optical observations of the abundance of pyrite in the samples and is nearly identical to that obtained in experimental studies in the thermal alteration behaviour of pyrite (Tudryn \& Tucholka, 2004).

Samples further from the fault trace that are inferred to alter above $250^{\circ} \mathrm{C}$ had large initial abundances of goethite/lepidocrocite(?). We therefore suggest that the observed susceptibility increase is likely a result of the dehydration of these phases to haematite and maghemite (Gialanella et al., 2010; Cornell \& Schwertmann, 1996). This may also explain why this thermal alteration behaviour is so variable between samples and specimens, due to the heterogeneous distribution of these phases. Not all samples that contained goethite/lepidocrocite(?) exhibited this alteration behaviour in their susceptibilities. Only samples that appeared to be optically dominated by goethite/lepidocrocite(?) exhibited this thermal alteration behaviour. We therefore argue that most samples did not contain significant enough concentrations of goethite/lepidocrocite(?) for this alteration to become obvious in the susceptibility data. 


\subsection{Testing for Rolling Hinge Deformation}

\subsubsection{Suitability of the Components of Magnetization}

We interpret the normal polarity component to be a metamorphic overprint acquired during uplift and exhumation of the footwall (during the Brunhes chron). This component is ideal to use to test for any rolling hinge deformation because this component was acquired recently at a latitude that is identical to the present day one and other deformation that has since affected it is well constrained and considered to be negligible.

Comparison of the average normal component with the expected field direction at the site latitude can therefore be used to test for any rolling hinge style deformation. The expected direction at the field site can be easily calculated. Although Earth's magnetic field is continuously changing, on average, the field can be approximated as a geocentric axial dipole (GAD) where declination is 0 and inclination varies as a function of latitude by the simple equation:

$\operatorname{Inc}=\tan ^{-1}(2 \tan \lambda)$

The site latitude of $9^{\circ} \mathrm{S}$ implies an expected (GAD) declination of $0^{\circ}$ and inclination of $17.6^{\circ}$. The Australian plate has been moving northward since the Cretaceous, however the change in latitude of the site over the last 780,000 years was $<<1$ degree (Torsvik et al., 2012). This is considered to have a negligible effect on the paleomagnetic vector $(<1$ degree). This site sits on a Papuan Peninsula block which is rotating anticlockwise at a rate of $0.66^{\circ}$ million years relative to the Australian Plate (Wallace et al., 2014). This deformation would produce a paleomagnetic vector that is deflected west by $<1$ degree over the last 780,000 years and therefore is considered to also be negligible.

The comparison of the mean paleomagnetic vector with the expected field direction to gauge any potential rotation rests on the assumption that secular variation of the geomagnetic field has been effectively averaged by the paleomagnetic sampling. To test whether secular variation has been effectively averaged, we follow the method of Deenen et al. (2011). The angular standard deviation of 25 Virtual Geomagnetic Poles (VGPs) calculated from the 25 normal polarity directions used in our grand mean is $15^{\circ}$. This is close to the average value of $16^{\circ}$ shown by Deenen et al. (2011) to represent 
secular variation-induced scatter in data covering the past 5 million years. Deenen et al. (2011) conclude that this figure is independent of latitude. They further propose formulae for maximum and minimum acceptable values of Alpha-95 (of the VGPs) in order to justify the assumption that secular variation has been adequately sampled. For a data set of 25 directions/VGPs, $\mathrm{A} 95_{\max }$ and $\mathrm{A} 95_{\min }$ are $10.8^{\circ}$ and $4.7^{\circ}$, respectively. For our data set we obtain a A95 value of 5.4 $4^{\circ}$ This value is between the maximum and minimum acceptable values of A95 for our sample size, indicating that secular variation has been effectively averaged by the sampling. This is consistent with a large time interval sampled with known slip rate of the fault, and protracted sampling during slow cooling.

This analysis also rests on the assumption that deformation mechanisms other than back-tilting about the strike of the Mai'iu fault have not affected the paleomagnetic vector. As mentioned above the movement of the Australian Plate and the Papuan Peninsula block over the last 780,000 years has had a negligible effect on the remanence vector. We posit that it is unlikely that foliation development during metamorphism affected the paleomagnetic vector (i.e., strain-induced rotation of the grains carrying the magnetic remanence) because the remanence is interpreted to have been acquired during uplift and exhumation of the footwall rocks during the Brunhes chron, following the development of metamorphic and mylonitic foliation.

We must also consider whether the orientation of the foliation biases the remanent magnetization of these samples. The acquisition of remanence in a rock parallel to the geomagnetic field occurs because the distribution of easy axes of the magnetic grains is random (Fig. 4). This is valid in rock types such as extrusive volcanic rocks. Foliated metamorphic rocks may exhibit a shape preferred or crystallographic preferred orientation of magnetic grains that may bias the magnetization to lie along the foliation plane. To test whether this is the case for the Goropu Metabasalt we measure the angle between the paleomagnetic vector and the down-dip direction of the foliation plane for each sample considered in the mean normal direction. Consistent angles of less than 10 or $15^{\circ}$ may indicate significant deflections from the geomagnetic field. With the exception of four of the samples the measured angles vary from $\sim 40-75^{\circ}$ (Fig. 49). This indicates that the ChRM direction of the samples is controlled by something other than the foliation. 


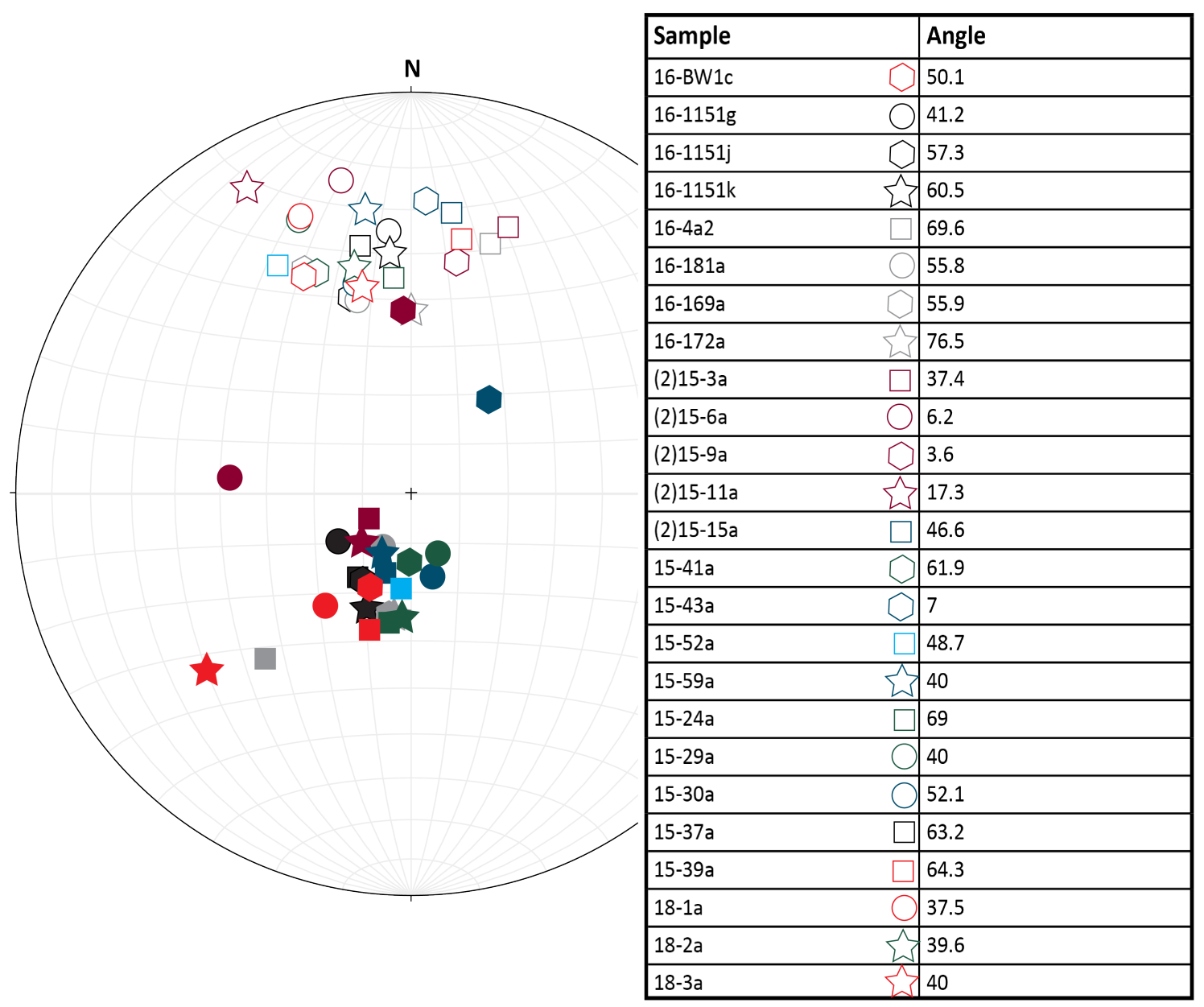

Figure 49: Comparison of the paleomagnetic vector with the foliation plane. Left: Stereoplot showing the mean paleomagnetic vector (open shapes) and downward pole to the foliation (closed shapes) for each sample (unique shape and colour; see table). Right: Table listing the angle between the mean paleomagnetic vector and down-dip direction of the foliation for each sample (90-[angle between the paleomagnetic vector and the downward pole to the foliation]).

\subsubsection{Rotation Analysis and Tectonic Implications}

Previous paleomagnetic analyses on the footwalls of oceanic detachment faults have been limited by the fact that the samples are generally azimuthally unoriented (Garcés \& Gee, 2006; Zhao \& Tominaga, 2009). This means that the number of possible solutions that could give rise to the difference in inclination is infinite. In this study this limitation does not apply and we have determined the mean declination and inclination of the normal component of magnetization in 25 samples in the footwall of the Mai'iu fault. From our data, the possible rotation axes that could produce the observed discrepancy between the expected and observed (normal component) direction in the footwall rocks must lie along a great circle that is equidistant between the two vectors, with implied magnitudes of rotation varying along the great circle (Fig. 50). For any pair of points, this solution is non-unique, with any number of chosen axes capable of 
producing large differences in rotation estimates (Fig. 50). This effect is compounded by the uncertainty of the mean remanence direction of the footwall rocks (Fig. 50).

Possible solutions may be limited by adding independent geological constraints on the rotation axis. For rolling hinge deformation we assume that the axis is horizontal and roughly parallel to the strike of the Mai'iu fault. This is a reasonable approximation for an almost purely dip slip fault with a known slip vector that trends NNE (Little et al., 2019). Averaging out the km-scale corrugations in the fault surface of the Mai'iu fault we obtain an average strike of the Mai'iu fault of $115 \pm 10^{\circ}$ (Fig. 50). The $10^{\circ}$ uncertainty envelope represents both our uncertainty in the strike of our potential rotation axis, and the plunge i.e. the rotation axis may not be prefectly horizontal.

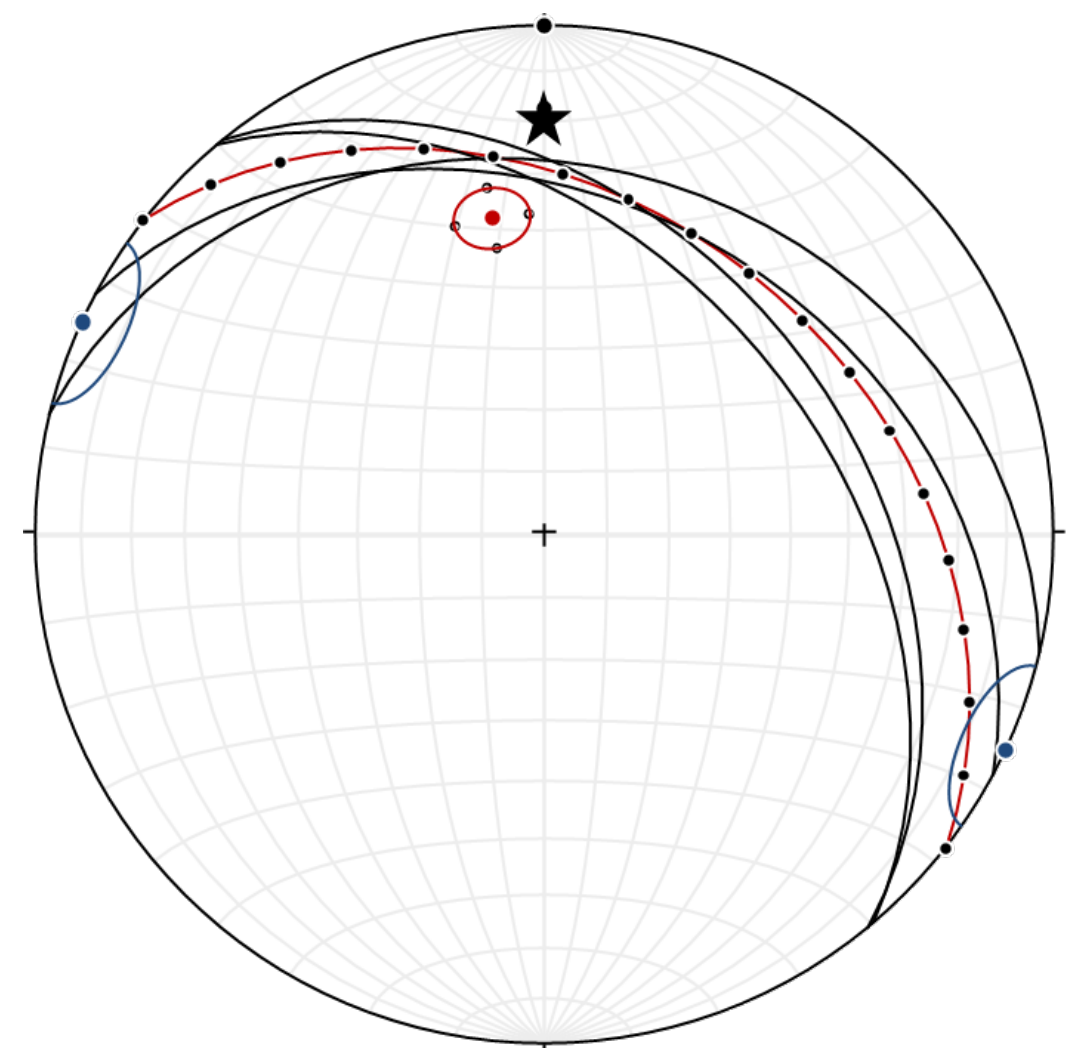

Figure 50: Stereoplot of the observed mean paleomagnetic direction and expected direction, and possible rotation axes. Plotted are the bisecting planes for the expected and observed direction pairs. Possible rotation axes lie along this bisecting plane. This figure shows the great circle bisectrixes for 5 observed directionexpected direction pairs (taking the mean paleomagnetic value and the extreme ends of the $\alpha_{95}$ ). For our analysis we selected 1000 points at random within the $\alpha_{95}$ envelope which produced 1000 great circle bisectrixes. Star: expected direction. Red: Observed mean paleomagnetic vector. Blve: Mean strike value for the Mai'iu fault.

In our rotation analysis we used the methodology of MacLeod et al. (2011), described here. To take into account our cone of confidence around our mean paleomagnetic vector we used a random number generator to select 1000 individual directions within the $\alpha_{95}$ envelope. This produced 1000 different observed and expected direction pairs. 
For each pair we calculated a great circle bisectrix containing the possible rotation axes that may be responsible for the rotation. Possible rotation axes were calculated at 1 degree increments along the great circle bisectrixes. With 1000 random expected and observed direction pairs this produces 360,000 possible rotation axes and solutions. Of these solutions 9,821 were accepted because they lie within the uncertainty envelope of the independently estimated rotation axis (the strike of the Mai'iu fault). The result is a probability density function of rotation magnitudes calculated from the 9,821 acceptable solutions (Fig. 51). The mean footwall rotation is $23.9^{\circ} \pm 2.6^{\circ}(1 \sigma)($ Fig. 51). Given the $<20-22^{\circ}$ surface dip of the Mai'iu fault at the sample sites this magnitude of backrotation indicates an original dip of $41.3-48.5^{\circ}$. This analysis is advantageous because it provides a self-check. The fact that many of the great circles bisectrixes intersect our geologically plausible rotation axis indicates that our assumption that the footwall has rotated about the strike of the Mai'iu fault is a reasonable one that is supported by the data and great circle analysis.

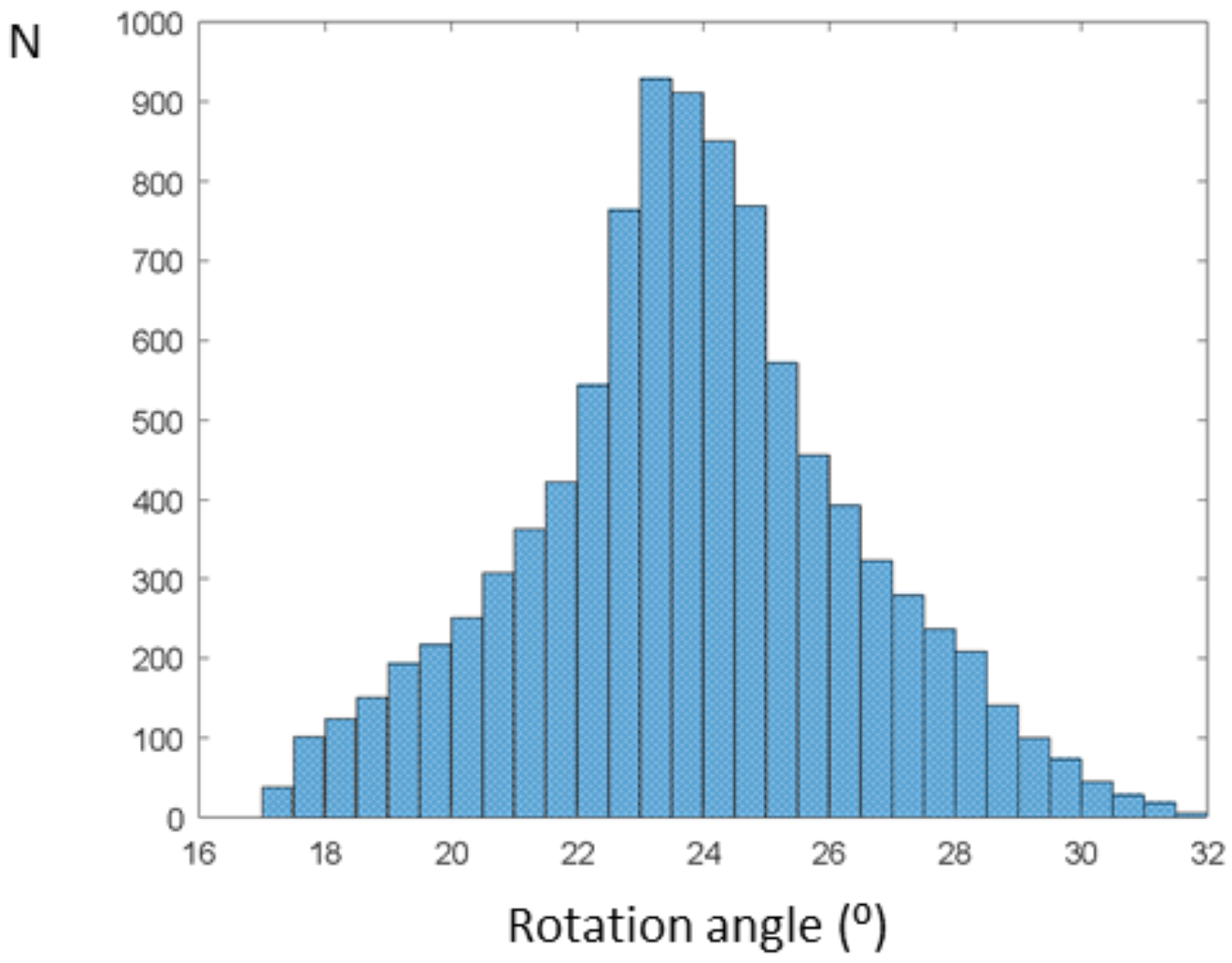

Figure 51: Probability density function of calculated rotation angles, based on the plausible geological rotation axes that could have produced a discrepancy between the expected and observed direction of the NRM of the footwall Goropu Metabasalt.

A small number of the samples that were included in the mean paleomagnetic vector $(n=7)$ were taken from locations in which the dip of the fault is shallower than $20-22^{\circ}$, and therefore may have recorded differing degrees of rotation. We performed the same 
analysis using just the mean paleomagnetic vector for the Group 1 samples to test whether the result would be significantly different. This yields an estimate for the magnitude of rotation of $21.8^{\circ} \pm 3.3^{\circ}$. This implies original dips of $38.5^{\circ}-47.1^{\circ}$ (assuming a $20-22^{\circ}$ at the surface near the trace of the fault). Though slightly smaller, this magnitude is not significantly different from, and largely overlaps with, our previous estimate. We therefore prefer to use the overall mean paleomagnetic vector that includes both Group 1 and 2 samples, which is better constrained.

We suggest that the observed back-rotation of the footwall rocks is unlikely to have been caused by domino tilting because major normal faults other than the Mai'iu fault are sparse and have much less finite slip than the Mai'iu fault (Little et al., 2019). We also suggest that it is unlikely that the paleomagnetic vector has recorded any other deformation. Present deformation of the Suckling-Dayman MCC is geologically and geodetically dominated by slip along the Mai'iu fault (Wallace et al., 2014). Plate movements over the last several million years have been shown to have a negligible effect on the expected paleomagnetic vector (section 5.2.1). Furthermore, there is independent and supporting geomorphic and geological evidence to suggest that the Mai'iu fault has evolved through a rolling hinge mechanism (section 2.2, Little et al., 2019; Mizera et al., in review).

Our paleomagnetic data indicates that the footwall of the Mai'iu fault has back-rotated by at least $23.9 \pm 2.6^{\circ}(1 \sigma)$. This implies an original fault dip between $41.3-48.5^{\circ}$. We note that this is a minimum estimate for the dip of the fault as it refers only to the fraction of rotation that has occurred since the remanent magnetization of the footwall rocks was acquired. If the normal component was acquired in the last 780,000 years and the current $1 \mathrm{~cm} / \mathrm{yr}$ slip rate of the fault has been stable since then this magnetization would have been acquired at a depth of $<9 \mathrm{~km}$.

This estimate of original fault dip is consistent with other geological constraints on the original dip of the Mai'iu fault. Fault-bedding cut-off angles for bedding in the footwall slice of Gwoira Conglomerate indicates an original fault dip at the surface of $\sim 40-49^{\circ}$ (Webber, 2017; Little et al., 2019). These sedimentary beds are constrained to be between $4 \mathrm{Ma}$ and early Pleistocene in age based on cosmogenic nuclide burial dating and dating of tephra, indicating a surface dip of $40-49^{\circ}$ at that time. Microseismicity today indicates the fault is dipping, at depths of $10-25 \mathrm{~km}$, at $30^{\circ}$ to $40^{\circ}$ (Eilon et al., 
2015; Abers et al., 2016). Our paleomagnetic result indicates the original dip of the fault was slightly steeper in the past and therefore that rolling hinge deformation has caused a net shallowing of the fault. This is also consistent with the fact that the reversed component, potentially of TVRM origin and older than the normal component, is steeper than the normal component. Furthermore, a geodynamical model using an original fault dip of $45^{\circ}$ and run for 3.5 million years with a high-resolution finite element code is able to approximate most first order characteristics of the SucklingDayman MCC today (Biemiller et al., in review). This includes its elevation and shape, and total exhumation and slip (Biemiller et al., in review).

Given the domal shape of the Suckling-Dayman MCC one might expect to see an increasing inclination of the components of magnetization in the Goropu Metabasalt with decreasing fault dip, if the fault has indeed evolved through a rolling hinge mechanism. We test this by plotting the inclination of the normal component for Group 1 and 2 samples (that were considered in our rotation analysis) against the average dip of the fault at the location the samples were taken from (Fig. 52). Estimates of fault dip at each site is based on a 3D LIDAR-based model of the Suckling-Dayman MCC (Mizera et al., in review). Our paleomagnetic data indicates a slight steepening of $0.5^{\circ}$ of inclination for every $1^{\circ}$ of fault shallowing, however, the inclination values have large errors and are quite variable. We compare this to what would be expected of a fault striking $115^{\circ}$, with an original fault dip of $\sim 45^{\circ}$ (Fig. 52). For such a strike a slight declination anomaly will be produced, and a 1:1 correlation between inclination steepening and fault shallowing would not be observed, because the fault does not strike exactly EW. Of particular note is that the size of the errors on the paleomagnetic data is roughly the same amplitude as the expected inclination change (15 ) (Fig. 52). The variation of paleomagnetic inclination up-dip is permissive of rolling hinge style rotation of the fault surface. More data is required to possibly constrain this relationship further (Fig. 52). 


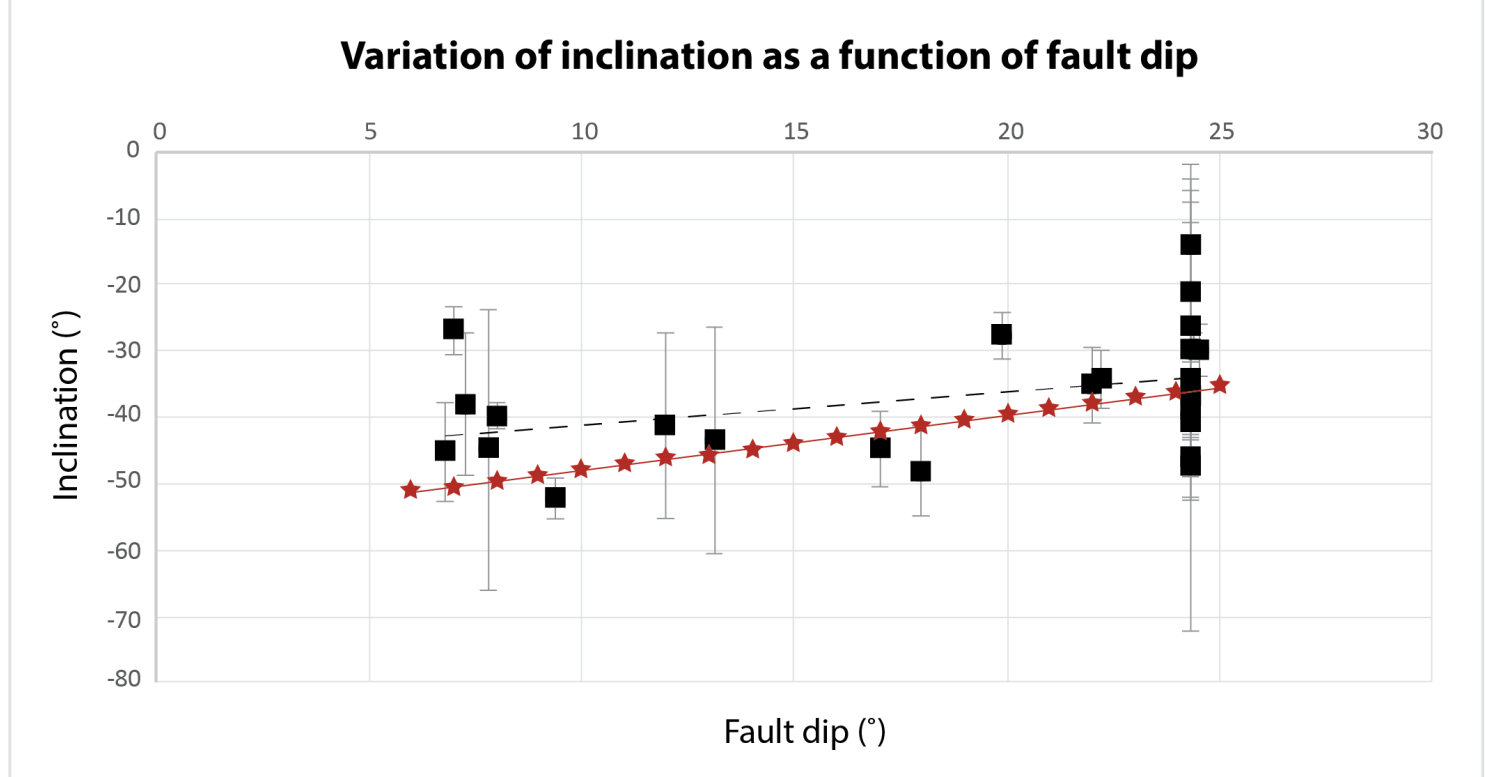

Figure 52: Fault dip vs. inclination for the normal component carried by each sample. A slight steepening of $0.5^{\circ}$ of inclination for every 1 degree of fault shallowing is observed. The data is, however, scattered and noisy, preventing a definitive conclusion. Black line: Trend line through the data. Red stars: expected inclination steepening assuming an original fault dip of $45^{\circ}$, a fault strike of $115^{\circ}$, and a GAD inclination of $-17.6^{\circ}$. Rotations were performed on a stereonet.

\subsection{Further Work}

Below I outline some possible avenues for further research. This is largely aimed at better constraining the origin of the magnetization in the Goropu Metabasalt. This will allow greater confidence in our interpretations.

- To the west of Mt Dayman are two large felsic igneous intrusions that are estimated to have intruded the Goropu Metabasalt 3-4Ma at a depth of $12 \mathrm{~km}$ (Oesterle et al., 2018). Sampling of the felsic intrusives and contact metamorphosed Goropu Metabasalt near the intrusion may help in constraining the timing of the isolated components of magnetization in this study relative to the intrusion of these igneous rocks.

- Paleomagnetic sampling of the Kutu Volcanics (the unmetamorphosed equivalent of the Goropu Metabasalt) exposed to the south of the SucklingDayman MCC will be helpful in the interpretation of the origin of the reversed component observed in this study, and constrain any processes that may have affected the remanent magnetization of the Goropu Metabasalt prior to metamorphism.

- Further work is required to constrain the paleo-temperatures of the footwall Goropu Metabasalt. This will help to further constrain the models of remanence 
acquisition discussed in this thesis. Lasar Raman Spectroscopy of carbonaceous material in the Goropu Metabasalt is currently being pursued.

- Further sampling below and around the summit of Mt Dayman is desired. This will help determine what paleomagnetic behaviour may be typical of the area, and the cause of the anomalous paleomagnetic behaviour observed in this study (Appendix 2).

- More data are desirable to further constrain the mean paleomagnetic vectors of each sample group and any potential inclination vs. fault dip relationships.

- Anisotropy of remanent magnetization experiments can be undertaken to further constrain the degree to which the magnetization is potentially biased by the foliation of the samples.

- Experiments can be undertaken to determine whether the magnetization is carried by dominantly SD or MD grains. This may explain why laboratory blocking temperatures in this study were anomalously high (based on the interpretation that both components of magnetization are a metamorphic overprint). 


\section{Chapter 6: Conclusions and Summary}

Sampling of the Goropu Metabasalt revealed two distinct components of magnetization. Close to the fault trace $(<1.5 \mathrm{~km})$ a moderately inclined, northerly trending, normal component of magnetization is preserved. Further southward and up-dip of the fault trace on older exhumed parts of the fault surface, this component of magnetization is carried in the lower blocking temperature range of the samples. In the higher blocking temperature range a more steeply inclined, southerly trending, reversed component of magnetization is preserved. The maximum blocking temperature that the normal component of magnetization is carried to decreases with increasing distance southward and up-dip from the fault trace.

The results of magnetic experiments indicate that the dominant carrier of these components of magnetization is fine-grained titanomagnetite $(\mathrm{x}<0.1)$. Due to its apparent extremely fine-grained size, we were unable to verify the presence of such titanomagnetite grains microscopically, despite our systematic application of SEMbased microscopic analytical techniques. These carrier grains may exist in the matrix and/or as inclusions in main assemblage minerals such as epidote. This titanomagnetite is most likely primary because it is extremely fine-grained and contains minor amounts of titanium. These observations are consistent with relict magnetite from MORB.

Based on the absence in significant abundances of any minerals that may contribute to a $\mathrm{CRM}$, and on the observation that the maximum unblocking temperature decreases systematically with increasing distance southward of the fault trace, I interpret the normal component of magnetization be a recent, thermoviscous component of magnetization acquired during the exhumation of the Goropu Metabasalt over the last 780,000 years (Brunhes chron). The origin of the reversed component remains equivocal. Two hypotheses are considered: 1) it is a primary magnetization acquired in the Cretaceous; or 2) it is a TVRM overprint acquired during exhumation. The second interpretation, which interprets the reversed component as being acquired during uplift of the Goropu Metabasalt during the Matuyama chron (2,600,000-780,000 years ago), is preferred on the basis that it is in better agreement with independent constraints on the thermal and temporal evolution of the footwall.

The normal component of magnetization, present in the two groups (Groups 1 and 2), 
can be combined into a grand mean (Dec: $350.4^{\circ}$, Inc: $-37.4^{\circ}, \alpha_{95}: 5.4^{\circ}, \mathrm{N}: 25$ ). Comparison of this direction with the expected direction of the geomagnetic field at the paleomagnetic sampling locality indicates $23.9 \pm 2.6^{\circ}(1 \sigma)$ of back-rotation has affected the footwall of the Mai'iu fault. Taking into account the known dip of the fault at the surface of $20-22^{\circ}$ this implies an earlier, pre-exposure fault dip of $41-49^{\circ}$. This conclusion strongly supports the rolling hinge model for deformation of large-slip normal faults and is reinforced by several other, completely independent constraints on the original fault dip. This is likely to be a minimum estimate because the normal component of magnetization is unlikely to have sampled the fault dip at depths greater than $\sim 9 \mathrm{~km}$ or periods older than 780,000 years.

This study is the first of its kind in the study of continental metamorphic core complexes to use paleomagnetism to demonstrate footwall back-warping as a result of its passage through a rolling hinge. Our study demonstrates, in particular, that this process for forming a shallow-dipping normal fault at the surface is not unique to oceanic detachments, but also occurs in continental rifts. The paucity of active examples in the continents, and lack of previous paleomagnetic studies, may explain why such a demonstration has been difficult. Below we provide a summary of our preferred interpretation for the evolution of the Mai'iu fault that incorporates the paleomagnetic data from this study.

The Goropu Metabasalt is known to have been erupted as a mid-ocean ridge basalt in the Late Cretaceous (Fig. 53a). The evidence for subsequent ocean floor processes that may have affected the primary remanent magnetization prior to subduction of the Goropu Metabasalt was erased by metamorphism and is unconstrained in this study (Fig. 53a). As the Goropu Metabasalt was subducted and metamorphosed, primary magnetite was progressively consumed by the growth of paramagnetic phases, and lost Ti content, during metamorphic reactions, resulting in a net decrease in the remaining fraction of titanomagnetite and a corresponding reduction in the intensity of the magnetization carried by the Goropu Metabasalt (Fig. 53b). The primary magnetization of the Goropu Metabasalt may have been overprinted due to unknown thermochemical effects, or due to significant abundances of PSD or MD grains in the samples (Fig. 53b). Subsequently the footwall metabasalt was remagnetized during exhumation and cooling of the footwall Goropu Metabasalt (Fig. 53c-e). Samples farthest from the fault trace were exhumed prior to the Brunhes chron and subsequently consist of only a single, 
reversed polarity overprint (Fig. 53c-d). It is unknown whether a primary magnetization is present in these samples. Samples from Group 2 were partially exhumed when the field reversed polarity $\sim 780,000$ years ago (Fig. 53d). As a consequence, they carry a reversed polarity component in the higher blocking temperature range (Fig. 53d). Group 1 and 2 samples carry a normal polarity component of magnetization in the lower blocking temperature range that was acquired as the samples were exhumed during the Brunhes chron (this component is carried to much higher unblocking temperatures in Group 1 samples) (Fig. 53d-e). The Mai'iu fault is inferred to have followed a rolling hinge evolution as indicated by the paleomagnetic data presented in this study. This process is inferred to have produced an overall net shallowing of the fault from $\sim 41-49^{\circ}$ (at depths of $<9 \mathrm{~km}$ ) to the $<20-22^{\circ}$ dip we observe today at the surface and the $30-40^{\circ}$ dip at depths of 10-25 km that is inferred from microseismicity (Fig. 53c-e). The reversed component in Group 2 samples is steeper than the normal component in the same samples because it is older, and likely to have recorded more rotation (Fig. 53d-e).

\footnotetext{
Figure 53: Summary of the geological history of the Mai'iu fault, as partially inferred from paleomagnetic data. A) Formation of the Goropu Metabasalt in the Cretaceous and acquirement of a primary TRM. Ocean floor processes (such as hydrothermal alteration and seafloor weathering) that subsequently affected the primary remanence prior to metamorphism are unknown. B) Subduction of the Goropu Metabasalt in the Eocene. Primary magnetite was mostly consumed and lost most of its titanium in metamorphic reactions. We suggest that the primary magnetization was most likely overprinted during this metamorphic event. C) Extensional reactivation of the Mai'iu fault. The dip of the fault is constrained to be more than $41.3-48.5^{\circ}$ based on the paleomagnetic results of this study. D) Sample 15-13a is exhumed prior to the last geomagnetic field polarity reversal and contains only a reversed component metamorphic overprint. Group 2 samples are only partially exhumed and acquire a reversed component of magnetization in the higher blocking temperature spectrum. E) Group 1 and 2 samples are exhumed to the surface and preserve a normal polarity component in the lower blocking temperature range. The temperature that this component is carried to decreases with increasing distance from the fault trace. This reflects the relative temperatures the samples were at when the geomagnetic field reversed polarity.
} 


\section{A) Late Cretaceous - Paleocene}

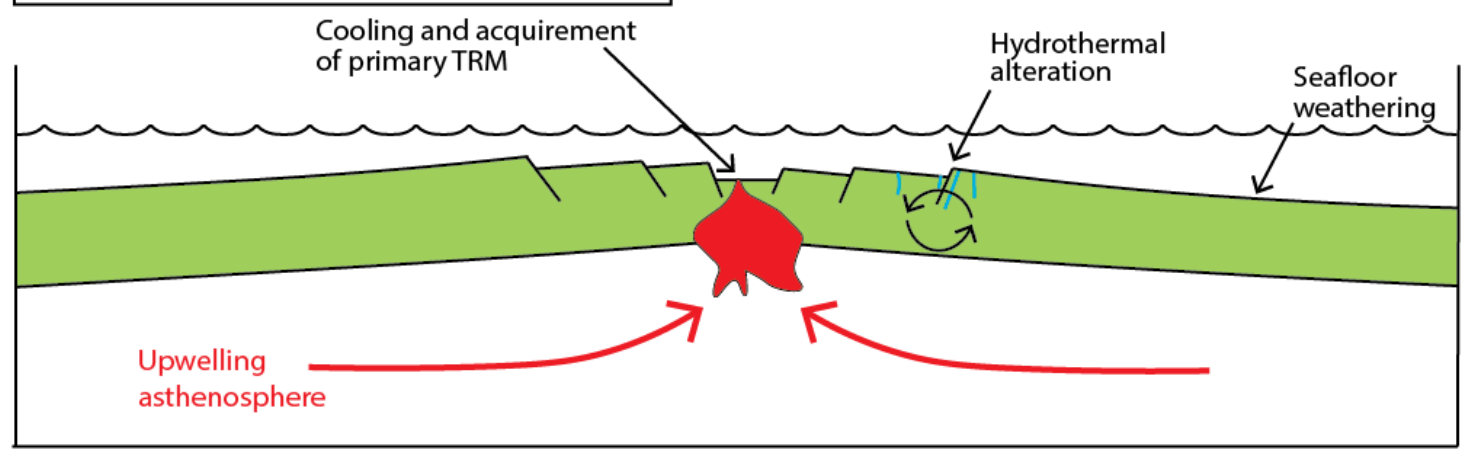

\section{B) Eocene}
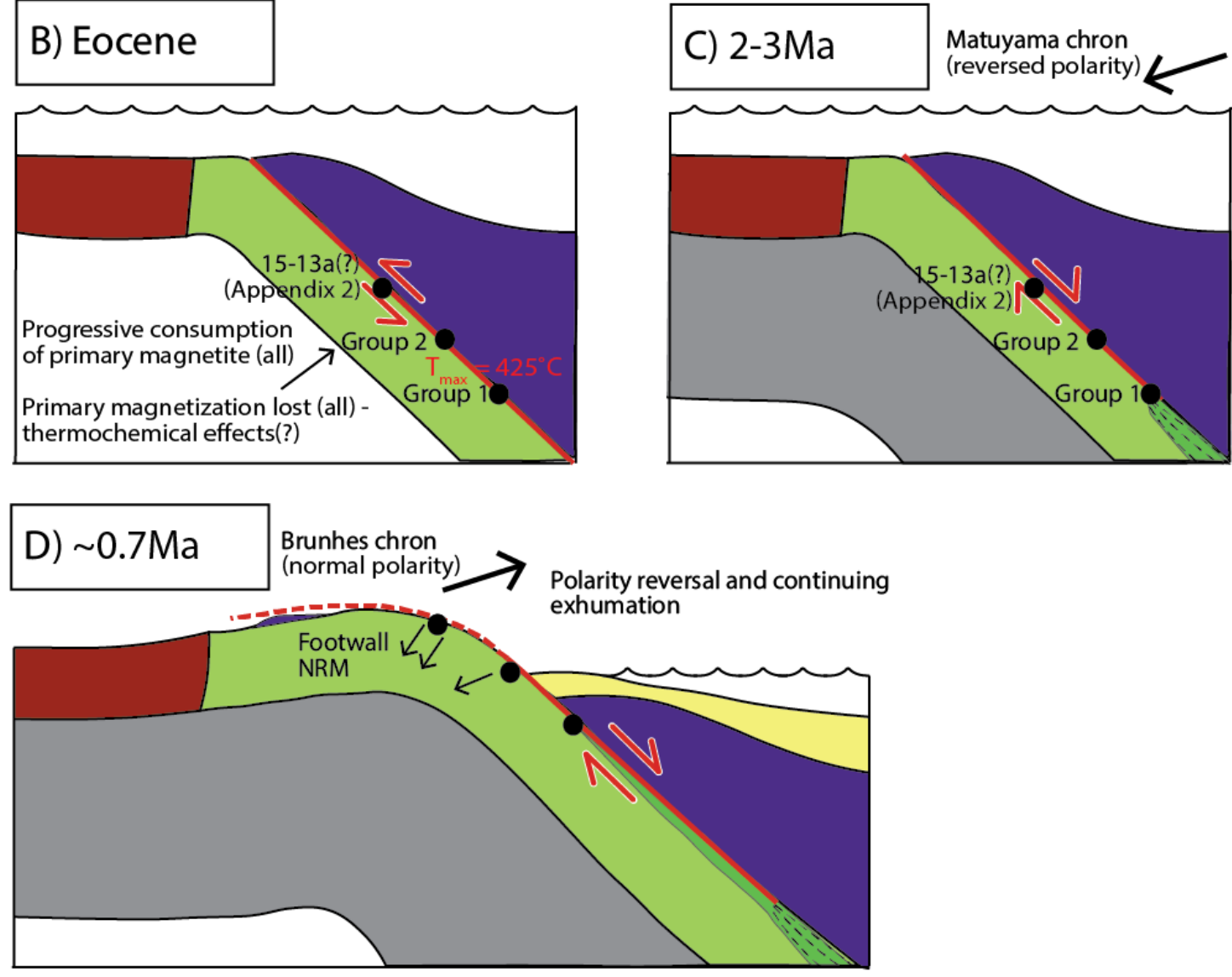

\section{E) Present Day \\ Brunhes chron \\ (normal polarity)}

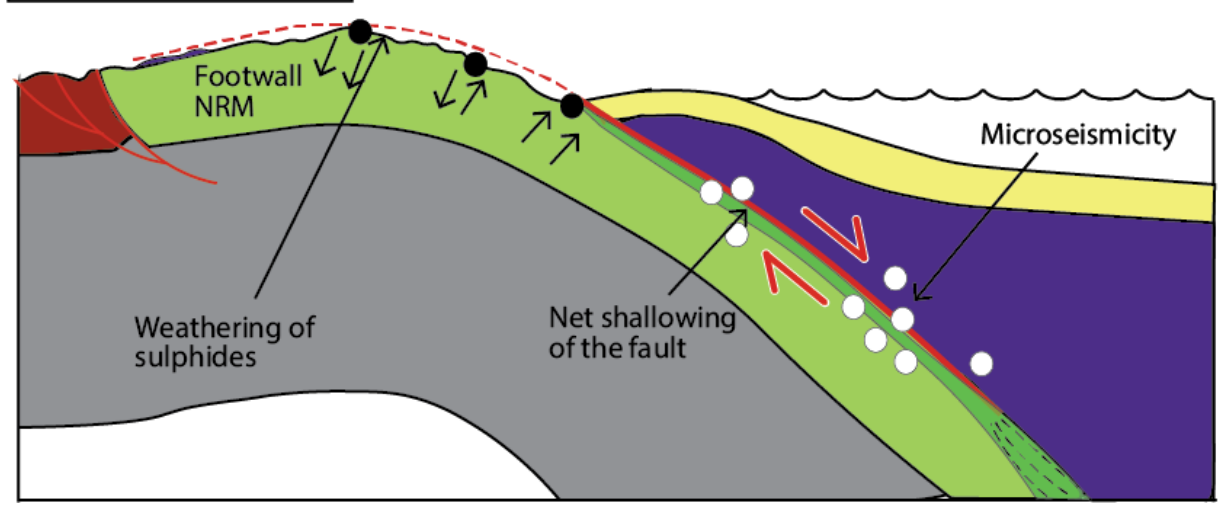




\section{References}

Abbot, L., Silver, E. \& Galewsky, J. (1994). Structural evolution of a modern arc-continent collision in Papua New Guinea. Tectonics, 13, 1007-1034.

Abbott, R., Louie, J., Caskey, S. \& Pullammanappallil, S. (2001). Geophysical confirmation of low-angle normal slip on the historically active Dixie Valley fault, Nevada. Journal of Geophysical Research, 106(B3), 4169-4181.

Abers, G. (1991). Possible seismogenic shallow-dipping normal faults in the Woodlark-D'Entrecasteaux extensional province. Geology, 19, 1205-1208.

Abers, G., Mutter, C. \& Fang, J. (1997). Shallow dips of normal faults during rapid extension: Earthquakes in the Woodlark-D'Entrecasteaux rift system, Papua New Guinea. Journal of Geophysical Research, 102(15), 301-15, 317.

Abers, G., Ferris, A., Craig, M., Davies, H., Lerner-Lam, A., Mutter, J. \& Taylor, B. (2002). Mantle compensation of active metamorphic core complexes at Woodlark rift in Papua New Guinea. Nature, 418, 862-865.

Abers, G., Eilon, Z., Gaherty, J., Jin, G., Kim, Y.-S., Obrebski, M. \& Dieck, C. (2016). Southeast Papuan crustal tectonics: imaging extension and buoyancy of an active rift. Journal of Geophysical Research, 121(2), 951-971.

Ade-Hall, J., Palmer, H. \& Hubbard, T. (1971). The magnetic and opaque petrological response to regional hydrothermal alteration. Geophysical Journal of the Royal Astronomical Society, 24, 137-174.

Allerton, S. \& Tivey, M. (2001). Magnetic polarity structure of the lower oceanic crust. Geophysical Research Letters, 28, 423-426.

Anderson, E. (1951). The dynamics of faulting and dyke formation with applications to Britain. Edinburgh: Oliver and Boyd.

Axen, G. (1992). Pore pressure, stress increase, and fault weakening in low angle normal faulting. Journal of Geophysical Research, 97(B6), 8979-8991.

Axen, G. \& Selverstone, J. (1994). Stress-state and fluid-pressure level along the Whipple detachment fault, California. Geology, 22, 835-838.

Axen, G. \& Bartley, J. (1997). Field tests of rolling hinges: Existence, mechanical types and implications for extensional tectonics. Journal of Geophysical Research, 102(B9), 20515-20537.

Axen, G. (2004). Mechanics of low-angle normal faults. In Rheology and deformation in the lithosphere at continental margins, Karner, G. et al. New York, NY: Columbia University Press.

Baines, A., Cheadle, M., Dick, H., Scheirer, A., John, B., Kusznir, N. \& Matsumoto, T. (2003). Mechanism for generating the anomalous uplift of oceanic core complexes: Atlantis Bank, southwest Indian Ridge. Geology, 31(12), 1105-1108.

Baldwin, S. \& Hill, E. (1993). Exhumation of high-pressure metamorphic rocks during crustal extension in the D'Entrecasteaux region, Papua New Guinea. Journal of Metamorphic Geology, 11, 261277.

Baldwin, S., Morteleone, B., Webb, L., Fitzgerald, P., Grove, M. \& Hill, J. (2004). Pliocene eclogite exhumation at plate tectonic rates in eastern Papua New Guinea. Nature, 431, 263-267.

Baldwin, S., Webb, L. \& Monteleone, B. (2008). Late Miocene coesite-eclogite exhumed in the Woodlark Rift. Geology, 36, 735-738.

Bartley, J. \& Wernicke, B. (1984). The Snake Range decollement interpreted as a major extensional shear zone. Tectonics, 3, 647-657.

Bartley, J., Fletcher, J. \& Glazner, A. (1990). Tertiary extension and contraction of lower-plate rocks in the Central Mojave metamorphic core complex, southern California. Tectonics, 9, 521-534.

Beiersdorfer, R. \& Day, H. (1995). Mineral paragenesis of pumpellyite in low-grade mafic rocks. Geological Society of America Special Paper, 296, 5-27.

Benes, V., Scott, S. \& Binns, R. (1994). Tectonics of rift propagation into a continental margin: Western Woodlark Basin, Papua New Guinea. Journal of Geophysical Research, 99, 4439-4455.

Bernard, P. et al. (1997). The $\mathrm{M}_{\mathrm{s}}=6.2$ June 15, 1995 Aigion earthquake (Greece): evidence for low angle normal faulting in the Corinth rift. Journal of Seismology, 1, 131-150. 
Biemiller, J., Ellis, S., Mizera, M., Little, T., Wallace, L. \& Lavier, L. (in review). The effect of tectonic inheritance on metamorphic core complex formation following failed subduction of continental crust. Earth and Planetary Science Letters.

Blackman, D., Cann, J., Janssen, B. \& Smith, D. (1998). Origin of extensional core complexes: Evidence from the Mid-Atlantic Ridge at Atlantis Fracture Zone. Journal of Geophysical Research, 103(B9), 21315-21333.

Boncio, P., Brozzetti, F. \& Lavecchia, G. (2000). Architecture and seismotectonics of a regional lowangle normal fault zone in central Italy. Tectonics, 19(6), 1038-1055.

Borradaile, G. (1993). The rotation of magnetic grains. Tectonophysics, 221(3-4), 381-384.

Borradaile, G. (1997). Deformation and Paleomagnetism. Surveys in Geophysics, 18, 405-435.

Buck, R. (1988). Flexural rotation of normal faults. Tectonics, 7(5), 959-973.

Burzyński, M., Michalski, K., Nejbert, K., Domańska-Siuda, J. \& Manby, G. (2017). High-resolution mineralogical and rock magnetic study of ferromagnetic phases in metabasites from Oscar II Land, Western Spitsbergen - towards reliable model linking mineralogical and paleomagnetic data. Geophysical Journal International, 210, 390-405.

Butler, R. (1992). Paleomagnetism: Magnetic Domains to Geologic Terranes. Hoboken, NJ: Blackwell Science Inc.

Byerlee, J. (1978). Friction of rocks. Pure and Applied Geophysics, 116(4-5), 615-626.

Caffi, P. (2008). Evolution of an active metamorphic core complex, Suckling-Dayman Massif, southeast Papua New Guinea (B. Sc (Honour's) Thesis, Macquarie University).

Cairns, E., Little, T., Turner, G., Wallace, L. \& Ellis, S. (2015). Paleomagnetic evidence for vertical axis rotations of crustal blocks in the Woodlark Rift SE Papua New Guinea: Miocene to present-day kinematics in one of the world's most rapidly extending plate boundary zones. Geochemistry Geophysics Geosystems, 16(7), 2058-2081.

Cann, J., Blackman, K., Smith, D., McAllister, E., Janssen, B., Mello, S. Avgerinos, E., Pascoe, A. \& Escartin, J. (1997). Corrugated slip surfaces formed at ridge-transform intersections on the MidAtlantic ridge. Nature, 385, 329-332.

Caskey, S., Wesnousky, S., Zhang, P. \& Slemmons, D. (1996). Surface faulting of the 1954 Fairview Peak ( $\mathrm{M}_{\mathrm{s}}$ 7.2) and Dixie Valley $\left(\mathrm{M}_{\mathrm{s}}\right.$ 6.8) earthquakes, central Nevada. Bulletin of the Seismological society of America, 86, 761-787.

Cassidy, K. \& Groves, D. (1988). Manganoan ilmenite formed during regional metamorphism of Archean mafic and ultramafic rocks from Western Australia. The Canadian Mineralogist, 26, 999-1012.

Chadima, M. \& Hrouda, F. (2006). Remasoft 3.0: A user-friendly paleomagnetic data browser and analyser. Travaux Geophysiques, XXVII, 20-21.

Chiaraluce, L., Chiarabba, C., Collettini, C., Piccinini, D. \& Cocco, M. (2007). Architecture and mechanics of an active low-angle normal fault: Alto Tiberina Fault, northern Apennines, Italy. Journal of Geophysical Research, 112(B10), B10310.

Christie, D., West, B., Pyle, D. \& Hanan, B. (1998). Chaotic topography, mantle flow and mantle migration in the Australian-Antarctic Discordance. Nature, 394, 637-644.

Clark, D. (1997). Magnetic petrophysics and magnetic petrology: aids to geological interpretation of magnetic surveys. Journal of Australian Geology \& Geophysics, 17(2), 83-103.

Collettini, C. \& Sibson, R. (2001). Normal faults, normal friction? Geology, 29, 927-930.

Collettini, C., Niemiejer, A., Viti, C. \& Marone, C. (2009). Fault zone fabric and fault weakness. Nature, 462(7275), 907-910.

Collettini, C. (2011). The mechanical paradox of low-angle normal faults: Current understanding and open questions. Tectonophysics, 510(3), 253-268.

Cooper, F., Platt, J., Platzman, E., Grove, M. \& Seward, G. (2010). Opposing shear senses in a subdetachment mylonite zone: Implications for core complex mechanics. Tectonics, 29, TC4019.

Cornell, R. \& Schwertmann, U. (1996). The iron oxides: structure, properties, reactions, occurrences and uses. New York, NY: VHC.

Craig, J. \& Vaughan, D. (1981). Ore Microscopy. Hoboken, NJ: Wiley.

Crittenden, M., Coney, P. \& Davis, G. (1980). GSA Memoirs: Cordilleran Metamorphic Core Complexes. Boulder, CO: The Geological Society of America. 
Daczko, N., Caffi, P., Halpin, J. \& Mann, P. (2009). Exhumation of the Dayman Dome metamorphic core complex, eastern Papua New Guinea. Journal of Metamorphic Geology, 27, 405-422.

Daczko, N., Caffi, P. \& Mann, P. (2011). Structural evolution of the Dayman dome metamorphic core complex, eastern Papua New Guinea. GSA Bulletin, 123(11/12), 2335-2351.

Davies, H. \& Smith, I. (1971). Geology of Eastern Papua: A synthesis. Geological Society of America Bulletin, 82, 8299-8312.

Davies, H. \& Smith, I. (1974). Tuffi-Cape Nelson, Papua New Guinea. Australian Government Publishing Service, Sheet SC/55-8, 4 (scale 1:250,000, Map and booklet), 34.

Davies, H. (1980). Folded thrust fault and associated metamorphics in the Suckling-Dayman Massif, Papua New Guinea. American Journal of Science, 280-A, 171-191.

Davies, H. \& Jaques, A. (1984). Emplacement of ophiolite in Papua New Guinea. Geological Society, London, Special Publications, 13, 341-349.

Davies, H., Symonds, P. \& Ripper, I. (1984). Structure and evolution of the southern Solomon Sea region. Bureau of Mineral Resources, Australian Journal of Geology and Geophysics, 9, 49-68.

Davies, H. \& Warren, R. (1988). Origin of eclogite-bearing, domed, layered metamorphic complexes (“core complexes") in the D'Entrecasteaux Islands, Papua New Guinea. Tectonics, 7(1), 1-21.

Davis, G. \& Coney, P. (1979). Geologic development of the Cordilleran metamorphic core complexes. Geology, 7(3), 120-124.

Davis, G. (1988). Rapid upward transport of mid-crustal mylonitic gneisses in the footwall of the Miocene detachment fault, Whipple Mountains, southeastern California. Geologische Rundschau, 77, 191-209.

Davis, G. \& Lister, G. (1988). Detachment faulting in continental extension; Perspectives from the Southwestern U.S. Cordillera. In S Clark Jr, B Burchfiel, J Suppe, Processes in Continental Lithospheric Deformation (133-159). Boulder, CO: The Geological Society of America.

Deenen, M., Langereis, C., van Hinsbergen, D. \& Biggin, A. (2011). Geomagnetic secular variation and the statistics of paleomagnetic directions. Geophysical Journal International, 186, 509- 520.

DesOrmeau, J., Gordon, S., Little, T., Bowring, S. \& Chatterjee, N. (2017). Rapid timescale of Earth's youngest known ultrahigh-pressure metamorphic event. Geology, 45, 795-798.

Dick, H. et al. (2000). A long in situ section of the lower ocean crust: results of ODP Leg 167 drilling at the Southwest Indian Ridge. Earth and Planetary Science Letters, 179(1), 31-51.

Dokka, R. (1993). Original dip and subsequent modification of a Cordilleran detachment fault, Mojave extensional belt. Geology, 21, 711-714.

Dorsey, R. \& Becker, U. (1995). Evolution of a large Miocene growth structure in the upper plate of the Whipple detachment fault, north-eastern Whipple Mountains, California. Basin Research, 7, 151-163.

Dunlop, D. \& Ozdemir, D. (1993). Thermal demagnetization of VRM and pTRM: No evidence for anomalously high unblocking temperatures. Geophysical Research Letters, 20(18), 1939-1942.

Dunlop, D. \& Ozdemir, D. (1997). Rock magnetism: fundamentals and frontiers. Cambridge, NY: Cambridge University Press.

Eilon, Z., Aber, G., Gaherty, J. \& Jin, G. (2015). Imaging continental breakup using teleseismic body waves: The Woodlark Rift, Papua New Guinea. Geochemistry Geophysics Geosystems, 16(8), 2529-2548.

Eneroth, E. (2002). Preservation of a magnetization carried by magnetite-inclusions during amphibolite grade metamorphic conditions? An example from Sarek Dykeswarm, Northern Swedish Caledonides. Geophysical Journal International, 150, 65-78.

Evans, M. \& Wayman, M. (1970). An investigation of small magnetic particles by electron microscopy. Earth and Planetary Science Letters, 9(4), 365-370.

Ferris, A., Abers, G., Zelt, B., Taylor, B. \& Roecker, S. (2006). Crustal structure across the transition from rifting to spreading: The Woodlark Rift system of Papua New Guinea. Geophysical Journal International, 166(2), 622-634.

Fisher, R. (1953). Dispersion on a sphere. Proceeds of the Royal Society of London, Series A(217), 295305. 
Fletcher, J., Bartley, J., Martin, M., Glazner, A. \& Walker, J. (1995). Large-magnitude continental extension: An example from the central Mojave metamorphic core complex. Geological Society of America Bulletin, 107, 1468-1483.

Floyd, J., Mutter, J., Goodliffe, A. \& Taylor, B. (2001). Evidence for fault weakness and fluid flow within an active low-angle normal fault. Nature, 411, 779-783.

Gaina, C., Muller, R., Royer, J. \& Symonds, P. (1999). Evolution of the Louisiade triple junction. Journal of Geophysical Research, 104(B6), 12927-12939.

Gans, P. \& Gentry, B. (2017). Dike emplacement, footwall rotation, and the transition from magmatic to tectonic extension in the Whipple Mountains metamorphic core complex, southeastern California. Tectonics, 35, 2564-2608.

Garcés, M. \& Gee, J. (2007). Paleomagnetic evidence of large footwall rotations associated with lowangle faults at the Mid-Atlantic Ridge. Geology, 35(3), 279-282.

Gautier, P., Brun, J. \& Jolivet, L. (1993). Structure and kinematics of upper Cenozoic extensional detachment on Naxos and Paros (Cyclades Islands, Greece). Tectonics, 12(5), 1180-1194.

Gialanella, S., Girardi, F., Ischia, G., Lonardelli, I., Mattarelli, M. \& Montagna, M. (2010). On the goethite to hematite phase transformation. Journal of Thermal Analysis and Calorimetry, 102, 867-873.

Gordon, S., Little, T., Hacker, B., Bowring, S., Korchinski, M., Baldwin, S., Kylander-Clark, A. \& Millet, M. (2012). Multi-stage exhumation of young UHP-HP rocks: timescales of melt crystallization in the D'Entrecasteaux Islands, southeastern Papua New Guinea. Earth and Planetary Science Letters, 351-352, 237-246.

Graham, J. (1956). Paleomagnetism and magnetostriction. Journal of Geophysical Research, 61(4), 735739.

Grant, F. (1984). Aeromagnetics, geology and ore environments I. Magnetite in igneous, sedimentary and metamorphic rocks: An overview. Geoexploration, 23, 303-333.

Hamilton, W. (1988). Extensional faulting in the Death Valley region. Geological Society of America Abstracts with Programs, 20, 165-166.

Hargraves, R. \& Young, W. (1969). Source of stable remanent magnetism in Lambertville diabase. American Journal of Science, 267, 1161-1177.

Hattori, I. \& Hirooka, H. (1979). Paleomagnetic results from Permian greenstones in central Japan and their geologic significance. Tectonophysics, 57(2-4), 211-235.

Hayes, G., Wald, D. \& Johnson, R. (2012). Slab1.0: A three-dimensional model of global subduction zone geometries. Journal of Geophysical Research, 117(B1), B01302.

Hayman, N., Knott, J., Cowan, D., Nemser, E., Sarna-Wojcicki, A. (2003). Quaternary low-angle slip on detachment faults in Death Valley, California. Geology, 31(4), 343-346.

Hayman, N., Grindlay, N., Perfit, M., Mann, P., Leroy, S. \& Mercier de Lepinay, B. (2011). Oceanic core complex development at the ultraslow spreading Mid-Cayman Spreading Center. Geochemistry, Geophysics, Geosystems, 12(3), 1-21.

Hoisch, T., Heizler, M. \& Zartmen, R. (1997). Timing of detachment faulting in the Bullfrog Hills and Bare Mountain area, southwest Nevada: Inferences from ${ }^{40} \mathrm{Ar} /{ }^{39} \mathrm{Ar}, \mathrm{U}-\mathrm{Pb}$, and fission-track thermochronology. Journal of Geophysical Research, 102, 2815-2833.

Holder, R. \& Holder, G. (1988). The Colville Batholith: Tertiary plutonism in northeast Washington associated with graben and core-complex (gneiss dome) formation. Geological Society of America Bulletin, 100, 1971-1980.

Holm, D. \& Wernicke, B. (1992). Black Mountains crustal section, Death Valley extended terrain, California. Geology, 18, 520-523.

Holm, D. \& Dokka, R. (1993). Interpretation and tectonic implications of cooling histories: An example from the Black Mountains, Death Valley extended terrane, California. Earth and Planetary Science Letters, 116, 63-80.

Holm, D., Geissman, J. \& Wernicke, B. (1993). Tilt and rotation of the footwall of a major normal fault system: Paleomagnetism of the Black Mountains, Death Valley extended terrane, California. Geological Society of America Bulletin, 105, 1373-1387.

Holm, D., Fleck, R. \& Lux, D. (1994). The Death Valley turtlebacks reinterpreted Miocene-Pliocene folds of a major detachment surface. Journal of Geology, 102, 718-727. 
Holm, D. (1995). Relation of deformation and multiple intrusion in the Death Valley extended region, California, with implications for magma entrapment mechanism. Journal of Geophysical Research, 10,495 - 10,505.

Howard, K. \& John, B. (1987). Crustal extension along a rooted system of imbricate low-angle faults: Colorado River extensional corridor, California and Arizona. In Coward, M., Dewey, J. \& Hancock, P. (eds.) Continental extensional tectonics, London: Blackwell Scientific Publications.

Ikari, M., Marone, C. \& Saffer, D. (2012). On the relation between fault strength and frictional stability. Geology, 39, 83-86.

Jackson, J. \& White, N. (1989). Normal faulting in the upper continental crust: observations from regions of active extension. Journal of Structural Geology, 11, 15-36.

Jaeger, J. \& Cook, N. (1979). Fundamentals of rock mechanics. $3^{\text {rd }}$ ed. London: Chapman and Hall.

Jaques, A. \& Robinson, B. (1977). The continent/island arc collision in Northern Papua New Guinea. Journal of Australian Geology and Geophysics, 2, 289-303.

Jaques, A. (1981). Petrology and petrography of cumulate peridotite and gabbro from the Marum Ophiolite, Papua New Guinea. Journal of Petrology, 22, 1-40.

Jarosewich, E., Nelen, J. \& Norberg, J. (1980). Reference samples for electron microprobe analysis. Geostandards Newsletter, 4(1), 43-47.

John, B. (1987). Geometry and evolution of a mid-crustal extensional fault system: Chemehuevi Mountains, Southeastern California. Geological Society, London, Special Publications, 28, 313335.

John, B. \& Foster, D. (1993). Structural and thermal constraints on the initiation angle of detachment faulting in the southern Basin and Range: Chemehuevi Mountains case study. Geological Society of America Bulletin, 105, 1091-1108.

Jolivet, L. Labrousse, L., Agard, P., Bailly, V., Lecomte, E., Mouthereau, M. \& Mehl, C. (2010). Rifting and shallow-dipping detachments, clues from the Corinth Rift and the Aegean. Tectonophysics, 483(3), 287-304.

Kent, D. (1985). Thermoviscous remagnetization in some Appalachian limestones. Geophysical Research Letters, 12, 805-808.

Kern, J. (1961). Stress stability of remanent magnetization. Journal of Geophysical Research, 66(11), 3817-3820.

Kirschvink, J. (1980). The least-squares line and plane and the analysis of paleomagnetic data. Geophysical Journal International, 62, 699-718.

Klein, C. \& Hurlbut, C. (1985). Manual of Mineralogy, $20^{\text {th }}$ ed. Hoboken, NJ: Wiley.

Koons, P. (1987). Some thermal and mechanical consequences of rapid uplift: An example from the Southern Alps, New Zealand. Earth and Planetary Science Letters, 86(2-4), 307-319.

Laird, J. (198). Phase equilibria in mafic schists from Vermont. Journal of Petrology, 21, 1-37.

Lattard, D., Engelmann, R., Kontny, A. \& Sauerzapf, U. (2006). Curie temperatures of synthetic titanomagnetites in the Fe-Ti-O system: Effects of composition, crystal chemistry, and thermomagnetic methods. Journal of Geophysical Research, 111(B12), B12S28.

Lecomte, E., Huet, B., Le Pourhiet, L., Labrousse, L. \& Jolivet, L. (2010). Extension in the Aegean Nappe-stacks: numerical model and their geological validation. Proceedings AGU Fall Meeting Abstracts, 1, 2299.

Lee, J. (1995). Rapid uplift and rotation of mylonitic rocks from beneath a detachment fault: Insights from potassium feldspar ${ }^{40} \mathrm{Ar} /{ }^{39} \mathrm{Ar}$ thermochronology, northern Snake Range, Nevada. Tectonics, 14, 54-77.

Lin, W., Faure, M., Monie, P. \& Panis, D. (2008). Mesozoic extensional tectonics in Eastern Asia: The south Liaodong Peninsula metamorphic core complex (NE China). The Journal of Geology, 116(2), 134-154.

Lister, G., Banga, G. \& Feenstra, A. (1984). Metamorphic core complexes of the Cordilleran type in the Cyclades, Aegean Sea, Greece. Geology, 12(4), 221-225.

Lister, G. \& Davis, G. (1989). The origin of metamorphic core complexes and detachment faults formed during tertiary continental extension in the northern Colorado River region, U.S.A. Journal of Structural Geology, 11(1/2), 65-94. 
Little, T., Baldwin, S., Fitzgerald, P. \& Monteleone, B. (2007). Continental rifting and metamorphic core complex formation ahead of the Woodlark spreading ridge, D'Entrecasteaux Islands, Papua New Guinea. Tectonics, 26, TC1002.

Little, T., Hacker, B., Gordon, S., Baldwin, S., Fitzgerald, P., Ellis, S. \& Korchinski, M. (2011). Diapiric exhumation of the of the world's youngest (UHP) eclogites in the gneiss domes of the D'Entrecasteaux Islands, Papua New Guinea. Tectonophysics, 510(1-2), 39-68.

Little, T., Webber, S., Mizera, M., Boulton, C., Oesterle, J., Ellis, S., Boles, A., van der Pluijm, J., Norton, K., Seward, D., Biemiller, J. \& Wallace, L. (2019). Evolution of a rapidly slipping, active low angle normal fault, Suckling-Dayman metamorphic core complex, SE Papua New Guinea. GSA Bulletin, doi: https:/ doi.org/10.1130/B35051.1.

Livaccari, R., Geissman, J. \& Reynolds, S. (1995). Large-magnitude extensional deformation in the South Mountains metamorphic core complex, Arizona. Geological Society of America Bulletin, 107(8), 877-894.

Livaccari, R. \& Geissman, J. (2001). Large-magnitude extension along metamorphic core complexes of Western Arizona and southeastern California: Evaluation with paleomagnetism. Tectonics, 20(5), 625-648.

Lowrie, W., Hirt, A. \& Kligfield, R. (1986). Effects of tectonic deformation on the remanent magnetization. Tectonics, 5(5), 713-722.

Lus, W., McDougall, I. \& Davies, H. (2004). Age of the metamorphic sole of the Papuan Ultramafic Belt ophiolite, Papua New Guinea. Tectonophysics, 392, 85-101.

MacLeod, C., Carlut, J., Escartin, J., Horen, H. \& Morris, A. (2011). Quantitative constraint on footwall rotations at the $1545^{\prime} \mathrm{N}$ oceanic core complex, Mid-Atlantic Ridge: Implications for oceanic detachment fault processes. Geochemistry Geophysics Geosystems, 12(5), 1-29.

Maffione, M., Morris, A \& Anderson, M. (2013). Recognizing detachment-mode seafloor spreading in the deep geological past. Nature Scientific Reports, 3, 2336.

Mann, P., Taylor, F., Lagoe, M., Quarles, A. \& Burr, G. (1998). Accelerating late Quaternary uplift of the New Georgia Island group (Solomon Island arc) in response to subduction of the recently active Woodlark Spreading centre and Coleman seamount. Tectonophysics, 295, 259-306.

Manning, A. \& Bartley, J. (1994). Postmylonitic deformation in the Raft River metamorphic core complex, northwestern Utah: Evidence of a rolling hinge. Tectonics, 13(3), 596-612.

Martinez-Martinez, J., Soto, J. \& Balanya, J. (2002). Orthogonal folding of extensional detachments: Structure and origin of the Sierra Nevada elongated dome (Betics, SE Spain). Tectonics, 21(3), 3 $-1-3-20$.

McFadden, P. \& McElhinny, M. (1988). The combined analysis of remagnetization great circles and direct observations in paleomagnetism. Earth and Planetary Science Letters, 87(1-2), 161-172.

McGrew, A. \& Snee, L. (1994). ${ }^{40} \mathrm{Ar} /{ }^{39} \mathrm{Ar}$ thermochronologic constraints on the tectonothermal evolution of the northern east Humboldt Range metamorphic core complex, Nevada. Tectonophysics, 238, 425-450.

Mizera, M., Little, T., Biemiller, J., Ellis, S., Norton, K. \& Webber, S. (in review). Structural and geomorphic evidence for rolling-hinge style deformation in the footwall of a continental active low angle normal fault, Mai'iu Fault, Woodlark Rift, SE Papua New Guinea. Tectonics.

Moore, D., Lockner, D. \& Hickman, S. (2016). Hydrothermal frictional strengths of rock and mineral samples relevant to the creeping section of the San Andreas Fault. Journal of Structural Geology, 89, 153-167.

Morris, A., Gee, J., Pressling, N., John, B., MacLeod, C., Grimes, C. \& Searle, R. (2009). Footwall rotation in an oceanic core complex quantified using reoriented Integrated Oceanic Drilling Program core samples. Earth and Planetary Science Letters, 287(1-2), 217-228.

Murad, E. (1979). Mossbauer spectra of goethite: evidence for structural imperfections. Mineralogical Magazine, 43, 355-361.

Murphy, M. (2007). Isotopic characteristics of the Gurla Mandhata Metamorphic core complex: Implications for the architecture of the Himalayan orogen. Geology, 35(11), 983-986.

Murphy, G., Patzold, R. \& Brown, C. (1981). Source of stable remanence in certain intrusive rocks. Physics of the Earth and Planetary Interior, 26, 72-80. 
Mutter, J., Mutter, C. \& Fang, J. (1996). Analogies to oceanic behaviour in the continental breakup of the western Woodlark basin. Nature, 380, 333-336.

Néel, L. (1955). Some theoretical aspects of rock magnetism. Advanced Physics, 4, 191-242.

Numelin, T., Marone, C. \& Kirby, E. (2007). Frictional properties of natural fault gouge from a low-angle normal fault, Panamint Valley, California. Tectonics, 26(2), TC2004.

Oesterle, J., Seward, D., Little, T. \& Stockli, D. (2018). The evolution of an actively exhuming metamorphic core complex, the Suckling-Dayman massif in Papua New Guinea. Thermo $2018-$ $16^{\text {th }}$ International Conference on Thermochronology, 16-21 September, 2018, Quedlinburg, Germany, Abstract Volume, Page 150.

Pariso, J., Scott, J., Kikawa, E. \& Johnson, H. (1991). A magnetic logging study of Hole 735B gabbros at the Southwest Indian Ridge. Proceedings of the Ocean Drilling Program Scientific Results, 118, 309-321.

Parrish, R., Carr, S. \& Parkinson, D. (1988). Eocene extensional tectonics and geochronology of the southern Omineca Belt, British Columbia and Washington. Tectonics, 7, 181-212.

Petersen, K. \& Buck, W. (2015). Eduction, extension and exhumation of ultrahigh-pressure rocks in metamorphic core complexes due to subduction initiation. Geochemistry Geophysics Geosystems, 16, 2564-2581.

Pettigrew, T. et al. (1999). Proceedings of the Ocean Drilling Program, Initial Reports, 179. College Station, TX: Ocean Drilling Program.

Platt, J., Behr, W. \& Cooper, F. (2014). Metamorphic core complexes: windows into the mechanics and rheology of the crust. Journal of the Geological Society, 172, 9-27.

Proffett, J. (1977). Cenozoic geology of the Yerington district, Nevada, and implications for the nature and origin of Basin and Range faulting. Geological Society of America Bulletin, 88, 247-266.

Pullaiah, G., Irving, E., Buchan, K. \& Dunlop, D. (1975). Magnetization change caused by burial and uplift. Earth and Planetary Science Letters, 28(2), 133-143.

Quin, T., Long, G., Benson, C., Mann, S. \& Williams, R. (1988). Influence of silicon and phosphorous on structural and magnetic properties of synthetic goethite and related oxides. Clay and Clay Minerals, 36(2), 165-175.

Ranero, C. \& Reston, T. (1999). Detachment faulting at ocean core complexes. Geology, 27-983-986.

Reitbrock, A., Tiberi, C., Scherbaum, F. \& Lyon-Caen, H. (1996). Seismic slip on a low-angle normal fault in the Gulf of Corinth: Evidence from high-resolution cluster analysis of microearthquakes. Geophysical Research Letters, 23, 1817-1820.

Rigo, A., Lyon-Caen, H., Armijo, R., Deschamps, A., Hatzfeld, D., Makropoulos, A., Papadimitriou, P. \& Kassaras, I. (1996). A microseismic study in the western part of the Gulf of Corinth (Greece): Implications for large-scale normal faulting mechanisms. Geophysical Journal International, 126, 663-688.

Rochette, P., Fillion, G., Mattéi, J. \& Dekkers, M. (1990). Magnetic transition at 30-40 Kelvin in pyrrhotite: insight into a widespread occurrence of this mineral in rocks. Earth and Planetary Science Letters, 98, 319-328.

Rogerson, R., Queen, L. \& Francis, G. (1993). The Papuan Ultramafic Belt arc complex. In Wheller, G. (ed.), Islands and basins: correlation and comparison of onshore and offshore geology. CCOP/SOPAC Miscellaneous Report, 159, 28-29.

Selverstone, J., Axen, G. \& Bartley, J. (1995). Fluid inclusion constraints on the kinematics of footwall uplift beneath the Brenner Line normal faults, eastern Alps. Tectonics, 14, 264-278.

Smith, I. \& Davies, H. (1976). Geology of the Southeast Papuan Mainland. Australian Bureau of Mineral Resources Bulletin, 165.

Smith, I. (2013). The chemical characterization and tectonic significance of ophiolite terrains in southeastern Papua New Guinea. Tectonics, 32(2), 159-170.

Speckbacher, R., Behrmann, J., Nagel, T., Stipp, M. \& Devey, C. (2011). Splitting a continent: Insights from submarine high-resolution mapping of the Moresby Seamount detachment, offshore Papua New Guinea. Geology, 39(7), 651-654.

Spencer, J. (1984). Role of tectonic denudation in warping and uplift of low-angle normal faults. Geology, 12, 95-98. 
Spencer, J. \& Chase, C. (1989). Role of crustal flexure in initiation of low-angle normal faults and implications for the structural evolution of the basin and range province. Journal of Geophysical Research, 94(B2), 1765-1775.

Spencer, J. \& Reynolds, S. (1989). Middle Tertiary tectonics of Arizona and adjacent areas. In Jenney, J. \& Reynolds, S. Geologic evolution of Arizona, Tucson, AZ: Geological Society Digest.

Spencer, J. (1999). Geologic continuous casting below continental and deep-sea detachment faults and at the striated extrusion at Sacsayhuaman, Peru. Geology, 27, 327-330.

Spencer, J. (2010). Structural analysis of three extensional detachment faults with data from the 2000 Space-Shuttle Radar Topography Mission. GSA Today, 20(8), 1-10.

Stacey, F. \& Banerjee, S. (1984). The Physical Principles of Rock Magnetism. Amsterdam: Elsevier.

Styron, R. \& Hetland, E. (2014). Estimated likelihood of observing a large earthquake on a continental low-angle normal fault and implications for low-angle normal fault activity. Geophysical Research Letters, 41(7), 2342-2350.

Taylor, B., Goodliffe, A., Martinez, F. \& Hey, R. (1995). Continental rifting and initial seafloor spreading in the Woodlark basin. Nature, 374, 534-537.

Taylor, B., Goodliffe, A. \& Martinez, F. (1999). How continents break-up: Insights from Papua New Guinea. Journal of Geophysical Research, 104, 7497-7512.

Taylor, B. \& Huchon, P. (2002). Active continental extension in the western Woodlark basin: a synthesis of Leg 180 results, in Huchon, P., Taylor, B. \& Klaus, A. (eds.), Proceedings of the Ocean Drilling Program, Scientific Results, 180, 1-36, College Station, TX: Ocean Drilling Program.

Thatcher, W. \& Hill, D. (1991). Fault orientations in extensional and conjugate strike-slip environments and their implications. Geology, 19, 1116-1120.

Thompson, R. \& Oldfield, F. (1986). Environmental Magnetism. Amsterdam: Springer.

Torsvik, T., Van der Voo, R., Preeden, U., Niocaill, C., Steinberger, B., Doubrovine, P., Hinsbergen, D., Domeier, M., Gaina, C., Tohver, E., Meert, J., McCausland, P. \& Cocks, R. (2012). Phanerozoic polar wander, paleogeography and dynamics. Earth Science Reviews, 114(3-4), 325-368.

Tregoning, P., Lambeck, K., Stolz, A., Morgan, P., McClusky, S., van der Beek, P., McQueen, H., Jackson, R., Little, R., Laing, A. \& Murphy, B. (1998). Estimation of current plate motions in Papua New Guinea from Global Positioning System observations. Journal of Geophysical Research, 103(B6), 12,181-12,203.

Tucholke, B., Lin, J. \& Kleinrock, M. (1998). Megamullions and mullion structure defining oceanic metamorphic core complexes on the Mid-Atlantic Ridge. Journal of Geophysical Research, 103(B5), 9857-9866.

Tudryn, A. \& Tucholka, P. (2004). Magnetic monitoring of thermal alteration for natural pyrite and greigite. Acta Geophysica Polonica, 52(4), 509-520.

Tulloch, A. \& Kimbrough, D. (1989). The Paparoa metamorphic core complex, New Zealand: Cretaceous extension associated with fragmentation of the Pacific margin of Gondwana. Tectonics, 8(6), 1217-1234.

Vadacca, L., Casarotti, E., Chiaraluce, L. \& Cocco, M. (2016). On the mechanical behaviour of a lowangle normal fault: the Alto Tiberina fault (northern Apennines, Italy) system case study. Solid Earth, 7, 1537-1549.

Walker, D. \& McDougall, I. (1982). ${ }^{40} \mathrm{Ar} /{ }^{39} \mathrm{Ar}$ and K-Ar dating of altered glassy volcanic rocks: The Dabi Volcanics, PNG. Geochimica et Cosmochimica Acta, 46, 2181-2190.

Wallace, L., Stevens, C., Silver, E., McCaffrey, R., Loratung, W., Hasiata, S., Stanaway, R., Curley, R., Rosa, R., Taugaloidi, J. (2004). GPS and seismological constraints on active tectonics and arccontinent collision in Papua New Guinea: Implications for mechanics of microplate rotations in a plate boundary zone. Journal of Geophysical Research, 109, B05404.

Wallace, L., Ellis, S., Little, T., Tregoning, P., Palmer, N., Rosa, R., Stanaway, R., Oa, J., Nidkombu, E. \& Kwazi, J. (2014). Continental breakup and UHP rock exhumation in action: GPS results from the Woodlark rift, Papua New Guinea. Geochemistry Geophysics Geosystems, 15, 4267-4290.

Webb, L., Baldwin, S., Little, T. \& Fitzgerald, P. (2008). Can microplate rotation drive subduction inversion? Geology, 36(10), 823-826. 
Webber, S. (2017). Using structural geology and cosmogenic nuclide dating to infer the slip rate and frictional strength of the active Ma'iu low angle normal fault, eastern Papua New Guinea (M. Sc Thesis Victoria University of Wellington, Wellington).

Webber, S., Norton, K., Little, T., Wallace, L. \& Ellis, S. (2018). How fast can low-angle normal faults slip? Insights from cosmogenic exposure dating of the active Mai'iu fault, Papua New Guinea. Geology, 46(3), 227-230.

Weissel, J. \& Watts, A. (1979). Tectonic evolution of the Coral Sea Basin. Journal of Geophysical Research, 84(B9), 4572-4582.

Weissel, J., Taylor, B. \& Karner, G. (1982). The opening of the Woodlark Basin, subduction of the Woodlark spreading system and the evolution of northern Melanesia since mid-Pliocene time. Tectonophysics, 87, 253-277.

Wernicke, B. (1981). Low angle normal faults in the Basin and Range Province: nappe tectonics in an extending orogen. Nature, 291, 645-648.

Wernicke, B \& Axen, G. (1988). On the role of isostasy in the evolution of normal fault systems. Geology, 16(9), 848-851.

Wernicke, B. (1995). Low-angle normal faults and seismicity: A review. Journal of Geophysical Research, 100(B10), 20,159-20,174.

Westaway, R. (2005). Active low-angle normal faulting in the Woodlark extensional province, Papua New Guinea: A physical model. Tectonics, 24(6), TC6003.

Whitney, D., Teyssier, C., Rey, P. \& Buck, R. (2013). Continental and oceanic core complexes. Geological Society of America Bulletin, 125(3/4), 273-298.

Winter, J. (2009). Principles of igneous and metamorphic petrology. Upper Saddle River, NJ: Prentice Hall.

Wintsch, R., Christoffersen, R. \& Kronenberg, A. (1995). Fluid-rock reaction weakening of fault zones. Journal of Geophysical Research, 100(B7), 13021-13032.

Woodhead, J., Hergt, J., Sandiford, M. \& Johnson, W. (2010). The big crunch: physical and chemical expressions of arc/continent collision in the western Bismarck arc. Journal of Volcanology and Geothermal Research, 190, 11-24.

Wu, Y., Fuller, M. \& Schmidt, V. (1974). Microanalysis of N.R.M. in a granodiorite intrusion. Earth and Planetary Science Letters, 23, 275-285.

Yin, A. (1989). Origin of regional, rooted low-angle normal faults: A mechanical model and its tectonic implications. Tectonics, 8(3), 469-482.

Zhao, X. \& Tominaga, M. (2009). Paleomagnetic and rock magnetic results from lower crustal rocks of IODP Site U1309: Implication for thermal and accretion history of the Atlantis Massif. Tectonophysics, 474(3), 435-448.

Zirakparvar, N., Baldwin, S. \& Vervoort, J. (2012). The origin and geochemical evolution of the Woodlark Rift, Papua New Guinea. Gondwana Research, 23, 931-943. 


\section{Appendix 1: Electronic Disk}

\section{Appendix 2: Anomalous Paleomagnetic Behaviour}

\section{NEAR FAULT TRACE SAMPLES}

Of the 18 samples measured from Biniguni Falls, 3 displayed behaviour that deviated from the typical behaviour (16-1151b, 16-1151c, 16-1151h).

\section{6-1151b}

Specimens from sample 16-1151b varied in strength from $10^{-3}$ and $10^{-4} \mathrm{~A} / \mathrm{m}$. Specimens taken from the top half of the sample and bottom half displayed varying paleomagnetic behaviour.

Specimens A2 - A4 carried a single, origin-bound magnetization that was northerly trending and very steeply inclined (Fig. 54; Table 7). This component was estimated using PCA between $\mathrm{NRM}-80^{\circ} \mathrm{C}$ to $350-450^{\circ} \mathrm{C}$ (Table 7). A sample average was computed by calculating a Fisher mean using the individual specimen directions. This direction is quoted in Table 7.

Specimens B2 - B4 (taken from the bottom half of the sample) carried a single reversed, southerly trending, steeply inclined component of magnetization (Fig. 54). This component was stable up to a blocking temperature of $300^{\circ} \mathrm{C}$, followed by an abrupt loss of almost all of the magnetization present in the specimens above $325-350^{\circ} \mathrm{C}$ (Fig. 54). This component was estimated using Fisher means between NRM- $80^{\circ} \mathrm{C}$ to $300^{\circ} \mathrm{C}$ (Table 7). Fisher means were used to compute an overall sample average from the individual specimen estimates. This direction is quoted in Table 7.

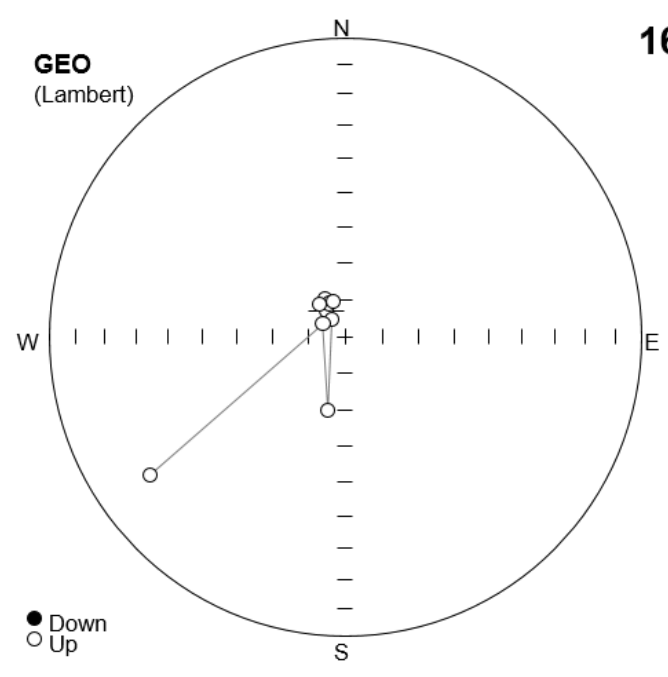

$16-1151 b A 2$

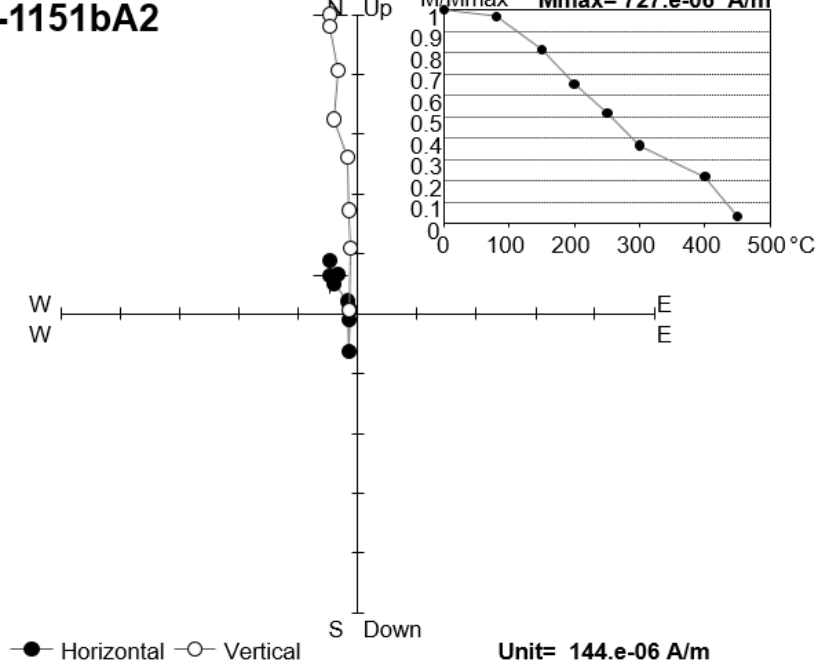




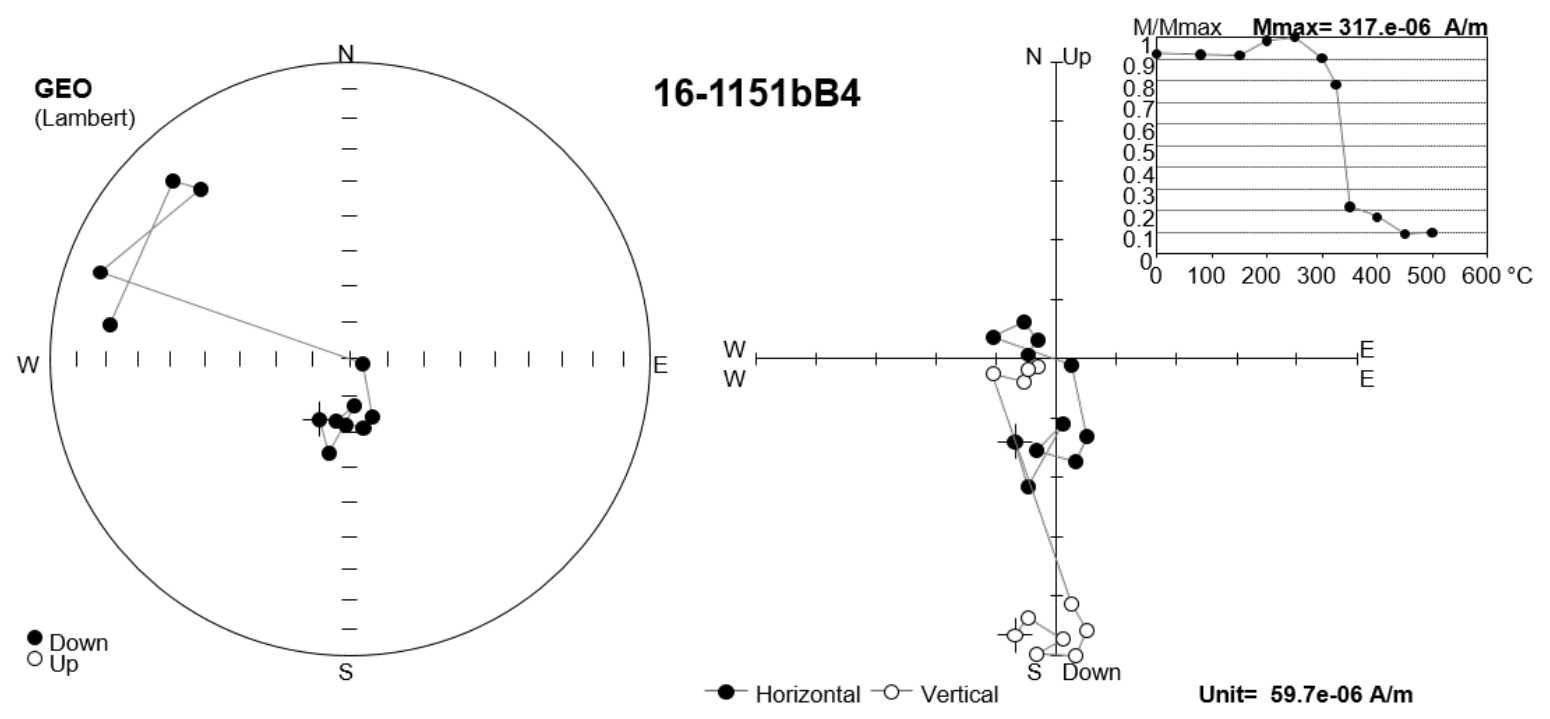

Figure 54: Representative thermal demagnetization plots for A and B specimens from 16-1151b. A specimens carry a single, normal polarity, steeply inclined component of magnetization. B specimens carry a single, reversed polarity component that is abruptly demagnetized at temperatures above $300^{\circ} \mathrm{C}$.

\section{6-1151c}

Specimens taken from $16-1151 \mathrm{c}$ carried a relatively strong NRM of $10^{-3} \mathrm{~A} / \mathrm{m}$. Specimens from 16-1151c exhibited the same behaviour as specimens taken from the bottom half of 16-1151b i.e. A single reversed, southerly trending, moderately inclined component of magnetization was stable to a blocking temperature of $300^{\circ} \mathrm{C}$, above which an abrupt loss of magnetization occurred (Fig. 55). This component was estimated for individual specimens using Fisher means. A Fisher mean was used to calculate the sample average from individual specimen estimates. This direction is quoted in Table 7. Specimens treated to alternating field demagnetization failed to demagnetize at fields less than 90mT (Fig. 55).

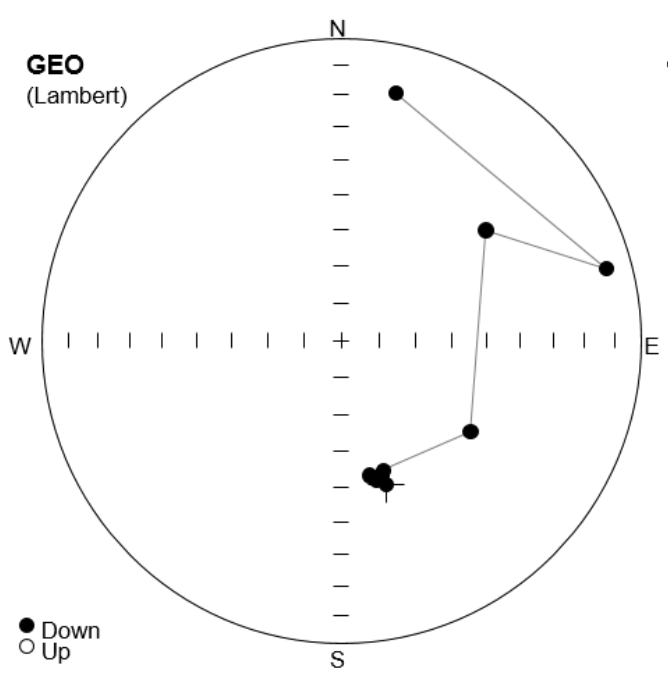

16-1151c2A2

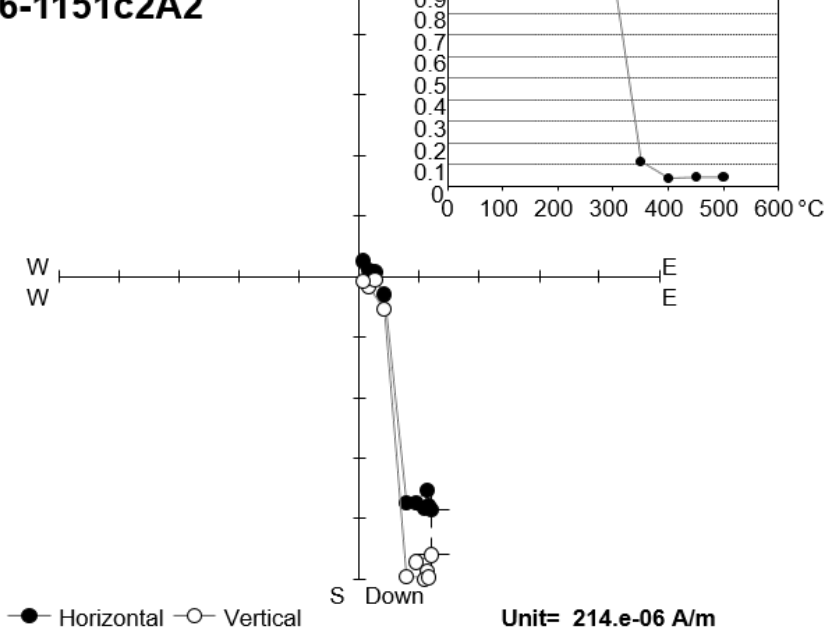




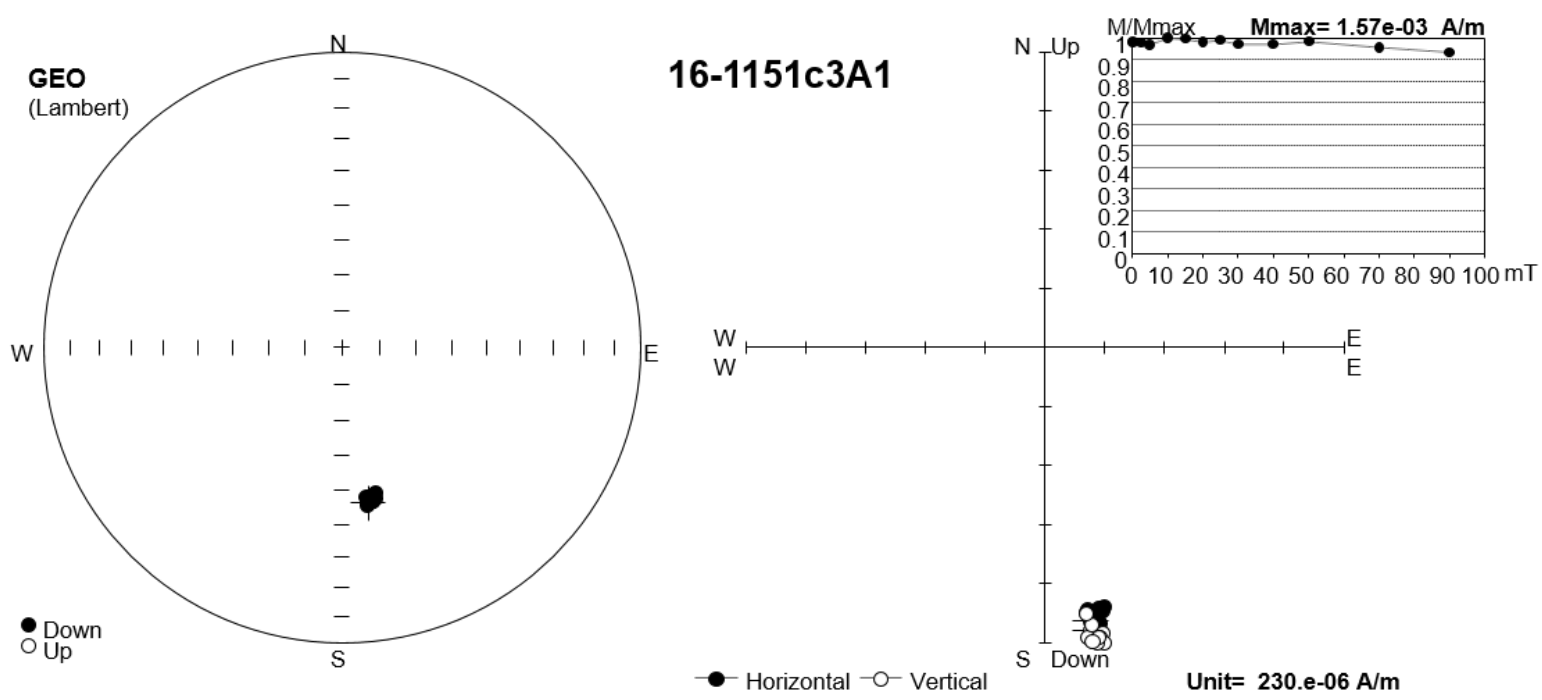

Figure 55: Representative thermal and alternating field demagnetization plots for 16-1151c. The specimens carry a single, reversed polarity, moderately plunging component of magnetization. Specimens exhibit an abrupt loss in magnetization at temperatures above $300^{\circ} \mathrm{C}$. Conversely specimens fail to demagnetize at fields less than $90 \mathrm{mT}$.

This demagnetization behaviour is consistent with the presence of a high coercivity, low Curie temperature phase such as pyrrhotite in samples 16-1151b and 16-1151c. However, the temperature-susceptibility curve for 16-1151c does not differ significantly from the other Biniguni Falls samples, with no evidence for the presence of pyrrhotite (Fig. 56). Furthermore, no pyrrhotite was observed in this sample during microscopic observations (Fig. 57). The cause of this anomalous paleomagnetic behaviour remains unresolved.

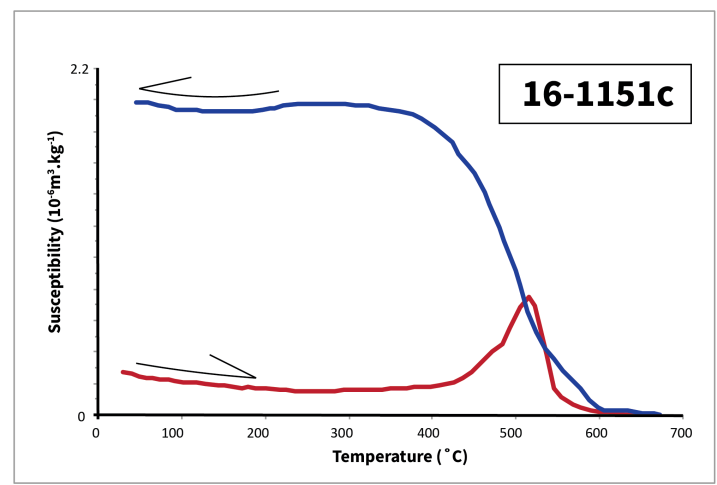

Figure 56: Temperature-susceptibility plot for 161151c. This plot does not differ significantly from the other Biniguni Falls samples.

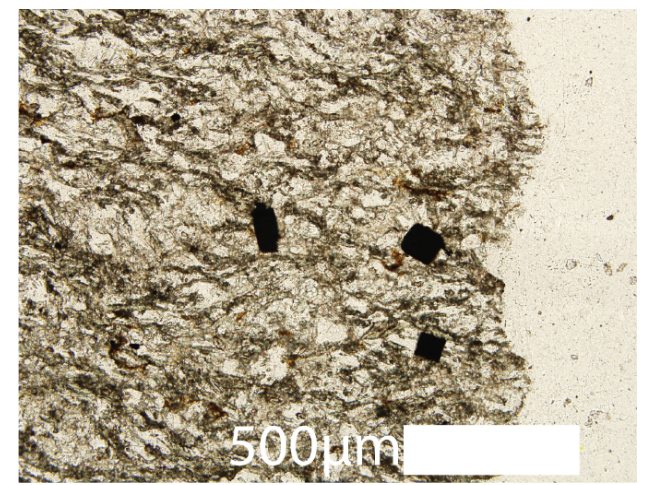

Figure 57: Photomicrograph of sample 16$1151 b$, showing euhedral pyrite grains (confirmed by EDS). In this sample, textural relations suggest the pyrite was grown after the development of the mylonitic foliation, as opposed to before as in other Biniguni Falls samples. Plane polarized transmitted light. 


\section{6-1151h}

Specimens from 16-1151h were generally weak, with NRM intensities of $10^{-5} \mathrm{~A} / \mathrm{m} .16-$ $1151 \mathrm{~h}$ carried two components - a normal component that was too noisy to obtain directional consistency between specimens is carried up until at least $400-450{ }^{\circ} \mathrm{C}$, as estimated from Zjiderveld plots (Fig. 58). The direction of the higher blocking temperature component was hidden by alteration and was therefore estimated using demagnetization great circles (Fig. 58). This component was reversed, moderately inclined, and southerly trending. The direction of this component is quoted in table 7.

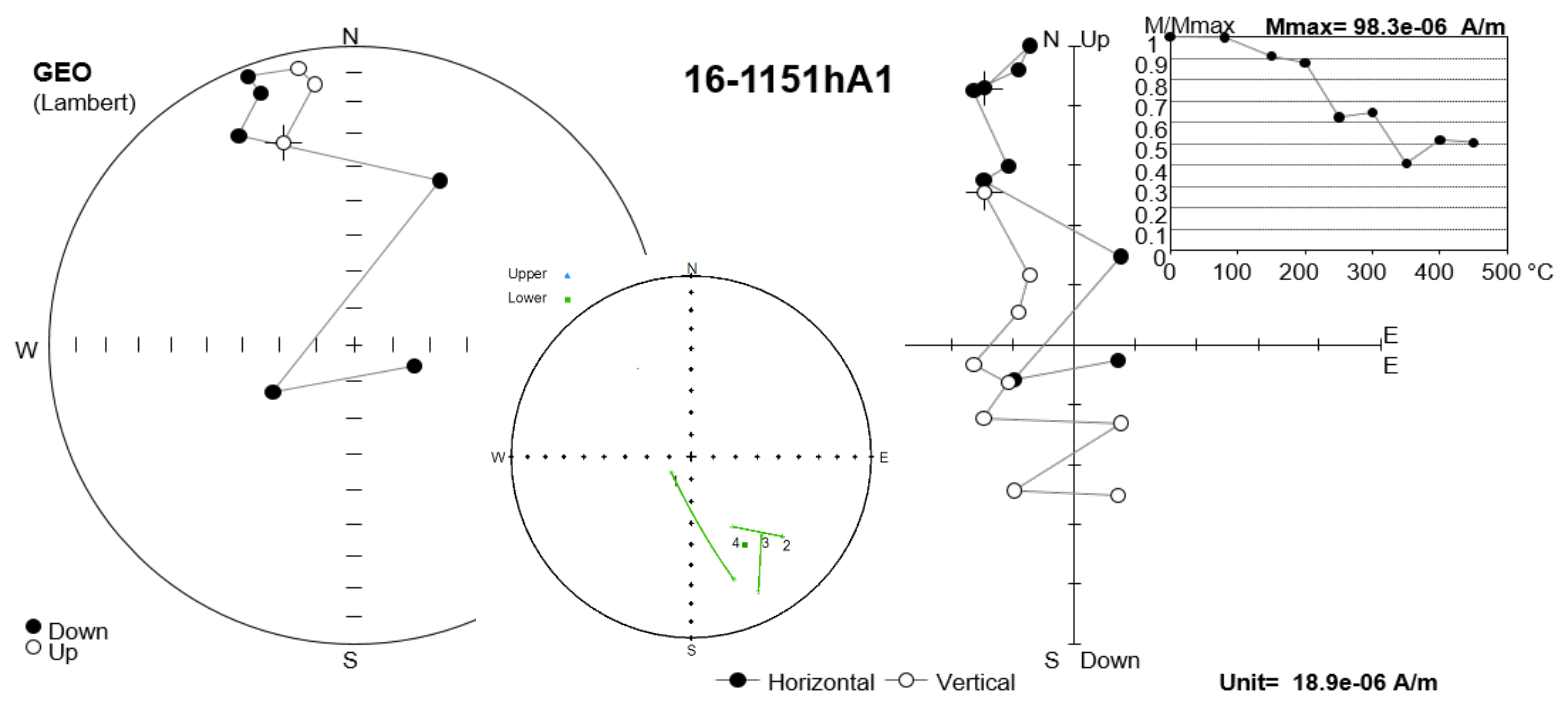

Figure 58: Representative thermal demagnetization plots for 16-1151h. The specimens carry a single, normal polarity component in the lower blocking temperature range (to at least $400-450^{\circ} \mathrm{C}$ ). In the higher blocking temperature range a reversed component is observed.

Although this sample was retrieved from Biniguni Falls, this behaviour was more consistent with samples that were observed further from the fault trace. There is no evidence to suggest this sample has not experienced a similar history as the Biniguni Falls samples. We therefore suggest that slight differences in grain size or mineralogy of the ferro/ferri- magnetic phases present in the sample produced a slightly different blocking temperature spectrum so that the reversed component could be carried and observed in the highest blocking temperature grains in this sample.

\section{5-50i}

Sample 15-50i is located a similar distance from the fault trace, further to the east of the Biniguni Falls locality. 15-50i carried a weak NRM between $10^{-4}$ and $10^{-5} \mathrm{~A} / \mathrm{m}$. These specimens carried a single, normal/reversed polarity component, however this 
component was anomalously shallow, even when compared to the present day field (Fig. 59; Table 7). Components were estimated using Fisher means from NRM- $400^{\circ} \mathrm{C}$ (Table 7). A Fisher mean was then used to calculate the sample average from the individual specimens. The direction of this component is quoted in Table 7.

Polished section work revealed a large $(>2 \mathrm{~mm})$ cataclasite vein that crosscut the mylonitic foliation (Fig. 60). Cataclastic deformation is interpreted to have occurred at temperatures of less than $250^{\circ} \mathrm{C}$ (Little et al., 2019). We infer that, in addition to this sample being weak, cataclastic reworking of the ferromagnetic/ferrimagnetic material may be responsible for the anomalous direction observed.
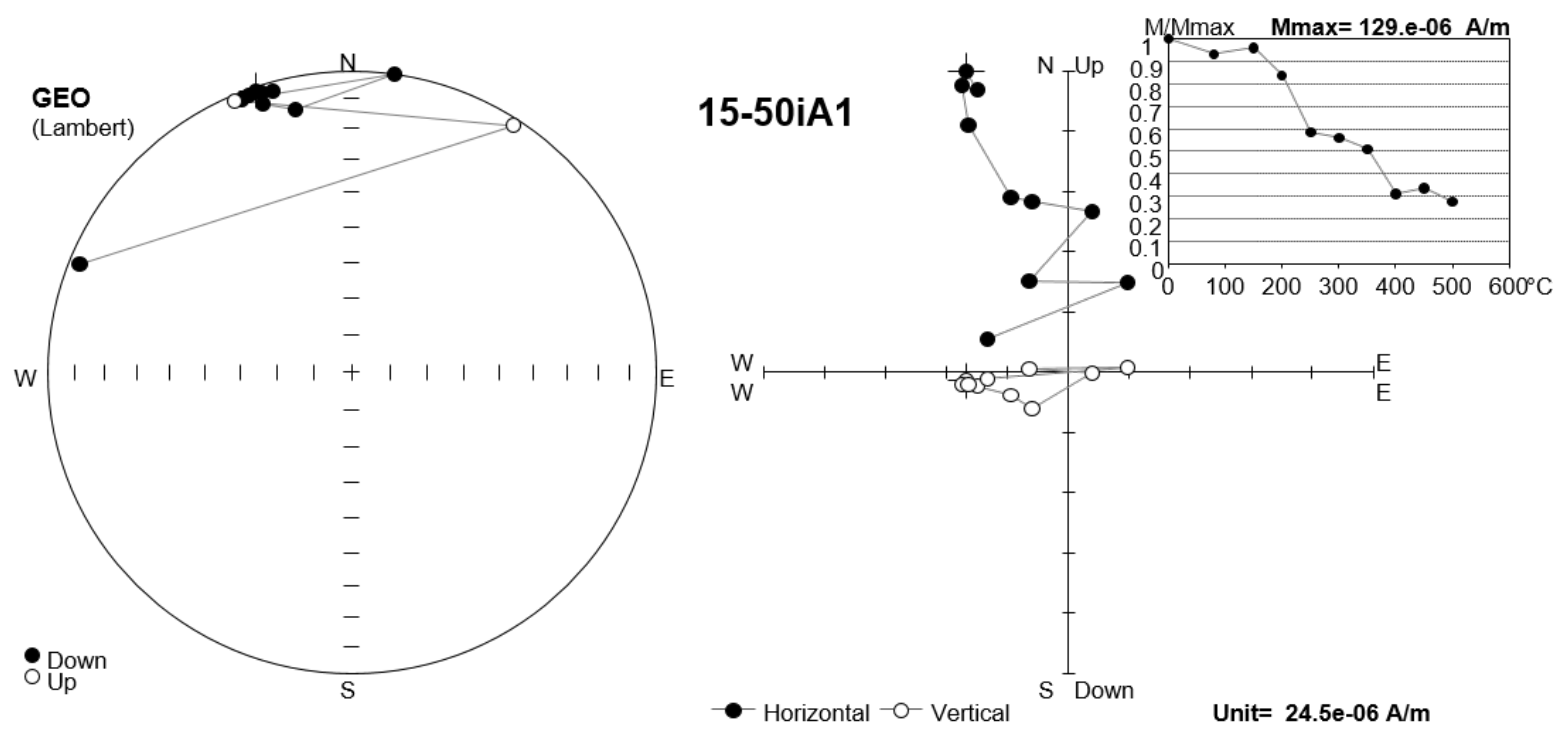

Figure 59: Representative thermal demagnetization plots for 15-50i. The specimens carry a single, normal or reversed polarity component that is extremely shallow $\left(<5^{\circ}\right)$.

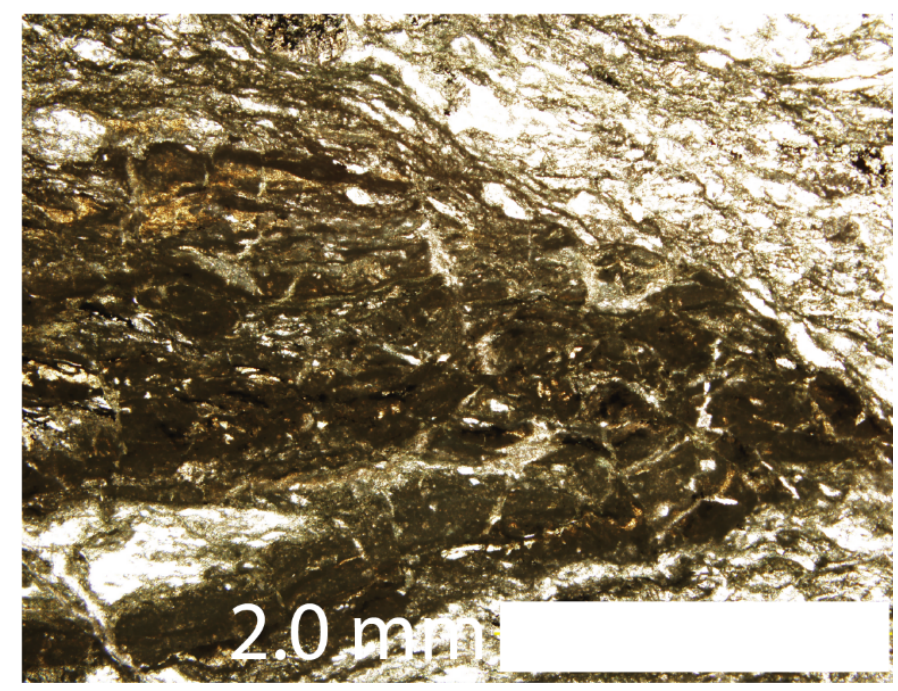

Figure 60: Photomicrograph of sample 15-50i, showing the presence of a large cataclasite vein. Plane polarized transmitted light. 


\section{SUMMIT SAMPLES}

Three samples were measured from near the summit of Mt Dayman (17-19 km from the fault trace) (Fig. 14). These samples displayed both differing demagnetization behaviour, temperature-susceptibility behaviour and isothermal remanent magnetization growth. These samples are therefore discussed separately.

\section{5-13a}

The NRM of $15-13 \mathrm{a}$ is weak relative to the other samples measured from this region $\left(10^{-04} \mathrm{~A} / \mathrm{m}\right)$. A moderately inclined, southerly trending, reversed component of magnetization was estimated by performing PCA between data from demagnetization temperatures of $150^{\circ} \mathrm{C}-250^{\circ} \mathrm{C}$. The sample mean was estimated by calculating a Fisher mean with individual specimen estimates and is quoted in Table 7. Substantial thermal alteration began to occur at temperatures above $250^{\circ} \mathrm{C}$ as indicated by an increase in susceptibility during the thermal demagnetization run (Appendix 1). This thermal alteration appeared to have a pronounced effect on the magnetization of the specimens (Fig. 61) and therefore points above $250^{\circ} \mathrm{C}$ are excluded from PCA estimates. Furthermore, this alteration makes it impossible to determine whether any components are present above $250^{\circ} \mathrm{C}$, and obtain directional estimates of such components (Fig. 61). Below $150^{\circ} \mathrm{C}$ a normal component of magnetization is present that we interpret to be of viscous or thermoviscous origin (Fig. 61).

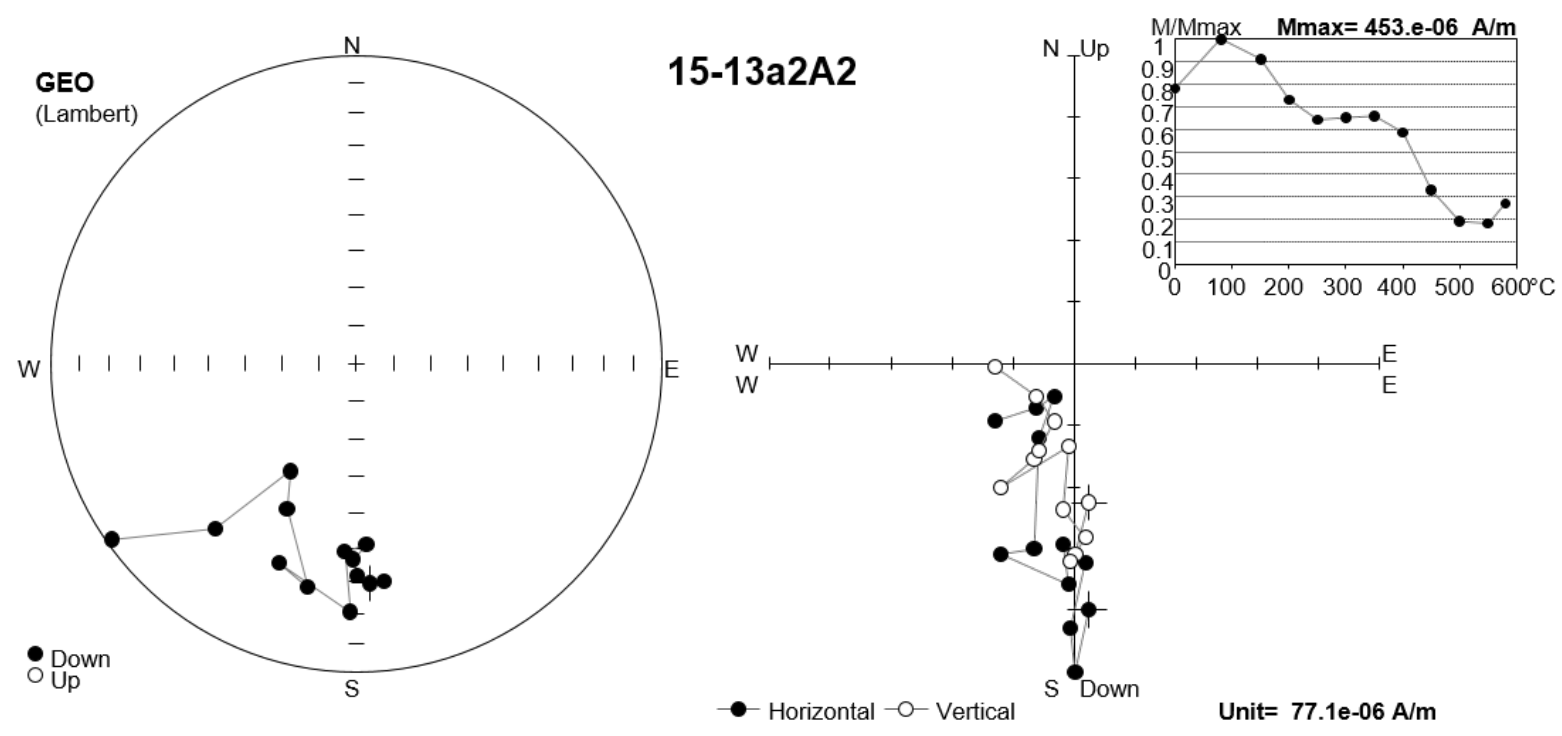

Figure 61: Representative thermal demagnetization plots for 15-13a. A moderately inclined, reversed component is estimated between $150-250^{\circ} \mathrm{C}$. Additional components that may be present in the sample are hidden by low temperature thermal alteration. 
15-13a exhibits a progressively decreasing susceptibility with temperature up to $350^{\circ} \mathrm{C}$ followed by an abrupt increase in susceptibility (Fig. 62). This is followed by a decrease in susceptibility $\sim 525^{\circ} \mathrm{C}$ (Fig. 62). This is similar to the temperature-susceptibility behaviour exhibited by $15-29$ a (section 4.1 .2 .1 ). A susceptibility drop at $\sim 525^{\circ} \mathrm{C}$ is consistent with titanomagnetite $(\mathrm{x}<0.1)$ as a carrier of magnetization in sample 15-13a. The heating and cooling curves are irreversible, however, so definitive conclusions on magnetic mineralogy prior to thermal alteration are impossible with this data alone. The susceptibilities are different by a factor of 30 indicating this alteration is substantial.

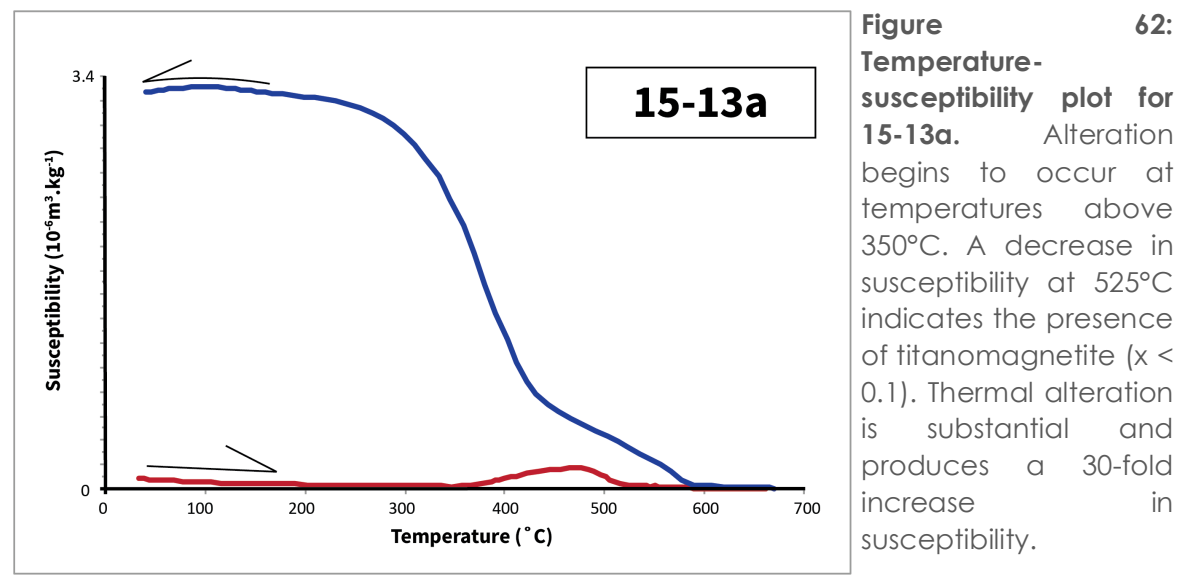

IRM experiments were also undertaken on this sample. A dominant peak is observed between 20-30mT (Fig. 63) consistent with titanomagnetite as the dominant carrier of magnetization in 15-13a. This is consistent with the temperature-susceptibility data, discussed above, which are indicative of the same. 15-13a does not saturate, however, indicating the presence of a higher coercivity phase (goethite or haematite). This is also similar to the behaviour observed in 15-29a (Group 2).

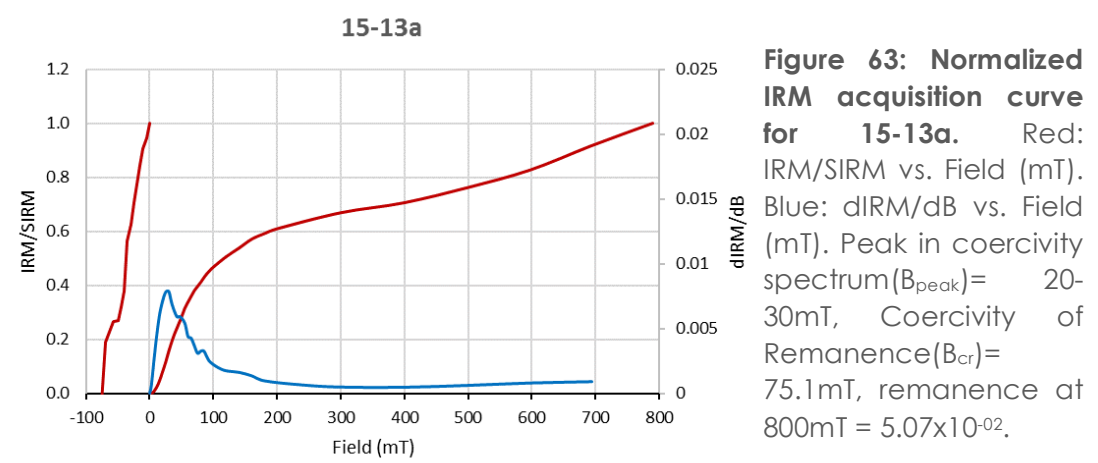

Together these experiments indicate the presence of titanomagnetite as the dominant carrier of magnetization in these samples, similar to Group 1 and 2 samples. We therefore suggest that the reversed component observed in 15-13a may be equivalent to 
the reversed component observed in Group 2 samples. The absence of the normal component that is observed in Group 1 and 2 samples may be due to the fact that this sample was exhumed and acquired a stable magnetization throughout its blocking temperature range prior to the last reversal of the geomagnetic field.

This sample is highly oxidized, containing large pseudomorphs of iron hydroxide after pyrite up to $2.5 \mathrm{~mm}$ (Fig. 64). Veins of iron hydroxide that cross-cut the foliation are also common (Fig. 64). Finer grained opaques were too small to be conclusively identified. Much like Group 1 and 2 samples, no iron oxides were conclusively identified in this sample. We suggest that these iron hydroxides are responsible for the thermal alteration observed in temperature-susceptibility experiments and during the demagnetization run.
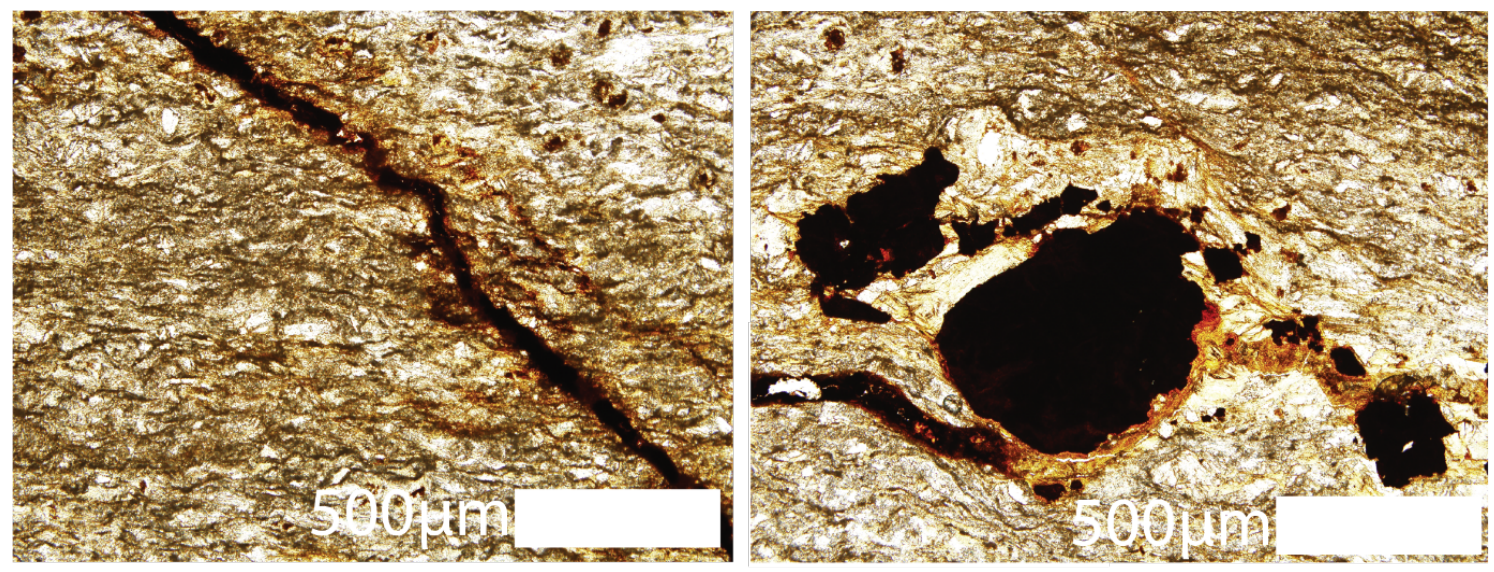

Figure 64: Photomicrographs of sample 15-13a, showing (left) A fine vein of iron hydroxide cross-cutting the metamorphic foliation and (right) a pseudomorph of an iron hydroxide after pyrite. Plane polarized transmitted light.

\section{5-9a}

15-9a carries a relatively strong magnetization $\left(10^{-02} \mathrm{~A} / \mathrm{m}\right)$ compared to other samples measured in this study. Two reversed components were observed in this sample; A moderately-inclined, southeasterly trending component is present in the lower blocking temperature range $\left(\mathrm{NRM}-250^{\circ} \mathrm{C}\right)$ (Fig. 65). In the higher blocking temperature range $\left(400-580^{\circ} \mathrm{C}\right)$ the component is similarly moderately-inclined and is more southeasterly trending (Fig. 65). The transition between these two components is gradual suggesting either the presence of grains with overlapping blocking temperature spectra or a process of gradual acquirement of NRM. The direction of these components was estimated using principal component analysis for individual specimens and then combined into a 
sample mean. This is quoted in Table 7.
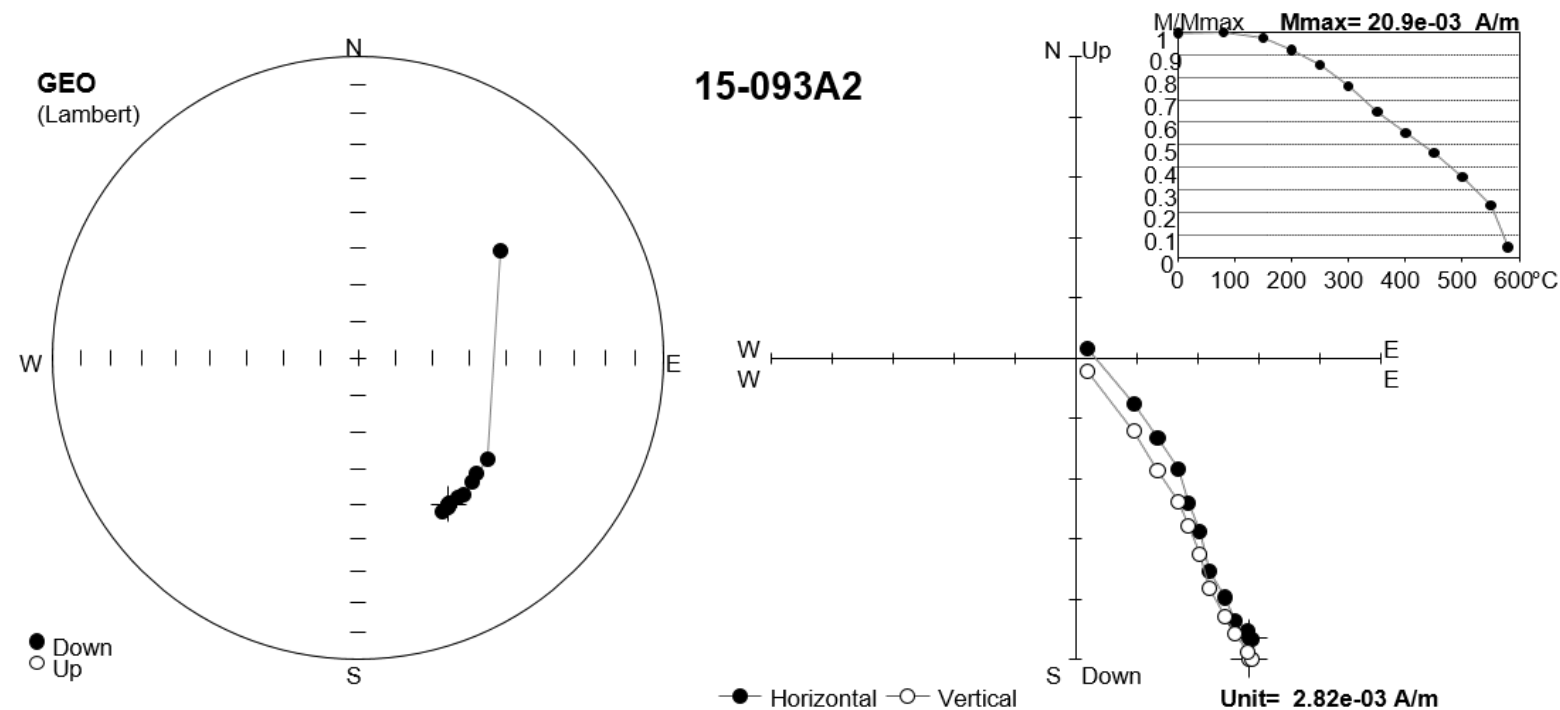

Figure 65: Representative thermal demagnetization plots for 15-9a. Two moderately inclined, reversed components are observed; The higher blocking temperature component is slightly more southeasterly trending.

15-9a displays a pronounced susceptibility drop at $670^{\circ} \mathrm{C}$ indicating maghemite or haematite as the carrier of magnetization (Fig. 66). The heating and cooling curves are mostly reversible indicating only minor thermal alteration. This is consistent with IRM experiments which suggest the magnetization of this sample is dominated by a high coercivity phase (Fig. 67). We suggest that this phase is haematite based on these observations and the weak strength of magnetization that this sample carries.

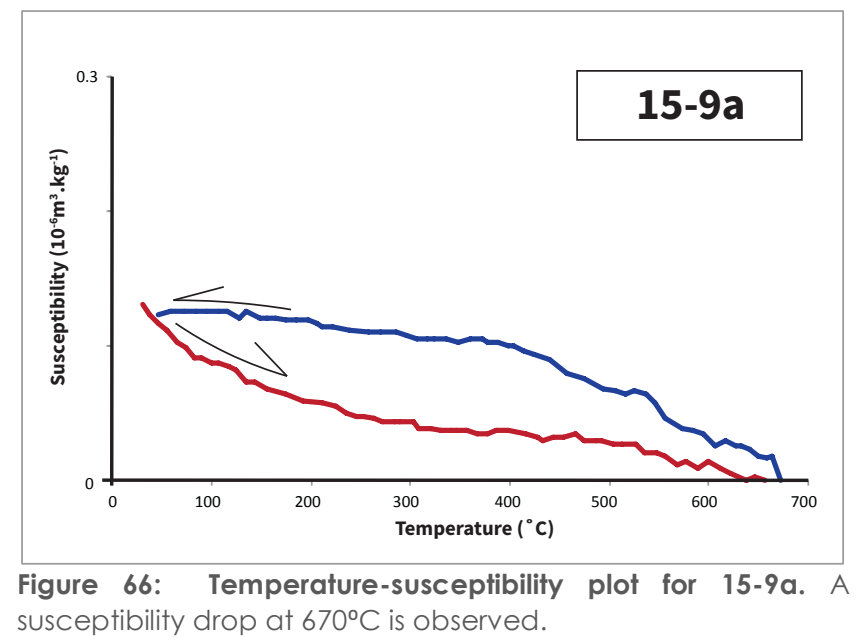




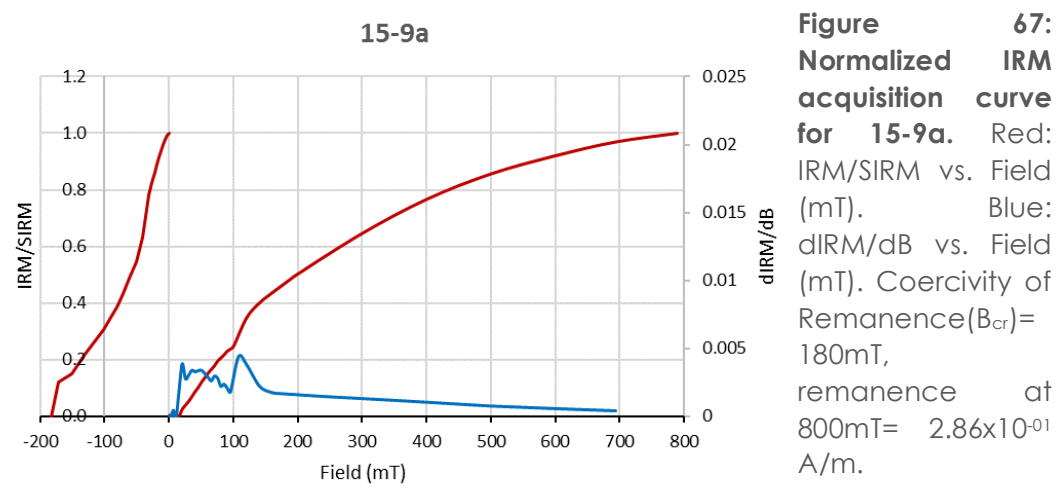

\section{$15-7 \mathbf{a}$}

Sample 15-7a carried an anomalously strong magnetization $\left(10^{+00} \mathrm{~A} / \mathrm{m}\right)$. Two reversed components were observed in 15-7a, similarly to 15-9a. The lower blocking temperature range $\left(\mathrm{NRM}-300^{\circ} \mathrm{C}\right)$ consists of a reversed, shallowly inclined, southwesterly trending component of magnetization (Fig. 68). In the higher blocking temperature range a reversed, shallowly inclined, southeasterly trending component of magnetization is present (Fig. 68). In one of the specimens the higher blocking temperature component is not observed (Appendix 1). The transition between these two components is gradual, much like in 15-9a. The directions of these components were estimated for individual specimens using PCA. A Fisher mean is used to calculate a sample mean which is quoted in table 7.

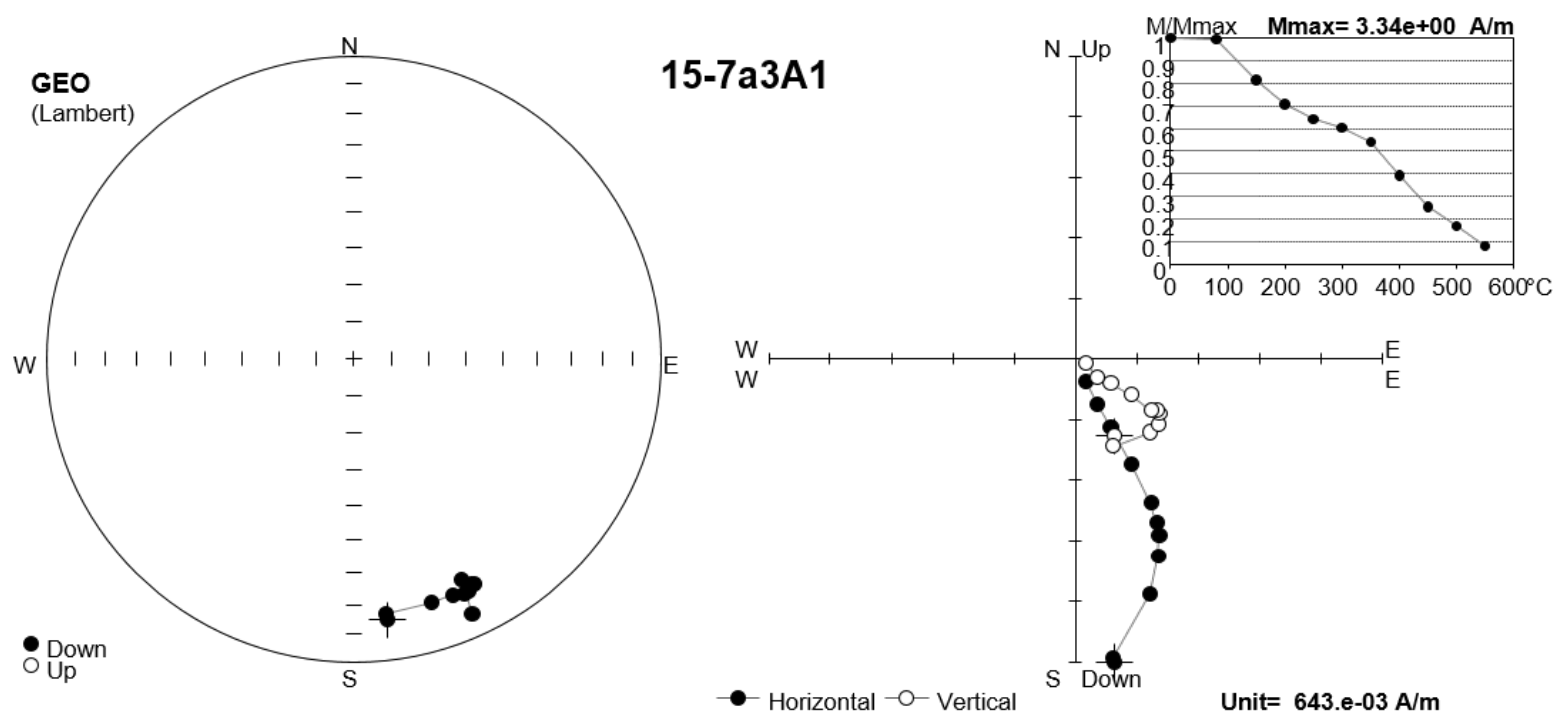

Figure 68: Representative thermal demagnetization plots for 15-7a. Two reversed components of magnetization are observed; A shallow, southwesterly trending component of magnetization in the lower blocking temperature range and a shallow, southeasterly trending component in the higher blocking temperature range. 
15-7a exhibits a pronounced susceptibility drop at temperatures of $650-660^{\circ} \mathrm{C}$ (Fig. 69) consistent with the presence of a high Curie temperature phase such as haematite or maghemite as the carrier of magnetization. Because the magnetization of this sample is anomalously strong we favour maghemite as the potential carrier. The heating and cooling curves are irreversible indicating thermal alteration has taken place (Fig. 69). Because the susceptibilities upon cooling are lower than they were prior to laboratory heating this indicates the breakdown of magnetic phase(s) to paramagnetic phase(s) or less magnetic phase(s), potentially the breakdown of maghemite to haematite.

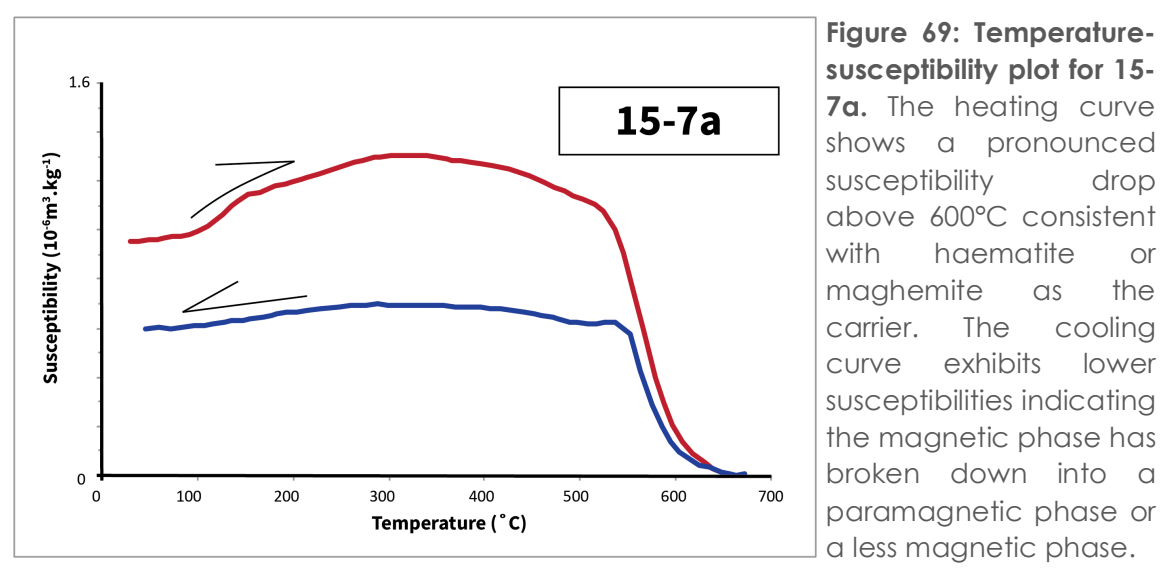

We suggest that neither of the reversed components preserved in samples 15-7a and 159a can be confidently interpreted as the same reversed component that is carried by Group 2 samples. This is because a) It is shallower than the component observed in Group 2 samples, b) it is carried by different ferromagnetic/ferrimagnetic phases, and c) the strength of these samples is anomalously strong compared to other samples measured for this study which may reflect different secondary processes affecting these samples such as chemical alteration or lightning strikes. Further conclusions cannot be drawn until more data is obtained. 


\begin{tabular}{|c|c|c|c|c|c|c|c|}
\hline Sample & $N(n)$ & Declination $\left({ }^{\circ}\right)$ & Inclination $\left({ }^{\circ}\right)$ & $\alpha_{95}$ & $\delta$ & $\mathrm{n}_{\text {specimen }}$ & PCA limits $\left({ }^{\circ} \mathrm{C}\right)$ \\
\hline $16-1151 b(A)$ & $3(3)$ & 348.4 & -80.8 & 3.4 & 1.8 & 3 & NRM-450 OA/A \\
\hline 16-1151b (B) & $4(3)$ & 163.7 & 65.1 & 16.6 & 8.9 & 3 & NRM-300 F \\
\hline $16-1151 c$ & $6(4)$ & 167.8 & 48.9 & 3.5 & 8.9 & 4 & NRM-300 F \\
\hline $16-1151 \mathrm{~h}$ & $6(3)$ & \multicolumn{6}{|c|}{ Normal Polarity - Too noisy to estimate } \\
\hline $16-1151 \mathrm{~h}$ & $6(3)$ & 148.6 & 42.3 & 180.0 & 17.8 & 3 & NRM-450 GC \\
\hline $15-50 i$ & $6(3)$ & 352.8 & 5.7 & 12.0 & 6.4 & 3 & NRM-400 F \\
\hline 15-13a & $4(3)$ & 167.8 & 31.5 & 17.0 & 9.0 & 3 & $150-250 \mathrm{~F}$ \\
\hline $15-9 a$ & $6(4)$ & 156.2 & 46.5 & 13.4 & 10.1 & 4 & NRM-300 \\
\hline $15-9 a$ & $6(4)$ & 142.9 & 42.8 & 5.1 & 3.9 & 4 & $400-5800$ \\
\hline $15-7 a$ & $5(3)$ & 204.1 & 12.4 & 8.2 & 4.4 & 3 & NRM-250 \\
\hline $15-7 a$ & $5(3)$ & 151.7 & 17 & 4.3 & 1.0 & 3 & $250-550 \mathrm{OA}$ \\
\hline
\end{tabular}

Table 7: Table of mean directions for anomalous paleomagnetic samples. $N(n)$ Number of specimens retrieved (number of specimens measured), $\alpha_{95}$ uncertainty envelope on the mean estimate $195 \%$ confidence), $\delta$ angular dispersion of data points considered in the average, $\mathrm{n}_{\text {specimen }}$ number of specimens that were used in the sample mean, PCA Principal Component Analysis, F Fisher mean, O Fitted to the origin, A Anchored to the last point, T Unblocking Temperature, GC Great circle

\section{Appendix 3: Mohr Diagram}

To accompany discussion in section 1.2.1.

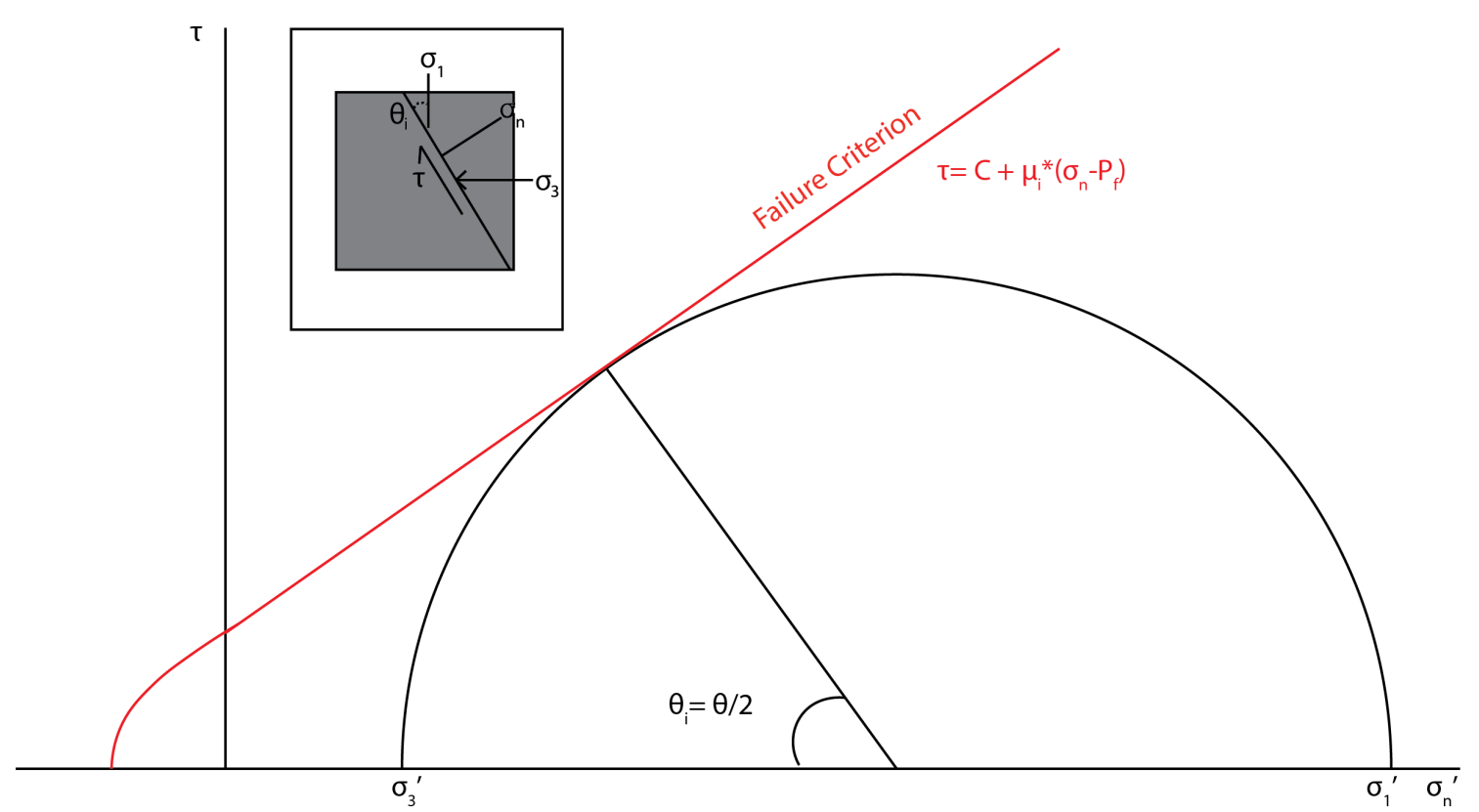

Figure 70: Mohr diagram illustrating a 2D stress state. The black semi-circle plots the resolved components of shear stress and effective normal stress on a plane at a given angle to the maximum principal compressive stress $\left(\sigma_{1}\right)$, as governed by equations 2 and 3 (section 1.2.1). The failure criterion is governed by equation 1 (slope is controlled by $\mu$ ). Failure occurs where the Mohr circle intersects the frictional failure envelope. This shows that faults ideally initiate at $\sim 30^{\circ}$ to $\sigma_{1}$. This translates to ideal dips of $\sim 60^{\circ}$ for normal faults. 